\title{
Article \\ Ganoderma (Ganodermataceae, Basidiomycota) Species from the Greater Mekong Subregion
}

\author{
Thatsanee Luangharn ${ }^{1,2,3}$ (), Samantha C. Karunarathna ${ }^{1,2}$, Arun Kumar Dutta ${ }^{4}$, Soumitra Paloi ${ }^{5}$, \\ Itthayakorn Promputtha ${ }^{6,7}$, Kevin D. Hyde ${ }^{1,3,8}$, Jianchu Xu ${ }^{1,2}$ and Peter E. Mortimer ${ }^{1, *}$ \\ 1 Centre for Mountain Futures (CMF), Kunming Institute of Botany, Kunming 650201, China; \\ 1.thatsanee1990@gmail.com (T.L.); samanthakarunarathna@gmail.com (S.C.K.); kdhyde3@gmail.com (K.D.H.); \\ J.C.Xu@cgiar.org (J.X.) \\ 2 CIFOR-ICRAF, World Agroforestry Centre (ICRAF), Kunming 650201, China \\ 3 Center of Excellence in Fungal Research, Mae Fah Luang University, Chiang Rai 57100, Thailand \\ 4 Department of Botany, West Bengal State University, Barasat 700126, India; arun.botany@gmail.com \\ 5 National Center for Genetic Engineering and Biotechnology (BIOTEC), National Science and Technology \\ Development Agency (NSTDA), 113 Thailand Science Park, Phahonuyothin Rd., Khlong Nueng, \\ Khlong Luang, Pathum Thani 12120, Thailand; soumitrabotany@gmail.com \\ 6 Department of Biology, Faculty of Science, Chiang Mai University, Chiang Mai 50200, Thailand; \\ itthayakorn.p@cmu.ac.th \\ 7 Research Center in Bioresources for Agriculture, Industry and Medicine, Chiang Mai University, \\ Chiang Mai 50200, Thailand \\ 8 Institute of Plant Health, Zhongkai University of Agriculture and Engineering, Haizhu District, \\ Guangzhou 510225, China \\ * Correspondence: peter@mail.kib.ac.cn
}

Citation: Luangharn, T.;

Karunarathna, S.C.; Dutta, A.K.; Paloi,

S.; Promputtha, I.; Hyde, K.D.; Xu, J.;

Mortimer, P.E. Ganoderma

(Ganodermataceae, Basidiomycota)

Species from the Greater Mekong

Subregion. J. Fungi 2021, 7, 819.

https://doi.org/10.3390/jof7100819

Academic Editor: Kuang R. Chung

Received: 29 July 2021

Accepted: 22 September 2021

Published: 30 September 2021

Publisher's Note: MDPI stays neutral with regard to jurisdictional claims in published maps and institutional affiliations.

Copyright: (c) 2021 by the authors. Licensee MDPI, Basel, Switzerland. This article is an open access article distributed under the terms and conditions of the Creative Commons Attribution (CC BY) license (https:// creativecommons.org/licenses/by/ $4.0 /)$.
Abstract: The cosmopolitan fungal genus Ganoderma is an important pathogen on arboreal plant hosts, particularly in tropical and temperate regions. It has long been used as a traditional medicine because of its medicinal properties and chemical constituents. In this study, Ganoderma collections were made in the Greater Mekong Subregion (GMS), encompassing tropical parts of Laos, Myanmar, Thailand, Vietnam, and temperate areas in Yunnan Province, China. The specimens used in this study are described based on micro-macro-characteristics and phylogenetic analysis of combined ITS, LSU, TEF1 $\alpha$, and RPB2 sequence data. In this comprehensive study, we report 22 Ganoderma species from the GMS, namely, G. adspersum, G. applanatum, G. australe, G. calidophilum, G. ellipsoideum, G. flexipes, G. gibbosum, G. heohnelianum, G. hochiminhense, G. leucocontextum, G. lucidum, G. multiplicatum, G. multipileum, G. myanmarense, G. orbiforme, G. philippii, G. resinaceum, G. sichuanense, G. sinense, G. subresinosum, G. williamsianum, and G. tsugae. Some of these species were reported in more than one country within the GMS. Of these 22 species, 12 were collected from Yunnan Province, China; three were collected from Laos; three species, two new records, and one new species were collected from Myanmar; 15 species and four new records were collected from Thailand, and one new species was collected from Vietnam. Comprehensive descriptions, color photographs of macroand micro-characteristics, the distribution of Ganoderma within the GMS, as well as a phylogenetic tree showing the placement of all reported Ganoderma from the GMS are provided.

Keywords: two new species; biogeography; ecological aspects; Lingzhi; medicinal mushroom; morphology

\section{Introduction}

Ganoderma was established by Karsten [1] with Polyporus lucidus (Curtis) Fr. (=Ganoderma lucidum (Curtis) P. Karst.) as the type species [2]. The genus has a worldwide distribution but is predominantly found in tropical and temperate regions, including Africa, America, Europe, and Asia [3-6]. Most members of Ganoderma are pathogenic in nature, inflicting various diseases to plants such as white rot and stem rot as well as 
wood decay [3,6-9]. The genus is circumscribed by sessile to stipitate basidiomata with double-walled basidiospores and interwall pillars [1,2]. Kirk et al. [10] mentioned that globally there are 80 species of Ganoderma, while two global fungal databases viz. Index Fungorum [11] and MycoBank [12] hold 459 and 503 records, respectively.

In light of an earlier taxonomic framework, Ganoderma included three subgenera viz. Ganoderma P. Karst., Elfvingia P. Karst., and Trachyderma Imazeki [13]. The subgenus Ganoderma includes two sections. Ganoderma and Phaenema contain laccate species (a cutis surface consisting of a palisade of inflated hyphal ends) with a shiny upper surface, whereas all non-laccate species (palisade is absent) with a dull upper surface are under the subgenus Elfvingia [14,15]. The subgenus Trachyderma has been deemed illegitimate and is treated as a synonym of Ganoderma due to the presence of the lichenized genus Trachyderma [15].

Ganoderma mushrooms have long been used as traditional medicine in many Asian countries [4]. In the Pharmacopoeia of the People's Republic of China, Ganoderma species are recorded as being used over two millennia [16]. Traditional Chinese books proposed and classified Ganoderma species based on basidiocarp coloration [17]. Ganoderma species are suitable sources of natural bioactive compounds of high and low molecular weight, especially polysaccharides, protein, sterols, and triterpenoids [18-20]. These compounds are known to possess extensive therapeutic properties, such as antibacterial, antifungal, antiviral, anticancer, antitumor, anti-inflammatory, anti-hypotensive, and antioxidative agents $[15,21-25]$. Moreover, these compounds also treat many immunological diseases [15,22], making Ganoderma species a popular functional food [26].

The Greater Mekong Subregion (GMS) consists of Cambodia, Lao People's Democratic Republic, Myanmar, Yunnan Province of the People's Republic of China, Thailand, and Vietnam. The GMS is a biodiversity hotspot with rich fungal diversity [27], as well as featuring a high diversity of endemic and endangered organisms. A variable climate, vegetation type, and habitat primarily characterize the GMS, supporting the existence of thousands of macrofungal species, many of which remain unknown [28-31]. Wild edible and medicinal macrofungi comprise an important source of income for people residing in the GMS. Past work has shown that the GMS is a hotpot of Ganoderma diversity, and thus of interest to the broader community of scientists working on this genus, yet no studies have attempted to bring all this information into one space and update the knowledge the known distribution of species, as well as introduce newly discovered species. Thus, our study seeks to clarify the status of Ganoderma in the GMS, where it is both an important medicinal and plant pathogenic mushroom.

There is much debate among taxonomists regarding how to best resolve nomenclatural confusion within Ganoderma. This stems from the high degree of phenotypic plasticity found in Ganoderma species [4,32-36]. Ganoderma lucidum was broadly defined from the original concept [34], with variations occurring in macro-characteristics of the basidiomes, resulting in many synonyms and general redundancy in the taxonomy of this species and genus $[34,37]$.

\subsection{Biogeography of Ganoderma}

Ganoderma lucidum (Curtis) P. Karst., the type species of Ganoderma, was described based on a specimen collected from the U.K. Moncalvo et al. [38] concluded that G. lucidum was distributed across northern and southern Europe and likely extended into China. The name Ganoderma lingzhi (Lingzhi) has been adopted in place of G. lucidum for specimens native to East Asia [4]. Among Ganoderma species, several species similar to G. lucidum have also been described worldwide: G. multipileum [39], G. Sichuanense [4,16,40] from China; G. resinaceum from Europe [41]; and G. oregonense, G. sessile, G. tsugae, and G. zonatum from the U.S. [42,43]. These species are accepted as members of the G. lucidum complex.

Taxonomic treatments of Ganoderma species remain unclarified due to the high degree of phenotypic plasticity [44,45]. Some Ganoderma species are distributed worldwide, such as G. applanatum and G. australe, while others are known only from specific localities $[2,46]$. Limited holotypes and unsettled geographical distributions have resulted in 
much ambiguity among Ganoderma taxa. Ganoderma has been reported from tropical Laos, Myanmar, Thailand, and Vietnam [30,31] and temperate China [6,31] in the GMS. Members of Ganoderma can be of significant importance in horticulture since they infect landscape plants, fruit trees, perennial crops, and economically important trees [27,29], which can be resulted in the death of affected trees. Ganoderma has been recorded mostly in a wide range of tree species, especially on hardwood trees [8]. Ganoderma has not been reported as host-specific. They are often found in natural forests (deciduous forests) and dominated on plantations trees [30,31]. Although Ganoderma has long been regarded as one of the genera with a worldwide distribution [30], the diversity and composition of Ganoderma in the GMS remains poorly understood. Here, we summarize and update the Ganoderma species distribution in the GMS based on location data from known collections (Figure 1). The extant Ganoderma species in the GMS are compiled in Table S1, and species diversity (SD) hotspots of Ganoderma in GMS are shown in Figure 2.

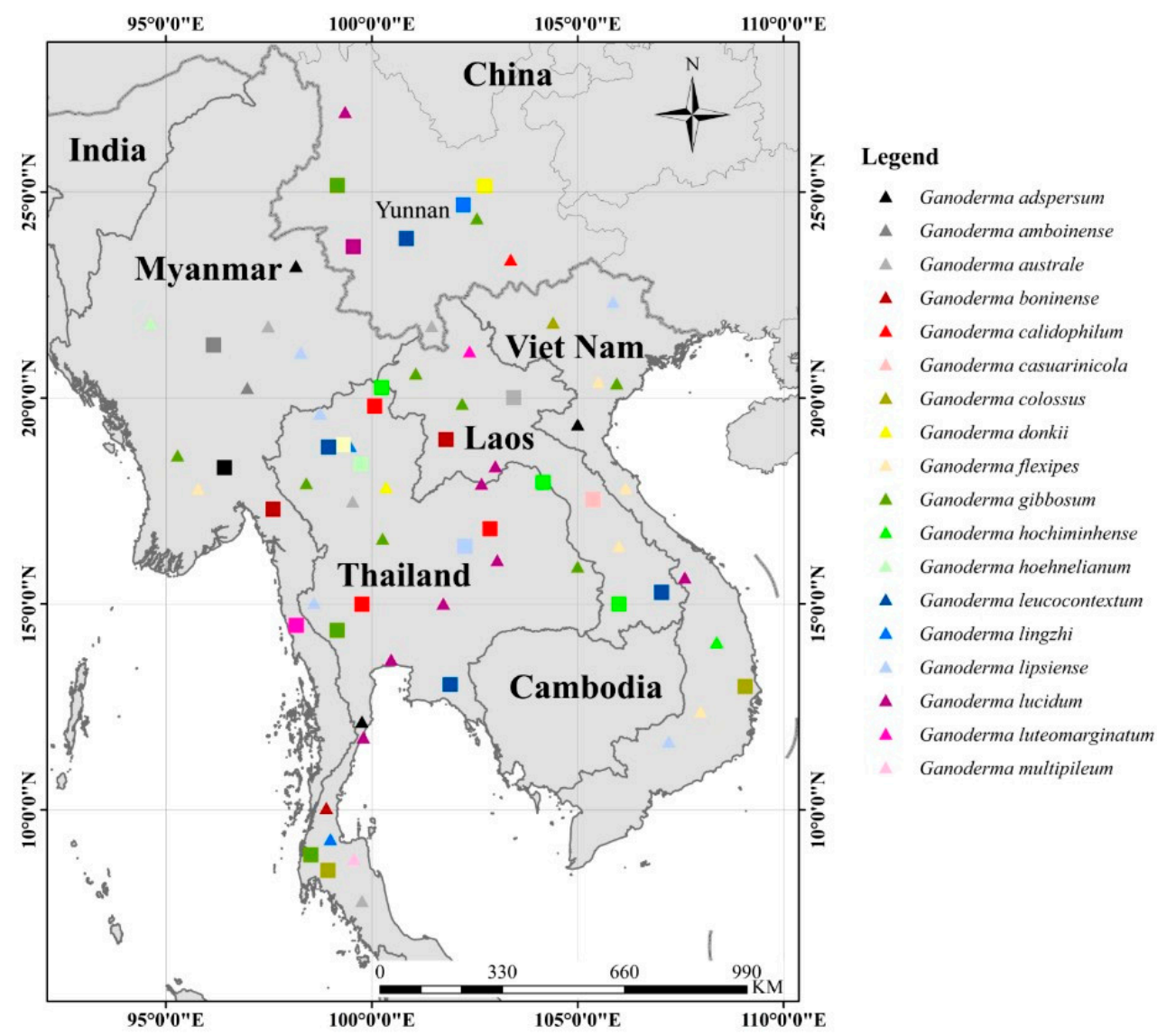

Ganoderma multiplicatum Ganoderma myanmarense - Ganoderma nasalanense

- Ganoderma neojaponicum

- Ganoderma orbiforme

[1] Ganoderma oregonense

- Ganoderma philippii

- Ganoderma resinaceum Ganoderma sichuanense

- Ganoderma sinense

- Ganoderma subfornicatum

Ganoderma torosum

- Ganoderma tropicum

- Ganoderma tsugae

- Ganoderma weberiamum

- Ganoderma weixiensis

- Ganoderma williamsiamum

Figure 1. Distribution of Ganoderma species in the GMS. 


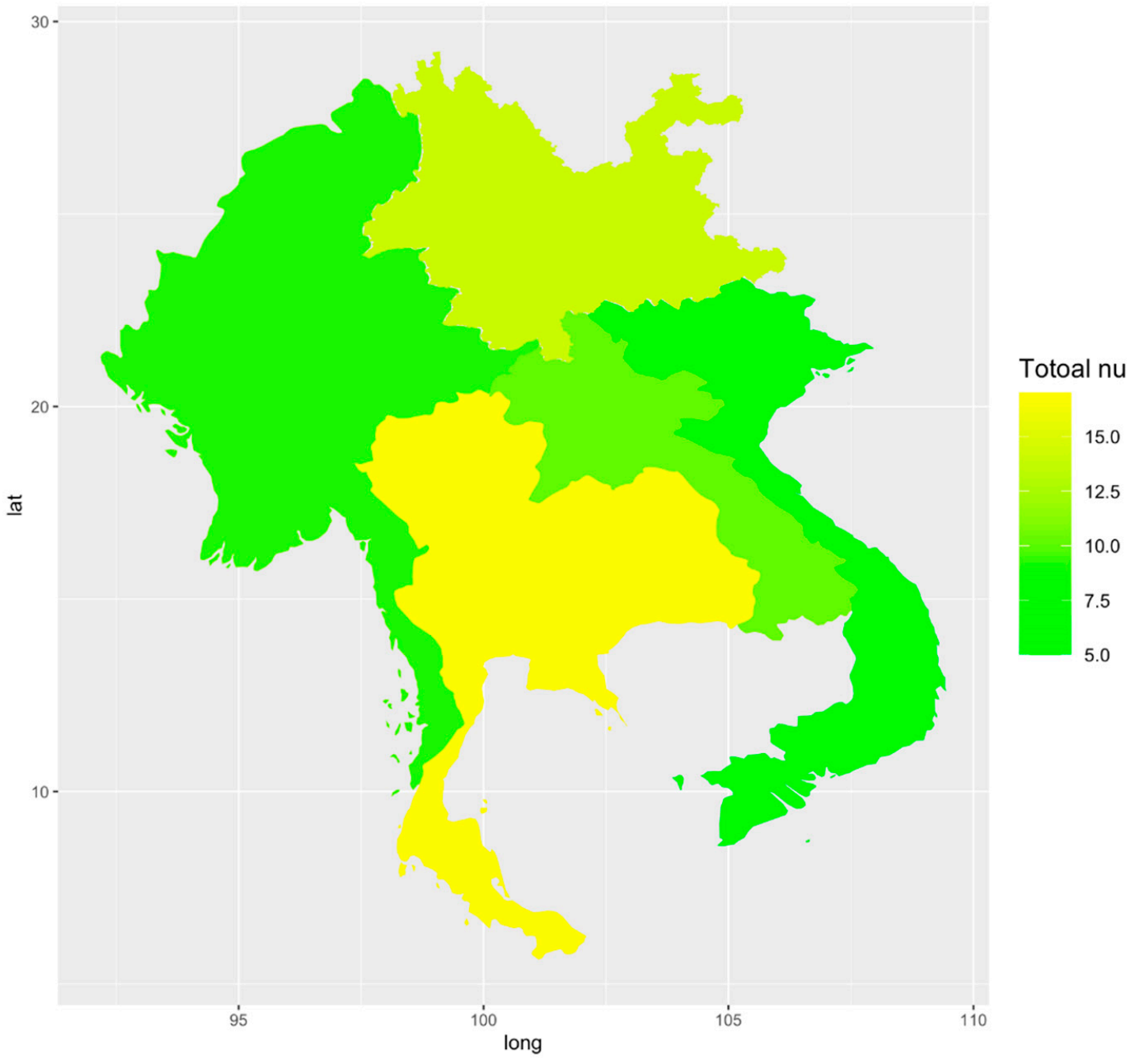

Figure 2. Species diversity (SD) hotspots of Ganoderma species in the GMS.

\subsection{Ecological Aspects of Ganoderma}

Wu and Dai [47] suggested that the morphology of Ganoderma species varies based on factors such as climate, nutrition, vegetation, and geography; moreover, morphology is not associated with the genetic material of a particular species. Basidiome features are influenced by the interaction of both intrinsic (genetic and physiological) and extrinsic (environmental) factors [48-51]. Therefore, comprehensive documentation of species ecology is necessary when studying Ganoderma. Criteria for identification vary: some authors strictly focus on geographical distribution, host-specificity, and macro-characteristics of basidiomes, while others focus on spore morphology as the primary taxonomic characteristic [52,53]. In the present study, ecological factors such as collection period, season, climate, host plant, and substrate of Ganoderma species were recorded.

Ganoderma species are known as both important wood-decaying fungi and pathogens that can survive on a wide range of hosts [54]. These fungi decay lignin, cellulose, and hemicellulose, resulting in a severe loss of woody plant strength $[9,55]$. They possess lignocellulose-decomposing enzymes useful for bioenergy production and bioremediation [56]. Diseases caused by Ganoderma species result in lower yields in economically important trees [54].

In this paper, we update biogeography records of Ganoderma by reporting species distributed across the Greater Mekong Subregion (GMS) as well as conducting morphological and phylogenetic studies on Ganoderma collected from temperate regions in Yunnan Province, China, and tropical regions of Laos, Myanmar, Thailand, and Vietnam (Table 1). 
Table 1. Species of Ganoderma, host plants, diseases, and main regions of distribution within the Greater Mekong Subregion.

\begin{tabular}{|c|c|c|c|c|}
\hline Ganoderma Species & Host Plant & Diseases & Region & Reference \\
\hline \multirow{2}{*}{ G. adspersum } & Pterocarpus sp. & Wood decay & Thailand & This study \\
\hline & Mangifera indica & Wood decay & Laos & This study \\
\hline \multirow[b]{2}{*}{ G. applanatum } & Acer sp. & & Vietnam & [57] \\
\hline & $\begin{array}{l}\text { Rhizophora apiculata, Machilus } \\
\text { yunnanensis, and hardwoods }\end{array}$ & $\begin{array}{l}\text { Wood decay, } \\
\text { Butt rot }\end{array}$ & $\begin{array}{c}\text { Thailand, } \\
\text { China, Myanmar, Laos }\end{array}$ & {$[30,58]$, this study } \\
\hline \multirow[b]{2}{*}{ G. applanatum } & Machilus yunnanensis & Wood decay & Yunnan, China & This study \\
\hline & Artocarpus sp., and Dipterocarpus sp. & Wood decay & Thailand & This study \\
\hline \multirow{2}{*}{ G. australe } & Anisoptera costata and Shorea robtusa & Wood decay, rotten wood & $\begin{array}{l}\text { Laos, Thailand, } \\
\text { and Myanmar }\end{array}$ & {$[30,59]$, this study } \\
\hline & Camellia sinensis var. assamica & Root rot & Thailand & [60] \\
\hline G. calidophilum & $\begin{array}{c}\text { Castanopsis sp. and Machilus } \\
\text { yunnanensis }\end{array}$ & Wood decay & Yunnan, China & This study \\
\hline G. casuarinicola & Pinus kesiya & White rot & Thailand & [31], this study \\
\hline G. ellipsoideum & Unknown & Wood decay & Thailand & This study \\
\hline G. flexipes & Pinus sp. and unknown & & $\begin{array}{l}\text { China, Myanmar, } \\
\text { Vietnam }\end{array}$ & {$[6,30,61]$, this study } \\
\hline \multirow{3}{*}{ G. gibbosum } & $\begin{array}{l}\text { Albizia mollis, Machilus yunnanensis, } \\
\text { and Pinus sp. }\end{array}$ & & Yunnan, China & This study \\
\hline & $\begin{array}{l}\text { Albizia lebbeck, Dendrocalamus strictus, } \\
\text { Dipterocarpus sp., Mangifera indica, } \\
\text { P. pterocarpum, and Pinus sp. }\end{array}$ & $\begin{array}{l}\text { Wood decay, rotten } \\
\text { wood }\end{array}$ & Thailand & This study \\
\hline & Hardwoods & Wood decay & China, Thailand & {$[30]$, this study } \\
\hline G. hochimin-hensis & Areca sp. & Root rot & Vietnam & This study \\
\hline G. hoehnelianum & Unknown & Wood decay & Myanmar & This study \\
\hline G. leucocontextum & Cyclobalanopsis glauca and C. glauca & Wood decay, root rot & Yunnan, China & [62], this study \\
\hline \multirow[b]{2}{*}{ G. lucidum } & Quercus sp. & Wood decay & Yunnan, China & This study \\
\hline & $\begin{array}{c}\text { Acacia sp., Dendrocalamus strictus, } \\
\text { and Pterocarpus sp. }\end{array}$ & Wood decay & Thailand & This study \\
\hline \multirow{2}{*}{ G. multipileum } & Unknown decayed hardwood & Wood decay & Yunnan, China & [30], this study \\
\hline & Pinus merkusii & Wood decay & Thailand & This study \\
\hline G. multiplicatum & Quercus sp. & Wood decay & Yunnan, China & This study \\
\hline G. myanmarense & Unknown tree & Wood decay & Myanmar & This study \\
\hline G. nasalaense & Not mention & Wood decay & Laos & [36] \\
\hline G. neojaponicum & Near hardwood roots & Wood decay & Myanmar & [30] \\
\hline \multirow[t]{3}{*}{ G. orbiforme } & Albizia mollis and Indochinese sp. & Wood decay & Thailand & This study \\
\hline & Unknown decayed hardwood & Wood decay & China, Laos & This study \\
\hline & Elaeis guineensis & Basal stem rot & Thailand & [63] \\
\hline G. philippii & Unknown & Root rot & Thailand & This study \\
\hline G. resinaceum & Albizia mollis & Basal stem rot & Yunnan, China & This study \\
\hline \multirow[t]{3}{*}{ G. sichuanense } & Quercus sp. & & China & {$[4,40]$} \\
\hline & $\begin{array}{c}\text { Pterocarpus sp., Mangifera indica, } \\
\text { Sesbania grandiflora, and Peltophorum } \\
\text { pterocarpum }\end{array}$ & Wood decay & Thailand & This study \\
\hline & $\begin{array}{c}\text { Castanopsis sp., Castanea sp., } \\
\text { Cyclobalanopsis sp, and Graucoides } \\
\text { schotky }\end{array}$ & $\begin{array}{l}\text { Wood decay, } \\
\text { root rot }\end{array}$ & Yunnan, China & [4], this study \\
\hline \multirow[b]{2}{*}{ G. sinense } & Albizia mollis and Quercus sp. & Rotten wood & Yunnan, China & [30], this study \\
\hline & $\begin{array}{l}\text { Dendrocalamus strictus and } \\
\text { Dipterocarpus sp. }\end{array}$ & $\begin{array}{l}\text { Wood decay, Rotten } \\
\text { wood }\end{array}$ & Thailand & This study \\
\hline
\end{tabular}


Table 1. Cont.

\begin{tabular}{ccccc}
\hline $\begin{array}{c}\text { Ganoderma } \text { Species } \\
\text { G. subresinosum }\end{array}$ & $\begin{array}{c}\text { Host Plant } \\
\text { Peltophorum pterocarpum and } \\
\text { Castanopsis sp. }\end{array}$ & $\begin{array}{c}\text { Diseases } \\
\text { Wood decay }\end{array}$ & $\begin{array}{c}\text { Region } \\
\text { Thailand }\end{array}$ & $\begin{array}{c}\text { Reference } \\
\text { This study }\end{array}$ \\
\hline G. thailandicum & Pinus merkusii & Wood decay & Thailand & [31], this study \\
\hline G. tropicum & Dipterocarpus sp. & Wood decay & Thailand & [31], this study \\
\hline G. tsugae & Larix sp., Picea sp. and Tsuga sp. & Butt rot, Wood decay & China & {$[57,64]$, this study } \\
\hline G. williamsianum & Unknown & Wood decay & Myanmar & This study \\
\hline
\end{tabular}

\section{Materials and Methods}

\subsection{Study Sites}

Ganoderma specimens were collected from the temperate parts of Yunnan Province, China, and tropical parts of Laos, Myanmar, Thailand, and Vietnam (Figure S1). Detailed collection site information, such as location, climate, the monthly temperature during the rainy season, host trees species, and native forest type, are provided in Table 2.

Table 2. Regional information for collection sites in the Greater Mekong Subregion, where collections occurred.

\begin{tabular}{|c|c|c|c|c|c|}
\hline Study Sites & China & Myanmar & Laos & Thailand & Vietnam \\
\hline Climate Type & Temperate & Tropical & Tropical & Tropical & Tropical \\
\hline Collecting date & $\begin{array}{l}\text { December 2016; } \\
\text { September- } \\
\text { December 2017; } \\
\text { September- } \\
\text { November } 2018\end{array}$ & July 2019 & June-July 2018 & $\begin{array}{l}\text { October-December 2017; } \\
\text { June } \\
\text { and November } 2018\end{array}$ & June 2019 \\
\hline $\begin{array}{l}\text { Monthly } \\
\text { temperature }\end{array}$ & $16-22{ }^{\circ} \mathrm{C}$ & $26-30{ }^{\circ} \mathrm{C}$ & $25-32{ }^{\circ} \mathrm{C}$ & $25-38{ }^{\circ} \mathrm{C}$ & $28-32{ }^{\circ} \mathrm{C}$ \\
\hline Forest type & $\begin{array}{c}\text { Coniferous forest, } \\
\text { dry evergreen forest, } \\
\text { and evergreen coniferous } \\
\text { forest }\end{array}$ & $\begin{array}{l}\text { Mixed deciduous } \\
\text { forest and tropical } \\
\text { rain forest. }\end{array}$ & $\begin{array}{l}\text { Deciduous forest } \\
\text { and tropical rain } \\
\text { forest }\end{array}$ & $\begin{array}{l}\text { Coniferous forest, } \\
\text { deciduous forest, } \\
\text { dry evergreen forest, } \\
\text { and tropical rain forest. }\end{array}$ & Deciduous forest \\
\hline Host tree species & $\begin{array}{c}\text { Albizia mollis, } \\
\text { Castanopsis spp., } \\
\text { Fagus spp., Machilus } \\
\text { yunnanensis, Pinus spp., } \\
\text { Pterocarpus macrocarpus, } \\
\text { Quercus spp., and Hevea } \\
\text { brasiliensis }\end{array}$ & $\begin{array}{l}\text { Unidentified tree } \\
\text { species }\end{array}$ & Mangifera indica & $\begin{array}{c}\text { Acacia sp., } \\
\text { Albizia lebbeck, Artocarpus } \\
\text { spp., Castanopsis spp., } \\
\text { Dendrocalamus strictus, } \\
\text { Dipterocarpus spp., Garuga } \\
\text { pinnata, Indochinese spp., } \\
\text { Maerus siamensis, } \\
\text { Mangifera indica, } \\
\text { Pterocarpus macrocarpus, } \\
\text { Peltophorum pterocarpum, } \\
\text { and Pinus spp. }\end{array}$ & Areca spp. \\
\hline
\end{tabular}

\subsection{Sample Collection and Isolation}

Fresh basidiomes of Ganoderma species were collected from China, Laos, Myanmar, Thailand, and Vietnam. The samples were photographed and transported back to the laboratory, where fresh macroscopic details were described. The cultures were aseptically isolated by using heat sterilized forceps, transferring sections of internal tissue from fruiting bodies onto potato dextrose agar (PDA) medium and incubated at $25-30{ }^{\circ} \mathrm{C}$, for $1-3$ weeks, under dark conditions [59]. After incubation, the agar surface was fully covered with white mycelium. The pure stock culture was then covered with mineral oil and deposited in the voucher culture collection of the Mae Fah Luang University culture collection (MFLUCC) Chiang Rai, Thailand. The cultures are being maintained at $4{ }^{\circ} \mathrm{C}$ for further studies. The voucher samples were then air-dried at $40{ }^{\circ} \mathrm{C}$ for $48 \mathrm{~h}$ until they were completely dehydrated. Finally, the material was deposited in the herbarium of Mae Fah Luang University (MFLU Herb.) with duplicates in the herbarium of Kunming Institute of Botany, Academia Sinica (HKAS), Yunnan Province, China. 


\subsection{Morphological Study}

Macro-characteristics were described following the method of Lodge et al. [65], while color notations were recorded following Ridgeway [66]. Macroscopic characteristics were determined according to the methodology described by Largent [67]. To observe microscopic characteristics, free-hand sections were made under a dissecting microscope (OLYMPUS SZ61) and mounted on a glass slide containing 3-5\% KOH, 1-3\% Congo red, and Melzer's reagent for highlighting all tissues [68]. Microphotography was performed with a Nikon ECLIPSE Ni (Nikon, Tokyo, Japan) compound microscope, with a Canon EOS 600D (Tokyo, Japan) digital camera fitted on the top of the microscope. Basidiospores and hyphal system sizes, colors, and shapes were recorded and photographed. Basidiospore measurements were taken using the Tarosoft ${ }^{\circledR}$ Image Framework program v. 0.9.0.7. For measuring basidiospore statistics, the Tulloss' standard format [69] was followed [Q $=\mathrm{L} / \mathrm{W}]$, where $\mathrm{Q}$, the quotient of basidiospore length to width $(\mathrm{L} / \mathrm{W})$ in side view and $\mathrm{Qm}$, the mean of Q-values $\pm \mathrm{SD}$. The calculation was performed by measuring at least 50 basidiospores from each basidiomata [70]. Photographs were edited in Adobe Illustrator CS v. 3.0.

\subsection{DNA Extraction, PCR Amplification, and Sequencing}

Dried internal tissues of the basidiomes were grounded, and total DNA was extracted using the Biospin Fungus Genomic DNA Extraction Kit (BioFlux ${ }^{\circledR}$ ). The ITS, LSU, RPB2, and TEF $1 \alpha$ genes were amplified by polymerase chain reaction (PCR). The PCR amplifications were performed in a total volume of $25 \mu \mathrm{L}$ of PCR mixtures containing $9.5 \mu \mathrm{L}$ $\mathrm{ddH}_{2} \mathrm{O}, 12.5 \mu \mathrm{L}$ of PCR master mix, $1 \mu \mathrm{L}$ of DNA template, and $1 \mu \mathrm{L}$ of each primer $(10 \mu \mathrm{M})$. PCR amplification was carried out using primer pairs ITS5/ITS4 for internal transcribed spacer rDNA region (ITS1, 5.8S rDNA and ITS2), LROR/LR5 for the nuclear ribosomal large subunit 28S rDNA (LSU), fRPB2-5F/fRPB2-7cR for the partial RNA polymerase second largest subunit region (RPB2) [71-73], and EF1-983F/EF1-2218R for the partial translation elongation factor 1-alpha (TEF1 $\alpha$ ) [74]. The PCR cycling amplification conditions differed following amplified markers. For ITS and LSU, the following condition was used: $3 \mathrm{~min}$ at $94{ }^{\circ} \mathrm{C}$, followed by 35 cycles of $95^{\circ} \mathrm{C}$ for $30 \mathrm{~s}, 55^{\circ} \mathrm{C}$ for $1 \mathrm{~min}, 72{ }^{\circ} \mathrm{C}$ for $1 \mathrm{~min}$, followed by a final extension at $72{ }^{\circ} \mathrm{C}$ for $10 \mathrm{~min}$. The amplification condition for TEF1 $\alpha$ consisted of initial denaturation at $5.30 \mathrm{~min}$ at $95^{\circ} \mathrm{C}$, followed by 35 cycles of $94{ }^{\circ} \mathrm{C}$ for $1 \mathrm{~min}, 57^{\circ} \mathrm{C}$ for $30 \mathrm{~s}$ and $72{ }^{\circ} \mathrm{C}$ for $1.30 \mathrm{~min}$, followed by a final extension at $72{ }^{\circ} \mathrm{C}$ for $10 \mathrm{~min}$. The cycling profile of $3 \mathrm{~min}$ at $94^{\circ} \mathrm{C}$ followed by 35 cycles of $95^{\circ} \mathrm{C}$ for $1 \mathrm{~min}$, $52{ }^{\circ} \mathrm{C}$ for $2 \mathrm{~min}$ and $72{ }^{\circ} \mathrm{C}$ for $1 \mathrm{~min}$, followed by a final extension at $72{ }^{\circ} \mathrm{C}$ for $10 \mathrm{~min}$, was used for RPB2. The sequencing of PCR products was carried out by Sangon Biotech (Shanghai) Co., Ltd., Shanghai, China. The nuclear ribosomal internal transcribed spacer region (nrITS) of the fungi was amplified, and the sequence was deposited in GenBank to obtain the accession number.

\subsection{Sequence Alignment and Phylogenetic Analyses}

Ganoderma specimens' sequences were subjected to standard BLAST searches of GenBank to determine the primary identity of the Ganoderma species. All the other sequences of taxa closely related to our Ganoderma species were retrieved from GenBank. Sequences with high similarity indices were determined from BLAST searches to find the closest matches with taxa and from recently published literature $[31,37,75]$. All sequences used to construct the phylogenetic tree are listed in Table 3. Sanguinoderma rugosum (Blume and T. Nees) Torrend (Cui 9011), and Tomophagus colossus (TC-02) were used as the outgroup taxa [62,76]. Sequences were aligned with MAFFT online server [77] and manually adjusted using Bioedit v. 7.2.5 [78] and Clustal X softwares [79]. Alignments were checked manually and optimized to allow maximum sequence similarity. Gaps were treated as missing data. Maximum parsimony (MP) analysis was performed using the PAUP beta 10 software version 4.0 [80]. 
Clades inferred from the MP analyses were further assessed by maximum likelihood (ML) bootstraps with 1000 replicates using random step-wise sequence additions, performed using RAxML-HPC2 on XSEDE v. 8.2.8 [81] on the CIPRES webportal [82], and carried out using raxmlGUI v. 1.3.1 [83]. The best-fitting substitution model for each single gene partition and the concatenated data set was determined in MrModeltest 2.3 [84]. Bayesian posterior probabilities (PP) with the GTR $+\mathrm{I}+\mathrm{G}$ model were used for each partition. Bayesian Markov chain Monte Carlo (MCMC) analyses were conducted in MrBayes v. 3.2.2 [85]. The number of generations was set at 3,500,000, with trees being sampled every 100th generations (a total of 35,000 trees), resulting in an average standard deviation of split frequencies below 0.01 . Based on the tracer analysis, the first sampled topologies of 8,750 trees representing $25 \%$ of total trees were discarded in the burn-in phase. The remaining 26,250 trees were used for calculating posterior probability (PP) values in the majority rule consensus tree.

Phylogenetic trees were visualized with FigTree v. 1.4.0 [86] and edited using Microsoft Office PowerPoint 2010 before being exported to Adobe Illustrator CS v. 3.0. Maximum likelihood (ML) and maximum parsimony (MP) bootstrap values equal to or greater than $70 \%$ and Bayesian posterior probabilities (BP) equal to or greater than 0.95 are presented above the branches.

Table 3. GenBank accession numbers for ITS, LSU, TEF1 $\alpha$, and RPB2 sequence data of the taxa used in this study and procured from GenBank based on the earlier studies for conducting phylogenetic analyses. Details of newly amplified sequences are represented in bold.

\begin{tabular}{|c|c|c|c|c|c|c|c|}
\hline \multirow{2}{*}{$\begin{array}{l}\text { Fungal } \\
\text { Species }\end{array}$} & \multirow{2}{*}{ Voucher } & \multirow{2}{*}{ Locality } & \multicolumn{4}{|c|}{ GenBank Accession no. } & \multirow{2}{*}{ References } \\
\hline & & & ITS & LSU & RPB2 & TEF1 $\alpha$ & \\
\hline G. adspersum & GACP15061220 & Thailand & MK345425 & - & MK371437 & MK371431 & [30] \\
\hline G. adspersum & MFLU 19-2177 & Laos & MN396652 & - & MN423113 & - & This study \\
\hline G. adspersum & MFLU 19-2178 & Thailand & MN396653 & - & MN423114 & MN423149 & This study \\
\hline G. adspersum & MFLU 19-2220 & Thailand & MN396655 & MN428663 & MN423116 & MN423151 & This study \\
\hline G. angustisporum & $\begin{array}{l}\text { Cui } 13817 \\
\text { (holotype) }\end{array}$ & Fujian, China & MG279170 & - & MG367507 & MG367563 & [37] \\
\hline G. angustisporum & Cui 14578 & $\begin{array}{l}\text { Guangdong, } \\
\text { China }\end{array}$ & MG279171 & - & - & MG367564 & [37] \\
\hline G. applanatum & FIN131R610 & - & EF060004 & - & - & - & GenBank \\
\hline G. applanatum & MFLU 19-2175 & Thailand & MN396333 & - & - & - & This study \\
\hline G. applanatum & MFLU 19-2188 & China & MN396332 & - & - & - & This study \\
\hline G. aridicola & $\begin{array}{l}\text { Dai } 12588 \\
\text { (holotype) }\end{array}$ & $\begin{array}{c}\text { Durban, South } \\
\text { Africa }\end{array}$ & KU572491 & - & - & KU572502 & [87] \\
\hline G. australe & GACP14081671 & $\begin{array}{l}\text { Hainan Island, } \\
\text { China }\end{array}$ & MH106871 & - & - & - & [88] \\
\hline G. australe & GACP14061914 & China & MK345428 & - & - & MK371432 & [30] \\
\hline G. australe & MFLU 13-0534 & Thailand & KP142173 & - & - & MN423152 & [59] \\
\hline G. australe & HKAS 97397 & China & MN396656 & MN428664 & - & - & This study \\
\hline G. australe & MFLU 19-2171 & Lao & MN396657 & - & - & - & This study \\
\hline G. austroafricanum & CBS138724 & South Africa & KM507324 & KM507325 & - & - & [9] \\
\hline G. boninense & WD 2028 & Japan & KJ143905 & KU220015 & KJ143964 & KJ143924 & [76] \\
\hline G. boninense & WD 2085 & Japan & KJ143906 & - & KJ143965 & KJ143925 & [76] \\
\hline G. boninense & GbHap1 & - & MK713555 & - & - & - & GenBank \\
\hline G. boninense & GB001 & - & KX092000 & - & - & - & GenBank \\
\hline G. calidophilum & MFLU 19-2174 & $\begin{array}{l}\text { Yunnan, } \\
\text { China }\end{array}$ & MN398337 & - & - & - & This study \\
\hline G. carocalcareum & $\begin{array}{c}\text { DMC } 322 \\
\text { (holotype) }\end{array}$ & Cameroon & EU089969 & - & - & - & [46] \\
\hline G. carocalcareum & DMC 513 & Cameroon & EU089970 & - & - & - & [46] \\
\hline G. casuarinicola & $\begin{array}{c}\text { Dai } 16336 \\
\text { (holotype) }\end{array}$ & $\begin{array}{l}\text { Guangdong, } \\
\text { China }\end{array}$ & MG279173 & - & MG367508 & MG367565 & [37] \\
\hline G. casuarinicola & HKAS104639 & Thailand & MK817650 & MK817654 & MK840868 & MK871328 & [31] \\
\hline G. chocoense & QCAM3123 & Ecuador & MH890527 & - & - & - & [89] \\
\hline G. curtisii & CBS 100132 & USA & JQ781849 & - & KJ143967 & KJ143927 & [76] \\
\hline G. destructans & CMW43670 & South Africa & KR183856 & KR183860 & - & - & [9] \\
\hline G. destructans & CMW42146 & South Africa & MG020245 & - & - & MG020200 & [9] \\
\hline G. ecuadorense & ASL799 & Ecuador & KU128524 & KX228350 & - & - & [90] \\
\hline G. ecuadorense & PMC126 & Ecuador & KU128525 & KU128529 & - & - & [90] \\
\hline
\end{tabular}


Table 3. Cont.

\begin{tabular}{|c|c|c|c|c|c|c|c|}
\hline \multirow{2}{*}{$\begin{array}{l}\text { Fungal } \\
\text { Species }\end{array}$} & \multirow{2}{*}{ Voucher } & \multirow{2}{*}{ Locality } & \multicolumn{4}{|c|}{ GenBank Accession no. } & \multirow{2}{*}{ References } \\
\hline & & & ITS & LSU & RPB2 & TEF1 $\alpha$ & \\
\hline G. ellipsoideum & $\begin{array}{l}\text { GACP14080966 } \\
\text { (holotype) }\end{array}$ & Hainan, China & MH106867 & - & - & - & [88] \\
\hline G. ellipsoideum & GACP14080968 & Hainan, China & MH106868 & - & - & - & [88] \\
\hline G. ellipsoideum & MFLU 19-2221 & Thailand & MN398339 & - & - & MN423157 & This study \\
\hline G. enigmaticum & Dai 15970 & Africa & KU572486 & - & MG367513 & KU572496 & [91] \\
\hline G. enigmaticum & Dai 15971 & Africa & KU572487 & - & MG367514 & KU572497 & [91] \\
\hline G. flexipes & Wei 5494 & China & JN383979 & - & - & - & [6] \\
\hline G. flexipes & MFLU 19-2198 & $\begin{array}{l}\text { Yunnan, } \\
\text { China }\end{array}$ & MN398340 & MN428665 & - & - & This study \\
\hline G. gibbosum & $\begin{array}{c}\text { SFC20150630- } \\
23\end{array}$ & Korea & KY364264 & - & - & - & [92] \\
\hline G. gibbosum & HKAS 97411 & $\begin{array}{l}\text { Yunnan, } \\
\text { China }\end{array}$ & MN398341 & & - & - & This study \\
\hline G. gibbosum & MFLU 19-2176 & Thailand & MN396311 & - & MN423118 & - & This study \\
\hline G. gibbosum & MFLU 19-2190 & Laos & MN396310 & - & MN423117 & - & This study \\
\hline G. hochiminhense & $\begin{array}{c}\text { MFLU 19-2224 } \\
\text { (holotype) }\end{array}$ & Vietnam & MN398324 & MN396390 & 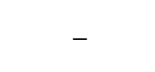 & MN423176 & This study \\
\hline G. hochiminhense & MFLU 19-2225 & Vietnam & MN396662 & MN396391 & - & MN423177 & This study \\
\hline G. hoehnelianum & Dai11995 & Yunnan, China & KU219988 & - & MG367497 & MG367550 & [91] \\
\hline G. hoehnelianum & MFLU 19-2168 & Myanmar & MN396316 & - & MN423123 & MN423158 & This study \\
\hline G. leucocontextum & Dai 15601 & China & KU572485 & - & MG367516 & KU572495 & [37] \\
\hline G. leucocontextum & HKAS 97401 & $\begin{array}{l}\text { Yunnan, } \\
\text { China }\end{array}$ & MN396317 & MN428670 & MN423124 & - & This study \\
\hline G. lingzhi & $\begin{array}{l}\text { Wu 1006-38 } \\
\text { (holotype) }\end{array}$ & Hubei, China & JQ781858 & - & JX029980 & JX029976 & [4] \\
\hline G. lobatum & JV1212/10J & USA & KF605676 & - & - & KU572501 & GenBank \\
\hline G. lucidum & Rivoire 4195 & France & KJ143909 & - & KJ143969 & - & [76] \\
\hline G. lucidum & Cui 14404 & Sichuan, China & MG279181 & - & MG367519 & MG367573 & [37] \\
\hline G. lucidum & MFLU 19-2161 & $\begin{array}{l}\text { Yunnan, } \\
\text { China }\end{array}$ & MN396338 & - & MN423135 & MN423168 & This study \\
\hline G. lucidum & MFLU 19-2162 & Thailand & MN396341 & - & MN423138 & - & This study \\
\hline G. martinicense & $\begin{array}{c}\text { LIP } \\
\text { SWMart08-55 } \\
\text { (holotype) }\end{array}$ & $\begin{array}{l}\text { Martinica, } \\
\text { France }\end{array}$ & KF963256 & - & - & - & [93] \\
\hline G. mbrekobenum & $\begin{array}{l}\text { UMN7-3GHA } \\
\text { (holotype) }\end{array}$ & Ghana & KX000896 & KX000897 & - & - & [90] \\
\hline G. mizoramense & $\begin{array}{l}\text { UMN-MZ4 } \\
\text { (holotype) }\end{array}$ & India & KY643750 & - & - & - & [94] \\
\hline G. multiplicatum & Dai 13122 & China & KU572488 & - & - & KU572498 & [95] \\
\hline G. multiplicatum & MFLU 19-2152 & $\begin{array}{l}\text { Yunnan, } \\
\text { China }\end{array}$ & MN401405 & - & - & MN423171 & This study \\
\hline G. multipileum & CWN 04670 & $\begin{array}{c}\text { Taiwan PRC, } \\
\text { China }\end{array}$ & KJ143913 & - & KJ143972 & KJ143931 & [87] \\
\hline $\begin{array}{l}\text { G. multipileum } \\
\text { G. mutabile }\end{array}$ & $\begin{array}{l}\text { MFLU 19-2166 } \\
\text { Yuan } 2289\end{array}$ & $\begin{array}{l}\text { Thailand } \\
\text { Yunnan, China }\end{array}$ & $\begin{array}{l}\text { MN401406 } \\
\text { JN383977 }\end{array}$ & $\begin{array}{l}- \\
-\end{array}$ & $\begin{array}{c}\text { MN423142 } \\
-\end{array}$ & $\begin{array}{c}\text { MN423172 } \\
-\end{array}$ & $\begin{array}{c}\text { This study } \\
\text { [76] }\end{array}$ \\
\hline G. myanmarense & $\begin{array}{c}\text { MFLU 19-2167 } \\
\text { (holotype) }\end{array}$ & Myanmar & MN396330 & MN428672 & - & - & This study \\
\hline G. myanmarense & MFLU 19-2169 & Myanmar & - & MN398325 & - & - & This study \\
\hline G. nasalaense & $\begin{array}{l}\text { GACP17060211 } \\
\text { (holotype) }\end{array}$ & Laos & MK345441 & MK346831 & - & - & {$[30]$} \\
\hline G. neojaponicum & ASI 7032 & Korea & JQ520193 & - & - & - & [96] \\
\hline G. orbiforme & Cui 13918 & Hainan, China & MG279186 & - & MG367522 & MG367576 & [37] \\
\hline G. orbiforme & GACP14061420 & Laos & MK345447 & MK346833 & - & - & [30] \\
\hline G. orbiforme & MFLU 17-1933 & Thailand & MN401408 & - & MN423144 & - & This study \\
\hline G. oregonense & CBS 265.88 & USA & JQ781875 & - & KJ143974 & KJ143933 & [76] \\
\hline G. philippii & E7098 & Malaysia & AJ536662 & - & - & - & [97] \\
\hline G. philippii & E7425 & Malaysia & AJ608713 & - & - & - & [97] \\
\hline G. philippii & MFLU 19-2222 & Thailand & MN401410 & MN398326 & - & MN423174 & This study \\
\hline G. philippii & MFLU 19-2223 & Thailand & MN401411 & MN398327 & - & MN423175 & This study \\
\hline G. podocarpense & $\begin{array}{l}\text { QCAM6422 } \\
\text { (holotype) }\end{array}$ & Ecuador & MF796661 & MF796660 & - & - & [94] \\
\hline G. resinaceum & HMAS86599 & England & AY884177 & - & JF915435 & - & GenBank \\
\hline G. resinaceum & CBS 194.76 & Netherlands & KJ143916 & - & - & KJ143934 & [76] \\
\hline G. resinaceum & MFLU 19-2153 & $\begin{array}{l}\text { Yunnan, } \\
\text { China }\end{array}$ & MN398315 & MN398328 & - & - & This study \\
\hline
\end{tabular}


Table 3. Cont.

\begin{tabular}{|c|c|c|c|c|c|c|c|}
\hline \multirow{2}{*}{$\begin{array}{l}\text { Fungal } \\
\text { Species }\end{array}$} & \multirow{2}{*}{ Voucher } & \multirow{2}{*}{ Locality } & \multicolumn{4}{|c|}{ GenBank Accession no. } & \multirow{2}{*}{ References } \\
\hline & & & ITS & LSU & RPB2 & TEF1 $\alpha$ & \\
\hline G. ryvardenii & $\begin{array}{l}\text { HKAS } 58053 \\
\text { (holotype) }\end{array}$ & $\begin{array}{l}\text { Cameroon, } \\
\text { Africa }\end{array}$ & HM138671 & - & - & - & [98] \\
\hline G. ryvardenii & HKAS 58054 & $\begin{array}{l}\text { Cameroon, } \\
\text { Africa }\end{array}$ & HM138672 & - & - & - & [98] \\
\hline G. sanduense & $\begin{array}{l}\text { GACP18012501 } \\
\text { (holotype) }\end{array}$ & China & MK345450 & - & - & - & [30] \\
\hline G. sanduense & GACP18012502 & China & MK345451 & - & - & - & [30] \\
\hline G. sessile & JV 1209/9 & USA & KF605629 & - & - & KJ143936 & [76] \\
\hline G. sessile & JV 1209/27 & USA & KF605630 & - & KJ143976 & KJ143937 & [76] \\
\hline G. shandongense & Dai 15785 & $\begin{array}{l}\text { Shandong, } \\
\text { China }\end{array}$ & MG279190 & - & MG367526 & MG367580 & [37] \\
\hline G. shandongense & Dai 15791 & $\begin{array}{l}\text { Shandong, } \\
\text { China }\end{array}$ & MG279192 & - & MG367528 & MG367582 & [37] \\
\hline G. sichuanense & $\begin{array}{c}\text { HMAS } 42798 \\
\text { (holotype) }\end{array}$ & Sichuan, China & JQ781877 & - & - & - & [4] \\
\hline G. sichuanense & MFLU 19-2164 & Thailand & MN396324 & - & MN423130 & MN423163 & This study \\
\hline G. sichuanense & HKAS 97398 & $\begin{array}{l}\text { Yunnan, } \\
\text { China }\end{array}$ & MN396319 & - & MN423126 & MN423159 & This study \\
\hline G. sichuanense & CGMCC5.2175 & Sichuan, China & KC662402 & - & - & - & [99] \\
\hline G. sinense & Wei 5327 & Hainan, China & KF494998 & KF495008 & MG367529 & KF494976 & [37] \\
\hline G. sinense & MFLU 19-2172 & Thailand & MN398319 & MN398332 & MN423146 & - & This study \\
\hline G. sinense & MLFU 19-2173 & $\begin{array}{l}\text { Yunnan, } \\
\text { China }\end{array}$ & MN398316 & MN398329 & - & - & This study \\
\hline G. steyaertianum & MEL:2382783 & Australia & КР012964 & - & - & - & GenBank \\
\hline G. steyaertianum & $6 \mathrm{WN} 20 \mathrm{~B}$ & Indonesia & KJ654462 & - & - & - & [100] \\
\hline G. subresinosum & $\begin{array}{c}\text { 7-SU-3-C-70 } \\
\text { (M)-B }\end{array}$ & Indonesia & KJ654472 & - & - & - & GenBank \\
\hline G. subresinosum & MFLU 17-1912 & Thailand & MN398321 & - & - & - & This study \\
\hline G. thailandicum & $\begin{array}{l}\text { HKAS104640 } \\
\text { (holotype) }\end{array}$ & Thailand & MK848681 & MK849879 & MK875831 & MK875829 & [31] \\
\hline G. thailandicum & HKAS104641 & Thailand & MK848682 & MK849880 & MK875832 & MK875830 & [31] \\
\hline G. tropicum & Yuan 3490 & Yunnan, China & JQ781880 & - & - & KJ143938 & [4] \\
\hline G. tropicum & Dai 16434 & Hainan, China & MG279194 & - & MG367532 & MG367585 & [37] \\
\hline G. tropicum & HKAS 97486 & Thailand & MH823539 & MH823540 & MH883621 & - & [75] \\
\hline G. tsugae & Dai12751b & USA & KJ143919 & - & KJ143977 & KJ143939 & {$[76]$} \\
\hline G. tsugae & HKAS 97406 & $\begin{array}{l}\text { Yunnan, } \\
\text { China }\end{array}$ & MG279195 & - & MG367533 & MG367586 & This study \\
\hline G. valesiacum & CBS428.84 & USA & JQ520218 & - & - & - & [96] \\
\hline G. weberianum & CBS219.36 & Philippines & JQ520219 & - & - & - & [96] \\
\hline G. weberianum & GanoTK17 & Cameroon & JN105705 & - & - & - & GenBank \\
\hline G. wiiroense & $\begin{array}{l}\text { UMN-20-GHA } \\
\text { (para type) }\end{array}$ & Ghana & KT952361 & - & - & - & [101] \\
\hline G. williamsianum & Dai 16809 & Thailand & MG279183 & - & MG367535 & MG367588 & [101] \\
\hline G. williamsianum & MFLU 19-2170 & Myanmar & MN398323 & MN398334 & - & - & This study \\
\hline G. wuzhishanense & GACP14081689 & Hainan, China & KU994772 & - & - & - & {$[76,102]$} \\
\hline G. zonatum & FL-02 & USA & KJ143921 & - & KJ143979 & KJ143941 & [76] \\
\hline $\begin{array}{l}\text { Sanguinoderma } \\
\text { rugosum }\end{array}$ & Cui 9011 & $\begin{array}{l}\text { Guangdong, } \\
\text { China }\end{array}$ & KJ531664 & - & MG367506 & KU572504 & {$[79]$} \\
\hline Tomophagus colossus & TC-02 & Vietnam & KJ143923 & - & - & KJ143943 & [76] \\
\hline
\end{tabular}

\section{Results}

In this study, we morphologically and phylogenetically analyze and report 22 Ganoderma species from the GMS, namely, G. adspersum, G. applanatum, G. australe, G. calidophilum, G. ellipsoideum, G. flexipes, G. gibbosum, G. heohnelianum, G. hochiminhense, G. leucocontextum, G. lucidum, G. multiplicatum, G. multipileum, G. myanmarense, G. orbiforme, G. philippii, G. resinaceum, G. sichuanense, G. sinense, G. subresinosum, G. williamsianum, and G. tsugae. Of these 22 species, 12 were from Yunnan Province, China; three were from Laos; three species, two new records, and one new species were from Myanmar; 15 species and four new records were from Thailand; and one new species was from Vietnam. The phylogenetic and morphological analyses results of the 22 Ganoderma species are detailed below. 


\subsection{Phylogenetic Analyses}

Phylogenetic analyses were inferred from the combined data set of ITS, LSU, RPB2, and TEF $1 \alpha$ sequences of 114 taxa, of which 112 taxa belong to the genus Ganoderma, and the remaining 2, Sanguinoderma rugosum Blume and T. Nees (Cui 9011) and Tomophagus colossus (Fr.) Murrill, Torreya (TC-02) are the outgroup taxa. The data set comprised 3524 characters with gaps (637 characters for ITS, 866 characters for LSU, 1016 characters for RPB2, and 1005 characters for TEF $1 \alpha$ ), of which 2459 characters were constant, 855 characters were variable and parsimony-informative, and 210 characters were parsimony-uninformative. Tree topologies resulted from the ML analysis were similar to that of the MP and Bayesian analysis. Hence, the best-scoring ML tree is shown in Figure 3.

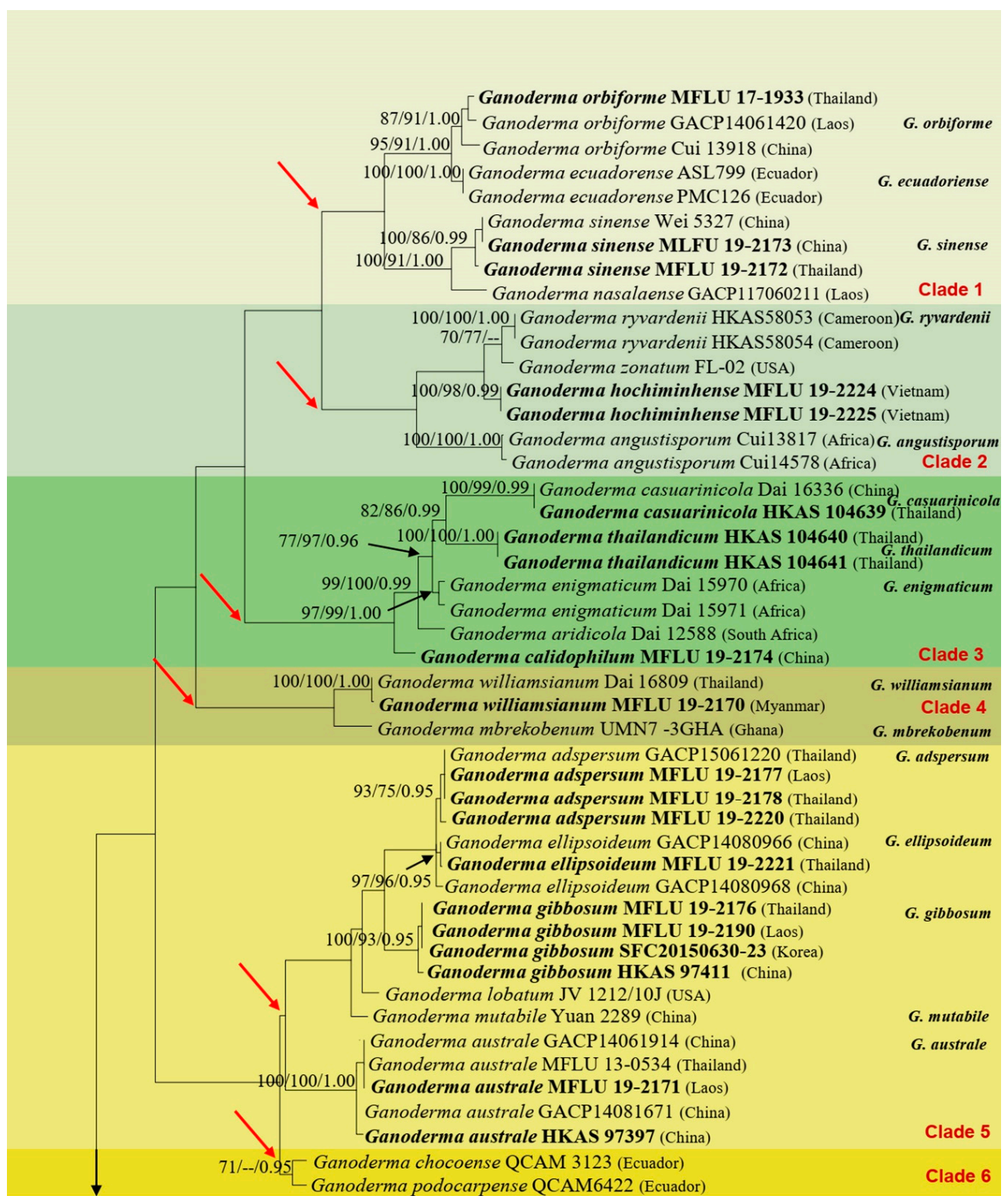

Figure 3. Cont. 


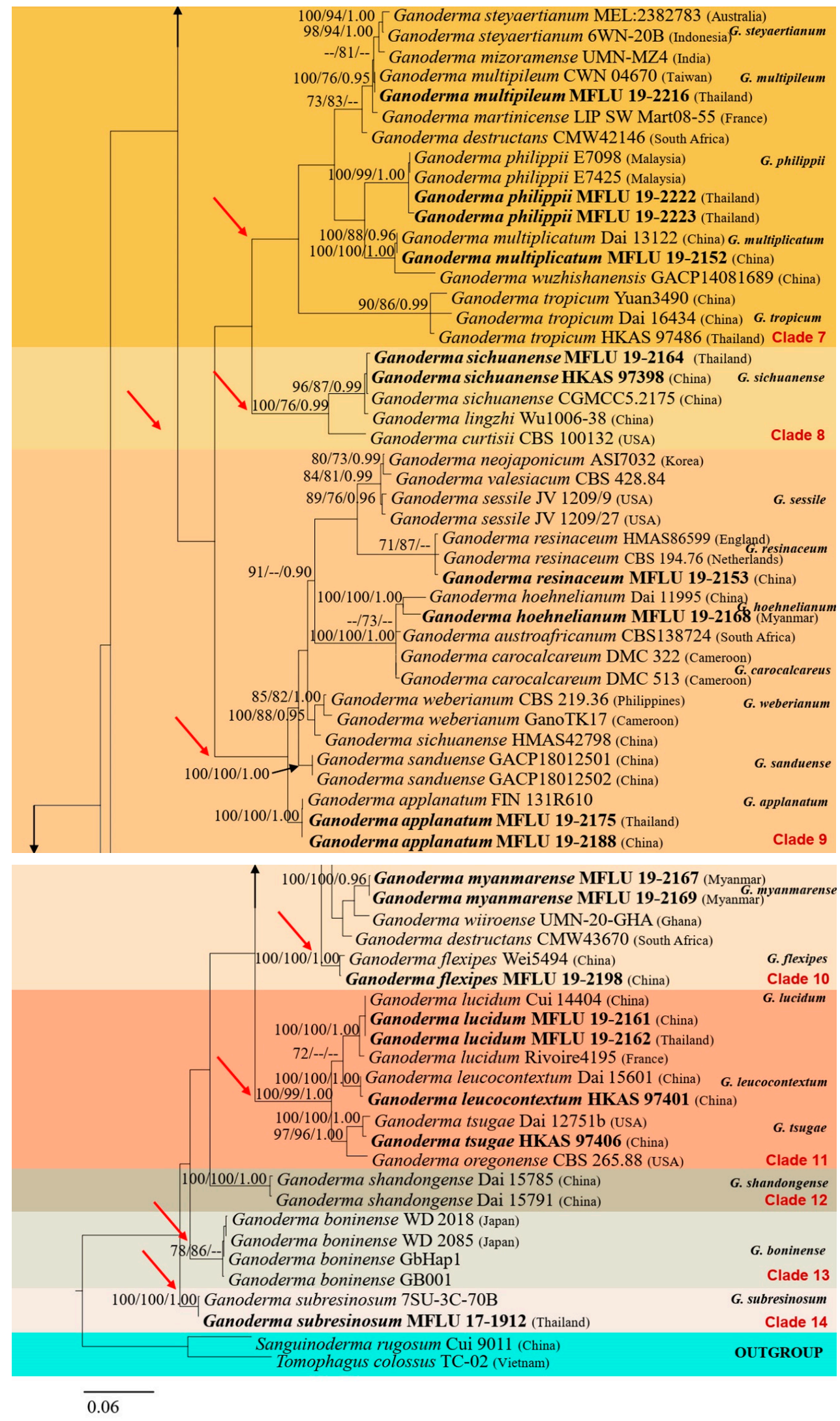

Figure 3. Maximum likelihood phylogenetic tree ML obtained from the DNA sequence data of ITS, LSU, RPB2, and TEF1 $\alpha$ data sets. Bootstrap values BS from maximum likelihood ML, left, maximum parsimony MP, middle, equal to or greater than $70 \%$ and Bayesian posterior probabilities PP, right, equal to or greater than 0.95 are indicated above or below the nodes as MLBS/MPBS/PP. The tree is rooted with Sanguinoderma rugosum Cui 9011 and Tomophagus colossus TC-02. New species, new record species, and known species obtained in this study are indicated in bold black. 
Ganoderma specimens used for this study, based on the collections made from China, Laos, Myanmar, Thailand, and Vietnam, were all placed within the Ganoderma clade. The phylogenetic tree includes 14 laccate clades, one non-laccate clade, and an outgroup clade. In this study, of a total of 22 Ganoderma species, 13 species (viz. G. australe, G. calidophilum, G. flexipes, G. gibbosum, G. leucocontextum, G. applanatum, G. lucidum, G. multiplicatum, G. resinaceum, G. sanduense, G. sichuanense, G. sinense, G. tsugae) from Yunnan Province, China, 3 Ganoderma species (G. adspersum, G. australe, G. gibbosum) from Laos, 2 Ganoderma species (G. hoehnelianum, G. williamsianum) from Myanmar, and 11 Ganoderma species (G. adspersum, G. applanatum, G. ellipsoideum, G. gibbosum, G. lucidum, G. multipileum, G. orbiforme, G. philippii, G. sichuanense, G. sinense, G. subresinosum) are reported from Thailand. Furthermore, two taxa, viz. G. myanmarense from Myanmar and G. hochiminhense from Vietnam, are described here as new species. The tree topologies provided considerably high support in the terminal nodes but failed to recover deeper nodes with high statistical support. The details of 13 Ganoderma species clades are provided in the following:

Clade 1 was statistically unsupported and comprised four species, viz. G. orbiforme, G. ecuadorense, G. sinense, and G. nasalaense. Three sequences of the laccate G. orbiforme from China, Laos, and Thailand clustered together with significant support values $(\mathrm{MLBS}=87 \% / \mathrm{MPBS}=91 \% / \mathrm{PP}=1.00)$, suggesting all of them to be the morphotype of the same taxon. However, G. orbiforme is closely related to G. ecuadorense but differed by strong statistical support $(\mathrm{MLBS}=95 \% / \mathrm{MPBS}=91 \% / \mathrm{PP}=1.00)$. Two isolates of G. sinense from China and Thailand clustered together (MLBS $=100 \% / \mathrm{MPBS}=86 \% / \mathrm{PP}$ $=0.99$ ) and show genotypic closeness with the taxon $G$. nasalaense $(\mathrm{MLBS}=100 \% / \mathrm{MPBS}$ $=91 \% / \mathrm{PP}=1.00)$. Clade 2 consists of the laccate G. angustisporum, G. ryvardenii, G. zonatum, and G. hochiminhense (MFLU 19-2224 and MFLU 19-2225). Two sequences of the newly described species, G. hochiminhense, from Vietnam clustered together with strong support values $(\mathrm{MLBS}=100 \% / \mathrm{MPBS}=98 \% / \mathrm{PP}=0.99)$ and comes sister to G. ryvardenii and G. zonatum although, this position is statistically unsupported.

Clade 3 was strongly supported (MLBS $=97 \% / \mathrm{MPBS}=99 \% / \mathrm{PP}=1.00)$ and contains the laccate G. casuarinicola from China (Dai 16336) and Thailand (HKAS 104639), two sequences of G. thailandicum (HKAS 104640 and HKAS 104641) from Thailand, G. enigmaticum (Dai 15970 and Dai 15971) from Africa, G. aridicola (Dai 12588) from South Africa and G. calidophilum (MFLU 19-2174) from China. Basal to Clade 3, two species viz. G. williamsianum and G. mbrekobenum formed Clade 4. The newly generated sequence of G. williamsianum from Myanmar (MFLU 19-2170) clustered with the same taxon sequence, previously deposited in the GenBank nucleotide database from Thailand (Dai 16809), with full support values $(\mathrm{MLBS}=100 \% / \mathrm{MPBS}=100 \% / \mathrm{PP}=1.00)$. The molecular data confirmed the presence of G. williamsianum in Myanmar, and this holds the first distributional record of the taxon from Myanmar.

Clade 5 consists of the non-laccate G. adspersum from Thailand (MFLU 19-2178 and MFLU 19-2220) and Laos (MFLU 19-2177) (MLBS = 93\%/MPBS = 75\%/PP = 0.95); holotype sequence of G. ellipsoideum from China (GACP14080966 and GACP14080968) and Thailand $(\mathrm{MFLU} 19-2221)(\mathrm{MLBS}=97 \% / \mathrm{MPBS}=96 \% / \mathrm{PP}=0.95) ; \mathrm{G}$. gibbosum from Laos (MFLU 19-2190), Thailand (MFLU 19-2176), China (HKAS 97411), and Korea (SFC20150630-23) $(\mathrm{MLBS}=100 \% / \mathrm{MPBS}=93 \% / \mathrm{PP}=0.95) ;$ G. lobatum (JV 1212/10J) from USA; G. mutabile (Yuan 2289) from China; and five sequences of G. australe from China (HKAS 97397, GACP14061914, GACP14081671), Thailand (MFLU 13-0534), and Laos (MFLU 19-2171) $(\mathrm{MLBS}=100 \% / \mathrm{MPBS}=100 \% / \mathrm{PP}=1.00)$. However, this clade is statistically unsupported

Clade 6 is formed by the cluster of Ecuadorean Ganoderma species viz. G. chocoense (QCAM 3123) and G. podocarpense (QCAM6422). This clade was unsupported by the maximum parsimony analysis but weakly supported by the maximum likelihood and Bayesian analyses (MLBS $=71 \% / \mathrm{PP}=0.95)$.

Clade 7 is statistically unsupported. This clade comprises of the isolate of the laccate G. multipileum from Thailand (MFLU 19-2216) and Taiwan, PRC (CWN 04670) (MLBS $=100 \% / \mathrm{MPBS}=76 / \mathrm{PP}=0.95)$ and shows its genetic closeness with that of $\mathrm{G}$. steyaer- 
tianum, G. mizoramense and G. destructans. Two newly amplified sequences of G. philippii from Thailand (MFLU 19-2222 and MFLU 19-2223) clustered with strong support values $(\mathrm{MLBS}=100 \% / \mathrm{MPBS}=99 / \mathrm{PP}=1.00)$ with the same species sequence, previously deposited from Malaysia (E7098 and E7425). The Chinese (Yuan 3490 and Dai 16434) and Thailand (HKAS 97486) strains of G. tropicum comes basal to this clade but, this position is not supported statistically. In Clade 8, two newly amplified sequences of G. sichuanense from China (HKAS 97398) and Thailand (MFLU 19-2164) clustered with strong support values $(\mathrm{MLBS}=96 \% / \mathrm{MPBS}=87 \% / \mathrm{PP}=0.99)$ with the sequence of the same species $\mathrm{G}$. sichuanense (CGMCC52175). Moreover, one of the Chinese sequences, G. lingzhi (Wu1006-38), clustered with all the three sequences of $G$. sichuanense, we suggesting wrong identification. earlier deposited in GenBank from China, G. curtisii stands sister to G. sichuanense, and this position is strongly supported (MLBS $=100 \% / \mathrm{MPBS}=76 \% / \mathrm{PP}=0.99$ ).

Clade 9 comprised five small subclades. The laccate G. sessile along with G. neojaponicum and G. valesiacum formed a subclade with moderate support (MLBS $=84 \% / \mathrm{MPBS}$ $=81 \% / \mathrm{PP}=0.99)$. Sister to this subclade, there remains another subclade containing the Chinese G. resinaceum along with sequences of the same taxon from the Netherlands (CBS 194.76) and England (HMAS86599) but, this position is statistically unsupported. The newly generated sequence of $G$. hoehnelianum from Myanmar (MFLU 19-2168) formed the next subclade with that of the Chinese collection (Dai 11995) and showed its genetic closeness with the laccate G. carocalcareum (DMC 322 and DMC 513) and G. austroafricanum (CBS138724) with full support values (MLBS $=100 \% / \mathrm{MPBS}=100 \% / \mathrm{PP}=$ 1.00). This subclade was followed by the cluster of two species viz. G. weberianum (CBS 219.36, GanoTK 17) and G. sichuanense (HMAS42798), but the position of these two taxa was statistically unsupported. Two Chinese sequences of G. sanduense (GACP18012501 and GACP18012502) form the next subclade. The basal subclade contained two newly generated sequences of G. applanatum from Thailand (MFLU 19-2175) and China (MFLU 19-2188) along with the previously deposited sequence of the same taxon with strong support values $(\mathrm{MLBS}=100 \% / \mathrm{MPBS}=100 \% / \mathrm{PP}=1.00)$. The newly described taxon, G. myanmarense from Myanmar (MFLU 19-2167 and MFLU 19-2169), falls in Clade 10 where the new species shows its genetic similarity with that of the laccate G. wiiroense from Ghana (UMN-20-GHA) and G. destructans from South Africa (CMW43670). G. flexipes remains basal to this cluster (Wei5494 and MFLU 19-2198). The newly generated sequence of G. flexipes (MFLU 19-2198) shows its full identity with one of the previously deposited Chinese G. flexipes sequences (Wei5494) and clustered with full support values (MLBS $=100 \% / \mathrm{MPBS}=100 \% / \mathrm{PP}=1.00$ ).

Clade 11 was enriched with the G. lucidum species complex where four sequences of G. lucidum from three countries viz. Thailand (MFLU 19-2162), China (MFLU 19-2161 and Cui $14404)$, and France clustered together $(\mathrm{MLBS}=100 \% / \mathrm{MPBS}=100 \% / \mathrm{PP}=1.00)$ and revealed G. leucocontextum (Dai 15601 and HKAS 97401), G. tsugae (Dai 12751b, HKAS 97406), G. oregonense as sister taxa with strong support values (MLBS $=100 \% / \mathrm{MPBS}=99 \% / \mathrm{PP}=1.00$ ).

Two sequences of the taxon G. shandongense (Dai 15785 and Dai 15791) formed Clade 12. This small clade was followed by another clade, Clade 13, which comprised of four sequences of $G$. boninense (Clade 13).

Clade 14 was the extreme basal clade where the sequence of G. subresinosum (MFLU 17-1912), collected from Thailand (MFLU 17-1912), clustered with full support (MLBS = 100\%/ $\mathrm{MPBS}=100 \% / \mathrm{PP}=1.00$ ) with one of the earlier sequences of the same taxon, deposited in the nucleotide sequence database.

\subsection{Taxonomy}

Ganoderma P. Karst., Revue Mycologique Toulouse. 3(9): 17 (1881)

= Dendrophagus Murrill, Bull. Torrey bot. Club. 32(9): 473 (1905)

= Elfuingia P. Karst., Bidr. Känn. Finl. Nat. Folk. 48: 333 (1889)

= Friesia Lázaro Ibiza, Revista Real Acad. Ci. Madrid. 14: 587 (1916)

= Ganoderma subgen. Trachyderma Imazeki, Bull. Tokyo Sci. Mus. 1: 49 (1939)

= Tomophagus Murrill, Torreya. 5: 197 (1905) 
= Trachyderma (Imazeki) Imazeki, Bull. Gov. Forest Exp. Stn Tokyo. $57: 97$ (1952)

Type species: Ganoderma lucidum (Leyss: Fr.) Karst.

Notes: (三) is homotypic, or nomenclatural, synonyms, $(=)$ is heterotypic, or taxonomic, synonyms.

Description: Basidiomes annual, dimidiate, sessile or sub-stipitate to stipitate. Pileus subdimidiate to dimidiate, flabelliform, perennial, stipitate or sessile. Pileus surface nonlaccate (dull) or weakly to strongly laccate, glossy, shiny, smooth, spathulate, shallow, furrows, sulcate, several layers thick, with thin- to thick-cuticle cells or cuticle of clavate end cells, thicker at the base than the margin, thin- to thick-crust overlaying the pileus, consistency hard, consistency hard, light weight when dried. Pileus color variable, light yellow to yellow, light brown, slightly brown to dark brown, sometimes homogeneous reddish gray to reddish-yellow. Context brown to dark brown, grayish orange to orange, sometimes grayish-yellow, mostly soft, sometimes spongy to firm-fibrous. Hymenophore di-trimitic, heterogeneous, non-septate or septate, usually yellow, slightly light orange, or light brown to brown, sometimes with melanoid bands. Tubes are hard, woody when dried. Tube layers single or stratified, pale to purplish-brown, almost hyaline with clamp connections, occasionally branched at apex, thin- to thick-walled. Stipe central or lateral, glossy with a distinct cuticle. Margin actively growing, entirely white when fresh, round, soft and smooth when young, slippery when touched from youth to maturity, and tough when broken. Pores 4-7 in number per $\mathrm{mm}$, angular, entire, subcircular to circular, regular, cream or white when young, light yellow, light orange to brown when mature. Pore surface usually white to cream when fresh, turning yellowish-white to pale yellow on drying, some sections reddish gray to brown, and brownish gray when wet.

Hyphal structure: Hyphal system di-trimitic, including generative, skeletal, and binding hyphae; mostly generative hyphae with clamp connections, hyaline, brown, non-septate, or septate, often with long and tapering branches. Basidia broadly ellipsoid, tapering abruptly at the base. Cystidia absent. Basidiospores broadly to narrowly ellipsoid or oblong, sometimes globose to subglobose, with double walls, truncate apex, apical germ pore present, usually with light brown to brown endosporium, hyaline exosporium with thin inter-walled pillars, hyaline endosporium with thick outer walls, and some very thin exosporium.

Ecology: mostly on hardwoods, trunks, and stumps, occurring on several different living tree host species.

Notes: Justo et al. [103] treated Ganodermataceae as a synonym of Polyporaceae and included the genus Ganoderma under Polyporaceae. Later, Cui et al. [104] excluded Ganoderma from Polyporaceae due to the presence of double-walled basidiospores, unlike Polyporaceae. So, the distinctiveness of the genus Ganoderma lies in the presence of doublewalled and truncate basidiospores. Species with a laccate, glossy surface are present in both Ganodermataceae and Polyporaceae as centrally and laterally stipitate species.

\subsubsection{Taxonomy of Ganoderma from China}

Ganoderma angustisporum J.H. Xing, B.K. Cui and Y.C. Dai, Mycokeys 34: 98 (2018) Taxonomy and phylogenic analysis were described in Xing et al. [37]

Notes: Ganoderma angustisporum is characterized by annual, sessile, broadly basidiomes, strongly laccate on the upper surface of basidiomes, white pore surfaces, and almondshaped, slightly truncate, narrow 9.0-11.3 $\times 4.0-5.2 \mu \mathrm{m}$ basidiospores. It is a group of white-rot fungi that predominantly grow on living Casuarina equisetifolia in Fujian Province, China.

Ganoderma applanatum (Pers.) Pat., Hymenomyc. Eur. (Paris): 143 (1887) (Figure 4)

$\equiv$ Boletus lipsiensis Batsch, Elenchus fungorum. Continuatio prima.: 183, t. 25:130 (1786)

三Scindalma lipsiense (Batsch) Kuntze, Revisio generum plantarum. 3(2): 518 (1898)

$\equiv$ Polyporus lipsiensis (Batsch) E.H.L. Krause, Basidiomycetes Rostochienses.: 54 (1928) 
$\equiv$ Agaricus lipsiensis (Batsch) E.H.L. Krause, Basidiomycetum Rostochiensium, Suppl. 4: 142 (1932)

= Boletus applanatus Pers., Observationes mycologicae. 2: 2 (1799)

= Polyporus merismoides Corda, Deutschlands Flora, Abt. III. Die Pilze Deutschlands. 3: 139 (1837)

= Polyporus stevenii Lév., Annls Sci. nat., Bot.: 91 (1844)

= Polyporus leucophaeus Mont., Sylloge generum specierumque plantarum cryptogamarum.: 157 (1856)

= Polyporus leucophaeum Mont. (1856)

= Polyporus incrassatus Berk., Journal of the Linnean Society. Botany. 16: 41 (1877)

= Polyporus concentricus Cooke, Grevillea. 9(49): 13 (1880)

= Fomes gelsicola Berl., Malpighia. 3: 373 (1889)

= Fomes nigriporus Lázaro Ibiza, Revista de la Real Academia de Ciencias Exactas Fisicas y Naturales Madri. 14: 662 (1916)

= Ungularia subganodermica Lázaro Ibiza, Revista de la Real Academia de Ciencias Exactas Fisicas y Naturales Madri. 14: 674 (1916)

= Fomes longoporus Lloyd, Mycological Writings. 6(62): 940 (1920)

Facesoffungi number: FoF 06249

Description: Basidiomes annual, perennial, sessile. Pileus $1.5-5.8 \mathrm{~cm}$ in length, $0.5-4.5 \mathrm{~cm}$ in width, and up to $1.5 \mathrm{~cm}$ thick at the base, sessile (without stipe), perennial, subdimidiate, sub-flabelliform to flabelliform, usually flat, convex, imbricate, umbonate or uneven, rarely ungulate, glabrous when present, broadly attached when mature, often with undefined concentric zones at the center that extend to the margin, thick at the base, slightly soft at the margin when mature. Pileus surface shiny, silky, smooth, and soft when young, hard when old, frequently furrowed and shallow sulcate, undulating, somewhat spathulate to uneven on the upper surface when mature, covered by irregularly ruptured thick crust, slightly non-laccate (dull) and faded from when mature to old, compact and hard when mature, woody to corky when old. Pileus color is usually homogenous with grayish-orange (6B3-6B5) at the center, slight brownish-orange (6C4), orange white (6A2), to pale orange (6A3), with yellowish-gray (4B2) at the margin when mature. Context up to $0.3-1 \mathrm{~cm}$ thick at the base, mostly light brown (7D5), brown (6E8) to dark brown (7F6-7F8) of cuticle cells, with walls varying in thickness to subsolid hyphae, some fibrous pithy context, usually separated by layers of context tissue at the base, and some occurred woody lines. Tube woody, hard, often dark brown (7F7-7F8) when dried, with sulcate at different levels. Stipe almost sessile and broadly attached when present, with a differentiated zone at the point of attachment. Margin up to $1 \mathrm{~cm}$ thick, white (5A1), yellowish-gray (4B2) when mature, turns light brown (6D4) to brown (6E8) when scratched or bruised, often slippery when wet, soft when young, thinner than the center. Pore 4-6 in number per mm, subcircular to circular, sometimes angular. Pore surface initially white (7A1), grayish-orange (7C3-7C4) when mature, turning to light brown (7D6) to brown (7D8) when scratched or bruised.

Hyphal structure: Hyphal system trimitic; generative hyphae 0.8-2.6 $\mu \mathrm{m}(\bar{x}=2.1$, $n=30$ ) in diam, almost hyaline, with clamp connections, abundant, thin-walled and occasionally thick-walled; skeletal hyphae 2.1-4.6 $\mu \mathrm{m}$ width $(n=30)$, usually thick-walled, hyaline, sometimes branched; binding hyphal 1.6-3.3 $\mu \mathrm{m}$ width $(n=30)$, thick-walled and occasionally thin-walled, branched, and intertwined with the skeletal hyphae. Pileipellis a hymeniderm, grayish brown (6E4), which is composed of apically acanthus-like branched cells. Basidiospores mostly ellipsoid with double walls, with a size range of (9.8-)10.4-11.1$11.9(-12.1) \times(7.3-) 8.0-8.6-9.2(-9.9) \mu \mathrm{m},(\bar{x}=11.3 \times 8.7 \mu \mathrm{m}, n=50) \mu \mathrm{m}$, with $\mathrm{Q}=1.79-1.86$, $\mathrm{L}=11.23 \mu \mathrm{m}, \mathrm{W}=6.12 \mu \mathrm{m}$ (including myxosporium), $(6.2-) 7.6-8.6-9.7(-10.4) \times(5.0-)$ 5.8-7.1-8.2(-8.9) $\mu \mathrm{m}(\bar{x}=8.6 \times 7.1 \mu \mathrm{m}, n=50) \mu \mathrm{m}$, with $\mathrm{Q}=1.19-1.24, \mathrm{~L}=8.59 \mu \mathrm{m}$, $\mathrm{W}=7.12 \mu \mathrm{m}$ (excluding outer myxosporium), brownish-orange (7D4) to brown (7D77D8) in $\mathrm{KOH}$, and reddish-brown (8E6) to dark brown (8F4) in Melzer's reagent. Basidia 14-20 × 8-10 $\mu \mathrm{m}$, with four sterigmata. 

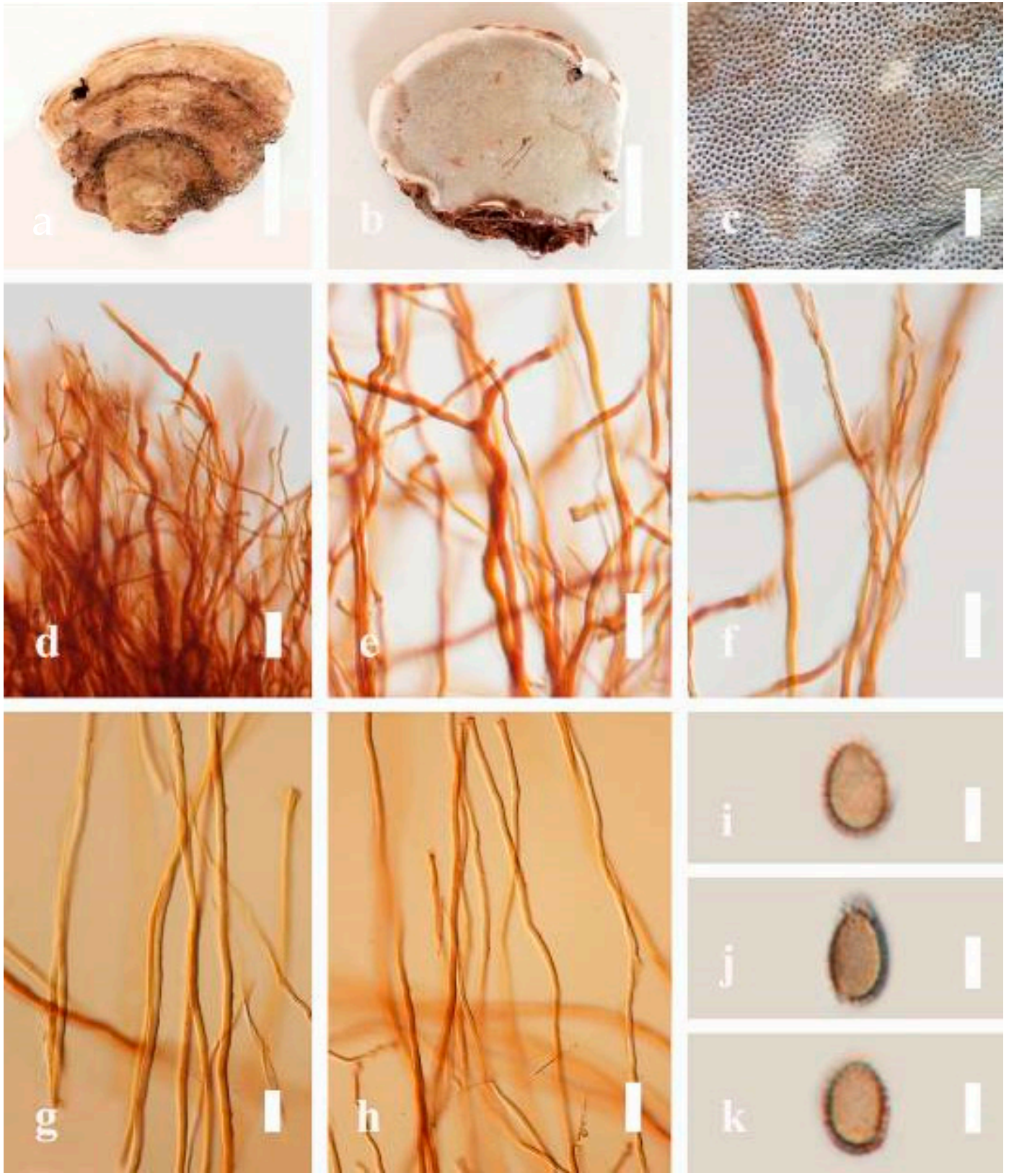

Figure 4. Morphology of Ganoderma applanatum (HKAS 107254, MFLU 19-2188): (a,b) mature basidiomes; (c) pore characteristics; (d-f) hyphae of trama in $\mathrm{KOH} ;(\mathbf{g}, \mathbf{h})$ generative hyphae of context in $\mathrm{KOH}$; $(\mathbf{i}-\mathbf{k})$ basidiospores. Scale bars: $(\mathbf{a}, \mathbf{b})=2 \mathrm{~cm},(\mathbf{c})=1000 \mu \mathrm{m},(\mathbf{d}-\mathbf{h})=20 \mu \mathrm{m},(\mathbf{i}-\mathbf{k})=5 \mu \mathrm{m}$.

Ecology: Solitary on stump of Machilus yunnanensis.

Specimens examined: CHINA, Yunnan Province, Baoshan, $25^{\circ} 09^{\prime} 35^{\prime \prime} \mathrm{N}, 99^{\circ} 09^{\prime} 49^{\prime \prime} \mathrm{E}$, 1973 m elev., 11 November 2017, T. Luangharn, HKAS 107254, MFLU 19-2188.

Notes: Ganoderma lipsiense has been treated by some researchers as the correct name for G. applanatum [15]. G. applanatum (=G. lipsiense) belongs in the subgenus Elfoingia, which is characterized by distinctive non-laccate species, a thin and acute margin of the pileus, and unbranched terminal endings of skeletal hyphae, with ellipsoid basidiospores [47,105-107]. G. applanatum causes white butt rot on angiosperm trees and is widely distributed in China [64]. Hence, our specimen of G. applanatum, collected from a temperate region of China, is described based on morphological characteristics and molecular phylogenetic data. Our results agree well with those of Ryvarden and Gilbertson [105].

Ganoderma australe (Fr.) Pat., Bull. Soc. mycol. Fr. 5(2-3): 65 (1889) (Figure 5) 
$\equiv$ Polyporus australis Fr., Elenchus Fungorum. 1: 108 (1828)

$\equiv$ Fomes australis (Fr.) Cooke, Grevillea. 14(69): 18 (1885)

$\equiv$ Placodes australis (Fr.) Quél., Enchiridion Fungorum in Europa media et praesertim in Gallia Vigentium. 171 (1886)

$\equiv$ Fomes applanatus var. australeis (Fr.) Cleland and Cheel, Journal of Proceedings of the Royal Society of New South Wales. 51: 518 (1918)

$\equiv$ Ganoderma applanatum subsp. australe (Fr.) Bourdot and Galzin, Bulletin de la Société Mycologique de France. 41: 184 (1925)

$\equiv$ Ganoderma applanatum f. australe (Fr.) Bourdot and Galzin, Bulletin de la Société Mycologique de France. 41: 184 (1925)

$\equiv$ Elfvingia australis (Fr.) G. Cunn., Bulletin of the New Zealand Department of Industrial Research. 164: 256 (1965)

= Polyporus tornatus Pers., Botanique (Nagpur). 5: 173 (1827)

= Polyporus scansilis Berk., Journal of the Linnean Society. Botany. 16: 53 (1877)

= Fomes annularis Lloyd, Mycol. Writ. 4(40): 6 (1912)

= Ganoderma tornatum var. tornatum (Pers.) Bres., Hedwigia. 53(1-2): 55 (1912)

$=$ Fomes konigsbergii Lloyd (1915)

= Fomes polyzonus Lloyd, Synopsis of the genus Fomes. (7): 269 (1915)

= Fomes pseudoaustraleis Lloyd, Synopsis of the genus Fomes. (7): 269 (1915)

= Fomes undatus Lázaro Ibiza, Revista de la Real Academia de Ciencias Exactas Fisicasy

Naturales Madri. 14: 661 (1916)

Facesoffungi number: FoF 06242

Description: Basidiomes annual, perennial, subdimidiate, sessile. Pileus $14-28 \mathrm{~cm}$ in length, $12-32 \mathrm{~cm}$ in width, and 1.4-3.2 cm thick. Pileus flabelliform, spathulate, subdimidiate, umbonate, single, sulcate, large, obtuse from host, radial from the center extending the margin, broadly attached, often thick at the center, slightly soft at the margin, consistency hard, and tough to break when dried. Pileus surface convex, corky, furrowed, spathulate, mostly umbonate or uneven, non-laccate (dull) on maturity or in old, usually slippery where the new hyphae are in active development (margin), slightly concentrically sulcate at the center toward margin, smooth, covered with thick and hard crust, irregularly ruptured crust overlying the surface, woody, and corky when dried, with cracked crust when mature, and tough to break when dried. Pileus color often brown (6E7-6E8) at the base, reddishorange (7B7-7B8), brownish-orange (7C6-7C8), almost covered with grayish-red (8C4-8C5) on the upper surface when old, slight reddish-brown (8F8, 9E7-9E8) close to the margin. Context up to $0.5-2 \mathrm{~cm}$ thick near stipe, fibrous, composed of coarse loose fibrils, brown (6D7-6D8) to dark brown (6F7), with reddish-brown (8D8-8D9) coarse loose fibrils, covered with thick crust. Tube $0.4-1.5 \mathrm{~cm}$ long, brown (7D8) to dark brown (6F8). Stipe sessile, broadly attached. Margin soft when young, slippery when fresh, blunt when mature, white (4A1). Pore 4-6 in number per $\mathrm{mm}$, subcircular to circular, sometimes angular. Pore surface initially white (4A1), slight to pale yellow (4A3) when mature, turned brownish-orange (6C7-6C8) when scratched or bruised or discolored when touched.

Hyphal structure: Hyphal system trimitic, dense and hard, thick-walled, typically with narrow lumen, flexuous, and many branches, usually brownish-orange (6C5-6C7) in $\mathrm{KOH}$; generative hyphae 2.2-3.8 $\mu \mathrm{m}$ broad $(n=30)$, thin-walled, hyaline, tapering at branch, with clamp connections; skeletal hyphae 2.9-4.2 $\mu \mathrm{m}$ broad $(n=30)$, sometimes branched, nearly solid, thick-walled; binding hyphae $2.6-4.0 \mu \mathrm{m}$ broad $(n=30)$, thickwalled, branched, more or less solid; hymenial with sword-like apices in the context. Pileipellis a hymeniderm, usually brownish-orange (6C5) to brown (6E8), composed of apically acanthus-like branched cells. Basidiospores mostly ellipsoid to broadly ellipsoid, double walls, (6.2-)7.1-9.4-10.4(-11.8) $\times(5.2-) 6.0-7.4-8.9(-9.7) \mu \mathrm{m}(\bar{x}=9.4 \times 7.4 \mu \mathrm{m}$, $n=50) \mu \mathrm{m}$, with $\mathrm{Q}=1.24-1.30, \mathrm{~L}=9.42 \mu \mathrm{m}, \mathrm{W}=7.43 \mu \mathrm{m}$ (including myxosporium), (5.3-) 6.7-7.8-9.6(-10.5) $\times(4.5-) 5.1-5.7-6.3(-7.2) \mu \mathrm{m}(\bar{x}=7.8 \times 5.7 \mu \mathrm{m}, n=50) \mu \mathrm{m}$, with $\mathrm{Q}=1.31-1.38, \mathrm{~L}=7.85 \mu \mathrm{m}, \mathrm{W}=5.83 \mu \mathrm{m}$ (excluding outer myxosporium), overlaid by hyaline, apically brown, bearing a fine, distinct, short, echinulae truncate, turgid vesicular 
appendix, inner wall orange (6B8) to brownish-orange (6C8) or light brown (7D5-7D6) to brown (7E7-7E8), outer wall mostly reddish-brown (8E7-8E8, 8F7) in $5 \% \mathrm{KOH}$.
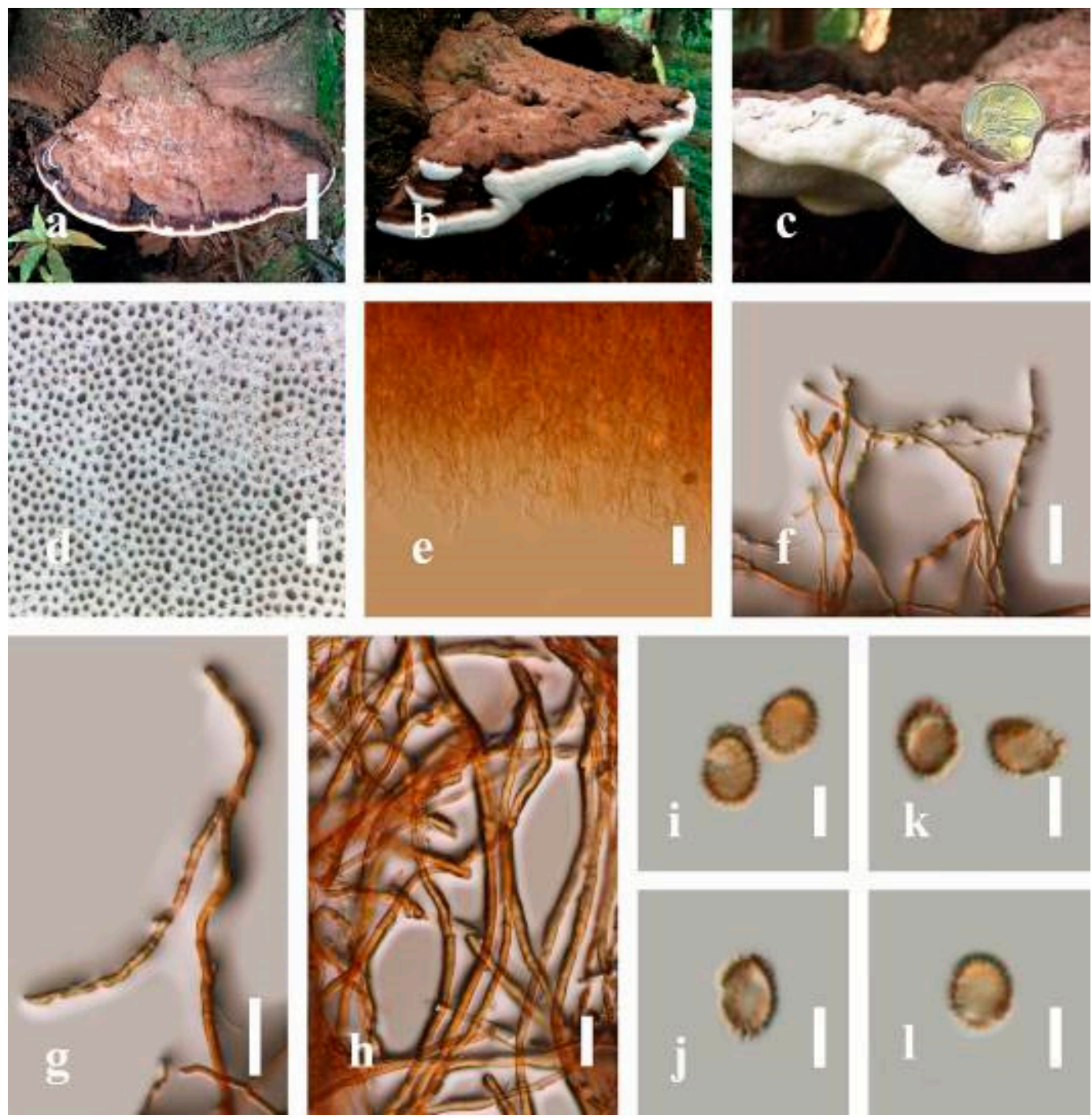

Figure 5. Morphology of Ganoderma australe (HKAS 97397): (a,b) mature basidiomes; (c) margin; (d) pore characteristics; (e) mycelia of tube layers; ( $\mathbf{f}-\mathbf{h})$ context hyphae as seen in Melzer's reagent; (i-1) basidiospores. Scale bars: $(\mathbf{a})=5 \mathrm{~cm}$, $(\mathbf{b})=3 \mathrm{~cm},(\mathbf{c})=1 \mathrm{~cm},(\mathbf{d})=500 \mu \mathrm{m},(\mathbf{e})=20 \mu \mathrm{m},(\mathbf{f})=20 \mu \mathrm{m},(\mathbf{g}, \mathbf{h})=10 \mu \mathrm{m},(\mathbf{i}-\mathbf{l})=5 \mu \mathrm{m}$.

Habitat: Solitary, growing on living Neocinnamomum delavayi (Lec.) H. Liou. tree or, decaying stump, and living Fagus spp.

Specimens examined: CHINA, Yunnan Province, Kunming Botanical Garden, $25^{\circ} 08^{\prime} 39^{\prime \prime} \mathrm{N}$, $102^{\circ} 44^{\prime} 30^{\prime}$ E, 1956 m, 27 September 2016, T. Luangharn, HKAS 97397.

Notes: Ganoderma australe belongs under the subgenus Elfvingia [38]. This fungus was initially described from the Pacific Islands [108]. G. australe belongs to the G. applanatumaustrale complex [2]. Ganoderma australe was established as a non-laccate (dull) pilei. The type specimen of this fungus is missing, while the neotype specimen is available in Europe [105]. Ganoderma applanatum and G. australe from Europe have been confused based on the macro-characteristic features [107]. The typification of G. australe remains unresolved and was exemplified by several authors [61,109-111], and its similar cultural characteristics also showed the phenotypic plasticity in morphological level and a higher level of nucleotide divergence in the ITS rDNA region that made G. australe a complex species [45]. 
Ganoderma australe is distinguished from G. applanatum by the larger dimensions of its basidiospores, different stipe features, thickness of the cuticle, and color of the context layer, all of which were considered in delimiting G. applanatum and G. australe $[2,105,107]$. G. applanatum is confined to northern temperate regions, while $G$. australe can be found in tropical and subtropical regions $[112,113]$. There are reports on the occurrence in Australia [14], China [30], New Zealand [114], southern India [51,95], Taiwan, PRC [115], and Thailand [30,59]. Ganoderma australe is a cosmopolitan species, which is known to cause white rot on woody material. It shows parasitic or pathogenic behavior on a wide range of both dead and living broadleaved deciduous trees [116-118]. Ganoderma australe is distributed worldwide, especially in tropical regions [14].

Ganoderma calidophilum J.D. Zhao, L.W. Hsu and X.Q. Zhang, Acta Mycologica Sinica 19: 270 (1979) (Figure 6)

Facesoffungi number: FoF 06244

Description: Basidiomes annual, stipitate, subdimidiate. Pileus $3-7 \mathrm{~cm}$ in length, $2-4 \mathrm{~cm}$ in width, and $0.2-1 \mathrm{~cm}$ thick. Pileus subdimidiate to dimidiate, spathulate, stipitate, sulcate, umbonate, radial from the center extending to the margin, tough to break when dried, often thick at the center, slightly soft at the margin, and light in weight when dried. Pileus surface corky, convex, furrowed, glabrous, glossy, incised, shiny, spathulate, shallow, sulcate when fresh, umbonate or uneven, laccate and glossy when mature, weakly laccate when old and in regions of developing hyphae (margin), slightly concentrically sulcate, layers smooth at the center when young, irregularly ruptured crust overlying the context, and tough to break when dried. Pileus color usually homogenous with brownish-red (8C7-8C8), brownish-red (9C7-9C8), reddish-brown (9D6-9D7) center, extending brownish-orange (6C7-6C8) toward the stipe, brownish-red (9C8) from the center to light brownish-orange (6C8), and usually light brown (6D8) at the margin when old. Context up to $0.2-0.6 \mathrm{~cm}$ thick near stipe, dry, fibrous, composed of coarse loose fibrils, brownish-orange (6C5-6C8) upper layers when fresh, brown (6D7) at lower layers, dark brown (8F7) when dried, covered with thin crust, trimitic hyphal system. Tube $0.3-0.9 \mathrm{~cm}$ in length, brown (7D8). Stipe 5$14 \mathrm{~cm}$ long, cylindrical, almost stipitate with broadly, irregularly ruptured crust overlying, strongly laccate with brown (7D8) when mature, dark brown (8F8) when old, and woody or corky when dried. Margin soft when young, laccate when mature, weakly laccate to laccate when old, blunt when old, usually light brown (6D8) when mature to old. Pore 4-5 in number per $\mathrm{mm}$, subcircular to circular, sometimes angular. Pore surface initially pale orange (5A3) to brownish-orange (6D8) when mature, discolored when touched, brown (6E8) when scratched or bruised.

Hyphal structure: Hyphal system trimitic hyphal, usually brownish-orange (6C5-6C7) in $\mathrm{KOH}$; generative hyphae 1.2-3.2 $\mu \mathrm{m}$ broad $(n=30)$, thin-walled, hyaline, without clamp connections; skeletal hyphae 3.2-6.4 $\mu \mathrm{m}$ broad $(n=30)$, sometimes branched, nearly solid, thick-walled, without clamp connections; binding hyphae $2.4-5.2 \mu \mathrm{m}$ broad $(n=30)$, usually thin to thick-walled, many branches, nearly solid, hymenial with sword-like apices in the context. Basidiospores mostly ellipsoid to broadly ellipsoid, with double wall, with a size range of (7.4-)8.5-11.9-12.6(-13.7) $\times(6.3-) 7.2-8.3-9.1(-9.6) \mu \mathrm{m}(\bar{x}=11.9 \times 8.3 \mu \mathrm{m}$, $n=50) \mu \mathrm{m}$, with $\mathrm{Q}=1.39-1.45, \mathrm{~L}=11.92 \mu \mathrm{m}, \mathrm{W}=8.35 \mu \mathrm{m}$ (including myxosporium), (6.8-)7.6-10.4-11.3(-12.8) × (5.4-)6.3-7.0-7.6(-8.1) $\mu \mathrm{m}(\bar{x}=10.4 \times 7.1 \mu \mathrm{m}, n=50) \mu \mathrm{m}$, with $\mathrm{Q}=1.43-1.49, \mathrm{~L}=10.39 \mu \mathrm{m}, \mathrm{W}=7.12 \mu \mathrm{m}$ (excluding outer myxosporium), overlaid by hyaline, apically and echinulae, truncate, turgid vesicular appendix, inner wall orange (6B8) to deep orange (6A8), reddish-orange (7A8, 7B7-7B8) or yellowish-red (8B8), outer wall usually reddish-brown (8D7-8D8; 8E8) in 5\% $\mathrm{KOH}$.

Habitat: Solitary, near the hardwood root of Castanopsis spp., living tree of Machilus yunnanensis.

Specimens examined: CHINA, Yunnan Province, Baoshan, $25^{\circ} 06^{\prime} 29^{\prime \prime} \mathrm{N}, 99^{\circ} 08^{\prime} 29^{\prime \prime} \mathrm{E}$, 1973 m elev., 11 November 2017, T. Luangharn, MFLU 19-2174.

Notes: Ganoderma calidophilum is a species originally described from Hainan Province, China, by Zhao [119]. Several reports have confirmed that this fungus is mentioned in 
Hainan Province polypore diversity checklists $[13,61,120,121]$. This fungus is distinctive in these forms, featuring a laccate pileus with broadly ellipsoid basidiospores with double walls, and it is widely found across subtropical and tropical Asia [108,119,122]. Wang and $\mathrm{Wu}$ [112] suggested that G. calidophilum is a synonym of G. flexipes. However, the evaluated G. calidophilum and G. flexipes are different in terms of pileus color, pileus shape and size, context, and basidiospore size [112]. In this study, we present our G. calidophilum collection from Yunnan Province, China, based on taxonomic and phylogenetic analyses. Our strain is similar to the described strain of Wang and $\mathrm{Wu}$ [119], Zhao et al. [119], and Bi et al. [123].
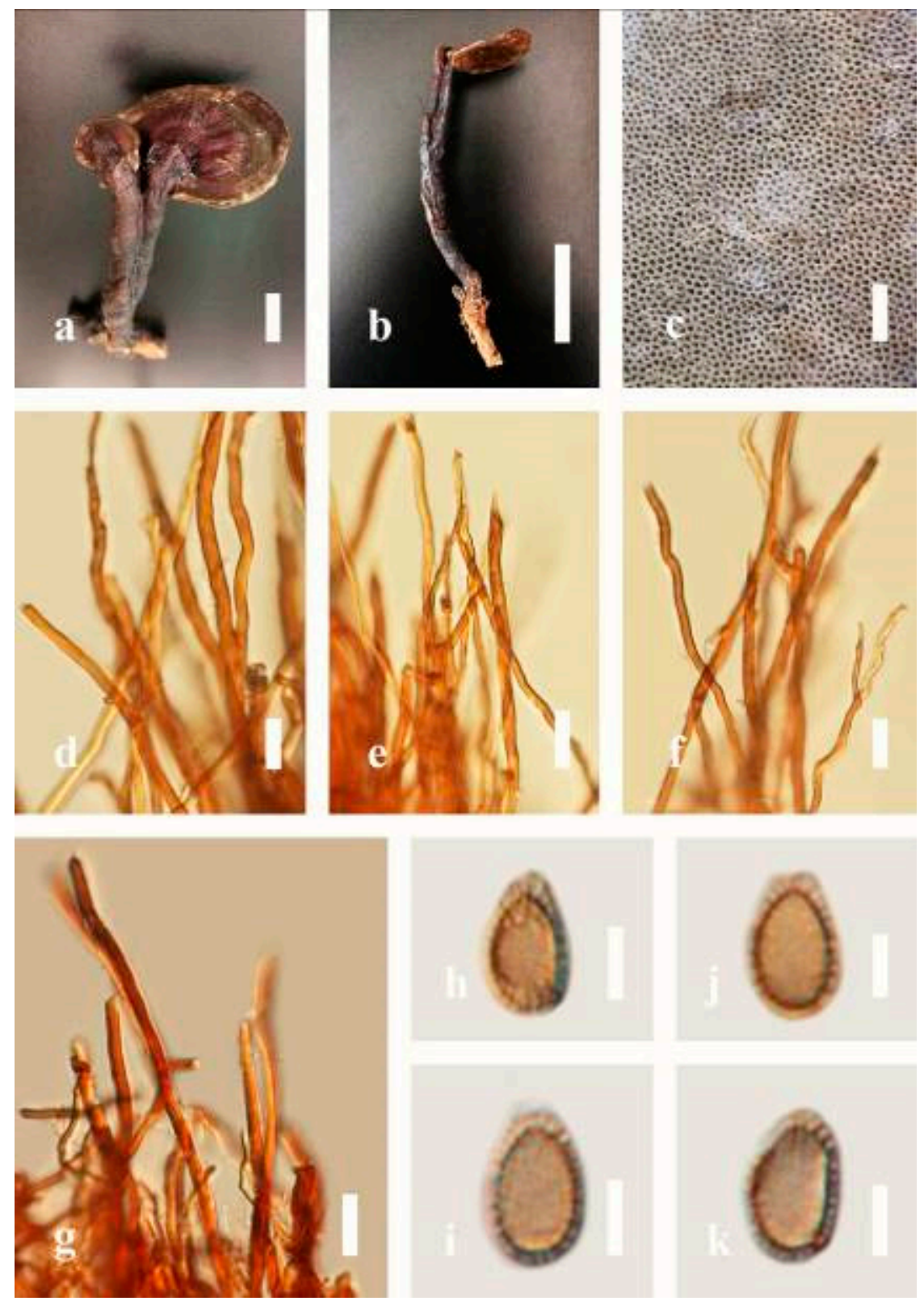

Figure 6. Morphology of Ganoderma calidophilum (MFLU 19-2174): (a,b) mature basidiomes; (c) pore characteristics; (d-f) context hyphae in Melzer's reagent; $(\mathrm{g})$ tube layer hyphae in Melzer's reagent; $(\mathbf{h}-\mathbf{k})$ basidiospores. Scale bars: $(\mathbf{a})=2 \mathrm{~cm},(\mathbf{b})=5 \mathrm{~cm},(\mathbf{c})=1000 \mu \mathrm{m},(\mathbf{d}-\mathbf{g})=20 \mu \mathrm{m},(\mathbf{h}-\mathbf{k})=5 \mu \mathrm{m}$.

Ganoderma flexipes Pat., Bulletin de la Société Mycologique de France. 23(1): 75 (1907) (Figure 7)

$\equiv$ Fomes flexipes (Pat.) Sacc. and Traverso, Sylloge Fungorum. 19: 710 (1910)

$\equiv$ Polyporus flexipes (Pat.) Lloyd, Synopsis of the stipitate Polyporoids. (7): 104 (1912)

Facesoffungi number: FoF 06245 
Description: Basidiomes annual or perennial, stipitate. Pileus $0.5-3.2 \mathrm{~cm}$ in length, $0.5-3 \mathrm{~cm}$ broad, up to $0.5 \mathrm{~cm}$ thick at the base. Pileus stipitate, sub-reniform to reniform, or subflabellate to flabellate, concentrically sulcate zones with tuberculate, glabrous when young to maturity, bumps when mature, often tough to break when dried. Pileus surface shiny, smooth, and soft when young, frequently furrowed and shallow sulcate on upper surface, undulating, somewhat spathulate to uneven when mature, covered by an irregularly ruptured thin crust, faded or weakly laccate when young, and laccate when mature., and woody when old. Pileus color usually homogenous with reddish-brown (8E8) to dark brown (9F7-9F8) at the center, slight to the margin from mature to old. Context up to $0.1-0.6 \mathrm{~cm}$ thick at the base, very dry, brown (7D7-7D8) to reddish-brown (8E7), containing fibrous pithy context and corky when old. Tube hard, often dark brown (7F8). Stipe almost $3-12 \mathrm{~cm}$ in length, $0.3-1.5$ in width, sub-cylindrical to cylindrical, often dark brown (7F8), and strongly laccate from mature to old. Margin soft when young, laccate when mature, some wavy, often light brown (6D5-6D6) on the upper surface. Pore 4-5 in number per mm, subcircular to circular, sometimes angular. Pore surface initially grayish-orange (6B4-6B6), turns brown (7D7) to reddish-brown (8D5-8D7) when scratched or bruised, discolored when touched.

Hyphal structure: Hyphal system trimitic, bearing clamp connections, hyaline, thickwalled, tapering branch, some swollen differentiated zone at the point of attachment; generative hyphae (1.8-)2.2-2.9-3.4(-3.8) $\mu \mathrm{m}$ broad $(n=30)$, thin-walled, hyaline, unbranched, with clamp connections; skeletal hyphae (3.0-)3.8-4.8-5.4(-6.2) $\mu \mathrm{m}$ broad $(n=30)$, with walls varying in thickness, with subsolid, binding hyphae (2.2-)2.8-3.8-4.5(-5.1) $\mu \mathrm{m}$ broad $(n=30)$, usually thick-walled, appearing alongside Bovista hyphae, and many branches, usually light yellow (4A4-4A5) to yellowish-orange (4B8) of thin-walled and orange (6A7) to deep orange (6A8) of thick-walled in Melzer's reagent. Pileipellis a hymeniderm, dark brown (6F8), composed of apically acanthus-like branched cells. Basidiospores mostly ellipsoid to broadly ellipsoid with double wall at maturity, (8.1-)8.8-9.7-10.6(-11.2) $\times(6.1-) 6.6-7.7-9.7(-10.4) \mu \mathrm{m}(\bar{x}=9.7 \times 7.7 \mu \mathrm{m}, n=50) \mu \mathrm{m}$, with $\mathrm{Q}=1.08-1.15, \mathrm{~L}=$ $9.68 \mu \mathrm{m}, \mathrm{W}=7.72 \mu \mathrm{m}$ (including myxosporium), (7.3-)7.8-8.3-8.7(-9.2) $\times(4.0-) 4.6-5.4-$ 5.8(-6.2) $\mu \mathrm{m}(\bar{x}=10.2 \times 6.4 \mu \mathrm{m}, n=50) \mu \mathrm{m}$, with $\mathrm{Q}=1.51-1.57, \mathrm{~L}=8.34 \mu \mathrm{m}, \mathrm{W}=5.39 \mu \mathrm{m}$ (excluding outer myxosporium), overlaid by hyaline, dextrinoid, echinulae, inner wall echinulate brown (5D8, 7E6-7E8), and outer wall usually dark brown (7E8) to reddish-brown (8E6-8E8) in Melzer's reagent.

Habitat: Solitary on the decaying hardwood of Pinus spp.

Specimens examined: CHINA, Yunnan Province, Baoshan, $25^{\circ} 06^{\prime} 29^{\prime \prime} \mathrm{N}, 99^{\circ} 08^{\prime} 29^{\prime \prime} \mathrm{E}$, 1973 m elev., November 2017, T. Luangharn, MFLU 19-2189.

Notes: Ganoderma flexipes is originally described from Vietnam by Patouillard [124]. It has been recorded from China, India, Laos, Nepal, and Pakistan [4,13,30,110,122]. G. flexipes is characterized by its small reddish-brown pileus, long and thin stipe, usually reddishbrown to dark brown context, and ellipsoid or ovoid basidiospores [125]. Among the Chinese Ganoderma species, G. flexipes is one of the most similar species to G. sichuanense as they share a reddish-brown pileal surface, similar basidiospores, and cuticle cells [4]. Our G. flexipes from China is very similar to the description of Ryvarden [125] and Hapuarachchi et al. [30], and basidiospores are within the range of 9.7-10.2 $\times 6.4-7.7 \mu \mathrm{m}$. 

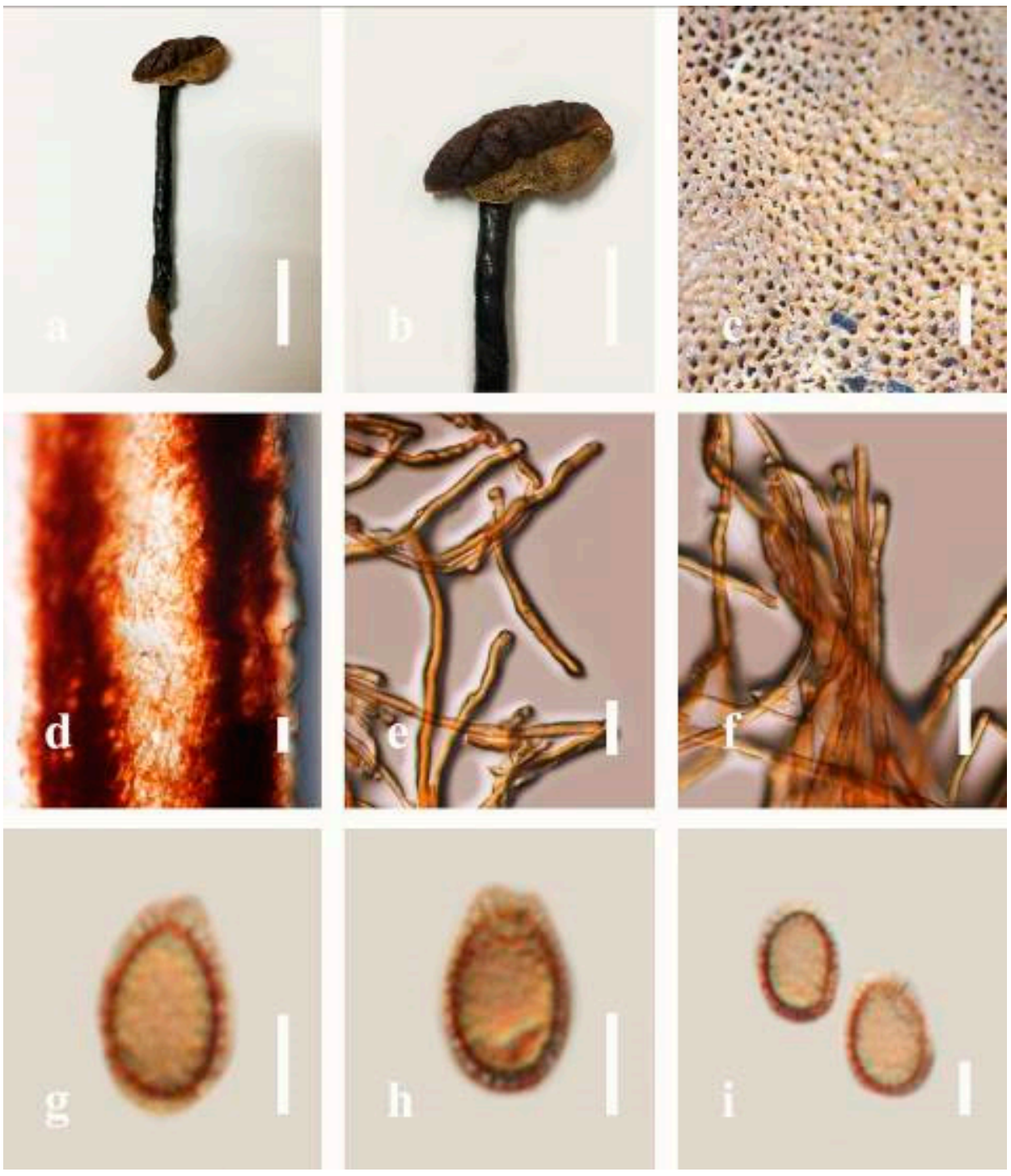

Figure 7. Morphology of Ganoderma flexipes (MFLU 19-2189): (a,b) mature basidiomes; (c) pore characteristics; (d) hyphae of tube layers in Melzer's reagent; (e,f) context hyphae in Melzer's reagent; $(\mathbf{g}-\mathbf{i})$ basidiospores. Scale bars: $(\mathbf{a})=3 \mathrm{~cm},(\mathbf{b})=2 \mathrm{~cm},(\mathbf{c})=500 \mu \mathrm{m},(\mathbf{d})=30 \mu \mathrm{m},(\mathbf{e}, \mathbf{f})=20 \mu \mathrm{m}$, $(\mathrm{g}-\mathbf{i})=5 \mu \mathrm{m}$.

Ganoderma gibbosum (Blume and T. Nees) Pat., Ann. Jard. Bot. Buitenzorg, suppl. 1: 114 (1897) (Figure 8)

$\equiv$ Polyporus gibbosus (Blume and T. Nees)., Nov. Act. Academiae Caesareae Leopoldino Carolinae Germanicae Naturae Curiosorum. 13: 19, t. 4(1-4) (1826)

$\equiv$ Fomes amboinensis var. gibbosus (Blume and T. Nees) Cooke, Grevillea. 13(68): 118 (1885)

$\equiv$ Fomes gibbosus (Blume and T. Nees) Sacc. Syll. Fung. 6: 156 (1888)

三 Scindalma gibbosum (Blume and T. Nees) Kuntze., Revisio generum plantarum 3(2): 518 (1898)

Facesoffungi number: FoF 06246

Description: Basidiomes annual or perennial, sessile. Pileus $8-21 \mathrm{~cm}$ in length, $6-13 \mathrm{~cm}$ in width, and 1-3.5 cm thick, convex, imbricate, umbonate, uneven, ungulate, subflabellate, subdimidiate, usually round when present, primordial, somewhat round and plump when young, somewhat imbricate, when seen from above flabelliform (fan-shaped), broadly attached, thick at the base, slightly soft at the margin when mature. Pileus surface non-laccate (dull), furrowed, incised, sulcate, smooth when young, usually silky, soft, and slippery sur- 
face when fresh, undulating on the upper surface, somewhat spathulate to uneven, with a crust (0.2-0.4 mm), woody from mature to older, and lined or cracked crust occurs when old. Pileus color usually homogenous with grayish-orange (6B3-6B6), brownish-orange (6C5-6C6), and brown (6D7-6D8) at the base extending to the margin of mature fruiting bodies. Context up to $0.5-1.8 \mathrm{~cm}$ thick, compact and hard, trimitic hyphal, with clamp connections, hyaline, with walls varying in thickness with simple septa, composed of narrow and sparingly branched; generative hyphae 1.3-3.2 $\mu \mathrm{m}$ broad $(n=30)$ with hyaline; skeletal hyphae $2.8-4.7 \mu \mathrm{m}$ broad $(n=30)$, usually thick-walled; binding hyphal $2.1-4.2 \mu \mathrm{m}$ width $(\mathrm{n}=30)$ with walls varying in thickness. Hymenophore reddish-brown (8D7). Tube layers $0.4-1.2 \mathrm{~cm}$ in length. Stipe almost sessile and broadly attached when present. Margin blunt-edged, wavy, slippery from young, softer, and often white (8A1) when youth to maturity, and light brown (6D5) when old, the present yellow line between the edge of the margin and close to the underside of basidiomes. Pore 4-7 in number per $\mathrm{mm}$, subcircular to circular. Pore surface white (11A1) when present, pale yellow (4A3) to grayish-yellow (4B3-4B4) when scratched or bruised, discolored when touched.

Hyphal structure: Hyphal system trimitic hyphal, with clamp connections, usually reddish-brown (8D7-8D8); generative hyphae (1.2-)1.5-2.4-3.0(-3.6) $\mu \mathrm{m}$ broad $(n=30)$, thin-walled and hyaline; skeletal hyphae (2.7-)3.2-3.6-4.2(-4.8) $\mu \mathrm{m}$ broad $(n=30)$, dextrinoid, abundant thick wall; binding hyphae (2.5-)3.0-3.5-4.0(-4.4) $\mu \mathrm{m}$ broad $(n=30)$, thick wall, branched, usually intertwined the generative and skeletal hyphae, mostly dark brown near the tube layers, appearing alongside Bovista-type ligative hyphae, hymenial, sword-like apices at the context. Pileipellis a hymeniderm, dark brown (6D8), composed of apically acanthus-like branched cells, dextrinoid. Basidiospores mostly ellipsoid to broadly ellipsoid or oblong with double walls, (5.8-)6.2-7.2-8.4(-9.2) $\times(5.4-) 5.7-5.4-6.8(-7.7)$ $\mu \mathrm{m}(\bar{x}=7.3 \times 5.6 \mu \mathrm{m}, n=50) \mu \mathrm{m}$, with $\mathrm{Q}=1.48-1.52, \mathrm{~L}=7.32 \mu \mathrm{m}, \mathrm{W}=5.68 \mu \mathrm{m}$ (including myxosporium), (4.8-)5.2-6.0-6.7(-7.2) × (4.6-)4.9-5.5-5.7(-6.2) $\mu \mathrm{m}(\bar{x}=6.2 \times 5.6 \mu \mathrm{m}$, $n=50) \mu \mathrm{m}$, with $\mathrm{Q}=1.08-1.14, \mathrm{~L}=6.24 \mu \mathrm{m}, \mathrm{W}=5.67 \mu \mathrm{m}$ (including myxosporium), overlaid by hyaline, dextrinoid, echinulae, echinulate brown inner wall, light yellow (4A4-4A5) to grayish-yellow (4B5-4B6) in 5\% $\mathrm{KOH}$. Basidia not seen.

Habitat: Solitary on decaying hardwood of Machilus yunnanensis, living tree of Albizia mollis and Pinus spp.

Specimens examined: CHINA, Yunnan Province, Kunming Institute of Botany garden,

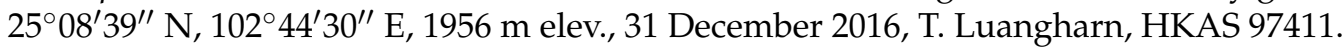

Notes: Ganoderma gibbosum belongs to the family Ganodermataceae, which was first described in Australia [126]. G. gibbosum has been recorded from China [40], India [95], Korea [92], Laos [30], and Thailand [30]. This species is distinctive in having non-laccate basidiomes and ellipsoids with double-walled basidiospores [40]. Ganoderma gibbosum has been reported to cause white rot and several other diseases in hard woods [7] and is widely distributed in both tropical and temperate areas [4]. It was considered to be a subspecies of G. applanatum [4], while G. applanatum was the earlier name of G. australe [127]. Ganoderma australe and G. gibbosum were renamed as G. incrassatum based on their monophyletic origin [128] since it had been well recognized that G. applanatum was synonymized with G. applanatum. 

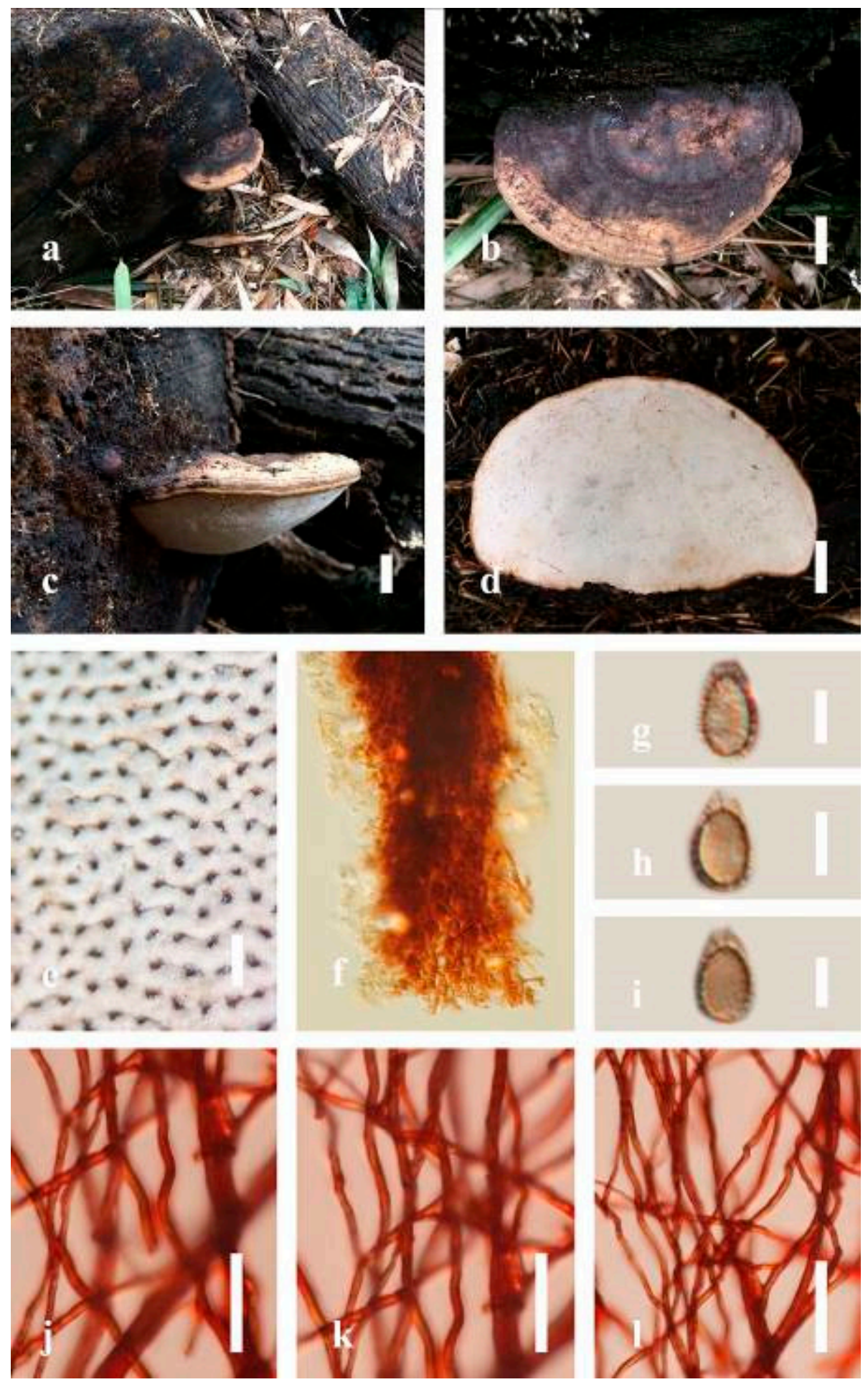

Figure 8. Morphology of Ganoderma gibbosum (HKAS 97411): (a,b) upper surface of mature basidiomes; (c) margin; (d) under surface of mature basidiomes; (e) pore characteristics; (f) hyphae of tube layers in Melzer's; (g-i) basidiospores in Melzer's; $(\mathbf{j}-\mathbf{l})$ context hyphae in Congo red. Scale bars: $(\mathbf{b}, \mathbf{d})=3 \mathrm{~cm},(\mathbf{c})=1 \mathrm{~cm},(\mathbf{e})=500 \mu \mathrm{m},(\mathbf{g}-\mathbf{i})=5 \mu \mathrm{m},(\mathbf{j}-\mathbf{1})=20 \mu \mathrm{m}$.

Ganoderma leucocontextum T.H. Li, W.Q. Deng, Sheng H. Wu, D.M. Wang and H.P. $\mathrm{Hu}$, Mycotaxon 56: 82 (2015) (Figure 9)

Facesoffungi number: FoF 06247

Description: Basidiomes flabelliform, subdimidiate, stipitate. Pileus 6-14 cm in length, $4-12 \mathrm{~cm}$ in width, and $1-3.2 \mathrm{~cm}$ thick. Pileus flabelliform, spathulate, stipitate, subdimidiate 
to dimidiate, umbonate, somewhat semicircular, plump, concentrically sulcate zone, broad and thick at the base, mostly radial from the center extending to the margin, tough to break when dried, often thick at the center, slightly soft at the margin, light in weight when dried, and not woody. Pileus surface convex, furrowed, imbricate, incised, glossy, shiny, spathulate, shallow sulcate when fresh, umbonate or uneven, usually smooth layers at center when young to age, non-laccate to weakly laccate when present, strongly laccate and glossy when mature, weakly laccate where the new hyphae are in active development (margin), irregularly ruptured crust overlying the context, and tough to break when dried. Pileus color usually homogenous with orange (6A7) and deep orange (6A8) at the center toward stipe, extending deep orange (5A8) from the center, slight deep yellow (4A8) where the new hyphae are in active development when mature, usually red (11B7-11B8) at the center, and orange (6A7) to deep orange (6A8)-(6B8) extending to the upper margin surface from mature to old. Context up to $0.3-2.4 \mathrm{~cm}$ thick near stipe, white context when fresh, yellowish-white (1A2) when dried, soft and fibrous, trimitic hyphal, with clamp connections, hyaline, with walls varying in thickness with simple septa, and unbranched. Tubes $0.3-1.2 \mathrm{~cm}$ in length. Stipe 3-10 cm in length, $4-7 \mathrm{~cm}$ in width, sub-cylindrical to cylindrical, almost stipitate, broad at the base, some presented short stipitate, strongly laccate with dark brown (8F7-8F8) to grayish ruby (12E6-12E7) when mature, and grayish brown (8E4) when old. Margin wavy, softer, slippery when young, laccate when mature, strongly laccate when old, orange yellow (4A7) to deep yellow (4D8) where the new hyphae are in active development, deep orange (6A7-6A8) to brown (6D8) from mature to old. Pore 4-6 in number per $\mathrm{mm}$, subcircular, some circular, or angular. Pore surface white (11A1) when present, yellowish-white (2A2) when mature, brownish-orange (6C7-6C8) when scratched or bruised, discolored when touched.

Hyphal structure: Hyphal system trimitic, usually golden brown (5D7), yellowishbrown (5D8) to reddish-brown (8D7-8D8) in $\mathrm{KOH}$; generative hyphae 2.3-5.2 $\mu \mathrm{m}$ broad $(n=30)$, thin-walled, hyaline, with clamp connections; skeletal hyphae $2.6-5.5 \mu \mathrm{m}$ broad $(n=30)$, thick-walled, unbranched or rearly branched; binding hyphae 1.8-4.2 $\mu \mathrm{m}$ width $(n=30)$, usually thin to thick-walled, branched, hymenial with sword-like apices in the context. Basidiospores mostly ellipsoid to broadly ellipsoid, double walls, (8.8-)9.3-10.711.4(-12.6) $\times(6.8-) 7.4-8.3-8.7(-9.2) \mu \mathrm{m}(\bar{x}=10.5 \times 8.4 \mu \mathrm{m}, n=50) \mu \mathrm{m}$, with $\mathrm{Q}=1.22-$ $1.28, \mathrm{~L}=10.52 \mu \mathrm{m}, \mathrm{W}=8.41 \mu \mathrm{m}$ (including myxosporium), (7.8-)8.1-8.5-8.8(-9.1) $\times(5.2-)$ 5.7-6.0-6.5(-6.9) $\mu \mathrm{m}(\bar{x}=8.3 \times 6.2 \mu \mathrm{m}, n=50) \mu \mathrm{m}$, with $\mathrm{Q}=1.32-1.38, \mathrm{~L}=8.34 \mu \mathrm{m}$, $\mathrm{W}=6.18 \mu \mathrm{m}$ (excluding outer myxosporium), overlaid by hyaline, apically echinulae, truncate, some turgid, vesicular appendix, inner walled echinulate, golden yellow (5B7), grayish-orange (5D6) to yellowish-brown (5D7), outer walled reddish-brown in $5 \% \mathrm{KOH}$. Cystidia absent. Cultures characteristics white mycelial after incubation at $30{ }^{\circ} \mathrm{C}$ for 10 days.

Habitat: Solitary, on the decaying hardwood of unknown tree.

Specimens examined: CHINA, Yunnan Province, Baoshan, $25^{\circ} 09^{\prime} 35^{\prime \prime} \mathrm{N}, 99^{\circ} 09^{\prime} 49^{\prime \prime} \mathrm{E}$, 1973 m elev., 26 October 2016, J. Xu, HKAS 97401.

Notes: Ganoderma leucocontextum was introduced by Li et al. [62] from the Tibet Autonomous Region of China. This species can be easily recognized by its stipitate, white context, thick stipe, broadly ellipsoid basidiospores (9-12.5 $\times 7-9 \mu \mathrm{m})$, coarse echinulae, mostly regular cuticle hyphae, and its deciduous wood habitat [62]. The holotype is similar to G. lucidum from Europe [62]; however, the illustrated differences in macro-characteristics of the European G. lucidum are smaller basidiospores (7-12 ×6-8 $\mathrm{mm}$ ), a deeper-colored context that is usually rust-colored, becoming dark purple to brown in older portions [105]. Additionally, G. leucocontextum also resembles the widely cultivated G. lucidum (G. lingzhi) in East Asia [62], but the Chinese G. lucidum has a deeper-colored context and is even darker near the tube layer, with shorter cutis elements $(20-40 \times 7-15 \mu \mathrm{m})$ and smaller spores $(8-11.5 \times 5.5-8.5 \mu \mathrm{m})$ (including myxosporium) than G. leucocontextum leucocontextum [5]. Our G. leucocontextum collection from Hainan Province agrees well with the descriptions provided by Li et al. [62] 

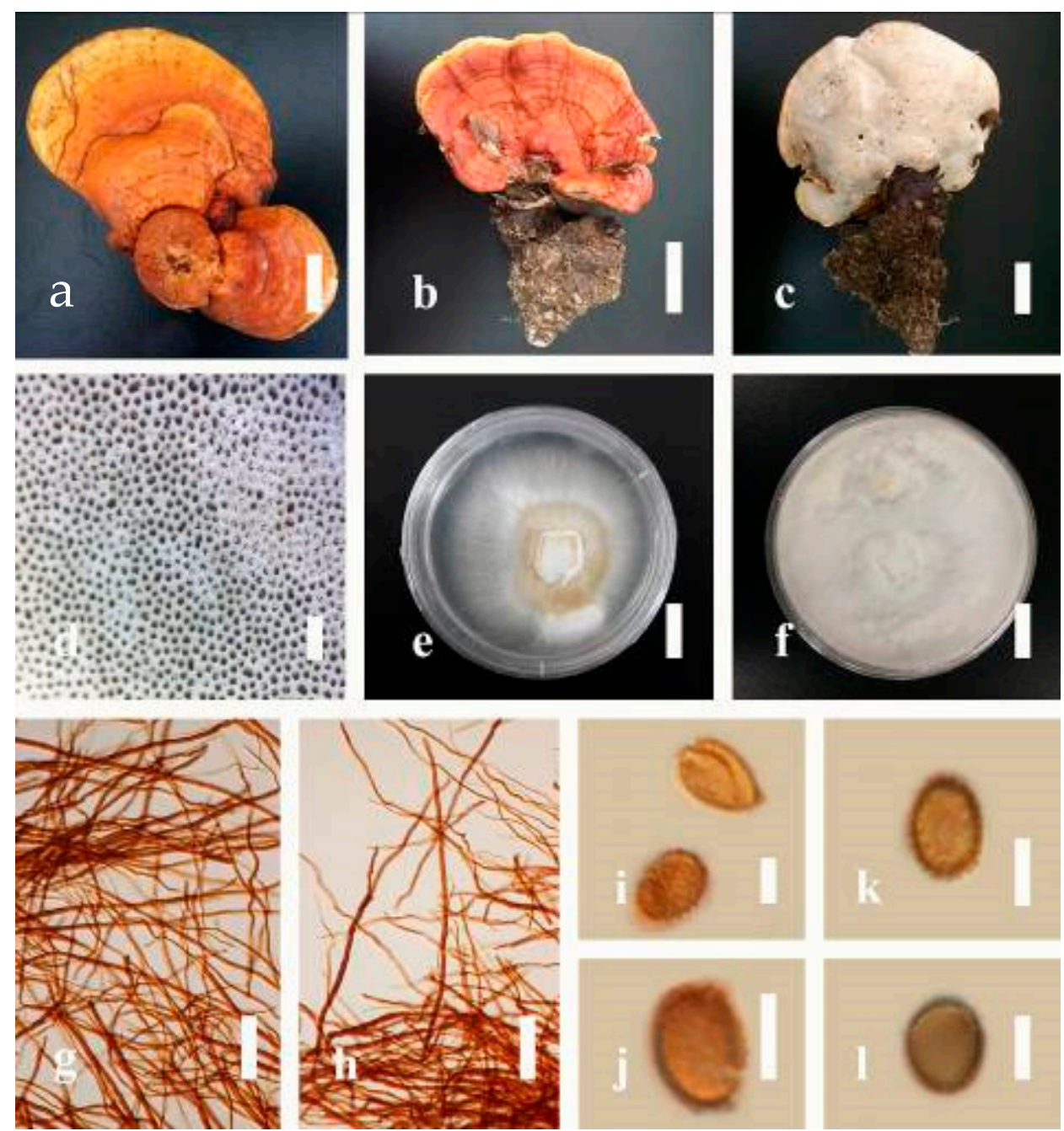

Figure 9. Morphology of Ganoderma leucocontextum: (a) mature basidiomes of the strain HKAS 97401; (b,c) mature basidiomes of the strain MFLU 19-2160; (d) pore characteristics; (e) culture after incubation at $25^{\circ} \mathrm{C}$ for 14 days; (f) culture after incubation at $25^{\circ} \mathrm{C}$ for 21 days; (g,h) context hyphae in $\mathrm{KOH} ;(\mathbf{i}-\mathbf{l})$ basidiospores. Scale bars: $(\mathbf{a}, \mathbf{e}, \mathbf{f})=2 \mathrm{~cm},(\mathbf{b}, \mathbf{c})=4 \mathrm{~cm},(\mathbf{d})=500 \mu \mathrm{m},(\mathbf{g}, \mathbf{h})=30 \mu \mathrm{m}$, $(\mathbf{i}-\mathbf{l})=5 \mu \mathrm{m}$.

Ganoderma lucidum (Curtis) P. Karst., Revue Mycologique Toulouse. 3(9): 17 (1881) (Figure 10)

$\equiv$ Boletus rugosus Jacq., Flora Austriaca. 2: 44, f. 169 (1774)

$\equiv$ Boletus lucidus Curtis, Fl. Londinensis. 4: 72, t. 224 (1781)

$\equiv$ Polyporus lucidus (Curtis) Fr., Systema Mycologicum. 1: 353 (1821)

$\equiv$ Grifola lucida (Curtis) Gray, A natural arrangement of British plants. 1: 644 (1821)

$\equiv$ Fomes lucidus (Curtis) Cooke, Grevillea. 13(68): 118 (1885)

$\equiv$ Placodes lucidus (Curtis) Quél., Enchiridion Fungorum in Europa media et praesertim in Gallia Vigentium.: 170 (1886)

$\equiv$ Phaeoporus lucidus (Curtis) J. Schröt., Kryptogamen-Flora von Schlesien. 3-1(4): 491 (1888)

= Boletus flabelliformis Leyss., Flora halensis.: 219 (1761)

= Agaricus pseudoboletus Jacq., Miscellanea austriaca ad botanicum, chemiam et historiam naturalem spectantia. 1: 26, t. 41 (1773)

= Boletus obliquatus Bull., Herbier de la France. 1: t. 7 (1781)

= Boletus vernicosus Bergeret, Phytonomatotechnie universelle. 1: 99 (1783)

= Agaricus lignosus Lam., Encyclopédie Méthodique, Botanique. 1-1: 51 (1783) 
= Boletus dimidiatus Thunb., Fl. Japonica.: 348, f. 39 (1784)

= Boletus castaneus Weber, Suppl. Fl. hols.: 13 (1787)

= Boletus laccatus Timm, Flora megapolitanae Prodomus exhibeus plantas ductatus Megapolitano.: 269 (1788)

= Boletus crustatus J.J. Planer, Index Plantarum quas in Agro Erfurtensi sponte provenientes.: 280 (1788)

= Agarico igniarium trulla Paulet, Traité des champignons. 2: 95, pl. 10:1-2 (1793)

= Boletus verniceus Brot., Flora Lusitanica. 2: 468 (1804)

= Ganoderma ostreatum Lázaro Ibiza, Revta R. Acad. Cienc. exact. fis. nat. Madr.: 110(1916)

= Ganoderma nitens Lázaro Ibiza, Revta R. Acad. Cienc. exact. fis. nat. Madr.: 104 (1916)

Facesoffungi number: FoF 06250

Description: Basidiomes imbricate, reniform, stipitate. Pileus up to $2-5 \mathrm{~cm}$ in length, $2-4 \mathrm{~cm}$ in width, and $0.8-2.2 \mathrm{~cm}$ thick. Pileus stipitate, reniform, imbricate, irregular, some laterally, and flabelliform with a contracted, concentrically sulcate zone, irregularly ruptured crust overlying the context, radial or branched from the center extending to the margin, tough to break when dried, often thick at the center, slightly soft at margin, and leathery when aged, tough to break when dried. Pileus surface weakly laccate when present, strongly laccate and glossy when mature, weakly laccate where the new hyphae are in active development (margin), smooth layer at the center from young to age, usually furrowed, incised, undulate to sulcate, somewhat spathulate to uneven, some woody or corky when old. Pileus color usually yellowish-red (8B7-8B8) at the center, slight to reddishorange (7B7-7B8), and orange (6A7-6A8) on upper pileus surface. Context up to $0.4-1.4 \mathrm{~cm}$ thick at the base, abundant thick-walled, subsolid hyphae, concentric lines of various shade, bearing clamp connections, light brown (6D6) to brown (6D8, 6E8), presenting dark brown (6F8) melanoid bands. Tube hard, often brown (7D7) to dark brown (7F7). Stipe up to $8-16 \mathrm{~cm}$ in length, up to $0.6-1.8 \mathrm{~cm}$ in width, central stipe, cylindrical, thick with uneven at the base (up to $1.8 \mathrm{~cm}$ ), usually dark brown (7F7-7F8), laccate, and cracked when old. Margin often $0.4-1 \mathrm{~cm}$, orange (6A7-6A8) on upper surface, and reddish-yellow (4A8) under surface, thin and soft than the center. Pore (75-)110-145(-165) $\mu \mathrm{m}$, circular, some angular, 4-6 in number per mm. Pore surface white (11A1) to light brown (7D6), turning brown (7D7-7D8) to dark brown (6F6) when scratched or bruised.

Hyphal structure: Hyphal system trimitic, with clamp connections, hyaline, thin-walled with abundant thick-walled with simple septa, sparingly branched, swollen by melanoid bands, usually pale orange (5A3), light orange (5A5), to reddish-orange (8A7-8A8) in $\mathrm{KOH}$; generative hyphae up to $1.7-3.2 \mu \mathrm{m}$ broad $(n=30)$, almost hyaline, usually thin to thickwalled, with clamp connections, and sparingly branched and flexuous; skeletal hyphae 3.0-6.4 $\mu \mathrm{m}$ broad $(n=30)$, usually thick-walled with clamp, and abundantly branched and flexuous; binding hyphae $2.0-5.6 \mu \mathrm{m}$ broad $(n=30)$, usually thick-walled with abundant branches, and occurring melanoid bands. Basidiospores ellipsoid to broadly ellipsoid, some globose with double walls, with a truncate apex, with double wall, mostly overlaid by hyaline myxosporium, eusporium bearing fine, short, and distinct, coarse, echinulae, hyaline, turgid, vesicular appendix, (7.7-)8.4-9.4-10.6(-11.5) $\times(5.2-) 5.9-6.3-7.1(-8.4) \mu \mathrm{m}$, $(\bar{x}=9.5 \times 6.4 \mu \mathrm{m}, n=50) \mu \mathrm{m}$, with $\mathrm{Q}=1.47-1.52, \mathrm{~L}=9.52 \mu \mathrm{m}, \mathrm{W}=6.34 \mu \mathrm{m}$ (including myxosporium), (6.0-)6.9-7.3-8.1(-8.5) $\times(4.6-) 4.9-5.3-5.8(-6.2) \mu \mathrm{m}(\bar{x}=7.5 \times 5.2 \mu \mathrm{m}, n=50) \mu \mathrm{m}$, with $\mathrm{Q}=1.41-1.47, \mathrm{~L}=7.52 \mu \mathrm{m}, \mathrm{W}=5.24 \mu \mathrm{m}$ (excluding outer myxosporium), brownishorange (6C8), (6D8) to brown (6E5) of endosporium (inner wall) with brown (7E7-7E8) exosporium (outer wall) in Congo red, brownish-orange (6C8) in $5 \% \mathrm{KOH}$, and yellowishbrown in Melzer's reagent.

Habitat: Solitary, on decaying hardwood of Quercus sp. in the native forest.

Specimens examined: CHINA, Yunnan Province, Honghe, $23^{\circ} 21^{\prime} 50^{\prime \prime} \mathrm{N}, 103^{\circ} 22^{\prime} 24^{\prime \prime} \mathrm{E}$, 874 m elev., 15 August 2017, T. Luangharn, MFLU 19-2161. 
Notes: Ganoderma lucidum (Curtis) P. Karst. was originally reported from temperate England [2]. Previously, it was characterized as Boletus lucidus Curtis and then Polyporus lucidus (Curtis) Fr. (1821) [1]. The species P. lucidus was characterized by having a laccate pileus and stipe. The molecular phylogenetic analyses indicated that the G. lucidum from Europe is not conspecific to the Chinese G. lucidum; thus, the European G. lucidum remained the true G. lucidum, and the Chinese G. lucidum was proposed as G. lingzhi [4], and most of the collections named G. lucidum in East Asia were not conspecific with the G. lucidum found in Europe [129]. Ganoderma lucidum is relatively common in Europe, while its geographic distribution in East Asia, East Africa, Europe, North America, Asia, and other parts of the world is largely unknown [38].
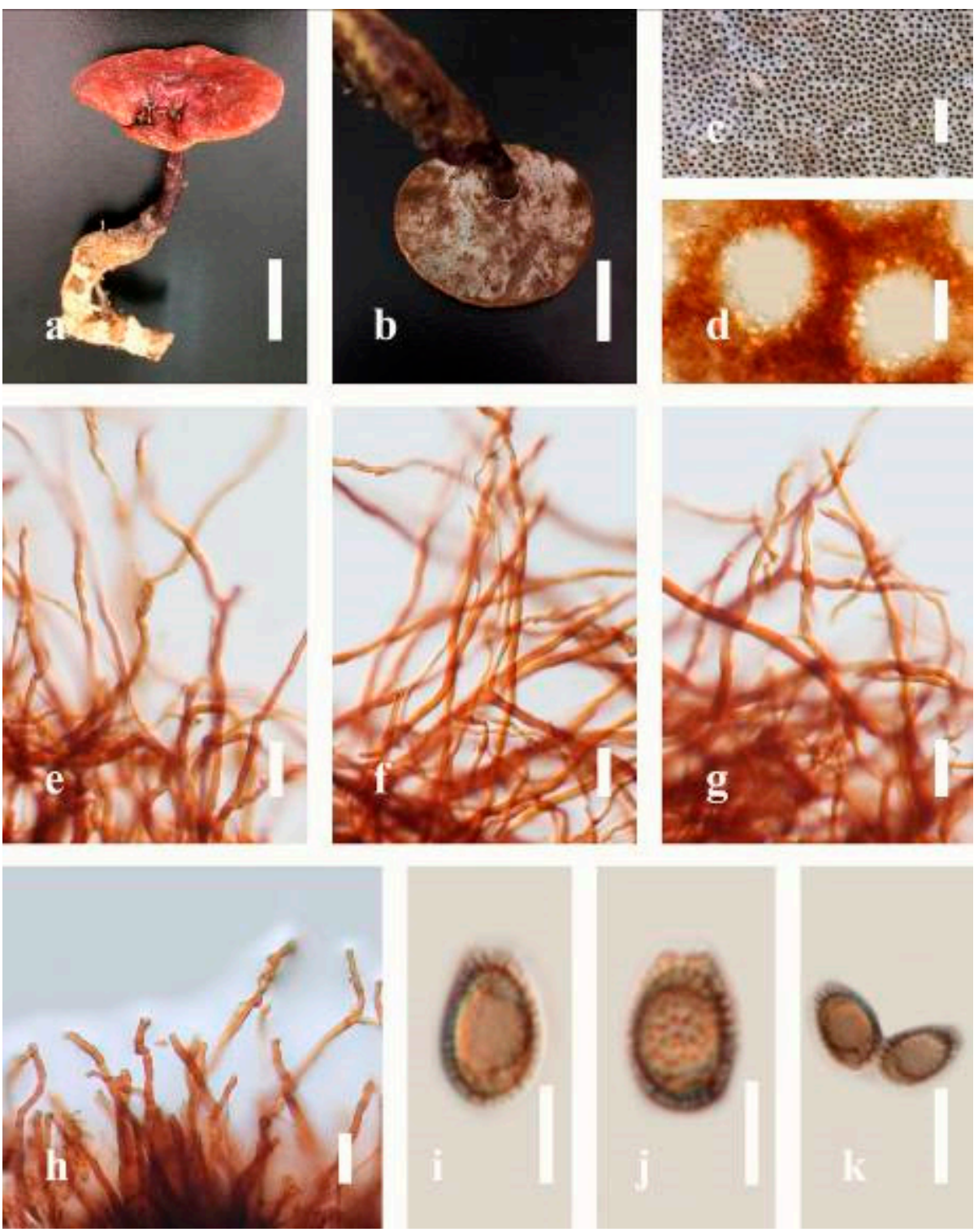

Figure 10. Morphology of Ganoderma lucidum (MFLU 19-2161): (a,b) mature basidiomes; (c) pore characteristics; (d) hyphae of pore characteristics in $\mathrm{KOH}$; (e) hyphae of trama in $\mathrm{KOH}$; (f,g) generative and skeletal hyphae of context in $\mathrm{KOH}$; (h) hyphae of tube layers in $\mathrm{KOH}$; (i-k) basidiospores. Scale bars: $(\mathbf{a}, \mathbf{b})=2 \mathrm{~cm},(\mathbf{c})=1000 \mu \mathrm{m},(\mathbf{d})=150 \mu \mathrm{m},(\mathbf{e}-\mathbf{g})=20 \mu \mathrm{m},(\mathbf{h})=15 \mu \mathrm{m},(\mathbf{i}-\mathbf{k})=5 \mu \mathrm{m}$.

Several studies of Ganoderma have used the name G. lucidum for any laccate Ganoderma species, as Ganoderma are ly highly variable, often resulting in taxonomic and phylogenetic confusion, especially with regards to G. lucidum [38]. The taxonomy of Ganoderma has been a constant topic of debate due to the high levels of phenotypic plasticity in its 
species. Several characteristics of Ganoderma are similar to G. lucidum, such as G. multipileum [39], G. oregonense [42], G. resinaceum [41], G. tsugae, G. lucidum, G. sichuanense, and $G$. sinense $[4,32,33,35,40,130]$ from China. Cao et al. [4] have clarified a different new species, Chinese G. lucidum as G. lingzhi, which has an East Asian distribution. The most striking characteristics that differentiate G. lucidum from G. lingzhi are the presence of melanoid bands in the context, a yellow pore surface, and thick dissepiments $(80-120 \mu \mathrm{m})$ at maturity [4]. The molecular evidence reveals G. lucidum and G. sinense as two clear different species [130].

In China, the first-reported G. lucidum was illustrated based on collections from Guizhou Province [124]. Then, Teng [131] reported more collections from different regions of China, and many subsequent collections have been reported [4,13,47,121,132]. Recently, this fungus has been reported to be distributed worldwide based on gross similarity of features, e.g., in Europe [105], Asia [13,133], America [134,135], and Africa [112]. Our collection from Yunnan Province, China, also agrees well with the descriptions provided from Asia.

Ganoderma multiplicatum (Mont.) Pat., Bulletin de la Société Mycologique de France 5: 74 (1889) (Figure 11)

三 Polyporus multiplicatus Mont., Annales des Sciences Naturelles Botanique. 1: 128 (1854)

三Fomes multiplicatus (Mont.) Cooke, Grevillea. 14 (69): 18 (1885)

三 Scindalma multiplicatum (Mont.) Kuntze, Revisio generum plantarum. 3 (2): 519 (1898)

Facesoffungi number: FoF 06251

Description: Basidiomes annual or perennial, stipitate with short base. Pileus 1.5$7.5 \mathrm{~cm}$ in length, $0.5-4 \mathrm{~cm}$ in width, and up to $1.5 \mathrm{~cm}$ thick at the base. Pileus dimidiate, flabelliform, reniform, usually flat, convex, imbricate, umbonate or uneven, rarely ungulate, glabrous when present, often with undefined concentric zones at the center that extend to the margin, and thick at the base, slightly soft at margin when mature. Pileus surface shiny, silky, smooth, and soft when young, non-laccate (dull) when mature, hard and woody when old, frequently furrowed and shallow sulcate, undulating, somewhat spathulate to uneven on upper surface when mature, covered by irregularly ruptured thick crust, slightly dull and faded when mature to old, compact and hard when mature, woody to corky from mature to old. Pileus color usually homogenous with grayish-orange (6B3) at the center slight to brownish-orange (6C4) and pale orange (6A3), usually yellowish-gray (4B2) at the margin when mature, and brown (6E8) when dried. Context up to $0.4-1 \mathrm{~cm}$ thick at the base, mostly brown (6E8) to dark brown (7F6-7F8) of cuticle cells, and dark brown (6F6) melanoid bands, thick-walled, some fibrous pithy context, usually separated by layers of context tissue at the base. Tube woody hard, often with dark brown (7F7-7F8) when dried, with sulcate at different levels. Stipe short stipitate, dark brown (7F7), and a differentiated zone at the point of attachment. Margin up to $1 \mathrm{~cm}$ thick, initially white (5A1), yellowish-gray (4B2) when mature, turns light brown (6D4) to brown (6E8) when scratched or bruised, often slippery when wet, softer when young, thinner than the center. Pore 4-7 in number per $\mathrm{mm}$, subcircular to circular, some angular. Pore surface initially white (7A1) to yellowish-white (1A2), becoming pale orange (5A3) when mature, light brown (7D6) to brown (7D8) when handled, scratched, and bruised.

Hyphal structure: Hyphal system trimitic; generative hyphae 2.1-4.8 $\mu \mathrm{m}(\bar{x}=2.2$, $n=30$ ) in diam, clamp, almost hyaline, thin to thick-walled, composed of narrow and spare branches; skeletal hyphae 3.2-6.5 $\mu \mathrm{m}$ width $(n=30)$, usually thick-walled, hyaline, some branched and intertwined hyphae; binding hyphal 2.4-5.7 $\mu \mathrm{m}$ width $(n=30)$, thick-walled, many branches, and comprised Bovista-type ligative hyphae. Pileipellis a hymeniderm, brown (6E8), composed of apically acanthus-like branched cells, dextrinoid. Basidiospores mostly ellipsoid with double walls, (7.8-)8.7-10.8-12.2(-13.3) × (6.9-)7.49.1-10.0(-10.7) $\mu \mathrm{m},(\bar{x}=10.7 \times 9.1 \mu \mathrm{m}, n=50) \mu \mathrm{m}$, with $\mathrm{Q}=1.15-1.22, \mathrm{~L}=10.79 \mu \mathrm{m}$, $\mathrm{W}=9.13 \mu \mathrm{m}$ (including myxosporium), (5.4-)5.9-6.6-7.1(-7.7) $\times(4.9-) 5.4-5.8-6.2(-6.7) \mu \mathrm{m}$ 
$(\bar{x}=6.6 \times 5.8 \mu \mathrm{m}, n=50) \mu \mathrm{m}$, with $\mathrm{Q}=1.11-1.17, \mathrm{~L}=6.64 \mu \mathrm{m}, \mathrm{W}=5.82 \mu \mathrm{m}$ (excluding outer myxosporium), inner walled deep orange (6A8), brownish-orange (7C7-7C8) in $\mathrm{KOH}$, outer walled dark brown (7E6), dark brown (7E8) to reddish-brown (8E8) in KOH. Cutis usually composed of clavate cells.

Habitat: Solitary on stump of Quercus spp.

Specimens examined: CHINA, Yunnan Province, Jinning District, $24^{\circ} 41^{\prime} 17^{\prime \prime} \mathrm{N}, 102^{\circ} 13^{\prime} 15^{\prime \prime} \mathrm{E}$, 1912 m elev., 8 October 2017, T. Luangharn, MFLU 19-2152.

Notes: Ganoderma multiplicatum was originally collected from French Guyana [2]. This species has a distinctive form with its reddish-black pileus, a not fully homogenous context, tuberculate hyphal ends in cuticle cells, with small subglobose to broadly ellipsoid basidiospores (7-8 × 5-6 $\mu \mathrm{m})$ [7,136-138]. Ganoderma multiplicatum has been considered most similar to G. chalceum [113], also considered a synonym of G. subamboinense Henn. [136], but Correia de Lima et al. [139] illustrated that G. chalceum and G. subamboinense are in different clades, suggesting they are not synonymous. Our G. multiplicatum specimen was collected from Yunnan Province, China. It is similar to the original description, showing ellipsoid basidiospores, while sub-globous basidiospores could not be observed. This species has been reported from Africa [140], Asia [61], China [13,61,119,122], India [141], Myanmar [30], Taiwan, PRC [122], and neotropical regions of Brazil, Colombia, and Venezuela [138].
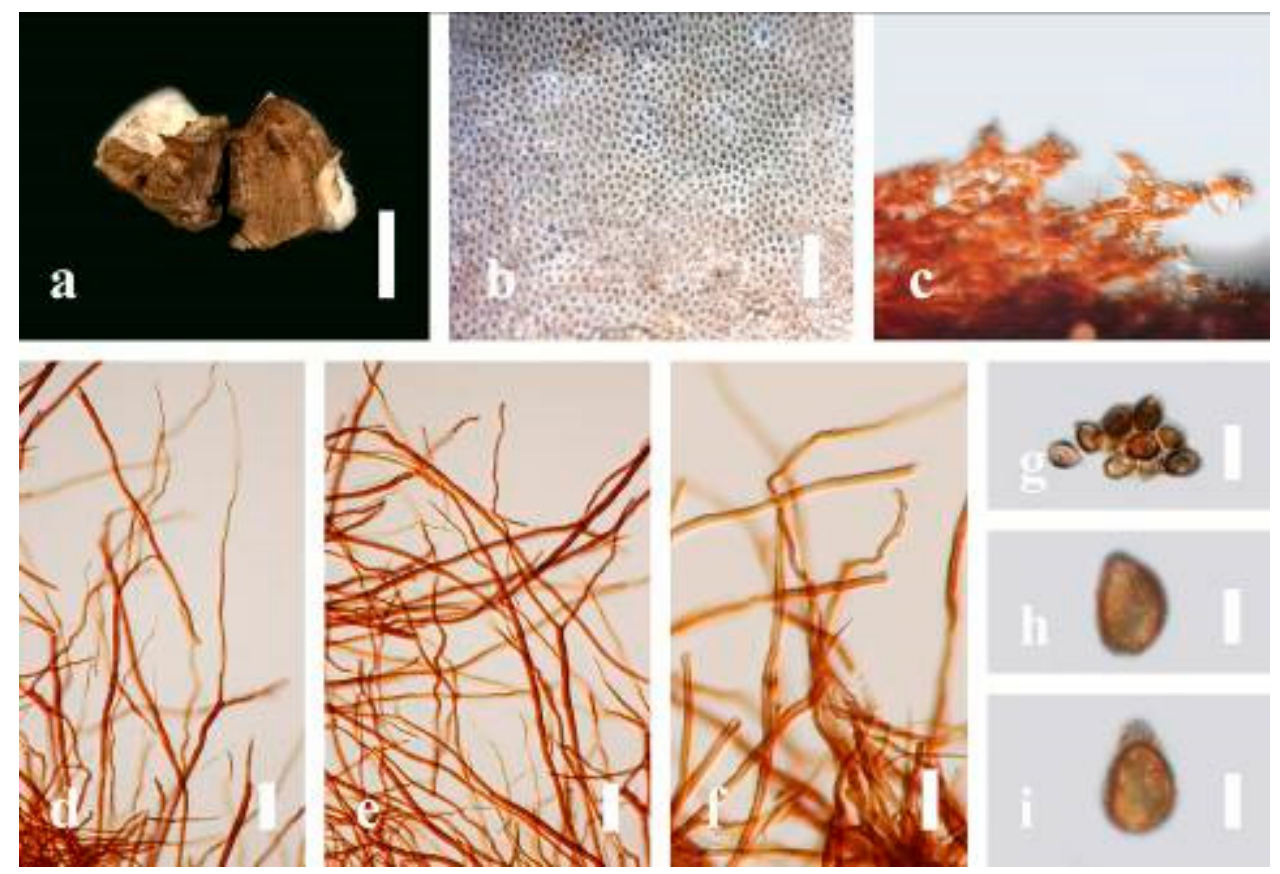

Figure 11. Morphology of Ganoderma multiplicatum (MFLU 19-2152): (a) mature basidiomes; (b) pore characteristics; (c) hyphae of tube layers in $\mathrm{KOH} ;(\mathbf{d}-\mathbf{f})$ context hyphae in $\mathrm{KOH}$; (g-i) basidiospores. Scale bars: $(\mathbf{a})=2 \mathrm{~cm},(\mathbf{b})=1000 \mu \mathrm{m},(\mathbf{d}-\mathbf{f})=20 \mu \mathrm{m},(\mathbf{g}-\mathbf{i})=5 \mu \mathrm{m}$.

Ganoderma resinaceum Boud., Bulletin de la Société Mycologique de France. 5; 72 (1889) (Figure 12)

三Fomes resinaceus (Boud.) Sacc., Sylloge Fungorum. 9: 179 (1891)

三Scindalma resinaceum (Boud.) Kuntze, Revisio generum plantarum. 3(2); 519 (1898)

$\equiv$ Friesia resinacea (Boud.) Lázaro Ibiza, Revta R. Acad. Cienc. exact. fis. nat. Madr.: 591 (1916)

$\equiv$ Ganoderma lucidum subsp. resinaceum (Boud.) Bourdot and Galzin, Bulletin de la Sociètè Mycologique de France. 41; 177 (1925)

$\equiv$ Ganoderma lucidum var. resinaceum (Boud.) Maire, Fungi Catalaunici: Contributions á lètude de la Flore Mycologique de la Catalogne: 38 (1933) 
= Ganoderma chaffangeonii Pat., Bulletin de la Société Mycologique de France. 5: 74 (1889)

= Polyporus polychromus Copel., Annales Mycologici. 2 (6): 507 (1904)

= Ganoderma praelongum Murrill, North American Flora. 9 (2): 121 (1908)

= Ganoderma argillaceum Murrill, North American Flora. 9 (2): 122 (1908)

= Ganoderma pulverulentum Murrill, North American Flora. 9 (2): 121 (1908)

= Ganoderma subperforatum G.F. Atk., Botanical Gazette Crawfordsville. 46 (5): 337 (1908)

= Ganoderma areolatum Murrill, Bulletin of the New York Botanical Garden. 8: 149 (1912)

= Mensularia vernicosa Lázaro Ibiza, Revista de la Real Academia de Ciencias Exactas Fisicas y Naturales Madri. 14: 740 (1916)

= Ganoderma subtuberculosum Murrill, Lloydia. 7 (4): 326 (1945)

Facesoffungi number: FoF 06252

Description: Basidiomes annual, perennial, short stipitate. Pileus $1.5-12.5 \mathrm{~cm}$ in length, $1-7 \mathrm{~cm}$ in width, and up to $2 \mathrm{~cm}$ thick at the base. Pileus dimidiate, flabelliform, reniform, convex, imbricate, umbonate or uneven, some ungulate, concentric zones at the center that extend to the margin, broadly attached, thick at the base, slightly soft at the margin when mature. Pileus surface glossy, shiny, silky, smooth, and soft when young, laccate when mature, furrowed and shallow sulcate, undulating, somewhat spathulate to uneven on upper surface when mature, covered by irregularly ruptured thin crust, slightly dull and faded when mature to old, compact and hard when mature, woody to corky when mature to old. Pileus color reddish-brown (10E7-10E8) at the center, slight to yellowish-red (8B7-8B8), reddish-orange (7A7-7A8), and light orange (5A5-5A6) closed to the margin, and white (4A1) at the margin. Context up to $0.4-1 \mathrm{~cm}$ thick at the base, mostly grayishyellow (4C6) to dark brown (7F6-7F8) cuticle cells, and dark brown (6F6) melanoid bands, thick-walled, some fibrous pithy context, usually separated by layers of context tissue at the base. Tube woody hard, often dark brown (7F7-7F8) when dried, concolorous with pore surface, and sulcate at different levels. Stipe short stipitate, usually reddish-brown (10E7-10E8), and a differentiated zone at the point of attachment. Margin up to $1.5 \mathrm{~cm}$ thick, initially white (5A1), yellowish-gray (4B2) when mature, turning light brown (6D4) to brown (6E8) when scratched or bruised, often slippery when wet, softer when young, thinner than the center. Pore 4-7 in number per $\mathrm{mm}$, angular to circular. Pore surface initially white (7A1) to yellowish-white (1A2), becoming light orange (5A5) when mature, light brown (7D6) to brown (7D8) when handled, scratched, or bruised.

Hyphal structure: Hyphal system trimitic; generative hyphae 2.1-4.7 $\mu \mathrm{m}(\bar{x}=3.6, n=30)$ in diam, clamp, almost hyaline, thin-walled, composed of sparse branches; skeletal hyphae 3.2-6.2 $\mu \mathrm{m}$ width $(n=30)$, usually thick-walled, hyaline, some branched and intertwined hyphae; binding hyphal 2.8-5.1 $\mu \mathrm{m}$ width $(n=30)$, thick-walled and occasionally thickwalled, without septate hyphae, many branches, and composed of Bovista-type ligative hyphae. Basidiospores mostly ellipsoid with double walls, (7.6-)8.4-9.4-10.5(-11.3) $\times(6.5-)$ 7.1-8.4-9.0(-9.8) $\mu \mathrm{m},(\bar{x}=9.3 \times 8.2 \mu \mathrm{m}, n=50) \mu \mathrm{m}$, with $\mathrm{Q}=1.10-1.16, \mathrm{~L}=9.31 \mu \mathrm{m}$, $\mathrm{W}=8.24 \mu \mathrm{m}$ (including myxosporium), (6.5-)7.1-8.2-9.1(-9.8) $\times(4.8-) 5.3-5.7-6.8(-7.3) \mu \mathrm{m}$ $(\bar{x}=8.1 \times 5.6 \mu \mathrm{m}, n=50) \mu \mathrm{m}$, with $\mathrm{Q}=1.42-1.48, \mathrm{~L}=8.13 \mu \mathrm{m}, \mathrm{W}=5.62 \mu \mathrm{m}$ (excluding outer myxosporium), inner walled orange (5A6) to deep orange $(5 \mathrm{~A} 7-5 \mathrm{~A} 8,6 \mathrm{~A} 8)$ in $\mathrm{KOH}$ and grayish brown (5C5-5C6) in Melzer's reagent, outer walled dark brown (7E6-7E8) to reddish-brown (8E8) in $\mathrm{KOH}$ and light brown (6D5-6D6) to brown (6D7-6D8) in Melzer's reagent.

Habitat: Solitary, on living tree of Albizia mollis (Wall.) Boiv.

Specimens examined: CHINA, Yunnan Province, Kunming Institute of Botany, $25^{\circ} 08^{\prime} 39^{\prime \prime} \mathrm{N}$, $102^{\circ} 44^{\prime} 30^{\prime \prime}$ E, $1962 \mathrm{~m}, 12$ July 2017, T. Luangharn, MFLU 19-2153.

Notes: Ganoderma resinaceum was introduced by Boudier in 1889 from France [41]. This species has also been described by Steyaert [110] and Ryvarden and Gilbertson [105]. Ganoderma resinaceum is distinctively characterized by variable pileus coloration, a fi- 
brous spongy homogeneous context, larger basidiospores, and an amyloid pileipellis [7]. This species is considered to have characteristics similar to G. pfeifferi in its upper crust resinous layers. However, this species has a dark brown to umber context and wider spores. In addition, G. resinaceum also shares similarities with G. lucidum, while G. lucidum possesses a varying light context without a dark zone above the tubes and no resinous layer on the crust $[105,140]$. Ganoderma resinaceum was evaluated to the species complex base on molecular evidence [38], but in the phylogenetic analysis, it cannot be distinguished from G. lucidum [142]. However, several researchers suggested that G. resinaceum differs from G. lucidum $[4,76,143]$.

Ganoderma sanduense Hapuar., T.C. Wen and K.D. Hyde, Mycosphere 10, 274 (2019) Taxonomy and phylogenetic analyses are shown in Hapuarachchi et al. [30].

Notes: Ganoderma sanduense is characterized by its ferruginous laccate pileus, orbicular, strongly laccate, several layers thick, basidiospores 12.1-13.8 × 9.2-10.5 $\mu \mathrm{m}$, relatively large broadly ellipsoid to ellipsoid basidiospores, with a light brown eusporium bearing fine, hyaline, short, and distinct echinulae. This fungus is solitary on rotten wood in dry dipterocarp forests and in upper-mixed deciduous forests from Guizhou Province, China.
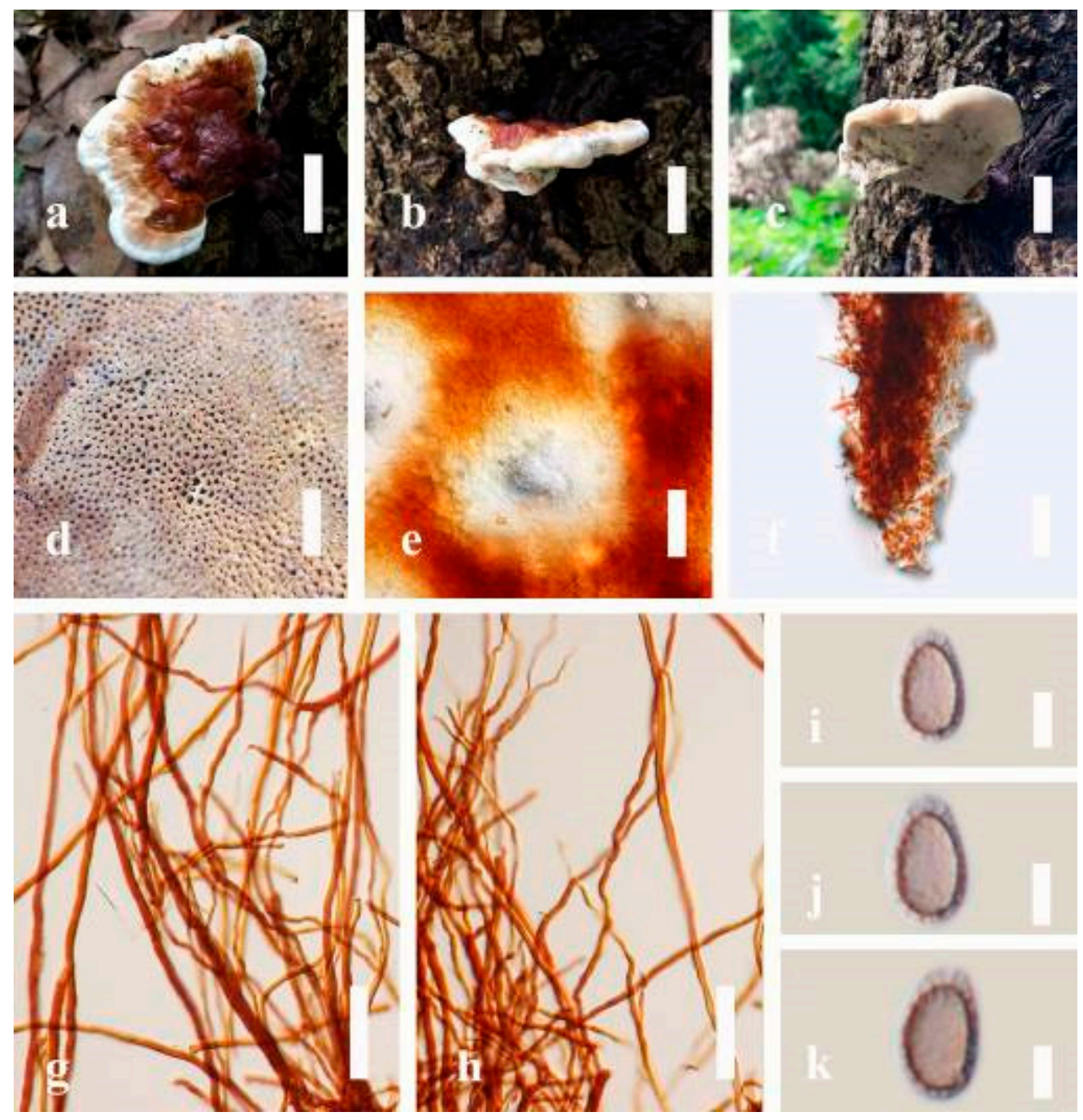

Figure 12. Morphology of Ganoderma resinaceum (MFLU 19-2153): (a-c) mature basidiomes; (d) pore characteristics; (e) hyphae of pore in $\mathrm{KOH}$; (f) hyphae of tube layers in $\mathrm{KOH} ;(\mathbf{g}$,h) context hyphae in $\mathrm{KOH}$; (i) basidiospores in Melzer's reagent; $(\mathbf{j}, \mathbf{k})$ basidiospores in $\mathrm{KOH}$. Scale bars: $(\mathbf{a}-\mathbf{c})=4 \mathrm{~cm}$, $(\mathbf{d})=1000 \mu \mathrm{m},(\mathbf{e})=150 \mu \mathrm{m},(\mathbf{f})=30 \mu \mathrm{m},(\mathbf{g}, \mathbf{h})=50 \mu \mathrm{m},(\mathbf{i}-\mathbf{k})=5 \mu \mathrm{m}$. 
Ganoderma sichuanense J.D. Zhao and X.Q. Zhang, Acta mycol. sin.: 159 (1983) (Figure 13)

Facesoffungi number: FoF 06248

Description: Basidiomes annual or perennial, stipitate. Pileus $0.5-3.2 \mathrm{~cm}$ in length, $0.5-3 \mathrm{~cm}$ in width, up to $1 \mathrm{~cm}$ thick at the base. Pileus reniform to circular, or subflabellate when seen from above, concentrically sulcate zones with turberculate, glabrous when youth to maturity, bumps when mature, often tough to break when dried, often with undefined concentric zones at the center that extend to the margin, thick at the center, slightly soft at the margin. Pileus surface shiny, silky, smooth, and soft when young, hard and woody old, frequently furrowed and shallow sulcate on upper surface, undulating, somewhat spathulate to uneven when mature, covered by irregularly ruptured thin crust, and strongly laccate from mature to old. Pileus color usually homogenous with yellowish-red (8A7-8A8) at the center, slight reddish-orange (7A7-7A8), and reddish-brown (8E8) at the deep-sulcate margin from mature to old. Context up to $0.2-0.8 \mathrm{~cm}$ thick at the base, some thin-walled, with abundant thick-walled to subsolid hyphae, containing fibrous pithy context, bearing clamp connections, with dark brown (7F7) melanoid bands occurring. Tube hard and woody, thin-walled, frequently branched, with clamped connection, and often dark brown (7F7-7F8) when dried. Stipe up to 3-812 cm in length, up to $0.3-1 \mathrm{~cm}$ in width, centrally stipitate, almost sub-cylindrical to cylindrical, concolorous with the pileus, often reddishbrown (8E7-8E8), and strongly laccate from mature to old. Margin soft when young, strongly laccate when mature, some wavy, slippery when wet, smooth, softer, thinner than the base, and soft than the center, often deep orange (5A8) to golden yellow (5B7-5B8) from mature to old. Pore 4-6 in number per mm, subcircular to circular, sometimes angular. Pore surface initially white (11A1), pale yellow (3A3) to yellow (3A7) when mature, turns light brown (7D5), brown (7D7-7D8) to dark brown (7F6-7F8) when scratched or bruised, becoming discolored when touched.

Hyphal structure: Hyphal system trimitic, with clamp connections, hyaline, thin to thick-walled, tapering at branch, sometimes swollen at the attachment point, composed of some narrow hyphae; generative hyphae (1.3-)1.8-2.3-2.6(-2.8) $\mu \mathrm{m}$ broad $(n=30)$, hyaline, and thin-walled; skeletal hyphae (2.1-)2.5-3.9-4.8(-5.2) $\mu \mathrm{m}$ broad $(n=30)$ abundant with walls varying in thickness, unbranched, sometimes subsolid; binding hyphae (1.7-)2.1-2.8-3.6(-4.3) $\mu \mathrm{m}$ broad $(n=30)$, usually with walls varying in thickness, narrow to subsolid, usually presenting as orange white (6A2), pale orange (6A3) to light orange (5A5) of thin-walled, and pale red (6A3) of thick-walled, with subsolid in $\mathrm{KOH}$. Pileipellis a hymeniderm, light brown (6D6), clavate-like cells, dextrinoid. Basidiospores mostly ellipsoid, some oblong with double walls, (8.0-)8.6-9.6-10.5(-11.0) $\times(6.2-) 6.7-8.4-9.6(-10.1)$ $\mu \mathrm{m}(\bar{x}=9.5 \times 8.3 \mu \mathrm{m}, n=50) \mu \mathrm{m}, \mathrm{Q}=1.11-1.17, \mathrm{~L}=9.49 \mu \mathrm{m}, \mathrm{W}=8.31 \mu \mathrm{m}$ (including myxosporium), (7.0-)7.4-7.9-8.5(-9.0) $\times(4.2-) 4.5-5.6-5.9(-6.4) \mu \mathrm{m}(\bar{x}=7.8 \times 5.6 \mu \mathrm{m}, n=50) \mu \mathrm{m}$, with $\mathrm{Q}=1.36-1.41, \mathrm{~L}=7.80 \mu \mathrm{m}, \mathrm{W}=5.62 \mu \mathrm{m}$ (excluding outer myxosporium), overlaid by hyaline, dextrinoid, echinulae, inner wall echinulate with grayish-orange (6B5-6B6) to brownish-orange (7D4-7D5), and outer walled usually dark brown (7E8-7E8) to reddishbrown (8E6-8E8) in $\mathrm{KOH}$.

Habitat: Solitary on the living tree of Graucoides schotky.

Specimens examined: CHINA, Yunnan Province, Xishan Forest Park, $24^{\circ} 57^{\prime} 53^{\prime \prime} \mathrm{N}$, $102^{\circ} 53^{\prime} 10^{\prime \prime}$ E, 2013 m elev., 29 October 2016, T. Luangharn, HKAS 97398.

Notes: Ganoderma sichuanense was originally described from the Sichuan Province, China, in 1983 [5]. However, G. sichuanense was published in 1983 [40] but has not been widely used. Ganoderma sichuanense was verified as "G. lucidum" (Lingzhi) based on both morphological and molecular data. This fungus was distinguished from other Ganoderma species. Ganoderma sichuanense was characterized by its distinctive substipitate to stipitate, flabellate to reniform, radially rugose pileus, laccate with a verrucose or tuberculose upper surface, pore surface yellowish when young, becoming brown or black when bruised, and small spores [13]. Originally the basidiospores were described as (7.4-9.5 $\times 5-7)$ $\mu \mathrm{m}[40]$, then updated to $(7.8-10.4 \times 5.2-6.4) \mu \mathrm{m}[13,61]$, and $(9-11.5 \times 6.5-8) \mu \mathrm{m}[5]$. 
The study basidiospores were 7.8-9.5 $\times 5.6-8.3 \mu \mathrm{m}$, which is in the range of the original report, which is not distinct from those of basidiospores found in other reports. Cao et al. [4] stated that $G$. sichuanense differs from G. lingzhi as its sessile basidiocarps and smaller basidiospores (7.4-9.2 × 5-6.6) $\mu \mathrm{m}$, with distinctive yellow context, thick dissepiments, absence of concentric growth zones in the context, basidiospore size, yellow pore surface, and presence of melanoid bands upon maturity [4,37]. Ganoderma sichuanense was yellowish-brown, with a dark brown eusporium bearing thick echinulae, overlaid by a hyaline myxosporium. However, among the Chinese Ganoderma species, G. flexipes, G. multipileum, G. sichuanense, G. tropicum, and G. tsugae are the most similar species to G. lingzhi because they share a reddish-brown pileal surface, similar basidiospores, and cuticle cells [4].
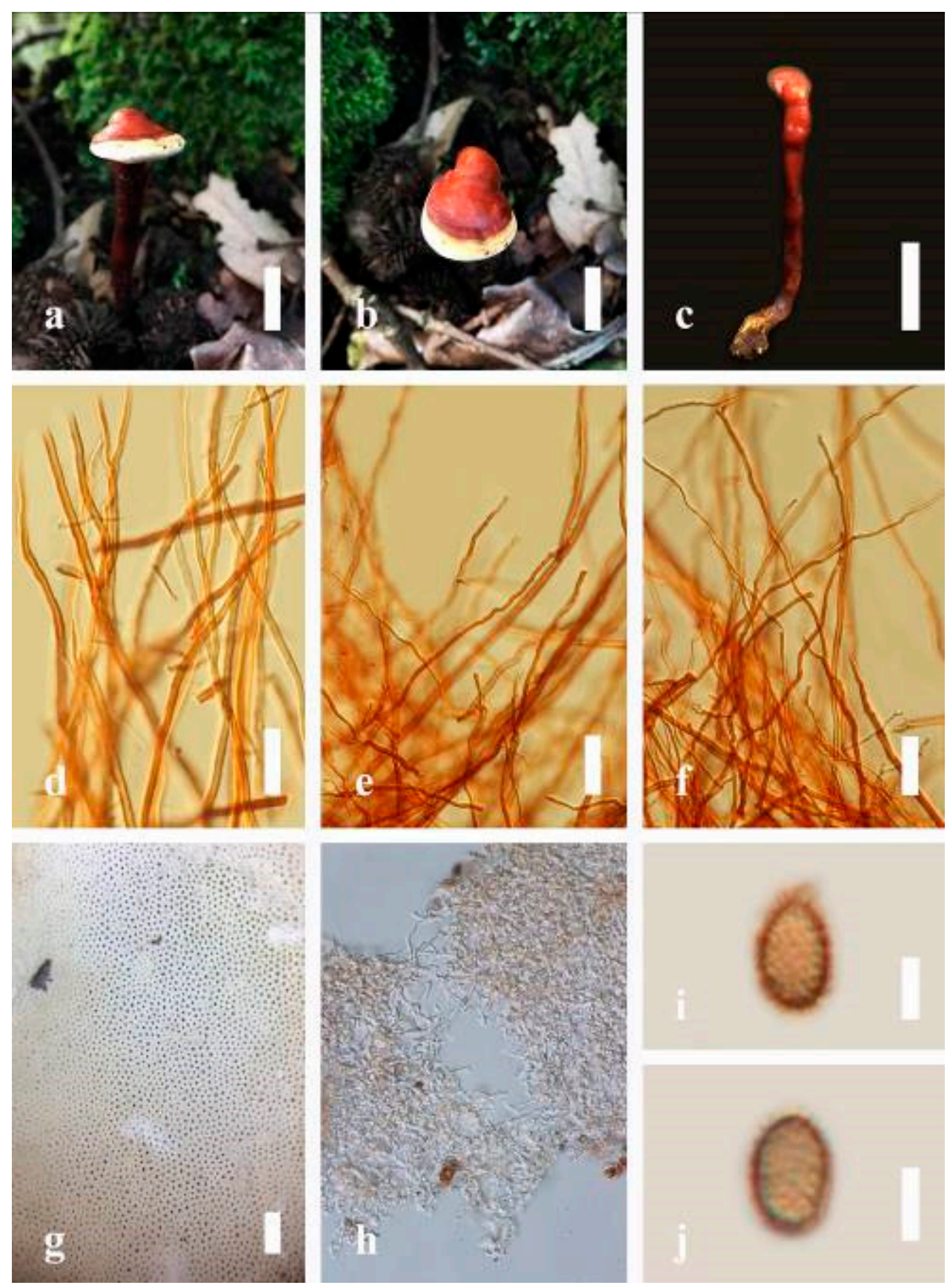

Figure 13. Morphology of Ganoderma sichuanense (HKAS 97398): (a-c) mature basidiomes; (d) hyphae of trama in $\mathrm{KOH} ;(\mathbf{e}, \mathbf{f})$ context hyphae in $\mathrm{KOH} ;(\mathbf{g})$ pore characteristics; (h) hyphae of pore in $\mathrm{KOH}$; $(\mathbf{i}, \mathbf{j})$ basidiospores. Scale bars: $(\mathbf{a}, \mathbf{b})=1 \mathrm{~cm},(\mathbf{c})=3 \mathrm{~cm},(\mathbf{d})=20 \mu \mathrm{m},(\mathbf{e}, \mathbf{f})=30 \mathrm{~cm},(\mathbf{g})=1000 \mu \mathrm{m}$, $(\mathbf{i}, \mathbf{j})=5 \mu \mathrm{m}$. 
Ganoderma sinense J.D. Zhao, L.W. Hsu and X.Q. Zhang, Acta Mycologica Sinica. 19: 272 (1979) (Figure 14)

= Ganoderma formosanum T.T. Chang and T. Chen. Transactions of the British Mycological Society. 82(4): 731 (1984)

Facesoffungi number: FoF 06253

Description: Basidiomes annual, stipitate, subdimidiate. Pileus 2-6 cm in length, 2-4 cm in width, and $0.3-1 \mathrm{~cm}$ thick. Pileus stipitate, subdimidiate to dimidiate, flabelliform, spathulate, umbonate, radial from the center extending to the margin, tough to break when dried, often thick at the center, slightly soft at the margin, light in weight when dried, and without woody. Pileus surface laccate, convex, some radial furrowed to furrowed, imbricate, incised, glossy, shiny, spathulate, shallow sulcate when fresh, umbonate or uneven, strongly laccate and glossy when mature, and weakly laccate where the new hyphae are in active development (margin), usually smooth layers at the center when young to age, irregularly ruptured crust overlying the context, and leathery when age when break. Pileus color usually homogenous with brownish-red (8C7-8C8) to reddish-brown (8D7-8D8) at the center toward stipe, extending brownish-red (9C8) from the center, slight to the margin when mature, usually reddish-brown (8E5-8E8) upper margin surface when old. Context up to $0.3-1 \mathrm{~cm}$ thick near stipe, dry, upper layer brownish-orange (6C8) when fresh, grayish-orange (5B5) at lower layers, with dark brown (8F7) when dried, soft and fibrous, covered with thin crust, some present woody, trimitic hyphal, hyaline, thin to thick-walled with simple septa, with branched. Tube $0.3-0.6 \mathrm{~cm}$ in length, brown (7D8). Stipe 4-16 cm in length, sub-cylindrical to cylindrical, almost stipitate with broadly and thick at the base, irregularly ruptured crust overlying, usually strongly laccate with brown (7D8) to dark brown (8F8) when mature, and dark brown (8F8) when old. Margin soft, some wavy, laccate when mature, weakly laccate when old, brownish-orange (6D8) when mature to old. Pore 4-6 in number per mm, subcircular to circular. Pore surface white (11A1) to yellowish-white (2A2) when mature, discolored when touched, brownish (6E7) to dark brown (6F7) when scratched or bruised.

Hyphal structure: Hyphal system trimitic, with clamp connections, usually light orange (5A5), orange (5A7), golden yellow (5B7-5B8), sometimes brownish-red (8C7) in $\mathrm{KOH}$; generative hyphae 1.3-2.4 $\mu \mathrm{m}$ broad $(n=30)$, hyaline, thin-walled, with clamp connections; skeletal hyphae 3.1-5.2 $\mu \mathrm{m}$ broad $(n=30)$, usually hyaline, thick-walled, unbranched, and solid; binding hyphae 2.9-5.2 $\mu \mathrm{m}$ width $(n=30)$, thin to thick-walled, with branched, hymenial with sword-like apices in the context. Basidiospores mostly ellipsoid to broadly ellipsoid, with double walls, with size range of (9.5-)10.2-11.4-12.3(-13.1) $\times(7.0-) 7.6-8.4-9.3(-10.2) \mu \mathrm{m}(\bar{x}=11.2 \times 8.5 \mu \mathrm{m}, n=50) \mu \mathrm{m}$, with $\mathrm{Q}=1.28-1.36, \mathrm{~L}=11.24$ $\mu \mathrm{m}, \mathrm{W}=8.50 \mu \mathrm{m}$ (including myxosporium), (8.3-)9.4-10.3-11.5(-12.3) $\times(6.1-) 6.7-7.1-7.5$ $(-8.0) \mu \mathrm{m}(\bar{x}=10.2 \times 7.2 \mu \mathrm{m}, n=50) \mu \mathrm{m}$, with $\mathrm{Q}=1.41-1.47, \mathrm{~L}=10.32 \mu \mathrm{m}, \mathrm{W}=7.13 \mu \mathrm{m}$ (excluding outer myxosporium), overlaid by hyaline, apically, short echinulae, truncate, some turgid vesicular appendix, inner wall echinulate, orange (5A7), deep orange (5A8, $5 \mathrm{~B} 8$ ), orange (6B8), with brownish-orange (6B8), outer wall usually brownish-red (8C7-8C8) in $5 \% \mathrm{KOH}$.

Habitat: Solitary on decaying and living tree of Albizia mollis (Wall.) Boiv., living tree Quercus sp.

Specimens examined: CHINA, Yunnan Province, Baoshan, $25^{\circ} 09^{\prime} 35^{\prime \prime}$ N, $99^{\circ} 09^{\prime} 49^{\prime \prime}$ E, 1973 m elev., 11 November 2017, T. Luangharn, MLFU 19-2173.

Notes: Ganoderma sinense was described from China, characterized by a uniformly brown to dark brown context and slightly longitudinally crested basidiospores [122]. This species was considered as a species with high phenotypic [13,36]. Our G. sinense collection was obtained from Yunnan Province, China, and agrees well with the description of the holotype as described by Wang and Wu [122]. Several reports have also illustrated G. sinense from China $[13,47,123]$. Ganoderma sinense is considered to have characteristics similar to G. lucidum, while G. sinense illustrates differences in macro- characteristics in its thin pileus, long stipes, and rarely branched skeletal hyphae with Bovista-type 
binding hyphae [106], and these two different species are distinguished in reports [130]. Ganoderma sinense is also reported to have similar characteristics with G. formosanum; hence, G. formosanum was treated as synonymous, and consequently, the earliest used valid name was G. sinense [122].
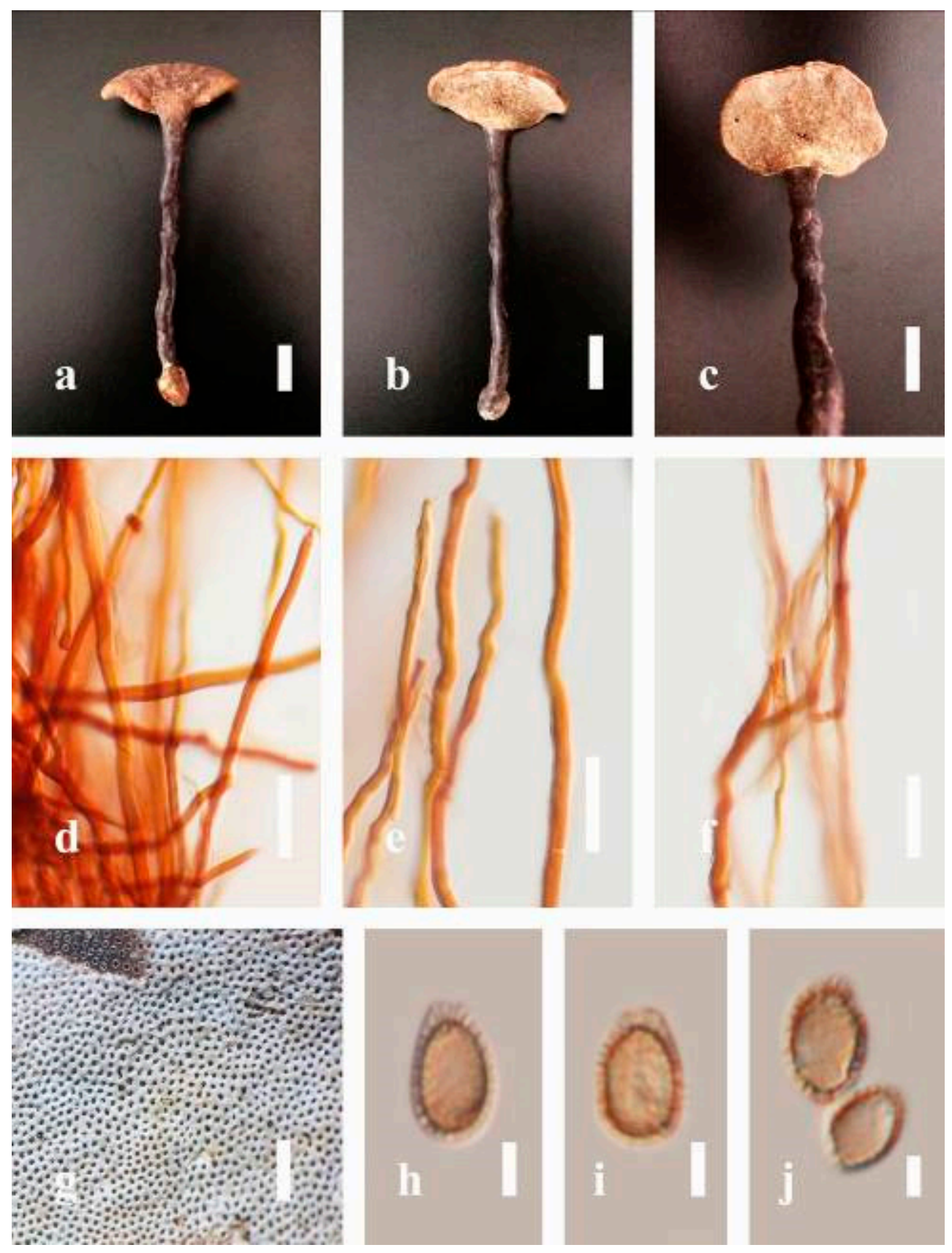

Figure 14. Morphology of Ganoderma sinense (MFLU 19-2173): (a-c) mature basidiomes; (d-f) context hyphae in $\mathrm{KOH}$; $(\mathbf{g})$ pore characteristics; $(\mathbf{h}-\mathbf{j})$ basidiospores in $\mathrm{KOH}$. Scale bars: $(\mathbf{a}-\mathbf{c})=2 \mathrm{~cm}$, $(\mathbf{d}-\mathbf{f})=20 \mu \mathrm{m},(\mathbf{g})=1000 \mu \mathrm{m},(\mathbf{h}-\mathbf{j})=5 \mu \mathrm{m}$.

Ganoderma tsugae Murrill, Bulletin of the Torrey Botanical Club. 29; 601 (1902) (Figure 15)

$\equiv$ Fomes tsugae (Murrill) Sacc. and D. Sacc., Sylloge Fungorum. 17: 123 (1905)

$\equiv$ Polyporus tsugae (Murrill) Overh.: 714 (1915)

= Polyporus metallicus Lloyd, Mycological Writings. 6 65): 1099 (1920)

Facesoffungi number: FoF 06254 
Description: Basidiomes annual, subdimidiate, stipitate. Pileus $2-16 \mathrm{~cm}$ in length, 2-9 $\mathrm{cm}$ in width, and $0.5-3 \mathrm{~cm}$ thick at the base. Pileus stipitate, subdimidiate to dimidiate, flabelliform, spathulate, umbonate, concentrically sulcate zone, radial from the center extending to the margin, tough to break when dried, often thick at the center, slightly soft at the margin, light in weight when dried, with woody or corky when dried. Pileus surface laccate, convex, radial furrowed, imbricate, incised, glossy, shiny, spathulate, shallow sulcate, umbonate or uneven, strongly laccate and glossy when mature, and weakly laccate where the new hyphae are in active development (margin), usually smooth layers at the center when young to age, irregularly rugose, irregularly ruptured, thin crust overlying the context, tough to break when dried. Pileus color usually homogenous with brownishred (8C7-8C8) to reddish-brown (8D7-8D8) at the center toward the stipe and margin surface when mature to old. Context up to $0.4-2.2 \mathrm{~cm}$ thick near the stipe, brownish-orange (7C7-7C8) to brown (7D8) on the upper layers, brownish-red (8C6) when dried, soft and fibrous, covered with thin crust, some present woody, dimitic hyphal, hyaline, thin-walled with simple septa, branched. Tube $0.3-1.6 \mathrm{~cm}$ in length, with dark brown (7F5). Stipe 4-10 cm in length, $2 \mathrm{~cm}$ thick, sub-cylindrical to cylindrical, almost stipitate and broad and thick at the base, irregularly ruptured crust overlying, usually strongly laccate with brown (7D8) to dark brown (8F8) when mature, usually dark brown (8F8) when old. Margin soft, some wavy, laccate when mature, and strong laccate when old, brownish-red (8C7-8C8) to reddish-brown (8D7-8D8) from mature to old. Pore 4-6 in number per mm, circular or angular. Pore surface yellowish-white (4A2) when present to yellowish-white (2A2) when mature, discolored when touched, brownish (6E7) when scratched or bruised.

Hyphal structure: Hyphal system trimitic, with clamp connections; generative hyphae 3.1-4.8 $\mu \mathrm{m}$ broad $(n=30)$, hyaline, thin-walled, with clamp connections; skeletal hyphae 3.1-6.8 $\mu \mathrm{m}$ broad $(n=30)$, usually hyaline, thick-walled, non-septate, unbranched, and solid; binding hyphae 3.9-5.0 $\mu \mathrm{m}$ width $(n=30)$, with walls varying in thickness, with many branches, some hymenial with sword-like apices in the context. Basidiospores mostly ellipsoid to broadly ellipsoid, with double walls, with size range of (9.7-)10.612.7-14.3(-15.8) × (7.3-)8.4-10.7-11.5(-12.4) $\mu \mathrm{m}(\bar{x}=12.7 \times 10.5 \mu \mathrm{m}, n=50) \mu \mathrm{m}$, with $\mathrm{Q}=1.18-1.24, \mathrm{~L}=12.68 \mu \mathrm{m}, \mathrm{W}=10.48 \mu \mathrm{m}$ (including myxosporium), (8.3-)9.4-10.8-12.6 $(-13.1) \times(6.1-) 6.9-7.6-8.3(-9.2) \mu \mathrm{m}(\bar{x}=10.7 \times 7.6 \mu \mathrm{m}, n=50) \mu \mathrm{m}$, with $\mathrm{Q}=1.36-1.45$, $\mathrm{L}=10.68 \mu \mathrm{m}, \mathrm{W}=7.59 \mu \mathrm{m}$ (excluding outer myxosporium), overlaid by hyaline, apically and short echinulae, truncate and turgid vesicular appendix, inner walled echinulate, brownish-orange (6C7-6C8), outer walled usually dark-brownish (6F7-6F8) in 5\% $\mathrm{KOH}$.

Habitat: Solitary, on decaying Quercus spp. tree.

Specimens examined: CHINA, Yunnan Province, Jinning District, $24^{\circ} 41^{\prime} 17^{\prime \prime} \mathrm{N}, 102^{\circ} 13^{\prime} 15^{\prime \prime} \mathrm{E}$, 1973 m elev., 11 November 2017, JC. Xu, HKAS 97406.

Notes: Ganoderma tsugae has been treated as a synonym of G. lucidum [144-146]. This fungus is characterized by a laccate and concentric yellowish-red pileus, stipitate, fan-shaped, sulcated with a yellow margin, ovoid, verrucose, and truncated basidiospores. G. tsugae is widely distributed across the USA $[35,109]$. The phylogenic analysis supported G. tsugae as an independent species distinct from G. lucidum, as it grows exclusively on conifers, especially on Tsuga and Abies species, while G. lucidum inhabits mostly angiospermous trees [76]. According to Loyd et al. [35], G. tsugae is similar to G. oregonense as they share a distinctly white context tissue, rough basidiospores, and are predominately associated with conifers decay. 

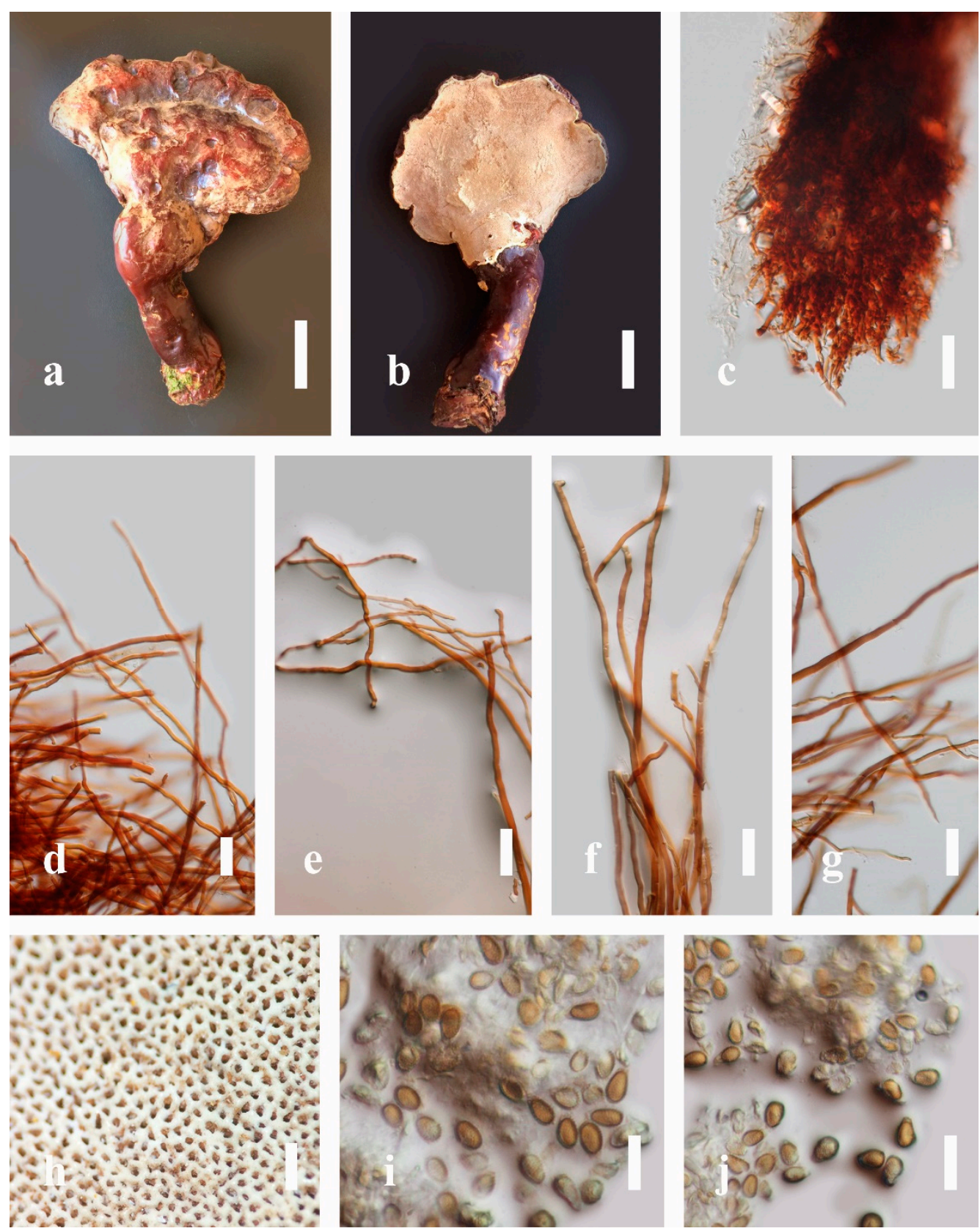

Figure 15. Morphology of Ganoderma tsugae (HKAS 97406): (a,b) mature basidiomes; (c) hyphae of tube layers; $(\mathbf{d}-\mathbf{g})$ context hyphae in $\mathrm{KOH}$; $(\mathbf{h})$ pore characteristics; $(\mathbf{i}, \mathbf{j})$ basidiospores. Scale bars: $(\mathbf{a}, \mathbf{b})=4 \mathrm{~cm},(\mathbf{c})=30 \mathrm{~cm},(\mathbf{d}-\mathbf{g})=30 \mu \mathrm{m},(\mathbf{h})=500 \mu \mathrm{m},(\mathbf{i}, \mathbf{j})=5 \mu \mathrm{m}$.

\subsubsection{Taxonomy of Ganoderma from Laos}

Ganoderma adspersum (Schulzer) Donk Proc. K. Ned. Akad. Wet., Ser. C, Biol. Med. Sci. 72(3): 273 (1969) (Figure 16)

$\equiv$ Polyporus adspersus Schulzer, Flora.: 11 (1878)

= Polyporus linhartii Kalchbr., Fungi Hong. 252 (1884)

= Ganoderma europaeum Steyaert, Bulletin du Jardin Botanique de l'État à Bruxelles. 31: $70(1961)$

Facesoffungi number: FoF 06241

Description: Basidiomes annual, subdimidiate, sessile. Pileus 3-22 cm in length, 2-14 $\mathrm{cm}$ broad, and 1-4 $\mathrm{cm}$ thick at the base. Pileus sessile, perennial, subdimidiate to dimidiate, flabelliform, spathulate, umbonate, concentrically sulcate zone, somewhat round 
and plump when young, somewhat imbricate with flabelliform (fan-shaped) when seen from above, broadly attached, radial from the center extending to the margin, tough to break when dried, thick at the base, slightly soft at the margin when mature, light in weight with woody or corky when dried. Pileus surface non-laccate (dull), convex, radially furrowed, incised, spathulate, shallow sulcate, usually silky, soft, and smooth when young, and slippery surface when fresh, thick crust overlaying the context, a differentiated zone at the point of attachment, and tough to break when dried. Pileus color usually homogenous with reddish-orange (7A8) to brown (7D7-7D8) at the center when mature, golden yellow (5B7), brownish-orange (5C5-5C6, 6D5) when old toward the stipe and margin surface. Context up to $0.5-2.5 \mathrm{~cm}$ thick near stipe, brown (7D8) to brownish-red (8F8) when mature or dried, soft and fibrous, covered with hard and thick crust, woody when old, trimitic hyphal system present, hyaline, thin to thick-walled, branched. Tube 0.5-1.5 cm in length, usually homogenous with orange (5A7) to dark orange (5A8), reddish-orange (7A7-7A8), and grayish-red (8C7). Stipe 1-5 cm in length, $6 \mathrm{~cm}$ thick at the base, almost sessile or some short, stipitate, broad and thick at the base, usually non-laccate, and brown (7D8) to dark brown (8F8) when mature. Margin 0.5-4 cm thick, round, soft, brown (7D8) when mature to old, and usually concolourous with the pileus. Pore 4-6 in number per mm, subcircular to circular. Pore surface yellowish-white (2A2) when mature, discolored when touched, brown (7D8) when scratched or bruised.

Hyphal structure: Hyphal system di-trimitic, with clamp connections, orange (6A7) to deep orange (6A8), brownish-yellow (6C8) to brownish-orange (7C8); generative hyphae 1.4-2.8 $\mu \mathrm{m}$ broad $(n=30)$, hyaline, thin-walled, with clamp connections; skeletal hyphae 2.1$4.4 \mu \mathrm{m}$ broad $(n=30)$, usually hyaline, thick-walled, and solid; binding hyphae 1.5-3.6 $\mu \mathrm{m}$ broad $(n=30)$, with walls varying in thickness, with many branches, some hymenial with sword-like apices in the context. Pileipellis a hymeniderm, brown (6E8) to dark brown (7F6), which is composed of apically clavate-like branched cells. Basidiospores mostly ellipsoid to broadly ellipsoid, sometimes ovoid, with double walls, with a size range of (6.9-)7.5-9.1-9.8(-10.6) × (4.7-)5.4-6.4-7.0(-7.7) $\mu \mathrm{m}(\bar{x}=9.1 \times 6.4 \mu \mathrm{m}, n=50) \mu \mathrm{m}$, with Q $=1.38-1.45, \mathrm{~L}=9.09 \mu \mathrm{m}, \mathrm{W}=6.41 \mu \mathrm{m}$ (including myxosporium), (5.6-)6.3-7.6-8.4(-9.2) $\times(4.2-) 4.7-5.6-6.1(-6.6) \mu \mathrm{m}(\bar{x}=7.6 \times 5.7 \mu \mathrm{m}, n=50) \mu \mathrm{m}$, with $\mathrm{Q}=1.35-1.40, \mathrm{~L}=7.6$ $\mu \mathrm{m}, \mathrm{W}=5.52 \mu \mathrm{m}$ (excluding outer myxosporium), overlaid by hyaline, apically, and short, echinulae, a truncate and turgid vesicular appendix, light yellow (4A4-4A5), grayishyellow (4B3-4B4) to brownish-orange (5C5-5C6), (5B8) of inner wall, outer wall usually yellowish-brown (5D8, 5E7-5E8) to brown (6D7-6D8) in 5\% KOH.

Habitat: Solitary, near the roots of a living Mangifera indica tree.

Specimens examined: LAOS, Luang Namtha Province, $20^{\circ} 35^{\prime} 47^{\prime \prime} \mathrm{N}, 101^{\circ} 04^{\prime} 07^{\prime \prime} \mathrm{E}, 935 \mathrm{~m}$ elev., 20 June 2018, T. Luangharn, MFLU 19-2177.

Notes: Ganoderma adspersum was first reported by Donk [147], who described it as Polyporus adspersus Schulzer. Ganoderma adspersum is characterized by a distinctive non-laccate, sessile, and applanate pileus. Ganoderma adspersum is often confused with G. applanatum, G. australe, and Polyporus [148]. Ryvarden [149] and Ryvarden and Gilbertson [105] considered the correct name of G. adspersum as a synonym of G. australe, with G. adspersum can be differentiated from G. applanatum by its thicker at the base, and larger basidiospores, while G. applanatum tends to emerge sharply at right angles $[105,110]$, with molecular analysis also supporting the differentiation [45,76,150-153]. Our collections agree well with the description provided by Ryvarden and Gilbertson [105]. 

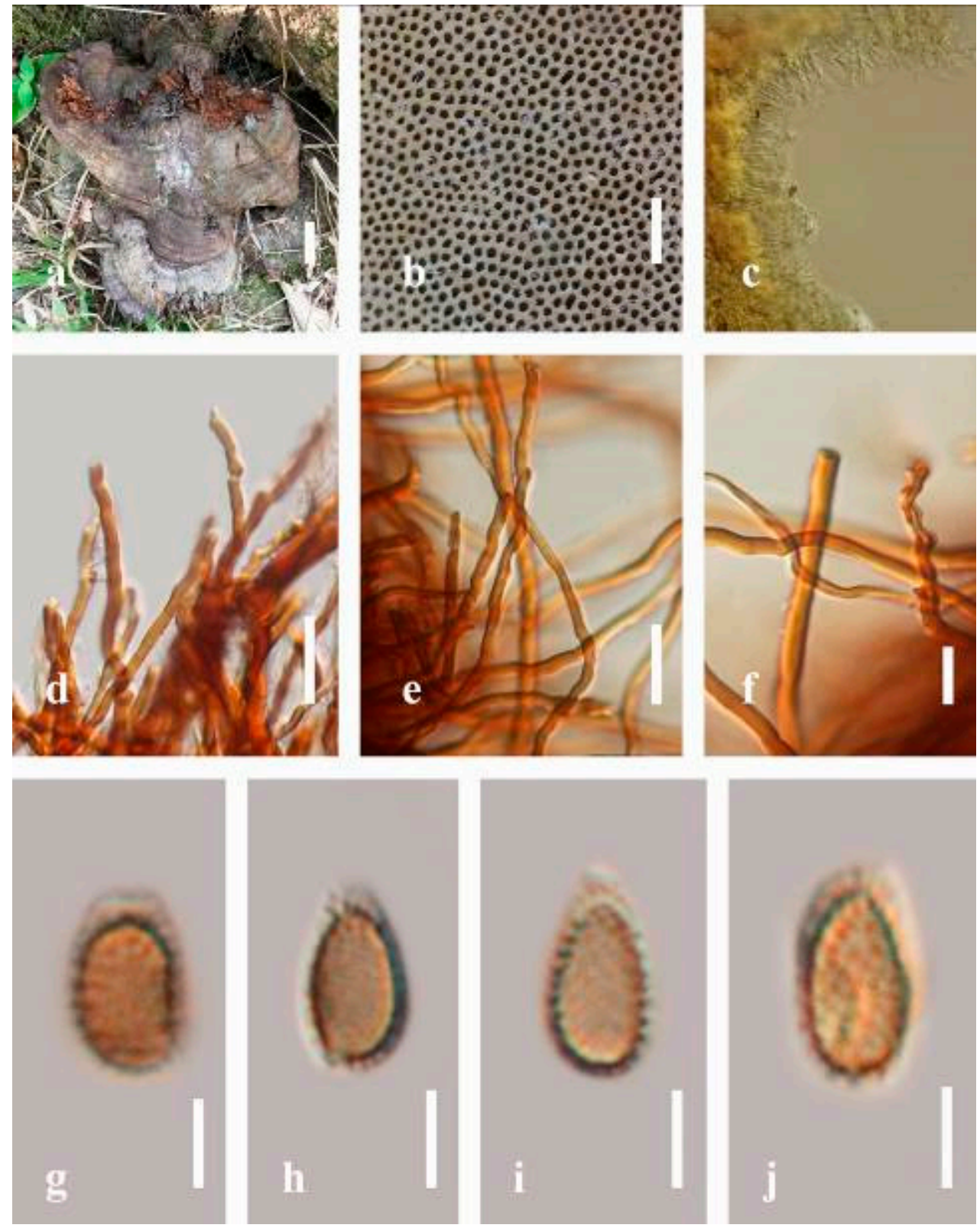

Figure 16. Morphology of Ganoderma adspersum (MFLU 19-2177): (a) mature basidiomes; (b) pore characteristics; (c) hyphae of pore; (d) hyphae of tube layers in $\mathrm{KOH} ;(\mathbf{e}, \mathbf{f})$ context hyphae in $\mathrm{KOH}$; $(\mathbf{g}-\mathbf{j})$ basidiospores. Scale bars: $(\mathbf{a})=3 \mathrm{~cm},(\mathbf{b})=1000 \mu \mathrm{m},(\mathbf{d}, \mathbf{e}) 20 \mu \mathrm{m},(\mathbf{f})=10 \mu \mathrm{m},(\mathbf{g}-\mathbf{j})=5 \mu \mathrm{m}$.

Ganoderma australe (Fr.) Pat., Bull. Soc. mycol. Fr. 5(2, 3): 65 (1889) (Figure 17) Facesoffungi number: FoF 06242

Description: Basidiomes annual, perennial, sessile. Pileus 6-11 cm in length, $2-6.5 \mathrm{~cm}$ broad, and $0.8-2 \mathrm{~cm}$ thick. Pileus single, flabelliform, subdimidiate, spathulate, umbonate, sulcate, obtuse from the host, broadly attached, consistency hard and tough when mature, tough to break when dried, often thick at the center, slightly soft at the margin, and usually woody and corky when dried. Pileus surface corky, convex, furrowed, spathulate, mostly umbonate or uneven, usually non-laccate (dull) when mature to old, smooth layers when present, deep sulcate at the center, thick and hard crust, irregularly ruptured crust overlying the surface, presented dark brown (7F8) cracked crust when old, and tough to break when dried. Pileus color often homogeneous with pale red (7A5), reddish-orange (7A6-7A7), brown (7D8), to orange red (8B7-8B8) on the upper surface of the base closed to the margin when mature to old. Context up to $0.5-1.2 \mathrm{~cm}$ thick near stipe, fibrous, composed of coarse 
loose fibrils, brown (6D7-6D8), dark brown (6F7) to reddish-brown (8D8, 8D9), covered with thick crust, trimitic hyphal, thick-walled, dense with simple septa, typically with narrow lumen, flexuous, and many branches. Tube $0.4-1 \mathrm{~cm}$ in length, brown (7D8) to dark brown (6F8). Stipe sessile with broad attached. Margin white (4A1) when present to mature, soft and slippery when growing fresh, shallow sulcate at the margin, covered and blunt when old. Pore 4-6 in number per $\mathrm{mm}$, subcircular to circular, sometimes angular. Pore surface initially white (4A1), slightly yellowish-white (3A2) when mature, brownish-red (8C4-8C5) when scratched, bruised, or discolored when touched.
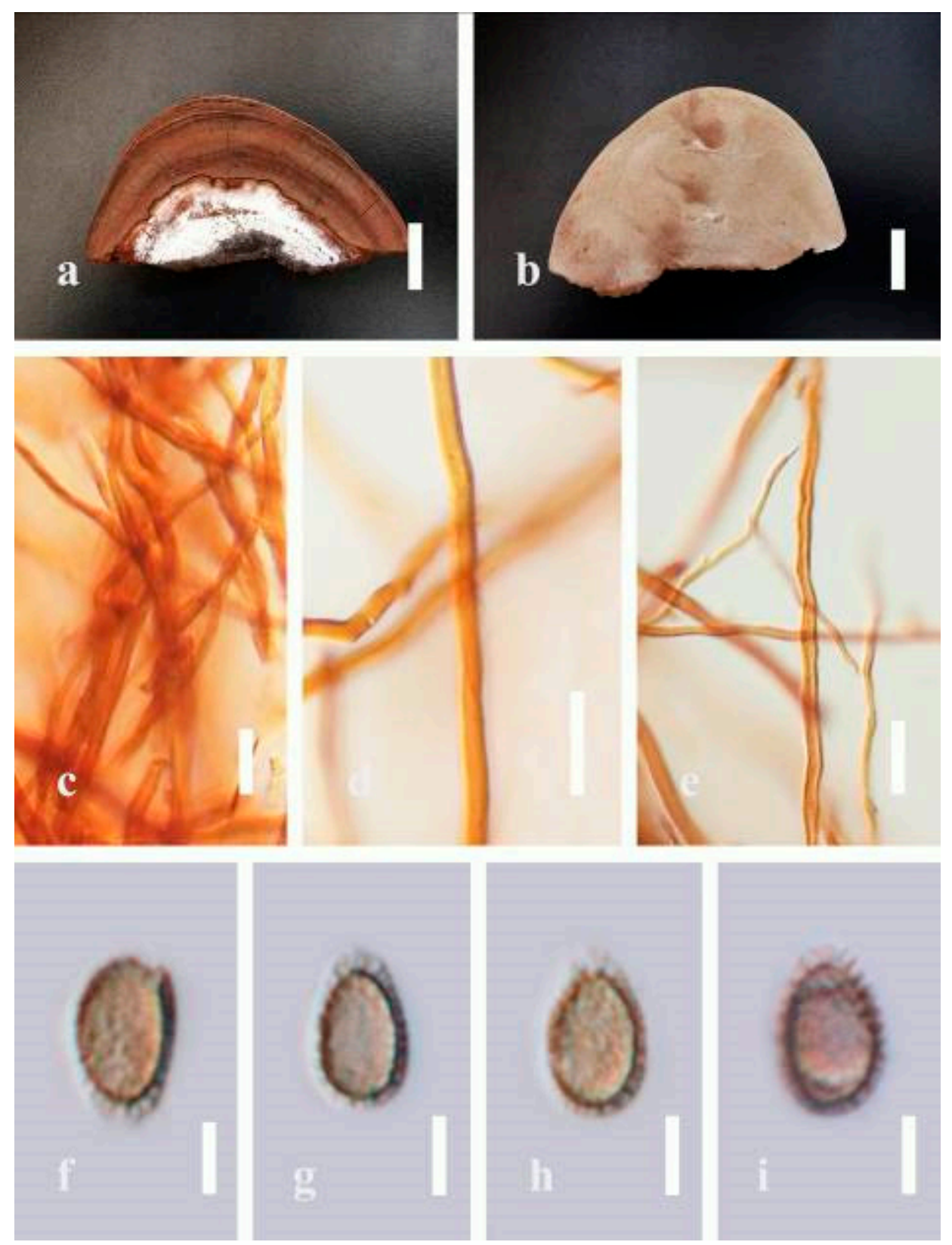

Figure 17. Morphology of Ganoderma australe (MFLU 19-2171): (a,b) mature basidiomes; (c-e) context hyphae in $\mathrm{KOH} ;(\mathbf{f}-\mathbf{i})$ basidiospores. Scale bars: $(\mathbf{a}, \mathbf{b})=2 \mathrm{~cm},(\mathbf{c}-\mathbf{e})=20 \mu \mathrm{m},(\mathbf{f}-\mathbf{i})=5 \mu \mathrm{m}$.

Hyphal structure: Hyphal system trimitic, with clamp connections, usually brownishorange (6C5-6C7) in $\mathrm{KOH}$; generative hyphae 2.0-3.4 $\mu \mathrm{m}$ broad $(n=30)$, thin-walled, hyaline, tapering branches, with clamp connections; skeletal hyphae 3.1-4.5 $\mu \mathrm{m}$ broad $(n=30)$, usually thick-walled, sometimes branches, nearly solid; binding hyphae 2.5-3.9 $\mu \mathrm{m}$ width $(n=30)$, usually thick-walled, many branches, nearly solid, and hymenial with sword-like apices in the 
context. Pileipellis a hymeniderm, brown (7D8), composed of apically acanthus-like branched cells, dextrinoid. Basidiospores mostly ellipsoid to broadly ellipsoid, with double walls, with a size range of (6.5-)7.6-10.1-11.4(-12.5) × (5.9-)6.7-8.5-9.2(-10.3) $\mu \mathrm{m}(\bar{x}=7.2 \times 5.9 \mu \mathrm{m}, n=$ 50) $\mu \mathrm{m}$, with $\mathrm{Q}=1.19-1.26, \mathrm{~L}=7.24 \mu \mathrm{m}, \mathrm{W}=5.92 \mu \mathrm{m}$ (including myxosporium), (5.1-)6.28.3-9.7(-10.9) $\times(4.4-) 5.6-6.8-7.7(-8.8) \mu \mathrm{m}(\bar{x}=8.2 \times 6.8 \mu \mathrm{m}, n=50) \mu \mathrm{m}$, with $\mathrm{Q}=1.17-1.26$, $\mathrm{L}=8.23 \mu \mathrm{m}, \mathrm{W}=6.79 \mu \mathrm{m}$ (excluding outer myxosporium), overlaid by hyaline, brown apically, bearing fine, distinct, short, echinulae, truncate, turgid vesicular appendix, inner wall light brown (6D4-6D5) to brown (7E7-7E8), and outer wall usually reddish-brown (8E5-8E6, 8F7) in 5\% KOH.

Habitat: Solitary, on the decaying hardwood of Canarium spp. tree species.

Specimens examined: LAOS, Luang Namtha Province, $20^{\circ} 35^{\prime} 47^{\prime \prime} \mathrm{N}, 101^{\circ} 04^{\prime} 07^{\prime \prime} \mathrm{E}, 935 \mathrm{~m}$ elev., 20 June 2018, T. Luangharn, MFLU 19-2171.

Ganoderma gibbosum (Blume and T. Nees) Pat., Ann. Jard. Bot. Buitenzorg, suppl. 1: 114 (1897) (Figure 18)

Facesoffungi number: FoF 06243

Description: Basidiomes annual or perennial, sessile, subflabellate, or subdimidiate. Pileus $2-16 \mathrm{~cm}$ in length, $2-9 \mathrm{~cm}$ broad, and $0.5-2.3 \mathrm{~cm}$ thick. Pileus conks, convex, imbricate, umbonate, uneven, ungulate, usually round when occurring, primordial, somewhat round and plump when young, flabelliform (fan-shaped) when seen from above, broadly attached when mature, thick at the base when mature. Pileus surface non-laccate, smooth when young, silky, soft, and slippery surface when fresh, furrowed on the surface with sulcate to undulating, somewhat spathulate to uneven, incised, compact, hard, and woody when older, covered with a tough crust $(0.1-0.2 \mathrm{~mm})$, usually dull and faded when mature to old, and some occurred the lined or cracked crust when older. Pileus color brownishorange (5C5), reddish white (7A2) at the base, and homogenous with grayish-orange (6B3), brownish-orange (7C5), and light brown (6D4) toward the center of maturity fruiting bodies, white (6A1) at the margin, and usually the color changes to dark brown (8F8) upon touch, becoming grayish-red (8C4-8F6), reddish-brown (8E6) to dull red (10C3) when old. Context up to $0.3-1.3 \mathrm{~cm}$ thick, trimitic hyphal with clamp connections, hyaline, with walls varying in thickness, simple septate, composed of narrow, and sparse branches; generative hyphae 1.0-3.4 $\mu \mathrm{m}$ broad $(\mathrm{n}=30)$, with walls varying in thickness, and hyaline; skeletal hyphae $4.0-6.4 \mu \mathrm{m}$ broad $(\mathrm{n}=30)$ with thick walls; binding hyphal $2.0-6.5 \mu \mathrm{m}$ broad $(\mathrm{n}=30)$. Hymenophore up to $3 \mathrm{~mm}$ in length, with reddish-brown (8D7). Tube layers $0.2-0.8 \mathrm{~cm}$ in length, up to $80-163 \mu \mathrm{m}$ in width, and non-presented when young. Stipe almost sessile, broadly attached when present. Margin wavy, blunt, slippery when wet, thinner at the base and soft than the center, often white (8A1) from youth to maturity, and light brown (6D5) when old. Pore 4-7 in number per mm, when fresh, angular, subcircular to circular. Pore surface white (11A1) to orange white (6A2) when fresh, scratched or bruised, and discolored when touched.

Hyphal structure: Hyphal system trimitic, with clamp connections, usually reddishbrown (8D7-8D8); generative hyphae 1.0-3.8 $\mu \mathrm{m}$ broad $(n=30)$, with walls varying in thickness, hyaline, and unbranched; skeletal hyphae 4.2-6.4 $\mu \mathrm{m}$ broad $(n=30)$, light brown (7D6) to brown (7D8) in Melzer's reagent with dextrinoid, usually thick-walled; binding hyphae 1.8-6.4 $\mu \mathrm{m}$ broad $(n=30)$, brown $(6 \mathrm{~F} 8)$ to reddish-brown (8D8) in Melzer's reagent, thick-walled, many branches, the generative and skeletal hyphae usually intertwined, mostly dark brown (6F7) near the tube layers; Bovista-type ligative hyphae, hymenial with sword-like apices in the context. Pileipellis a hymeniderm, brown (6D8) to light brown (6D6), composed of apically acanthus-like branched cells, dextrinoid. Basidiospores mostly ellipsoid to oblong ellipsoid or broadly ellipsoid, with double walls, with a size range of (4.4-)6.8-8.2-9.5(-10.2) × (3.6-)4.2-5.2-5.8(-6.5) $\mu \mathrm{m}(\bar{x}=8.3 \times 5.4 \mu \mathrm{m}, n=50) \mu \mathrm{m}$, with $\mathrm{Q}=1.49-1.56, \mathrm{~L}=8.34 \mu \mathrm{m}, \mathrm{W}=5.44 \mu \mathrm{m}$ (including myxosporium), (3.6-)5.3-6.0$7.2(-8.3) \times(2.8-) 3.9-4.5-5.4(-6.2) \mu \mathrm{m}(\bar{x}=6.2 \times 4.5 \mu \mathrm{m}, n=50) \mu \mathrm{m}$, with $\mathrm{Q}=1.34-1.40$, $\mathrm{L}=6.24 \mu \mathrm{m}, \mathrm{W}=4.51 \mu \mathrm{m}$ (excluding outer myxosporium), overlaid by hyaline, dextrinoid, 
echinulae, inner wall echinulate brown, light brown (6D6-6D8) to brown (6E8) in 5\% $\mathrm{KOH}$, and reddish-brown (8F6) to dark brown (8F8) in Melzer's reagent. Basidia not seen.

Habitat: Occasionally on decaying wood of Pinus spp.

Specimens examined: LAOS, Luang Prabang, $19^{\circ} 51^{\prime} 51^{\prime \prime} \mathrm{N}, 102^{\circ} 11^{\prime} 39^{\prime \prime} \mathrm{E}, 589 \mathrm{~m}$ elev., 12 July 2018, T. Luangharn, MFLU 19-2190.

Ganoderma nasalaense Hapuar., Pheng. and K.D. Hyde, Mycosphere 10(1): 272 (2019) Taxonomy and phylogeny analysis are shown in Hapuarachchi et al. [30].

Notes: Ganoderma nasalaense is characterized by its duplex context, rigid basidiomes, purplish-black laccate crust, dark brown to gray on the upper pileus surface, brown tube layer, purplish-brown pore surface, trimitic hyphal system, and relatively large, broadly ellipsoid to ellipsoid light brown basidiospores (12.1-13.8 $\times 9.2-10.5) \mu \mathrm{m}$, truncate, with fine and short echinulae $(10-12 \times 6.5-7.5) \mu \mathrm{m}$, and a cuticle composed of strongly amyloid, clavate cells, usually with several irregular lobes or protuberances $(30-80 \times 3-10.5) \mu \mathrm{m}$. This fungus is solitary on decaying hardwood tree trunks in Huaphanh Province, Laos.
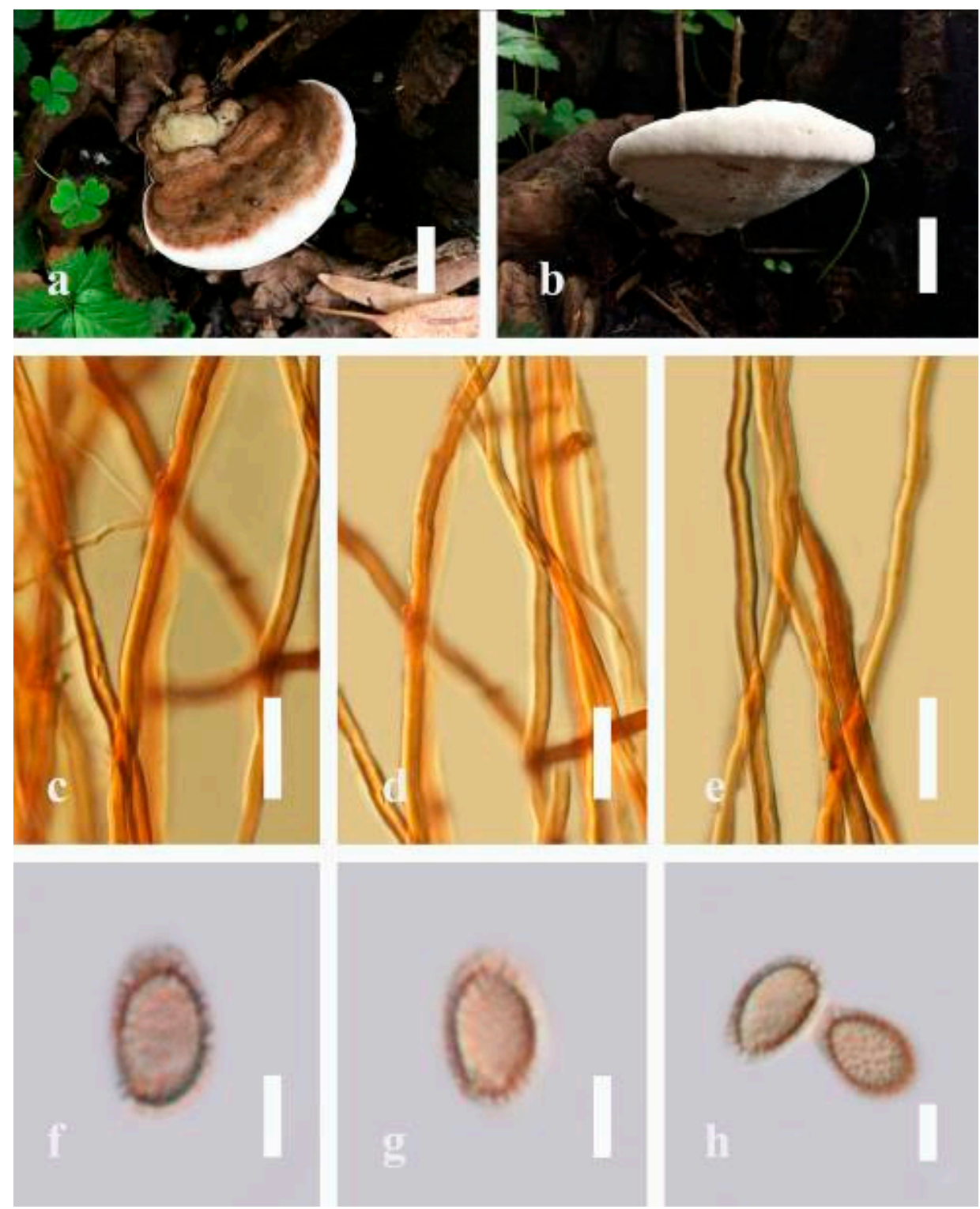

Figure 18. Morphology of Ganoderma gibbosum (MFLU 19-2190): (a,b) mature basidiomes; (c-e) context hyphae as seen in Melzer's reagent; $(\mathbf{f}-\mathbf{h})$ basidiospores. Scale bars: $(\mathbf{a}, \mathbf{b})=2 \mathrm{~cm},(\mathbf{c}-\mathbf{e})=20 \mu \mathrm{m}$, $(\mathbf{f}-\mathbf{h})=5 \mu \mathrm{m}$. 


\subsubsection{Taxonomy of Ganoderma from Myanmar}

Ganoderma hoehnelianum Bres., Annales Mycologici. 10 (5): 502 (1912) (Figure 19) Facesoffungi number: FoF 06260

Description: Basidiomes annual or perennial, sessile. Pileus is $0.5-4 \mathrm{~cm}$ in length, $0.5-3 \mathrm{~cm}$ broad, and up to $0.5 \mathrm{~cm}$ thick at the base. Pileus is applanate, umbonate, subreniform to reniform, or subflabellate to glabrous from youth to maturity, small in size, obtuse from host, often with undefined concentric zones at the center that extend to the margin, thick at the center, slightly thin and soft at the margin, and tough to break when dried. Pileus surface shiny, smooth, and soft when young, frequently furrowed and shallowly sulcate on the upper surface, which is undulating and somewhat spathulate to uneven in maturity, covered by a thin crust, faded or weakly laccate when young, laccate when mature, and woody when old. Pileus color homogenous, reddish-brown (8E4-8E8) to dark brown orange (9F5-9F8) at the center when mature. Context up to $0.1-0.3 \mathrm{~cm}$ thick at the base, brown (7D7-7D8), reddish-brown (8E7-8E8), and dark brown (7F7), abundantly thick-walled, with clamp connections, subsolid hyphae, containing a fibrous pithy context. Tube layers hard and corky, branched, with clamped connections, often brown (7D7) to dark brown (7F8). Stipe almost sessile, broadly attached when present. Margin obtuse from the center, soft and smooth when young, laccate when mature, slightly wavy and slippery when wet, often yellowish-white (3A2) on the upper surface, and pale yellow (4A3) under the margin. Pores 4-6 in number per mm. Pore surface usually white (11A1) to light orange (5A4) when young, grayish-orange (6B4-6B6) when mature, turning light brown (7D5-7D6), brown (7D7), and reddish-brown (8D5-8D7) when scratched or bruised, becoming discolored when touched.

Hyphal structure: Hyphal system is dimitic, bearing clamp connections, hyaline, with walls varying in thickness with simple septa and some swollen differentiated zones at the point of attachment, composed of several narrow hyphae, and sparingly branched; generative hyphae (1.8-)2.4-3.2-3.7(-4.2) $\mu \mathrm{m}$ broad $(n=30)$ are thin-walled and hyaline; skeletal hyphae (3.3-)3.9-5.2-5.8(-6.2) $\mu \mathrm{m}$ broad $(n=30)$ have walls of varying thickness, sometimes subsolid; binding hyphae (2.3-)2.9-4.2-4.9(-5.6) $\mu \mathrm{m}$ broad $(n=30)$ are usually thick-walled with many branches, and appear alongside Bovista hyphae, which are usually present from orange (5A6-5A7) to deep orange (6A8) and thin-walled, as well as also reddish-brown (8D7-8D8, 9D8) to brownish-red (9C8) in Melzer's reagent. Basidiospores are mostly ellipsoid and featuring several ovoid with double walls, (6.7-)7.5-9.8-11.8(-13.2) $\times(5.7-) 6.4-7.8-9.6(-10.8) \mu \mathrm{m}(\bar{x}=9.7 \times 7.8 \mu \mathrm{m}, n=50) \mu \mathrm{m}$, with $\mathrm{Q}=1.22-1.28, \mathrm{~L}=9.73 \mu \mathrm{m}$, $\mathrm{W}=7.78 \mu \mathrm{m}$ (including myxosporium), (5.8-)6.4-8.5-9.3(-10.2) $\times(4.8-) 5.3-6.1-6.8(-7.4) \mu \mathrm{m}$ $(\bar{x}=8.4 \times 6.4 \mu \mathrm{m}, n=50) \mu \mathrm{m}$, with $\mathrm{Q}=1.29-1.35, \mathrm{~L}=8.43 \mu \mathrm{m}, \mathrm{W}=6.41 \mu \mathrm{m}$ (excluding outer myxosporium), overlaid by a hyaline, dextrinoid, and echinulate whose inner wall presents as brownish-orange (5C5-5C6) to brownish-yellow (5C7-5C8) and dark brown (6F8) to reddish-brown (8E7-8E8) in Melzer's reagent.

Specimens examined: MYANMAR, Chin State, Tedim Township, 13 July 2019, P. E. Mortimer, MFLU 19-2168.

Notes: Ganoderma hoehnelianum was introduced by Bresadola in 1912 from Indonesia. Of distinctive note are its context color, basidiospore characteristics, and cuticular cells [154]. Wang and $\mathrm{Wu}$ [154] reported that the original Chinese G. hoehnelianum was an earlier name for G. shangsiense, and this fungus was also recorded as G. shangsiense in China's Hainan Province [30,91,120,121]. Our G. hoehnelianum is first recorded from Myanmar, and its description is consistent with the descriptions provided by Wang and $\mathrm{Wu}$ [154]. 

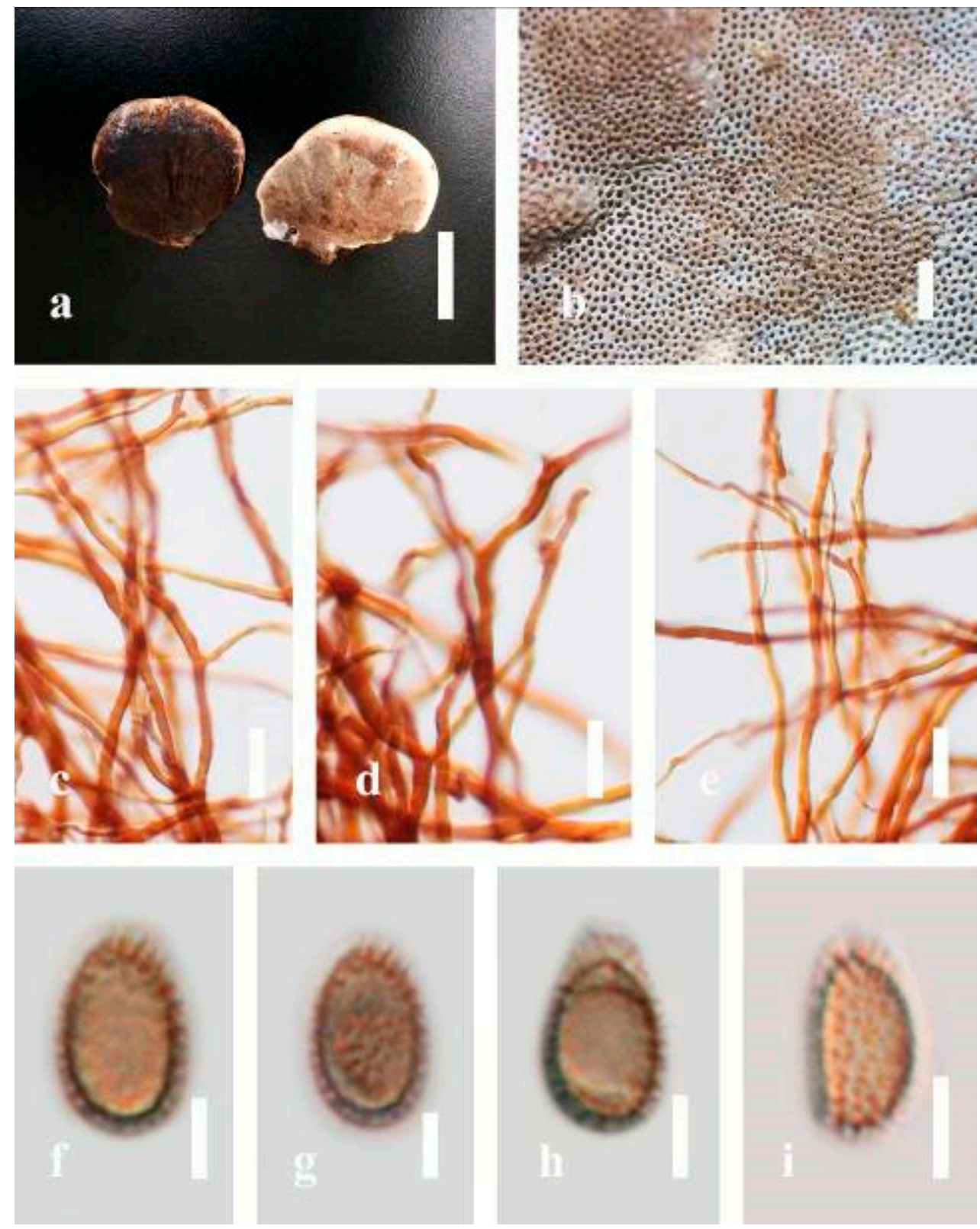

Figure 19. Morphology characteristics of Ganoderma hoehnelianum (MFLU 19-2168): (a) young basidiomes; (b) pore characteristics; (c-e) context hyphae in Melzer's reagent; (f-i) basidiospores. Scale bars: $(\mathbf{a})=2 \mathrm{~cm},(\mathbf{b})=1000 \mu \mathrm{m},(\mathbf{c}-\mathbf{e})=20 \mu \mathrm{m},(\mathbf{f}-\mathbf{i})=5 \mu \mathrm{m}$.

Ganoderma myanmarense Karunarathna, Mortimer, \& Luangharn, sp. nov. (Figure 20) FacesofFungi number: FoF 06262

Index Fungorum number: IF 556794

Diagnosis: Ganoderma myanmarense is characterized by its shell-like pileus with strongly laccate appearance colored orange, golden yellow at center, extending reddish-yellow and yellow at margin, usually homogenous reddish-brown when mature, a white to light yellow that indicates active development on the margin of the pileal surface, a white pore surface when fresh, an orange, deep orange to reddish-orange context, and absence of melanoid bands.

Holotype: MYANMAR, Chin State, Tedim Township, on dead wood of Casternopsis sp., 13 July 2019, LT2019 (MFLU 19-2167).

Etymology: The species epithet "myanmarense" refers to the country Myanmar, where the holotype specimen was collected. 

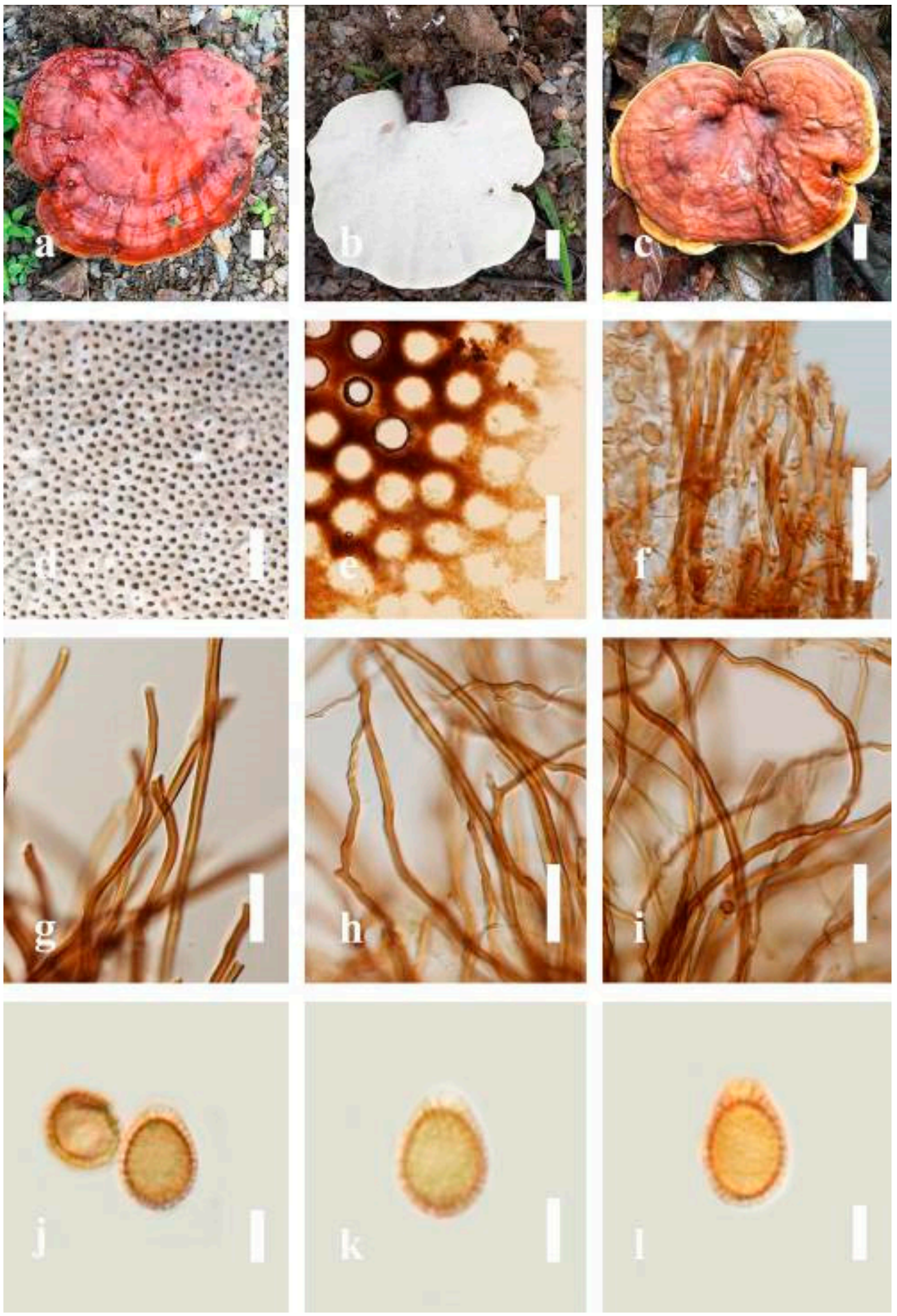

Figure 20. Characteristics of Ganoderma myanmarense: (a) the upper surface of mature basidiomes of the strain MFLU 19-2167; (b) the lower surface of mature basidiomes of strain MFLU 19-2167; (c) the upper surface of mature basidiomes of the strain MFLU 19-2169; (d,e) pore characteristics; (f) hyphae of tube layers in $\mathrm{KOH}$; (g) context hyphae in $\mathrm{KOH}$; (h) context hyphae with clamp connections in $\mathrm{KOH}$; (i) hyphae of trama in $\mathrm{KOH} ;(\mathbf{j}-\mathbf{l})$ basidiospores. Scale bars: $(\mathbf{a}, \mathbf{c})=2 \mathrm{~cm},(\mathbf{d})=500 \mu \mathrm{m}$, (e) $=150 \mu \mathrm{m},(\mathbf{f}-\mathbf{i})=20 \mu \mathrm{m},(\mathbf{j}-\mathbf{l})=5 \mu \mathrm{m}$.

Description: Basidiomes annual or perennial, stipitate. Pileus up to 5-16 cm in length, 4-15 cm in width, and 1-2.5 cm thick at the base. Pileus shell-like (involute from the margin toward the center), sub-reniform to reniform or subflabellate to circular when viewed from 
above, often with undefined zones at the center that extend to the margin, with a thick center that is slightly soft at the margin, and tough to break when dried. Pileus surface shiny, silky, smooth, and soft when fresh, hard when old, furrowed, sulcate to undulating, somewhat spathulate to uneven, incised, faded or weakly laccate when young, strongly laccate on maturity or when old. Pileus color homogenous, orange (5A6-5A7, 6B7-6B8), golden yellow (5B6), and yellowish-red (8A7-8A8) at the center, slightly reddish-orange (7A7-7A8) and reddish-brown (8E8) where deeply sulcate, reddish-yellow (4A7) and yellow (2A6) at the margin. Context up to $0.6-1.5 \mathrm{~cm}$ thick at the base, with some areas thin-walled, thick-walled, along with subsolid hyphae, bearing clamp connections, and absence of melanoid bands. Tube layers woody and hard, usually thin-walled, frequently branched, with clamped connections, and often dark brown (7F7) when dried. Stipe up to $3-8 \mathrm{~cm}$ in length, up to $1.3-4 \mathrm{~cm}$ in width, centrally stipitate, nearly sub-cylindrical to cylindrical, concolorous with the pileus, often dark brown (9F7-9F8) to violet-brown (11F7-11F8), strongly laccate from maturity to old. Margin obtuse from the center, strongly laccate at the edge, occasionally wavy, slippery when wet, smoother, softer, and thinner, at the base, often yellow (2A6), and deep orange (5A8) to golden yellow (5B7-5B8) on maturity to old. Pores 4-6 in number in number per $\mathrm{mm},(60-) 80-125(-165) \mu \mathrm{m}$, angular, subcircular to circular. Pore surface usually white (11A1), turnins light brown (7D5), brown (7D7-7D8) to dark brown (7F6-7F8) when scratched or bruised, becomes discolored when touched.

Hyphal structure: Hyphal system trimitic, with walls of varying thickness, clamp connections present, simple septate hyphae, hyaline, narrow and sparingly branched; generative hyphae (1.2-)1.8-2.2-2.4(-2.7) $\mu \mathrm{m}$ broad $(n=30)$, hyaline, thin-walled; skeletal hyphae (1.8-)2.5-3.8-4.5(-5.0) $\mu \mathrm{m}$ broad $(n=30)$, abundant and thick-walled, sometimes subsolid; binding hyphae (1.5-)1.9-2.7-3.3(-4.3) $\mu \mathrm{m}$ broad $(n=30)$, usually thick-walled. Basidiospores (8.2-)9.3-11.6-12.5(-13.6) $\times(5.3-) 6.0-7.1-7.8(-8.6) \mu \mathrm{m},(\mathrm{Qm}=1.7, \mathrm{Q}=1.2-2.4$, including myxosporium) $(n=50),(\bar{x}=11.5 \times 7.1 \mu \mathrm{m}, n=50) \mu \mathrm{m}$, with $\mathrm{Q}=1.57-1.65$, $\mathrm{L}=11.52 \mu \mathrm{m}, \mathrm{W}=7.13 \mu \mathrm{m}$ (including myxosporium), (7.5-)8.3-9.1-10.4(-11.9) $\times(4.9-) 5.4-$ 6.2-6.8(-7.5) $\mu \mathrm{m}(\bar{x}=9.0 \times 6.3 \mu \mathrm{m}, n=50) \mu \mathrm{m}$, with $\mathrm{Q}=1.40-1.48, \mathrm{~L}=9.04 \mu \mathrm{m}, \mathrm{W}=6.27 \mu \mathrm{m}$ (excluding outer myxosporium), mostly ellipsoid to broadly ellipsoid, or globose, double walls, overlaid by hyaline; exosporium (outer wall) smooth, hyaline, endosporium (inner wall) coarse and echinulate, with turgid vesicular appendix, and pale yellow inner wall that can also present in $\mathrm{KOH}$, and yellowish-brown (5E6-5E7) to brown (6E6-6E7) in Melzer's reagent, outer wall pale orange (6A3-6A4) to orange (6A6-6A7) in $\mathrm{KOH}$, reddish-orange (7A8), grayish-red (7B6-7B8), and dark brown (7F7-7F8) in Melzer's reagent.

Habitat: Solitary near the hardwood root of unknown tree species.

Additional specimens: MYANMAR, Chin State, Tedim Township, 13 July 2019, P. E. Mortimer, MFLU 19-2167 (holotype) and MFLU 19-2169 (paratype).

Ganoderma williamsianum Murrill, Bulletin of the Torrey Botanical Club 34: 478 (1907) (Figure 21)

E Elfvingia williamsiana (Murrill) Imazeki, Bulletin of the Government Forest Experimental Station Meguro. 57: 106 (1952)

Facesoffungi number: FoF 06261

Description: Basidiomes annual or perennial, stipitate. Pileus $0.5-1.5 \mathrm{~cm}$ in length, $0.5-1 \mathrm{~cm}$ in width, and up to $0.5 \mathrm{~cm}$ thick at the base. Pileus sub-reniform to reniform, or subflabellate to circular when young, often with concentric zones at the center that extend to the margin, thick at the center, slightly soft at the margin, tough to break when dried. Pileus surface shiny, silky, and soft when young, generally furrowed, smooth, sulcate to undulating, somewhat spathulate to uneven when mature, hard and woody when old, incised on the surface, faded or weakly laccate when young, and usually laccate when mature. Pileus color usually homogenous, orange (5A7-5A8) to deep orange (5B7-5B8), slightly white (5A1), and yellowish-white $(3 \mathrm{~A} 2,4 \mathrm{~A} 2)$ at the margin when young. Context is up to $0.3-1.5 \mathrm{~cm}$ thick at the base, which is usually thick-walled, with abundant walls varying in thickness, subsolid hyphae containing a fibrous pithy context with clamp connections, and brown (7D8) melanoid bands when mature. The tube layers hard, frequently 
branched with clamp connections, and often dark brown (7F8). Stipe $1.5 \mathrm{~cm}$ in length, $1 \mathrm{~cm}$ in width when young, lateral to nearly dorsal, entrally stipitate, almost sub-cylindrical to cylindrical, concolorous with the pileus, thick when young, and often brownish-orange (7C6) to dark brown (9F7-9F8). Margin obtuse from the center, blunted when young, occasionally wavy, slippery when wet, smooth and soft when young $(1.5 \mathrm{~cm})$, and often white (3A1) to yellowish-white (3A2) when young. Pore surface white (11A1) to yellowish-white (3A2), turns light brown (7D5) to brown (7D7-7D8) when scratched or bruised, becomes discolored when touched.
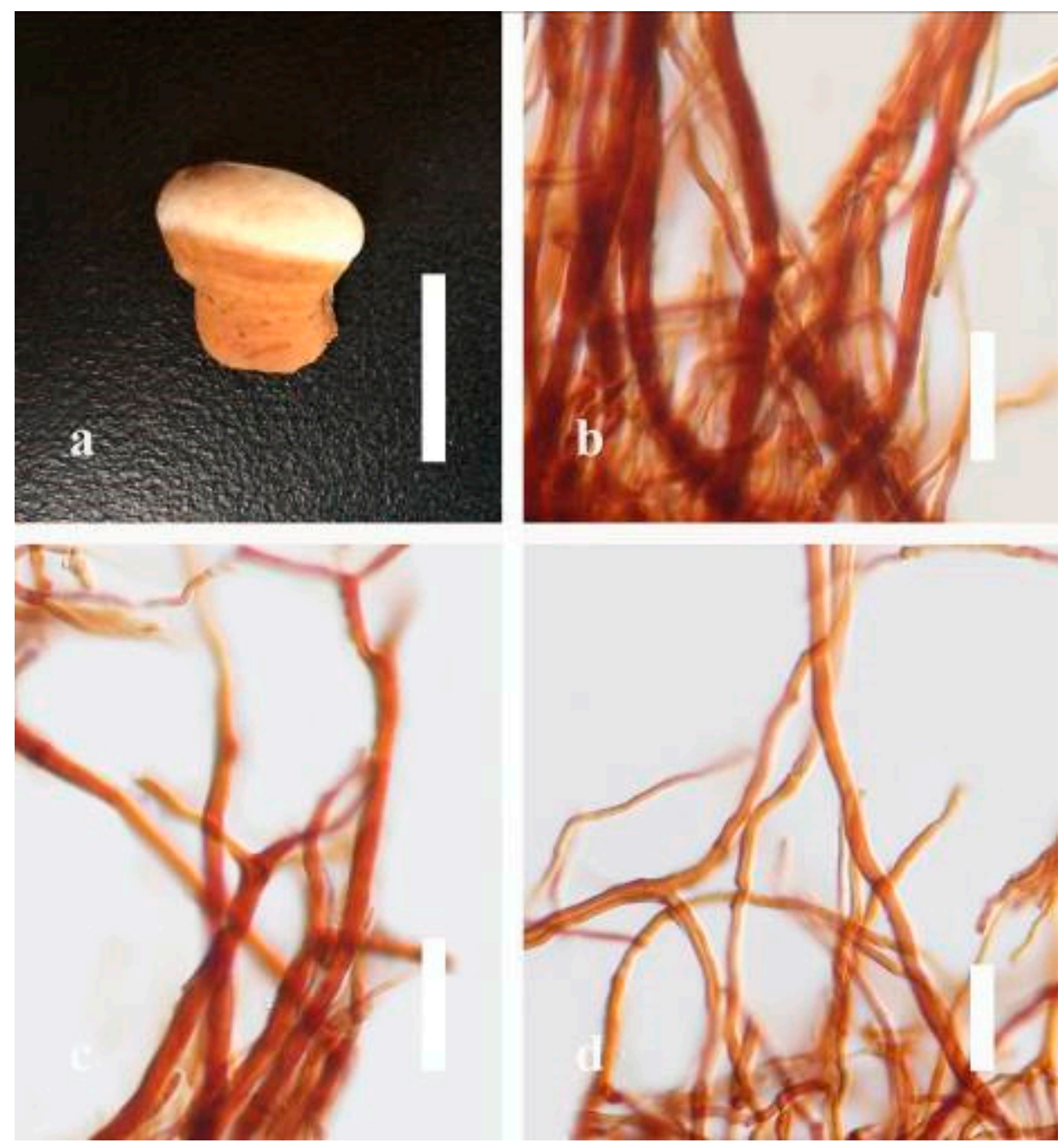

Figure 21. Morphology characteristics of Ganoderma williamsianum (MFLU 19-2170): (a) young basidiomes; (b-d) context hyphae in Melzer's reagent. Scale bars: $(\mathbf{a})=2 \mathrm{~cm},(\mathbf{b}-\mathbf{d})=20 \mu \mathrm{m}$.

Hyphal structure: Hyphal system trimitic, bearing clamp connections, hyaline, with walls of varying thickness, simple septate, swollen differentiated zones at the point of attachment, composed of several narrow hyphae, and sparingly branched; generative hyphae (1.6-)1.92.3-2.5(-2.6) $\mu \mathrm{m}$ broad $(n=30)$, thin-walled and hyaline; skeletal hyphae (3.1-)3.4-3.9-4.3 $(-4.8) \mu \mathrm{m}$ broad $(n=30)$, with walls of varying thickness, with some subsolid; binding hyphae (1.6-)1.9-2.6-2.9(-3.4) $\mu \mathrm{m}$ broad $(n=30)$, usually thick-walled, appearing alongside Bovista hyphae with many branches, whose thick walls usually present as light orange (5A5), orange (5A6-5A7, 6B7-6B8) to deep orange (5A8, 6A8), and reddish-brown (8D78D8) to brownish-red (9C8) in Melzer's reagent. Basidiospores not observed.

Specimens examined: MYANMAR, Chin State, Tedim Township, 13 July 2019, P. E. Mortimer, MFLU 19-2170. 
Notes: Ganoderma williamsianum belongs to the group of laccate Ganoderma. This fungus was originally reported in the Philippines and is easily recognized, with its small, dense, ungulate of pileus with pale, yellow pores, large spores, and a short skeletal [2,113]. Among the Ganoderma species, there are some similarities between G. williamsianum and G. brownii, such as both having yellow pores [109]; however, G. brownii can be differentiated from G. williamsianum by its dull pileus with a hard crust [155], skeletal hyphae with occasional branching, and smaller basidiospores [109,110,137,155]. Ganodermawilliamsianum is the earliest valid name for G. meijiangense [154], containing similarities to G. meijiangense, such as both having sessile, annual crust basidiomes, and white margin, but G. williamsianum can be differentiated from G. meijiangense by its distinguishing dark brown context, without any layer of black crust and a distinct cuticular composition [61]. Our G. williamsianum collection from Myanmar marks a new record, as it shares traits similar to Moncalvo and Ryvarden [2], with sessile, annual crust-like basidiomes, and white margin, trimitic hyphal system bearing clamp connections, hyaline, and walls of varying thickness.

\subsubsection{Taxonomy of Ganoderma from Thailand}

Ganoderma adspersum (Schulzer) Donk Proc. K. Ned. Akad. Wet., Ser. C, Biol. Med. Sci. (Figure 22)

Facesoffungi number: FoF 06241

Description: Basidiomes annual to perennial, applanate, subdimidiate. Pileus $2-14 \mathrm{~cm}$ in length, $2-7 \mathrm{~cm}$ in width, and $0.5-1.8 \mathrm{~cm}$ thick at base. Pileus subdimidiate to dimidiate, flabelliform, spathulate, umbonate, concentrically sulcate zone, sessile or short stipitate, distinctly contracted base, somewhat round and plump when young, somewhat imbricate when viewed from above, flabelliform (fan-shaped), usually broadly attached with radial from center extending to the margin, tough when break, thick at base, slightly soft at the margin when mature, light weight when dried, and woody and corky texture when dried. Pileus surface non-laccate (dull), convex, radial furrowed, incised, spathulate, shallow sulcate, usually silky, soft, smooth when young, and slippery surface when fresh, thick crust overlying the context, differentiated zone at the point of attachment, several layers thick, and leathery when broken. Pileus color usually homogenous with brown (7D77D8, 7E7-7E8, 8D8) at center toward stipe to margin surface when mature. Context up to $0.3-1.3 \mathrm{~cm}$ thick near the stipe, brown (7D8) to brownish-red (8F8) when mature and dried, soft and fibrous, covered with hard and thick crust, woody when old, trimitic hyphal, hyaline, with walls varying in thickness, with branches. Tube $0.2-1 \mathrm{~cm}$ in length, usually homogenous with orange (5A7) to dark orange (5A8), reddish-orange (7A7-7A8), and grayish-red (8C7). Stipe $1-3.8 \mathrm{~cm}$ in length, $3.5 \mathrm{~cm}$ thick at base, almost sessile, some shortly stipitate, broadly thick at base, usually non-laccate, brown (7D8) to dark brown (8F8) when mature. Margin round, soft, occurring brown (7D8) from mature to old, presented numerous undulations, and usually concolorous with the pileus. Pores 4-6 in number in number per mm, subcircular to circular. Pores surface yellowish-white (2A2) when mature, turns brown (7D8) when scratched or bruised.

Hyphal structure: Hyphal system di-trimitic, with clamp connections; generative hyphae 1.2-2.8 $\mu \mathrm{m}$ broad $(n=30)$, hyaline, thin-walled, with clamp connections; skeletal hyphae $2.0-4.4 \mu \mathrm{m}$ broad $(n=30)$, usually hyaline, thick-walled, solid; binding hyphae 1.6-3.7 $\mu \mathrm{m}$ width $(n=30)$, with walls varying in thickness, many branches, without clamp connections, some hymenial with sword-like apices in the context. Basidiospores mostly ellipsoid, sometimes ovoid with double walls, (7.0-)7.7-9.0-9.9(-10.7) $\times(4.8-) 5.3-6.5-7.1(-7.8)$ $\mu \mathrm{m}(\bar{x}=8.9 \times 6.7 \mu \mathrm{m}, n=50) \mu \mathrm{m}$, with $\mathrm{Q}=1.30-1.37, \mathrm{~L}=8.91 \mu \mathrm{m}, \mathrm{W}=6.69 \mu \mathrm{m}$ (including myxosporium), (5.8-)6.4-7.7-8.6(-9.4) × (4.1-)4.5-5.6-6.0(-6.5) $\mu \mathrm{m}(\bar{x}=7.7 \times 5.5 \mu \mathrm{m}, n=50)$ $\mu \mathrm{m}$, with $\mathrm{Q}=1.35-1.42, \mathrm{~L}=7.69 \mu \mathrm{m}, \mathrm{W}=5.52 \mu \mathrm{m}$ (excluding outer myxosporium), overlaid by hyaline, apically and shortly echinulate, truncate and turgid vesicular appendix, inner wall brownish-yellow (5C7-5C8) and light brown (6D7-6D8), outer wall usually brownish-orange (7C8), brown (7D7-7D8) to dark brown (7E7) in 5\% $\mathrm{KOH}$.

Habitat: Solitary on decaying Pterocarpus sp. 
Specimens examined: THAILAND, Kanchanaburi Province, 10 November 2018, T. Luangharn, MFLU 19-2178.
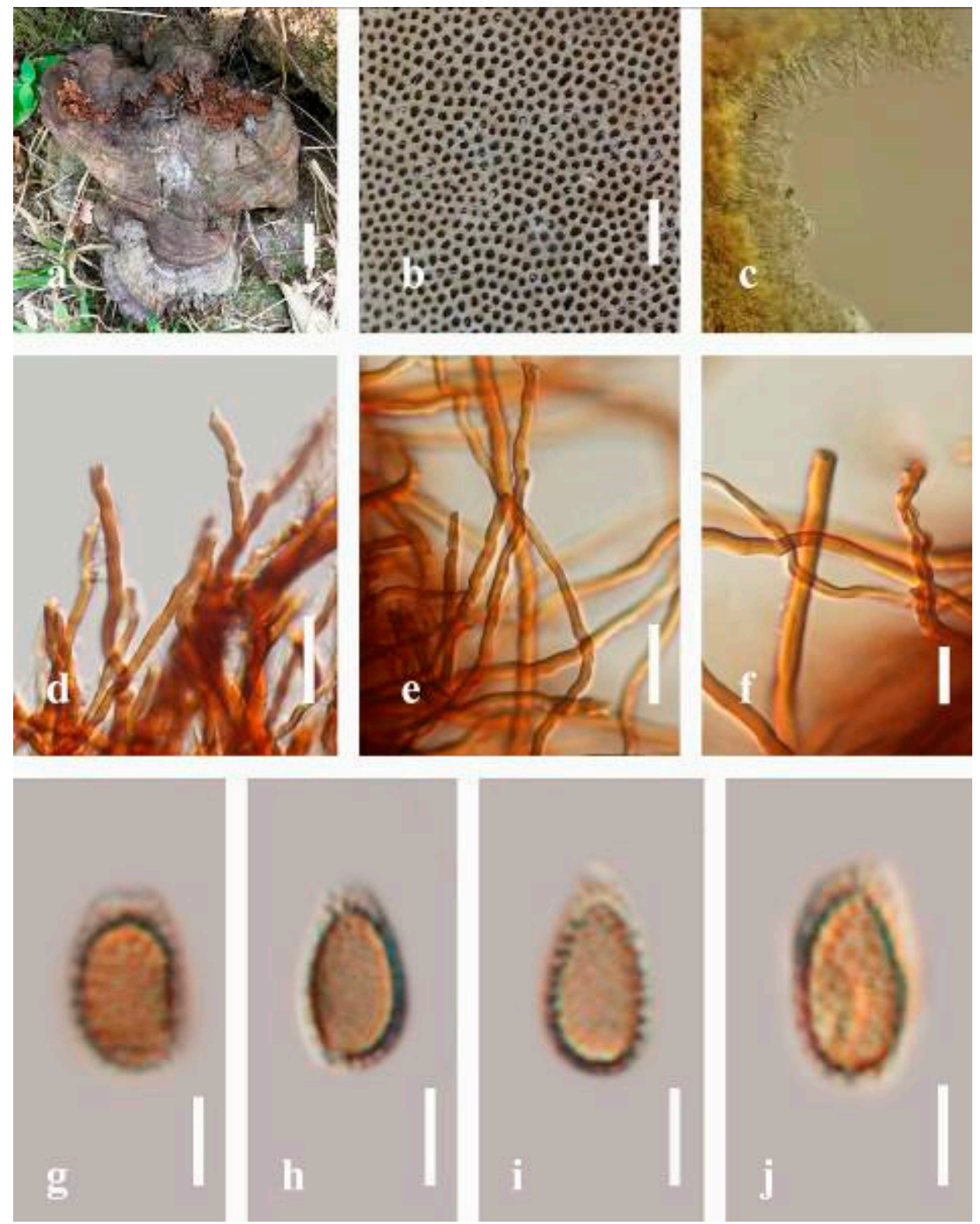

Figure 22. Morphology of Ganoderma adspersum (MFLU 19-2178): (a) mature basidiomes; (b) pores characteristics; (c) hyphae of tube layers in $\mathrm{KOH} ;(\mathbf{d}-\mathbf{f})$ hyphae of thama in $\mathrm{KOH} ;(\mathbf{g}-\mathbf{j})$ basidiospores. Scale bars: $(\mathbf{a})=2 \mathrm{~cm},(\mathbf{b})=1000 \mu \mathrm{m},(\mathbf{c}-\mathbf{f})=20 \mu \mathrm{m},(\mathbf{g}-\mathbf{j})=5 \mu \mathrm{m}$.

Ganoderma applanatum (Batsch) G.F. Atk., Annales Mycologici 6: 189 (1908) (Figure 23) Facesoffungi number: FoF 06249

Description: Basidiomes annual or perennial, subdimidiate to dimidiate, sessile. Pileus $2-12 \mathrm{~cm}$ in length, $2.5-6 \mathrm{~cm}$ in width, and $0.8-3.1 \mathrm{~cm}$ thick at the base. Pileus sessile, perennial, subdimidiate to dimidiate, subflabelliform to flabelliform, convex, imbricate, umbonate or uneven, rarely ungulate, with broadly attached when mature, thicker at base, slightly soft at margin when mature. Pileus surface furrowed, tuberculate to undulate, uneven, and incised when old, non-laccate (dull), compact and hard when mature, woody to corky texture when mature to old, covered with a thin crust $(0.1-0.25 \mathrm{~mm})$ overlies the pileus, and some cracked crust when old. Pileus color differentiated zone with peach red (7A4) to reddish-orange (7A6, 7B6) at base, toward to brownish-orange (7C6-7C8) with 
radius light brown (7D5) zone at center, and extend to dark brown (6F8) closed to active mycelium (margin) of maturity fruiting bodies. Context up to $0.5-2.3 \mathrm{~cm}$ thick, mostly brown (6E8) to dark brown (7F6-7F8) of cuticle cells, upper layers light orange (5A5), lower reddish-brown (8D8) with fibrous, some fibrous pithy context, usually separated layers of context tissue at base, and some occurred woody line. Tubes $0.8-2 \mathrm{~cm}$ in length, up to 70-160 $\mu \mathrm{m}$ in width, with sulcate at different levels. Stipe almost sessile (without stipe) with broadly attached when present, with differentiated zone at the point of attachment. Margin up to $1 \mathrm{~cm}$ thick, round, soft, often white (5A1), turning to light brown (6D4) and brown (6E8) when scratched or bruised, slippery when wet, soft when young, and thin than the center. Pore angular, subcircular, 4-6 in number per mm. Pore surface white (7A1) when fresh, quickly turning to light brown (7D6) to brown (7D8) when handled, scratched, and bruised.

Hyphal structure: Hyphal system trimitic; generative hyphae 0.5-2.8 $\mu \mathrm{m}(\bar{x}=2.4, n$ $=30$ ) in diam, clamp connections, almost hyaline, abundant thin-walled and occasionally thick-walled, composed of narrow and sparingly branched; skeletal hyphae 2.7-4.9 $\mu \mathrm{m}$ broad $(n=30)$, usually thick-walled, hyaline, sometimes branched; binding hyphae 1.2-3.6 $\mu \mathrm{m}$ broad $(n=30)$, thick-walled, some branched, and intertwined the skeletal hyphae. Pileipellis a hymeniderm, brown (6E4), which composed of apically acanthus-like branched cells. Basidiospores mostly ellipsoid to broadly ellipsoid, sometimes subcircular with double walls, overlaid by hyaline, exosporium (outer wall) hyaline, endosporium (inner wall) coarse echinulate, with turgid vesicular appendix, truncate at the distal end, (10.0-)10.5-11.3-11.9(-12.4) × (7.2-)8.0-8.8-9.4(-10.2) $\mu \mathrm{m},(\bar{x}=11.2 \times 8.6 \mu \mathrm{m}, n=50) \mu \mathrm{m}$, with $\mathrm{Q}=1.28-1.33, \mathrm{~L}=11.23 \mu \mathrm{m}, \mathrm{W}=8.62 \mu \mathrm{m}$ (including myxosporium), (6.3-)7.4-8.5-9.3 $(-10.1) \times(4.9-) 6.3-7.4-8.7(-9.3) \mu \mathrm{m}(\bar{x}=8.4 \times 7.5 \mu \mathrm{m}, n=50) \mu \mathrm{m}$, with $\mathrm{Q}=1.09-1.13$, $\mathrm{L}=8.42 \mu \mathrm{m}, \mathrm{W}=7.58 \mu \mathrm{m}$ (excluding outer myxosporium), brown (7D7-7D8) in $\mathrm{KOH}$, and reddish-brown (8E6) to dark brown (8F4) in Melzer's reagent. Basidia 14-20 × 8-10 $\mu \mathrm{m}$, with four sterigmata.

Habitat: Solitary on rotten wood, dead trunks, and decaying stumps of Artocarpus spp., and Dipterocarpus spp.

Specimens examined: THAILAND, Kanchanaburi Province, 10 November 2018, T. Luangharn, MFLU 19-2175.

Ganoderma australe (Fr.) Pat., Bull. Soc. mycol. Fr. 5(2, 3): 65 (1889)

Facesoffungi number: FoF 02906

Characteristics follow Luangharn et al. [59].

Description: Basidiomes applanate, spathulate. Pileus $2-7 \mathrm{~cm}$ in length, $1-15 \mathrm{~cm}$ in width, and $0.5-3 \mathrm{~cm}$ thick near the base. Pileus circular, applanate, spathulate, sometimes flabelliform clusters when young, dimidiate, semicircular at maturity, smooth when present. Pileus surface convex, furrow, glabrous, glossy, laccate, and consistently hard when fresh, and tough and light in weight when dry. Pileus color distinct concentric zones with light brown (6D4) to brown (6E8) at the center, slightly pale orange (5A3) to white (5A1) at the margin when young, becoming reddish-brown (8E6) to dark brown (9F8) at the center, dull red (8C4), and pale red (7A3) to white (8A1) at the margin at old age on the upper surface, brown to dark brown when dried, separated by a layer of context, usually brown to gray in winter or may fade as weathering destroys pigments on the pileus surface. Tube layers $0.2-1.2 \mathrm{~cm}$ in length, $50-180 \mu \mathrm{m}$ in width, thick-walled. Stipe 3-5 cm in length, $1.5-3.5 \mathrm{~cm}$ in width, $1.3-3.3 \mathrm{~cm}$ thick, applanate, with umbo that slightly extended at the base. Margin up to $0.5-3 \mathrm{~cm}$ thick, thinner and lighter than the base, soft, round, pale yellow (4A3) to grayish brown (5D3) and reddish gray (8B2), changing to grayish-orange (6E3) when touched, thick toward the margin and downward toward the poreless marginal part of hymenophore. Pore angular, 4-6 in number in number per mm. Pore surface white (2A1) to pale yellow (2A3) in growing specimen, immediately discolored when bruised, cream to grayish brown (5D3) when fresh, with brownish gray (5C2) to brown (4D7) when dried. 

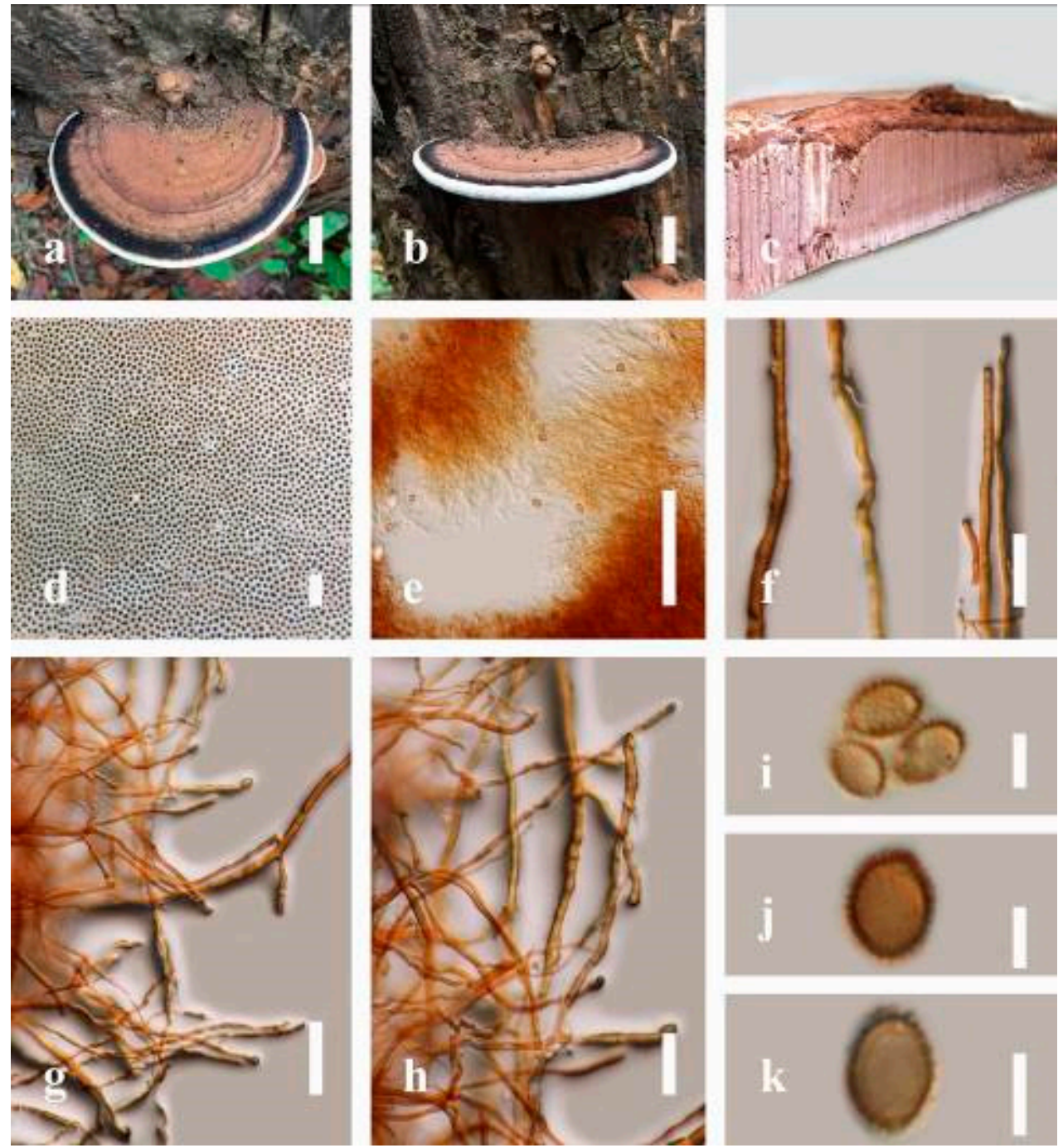

Figure 23. Morphology of Ganoderma applantum (MFLU 19-2175): (a,b) mature basidiomes; (c) section of the basidiomes; (d) pore characteristics; (e) hyphae of pore layers; (f) generative hyphae of context in Melzer's reagent; $(\mathbf{g}, \mathbf{h})$ thick-walled with sparing branched of generative and skeletal hyphae of context in Melzer's reagent; (i-k) basidiospores in Melzer's reagent. Scale bars: $(\mathbf{a}, \mathbf{b})=2 \mathrm{~cm}$, $(\mathbf{d})=50 \mu \mathrm{m},(\mathbf{e})=150 \mu \mathrm{m},(\mathbf{f})=10 \mu \mathrm{m},(\mathbf{g})=30 \mu \mathrm{m},(\mathbf{h})=20 \mu \mathrm{m},(\mathbf{i}-\mathbf{k})=5 \mu \mathrm{m}$.

Hyphal structure: Hyphal system di-trimitic, contextual generative hyphae, binding, and skeletal hyphae, generative hyphae, 1-5 $\mu \mathrm{m}$ broad, with clamp connections, hyaline, thin-walled; binding hyphae 2-6 $\mu \mathrm{m}$ broad, thin to thick-walled, branched, with clamp connections; skeletal hyphae, hyaline, pale brown to brown, thick-walled, $2-7 \mu \mathrm{m}$ broad. Basidiospores (6.4)6.9-9.3-10.4(11.1) × (5.8)6.4-7.9-8.8(9.7) $\mu \mathrm{m},(\bar{x}=9.4 \times 7.7 \mu \mathrm{m}, n=50)$, with $\mathrm{Q}=1.20-1.21, \mathrm{~L}=9.63 \mu \mathrm{m}, \mathrm{W}=7.96 \mu \mathrm{m}$ (including myxosporium), (5.4)6.3-7.0-8.1(8.9) $\times(3.4) 3.8-5.9-6.5(7.3) \mu \mathrm{m},(\bar{x}=7.1 \times 5.8 \mu \mathrm{m}, n=50) \mu \mathrm{m}$, with $\mathrm{Q}=1.19-1.25, \mathrm{~L}=7.29 \mu \mathrm{m}$, $\mathrm{W}=5.93 \mu \mathrm{m}$ (excluding outer myxosporium), reddish-brown, mostly broadly ellipsoid at maturity, some distinct tapering at the distal end, truncate, double wall, thick-walled inner endosporium. Basidia not observed. Cultures characteristics turned white after incubation at $30{ }^{\circ} \mathrm{C}$ for 10 days. Odor distinctive when dried.

Habitat: Solitary on hardwood Shorea robtusa, or rotten wood, dead trunks, decaying hardwood, decaying stumps, and occasionally occurring on standing trees or trunks of many broad-leaf trees.

Specimens examined: THAILAND, Chiang Mai Province, August 2012; T. Luangharn, MFLU 13-0534, MFLUCC 12-0527. 
Ganoderma casuarinicola J.H. Xing, B.K. Cui and Y.C. Dai., MycoKeys 34: 93-108 (2018)

Facesoffungi number: FoF 06130

Taxonomy and phylogeny analysis are shown in Luangharn et al. [31]

Notes: Ganoderma casuarinicola was collected on a Pinus kesiya stump in a pine forest. This fungus is distinctive by its strongly laccate, shallow sulcate, reddish-brown pileus surface, lateral stipe, white pore surface, and brown context. Thai G. casuarinicola shows its annual, applanate to dimidiate, $3-16 \mathrm{~cm}$ long and $1.5-3 \mathrm{~cm}$ wide pileus, larger than Guangdong collection. Our G. casuarinicola collections show longer tubes of 6-14 mm, while the tubes of the Guangdong collection are $9 \mathrm{~mm}$ long; however, our collections reveal a thinner margin (0.8-1.2 cm thick) than the Guangdong collection ( $2 \mathrm{~cm}$ thick). However, the type of $G$. casuarinicola from the Guangdong collection does not have the melanoid band [37], while our collection features a dark brown melanoid band. Micro- characteristics are dense light brown to brown context layers; walls of varying thickness in generative hyphae; thin-walled binding hyphae; and a thick-walled skeletal. Our G. casuarinicola collection has mostly distinctive yellowish-brown basidiospores, with a smaller size range of (8.7)10.8-13.5(14.4) × (6.6)7.6-8.9(9.8) $\mu \mathrm{m}$ than the type of G. casuarinicola (8.3-)9.0-10.2 $(-11.5) \times(4.5-) 5.0-6.0(-7.0) \mu \mathrm{m}$ (including myxosporium).

Ganoderma ellipsoideum Hapuar., T.C. Wen and K.D. Hyde, Mycosphere. 9(5): 951 (2018) (Figure 24)

Facesoffungi number: FoF 06255

Description: Basidiomes annual, sessile. Pileus $3-9 \mathrm{~cm}$ in length, $2.2-5 \mathrm{~cm}$ in width, and $1.5-3.5 \mathrm{~cm}$ thick at the base. Pileus annual, convex, imbricate, sessile, umbonate, uneven, ungulate, subflabellate or subdimidiate, somewhat imbricate, when seen from above flabelliform (fan-shaped), usually round, when present primordial, somewhat round and plump when present, broadly attached, thick at base, slightly soft at margin when mature. Pileus surface non-laccate (dull), furrowed, incised, sulcate, smooth when young, undulating on the upper surface, somewhat spathulate to uneven, covered by a thin and hard crust (0.1-0.4 mm), and woody when older. Pileus color usually homogenous with reddish-brown (9E7-9E8) to dark brown (9F7-9F8) at the base at the center, extending white (4A1) to brown (7E7) on the upper margin surface of mature fruiting bodies. Context up to $0.5-2.5 \mathrm{~cm}$ thick, compact and hard, trimitic hyphal, with clamp connections, hyaline, thin-walled with simple septa, sparingly branched; generative hyphae 1.2-3.7 $\mu \mathrm{m}$ broad $(n=30)$, hyaline, simple septate, with clamp connections; skeletal hyphae $1.8-4.2 \mu \mathrm{m}$ broad $(n=30)$, usually thick-walled, unbranched; binding hyphal 2.0-4.8 $\mu \mathrm{m}$ width $(n=30)$ with sparingly branched, thick-walled, without clamp connection. Hymenophore usually brown (7D8) to reddish-brown (8E8). Tube layers $0.5-2.2 \mathrm{~cm}$ in length. Margin blunt-edged, wavy, slippery when young, and often white (8A1), where the new hyphae are in active development when young to mature. Pore 4-6 in number per $\mathrm{mm}$, angular, subcircular to circular. Pore surface white (11A1) to pale yellow (2A3), turns brown (7E7) to dark brown (7F7-7F8) when scratched or bruised.

Hyphal structure: Hyphal system trimitic, with clamp connections, with brown (7E7); generative hyphae (1.2-)1.6-2.4-3.0(-3.8) $\mu \mathrm{m}$ broad $(n=30)$, branched, thin-walled, hyaline, with grayish-yellow (4B5) in $\mathrm{KOH}$; skeletal hyphae (1.7-)3.1-3.8-4.3(-4.8) $\mu \mathrm{m}$ broad $(n=30)$, dextrinoid, abundant thick-walled, with unbranched; binding hyphae (2.1-)3.13.7-4.2(-4.6) $\mu \mathrm{m}$ broad $(n=30)$, thick-walled, frequently branched, usually intertwined the generative and skeletal hyphae, mostly brown (7E7) to dark brown (7F5) near the tube layers; Bovista-type ligative hyphae, hymenial with sword-like apices in the context. Basidiospores mostly ellipsoid with double walls, (4.8-)5.3-6.6-7.2(-7.7) $\times(3.1-) 3.5-4.3-5.0(-5.4)$ $\mu \mathrm{m}(\bar{x}=6.8 \times 4.5 \mu \mathrm{m}, n=50) \mu \mathrm{m}$, with $\mathrm{Q}=1.34-1.43, \mathrm{~L}=6.28 \mu \mathrm{m}, \mathrm{W}=4.52 \mu \mathrm{m}$ (including myxosporium), (3.6-)4.1-5.5-6.0(-6.4) × (1.7-)2.1-2.8-3.3(-3.7) $\mu \mathrm{m}(\bar{x}=5.49 \times 2.83 \mu \mathrm{m}$, $n=50) \mu \mathrm{m}$, with $\mathrm{Q}=1.83-1.92, \mathrm{~L}=5.50 \mu \mathrm{m}, \mathrm{W}=2.94 \mu \mathrm{m}$ (including myxosporium), overlaid by hyaline, dextrinoid, echinulae, inner wall echinulate brownish-yellow (5C7-5C8) to brown (7D7-7D8) in 5\% KOH. Basidia not seen. 
Habitat: Solitary on rotten wood of Acacia sp.

Specimens examined: THAILAND, Chiang Mai Province, Mae Taeng, Mushroom Research Centre, $19^{\circ} 07^{\prime} 200^{\prime \prime}$ N, $98^{\circ} 41^{\prime} 44^{\prime \prime}$ E, 652 elev., 14 June 2019, P. E. Mortimer, MFLU 19-2221.
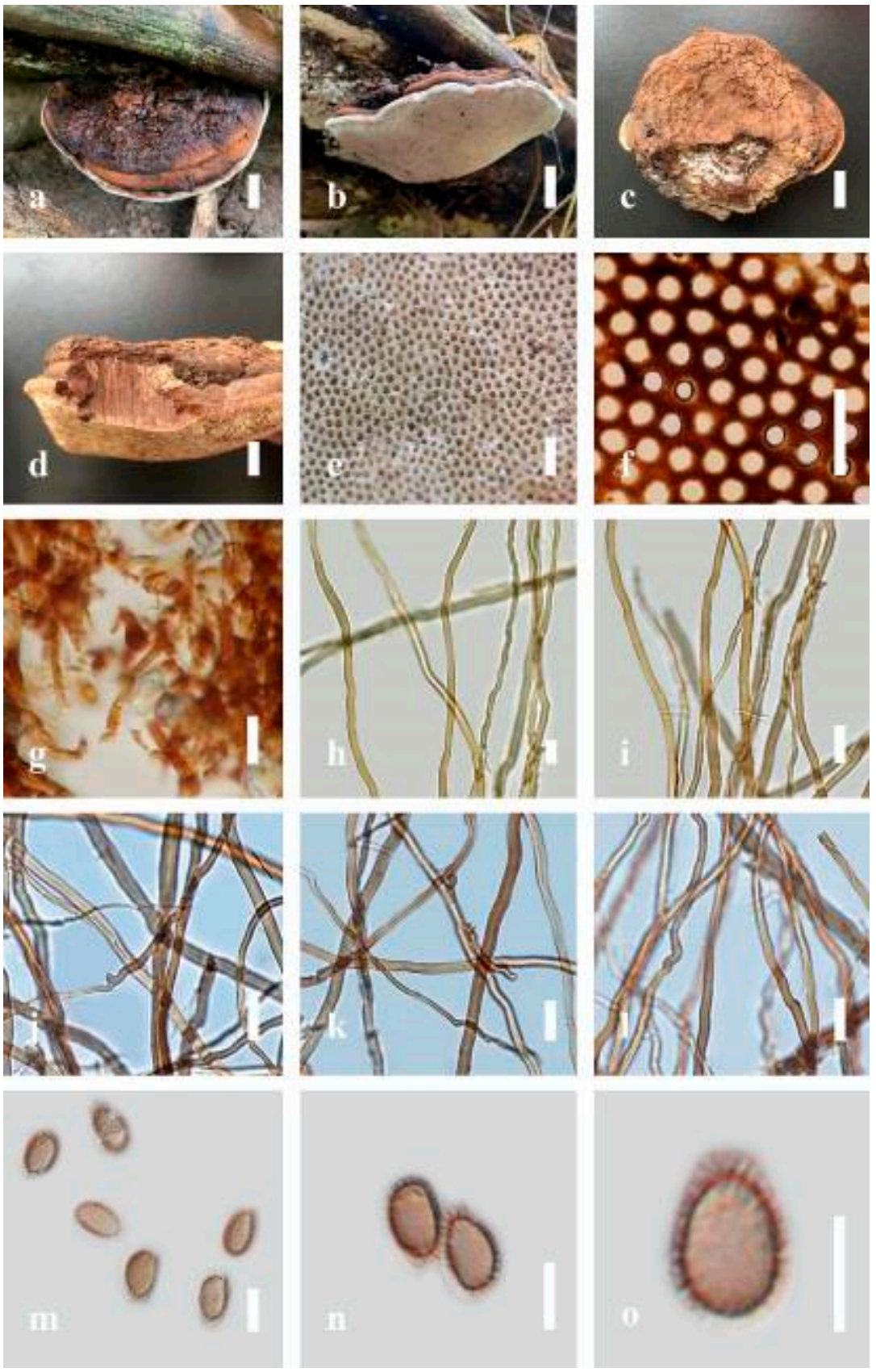

Figure 24. Morphology characteristics of Ganoderma ellipsoideum (MFLU 19-2221): (a) the upper surface of mature basidiomes when fresh; (b) the lower surface of mature basidiomes when fresh. (c) the upper surface of mature basidiomes when dried; (d) margin; (e,f) pore characteristics; (g) hyphae of tube layers; $(\mathbf{h}, \mathbf{i})$ hyphae from trama in $\mathrm{KOH} ;(\mathbf{j}-\mathbf{l})$ hyphae from trama in $\mathrm{KOH} ;(\mathbf{m}-\mathbf{o})$ basidiospores in $\mathrm{KOH}$ reagent. Scale bars: $(\mathbf{a}-\mathbf{d})=2 \mathrm{~cm},(\mathbf{e}, \mathbf{f})=500 \mu \mathrm{m},(\mathbf{g})=200 \mu \mathrm{m},(\mathbf{g}-\mathbf{l})=20 \mu \mathrm{m},(\mathbf{m}, \mathbf{n})=5 \mu \mathrm{m}$.

Ganoderma gibbosum (Blume and T. Nees) Pat., Ann. Jard. Bot. Buitenzorg, suppl. 1: 114 (1897) (Figure 25) 

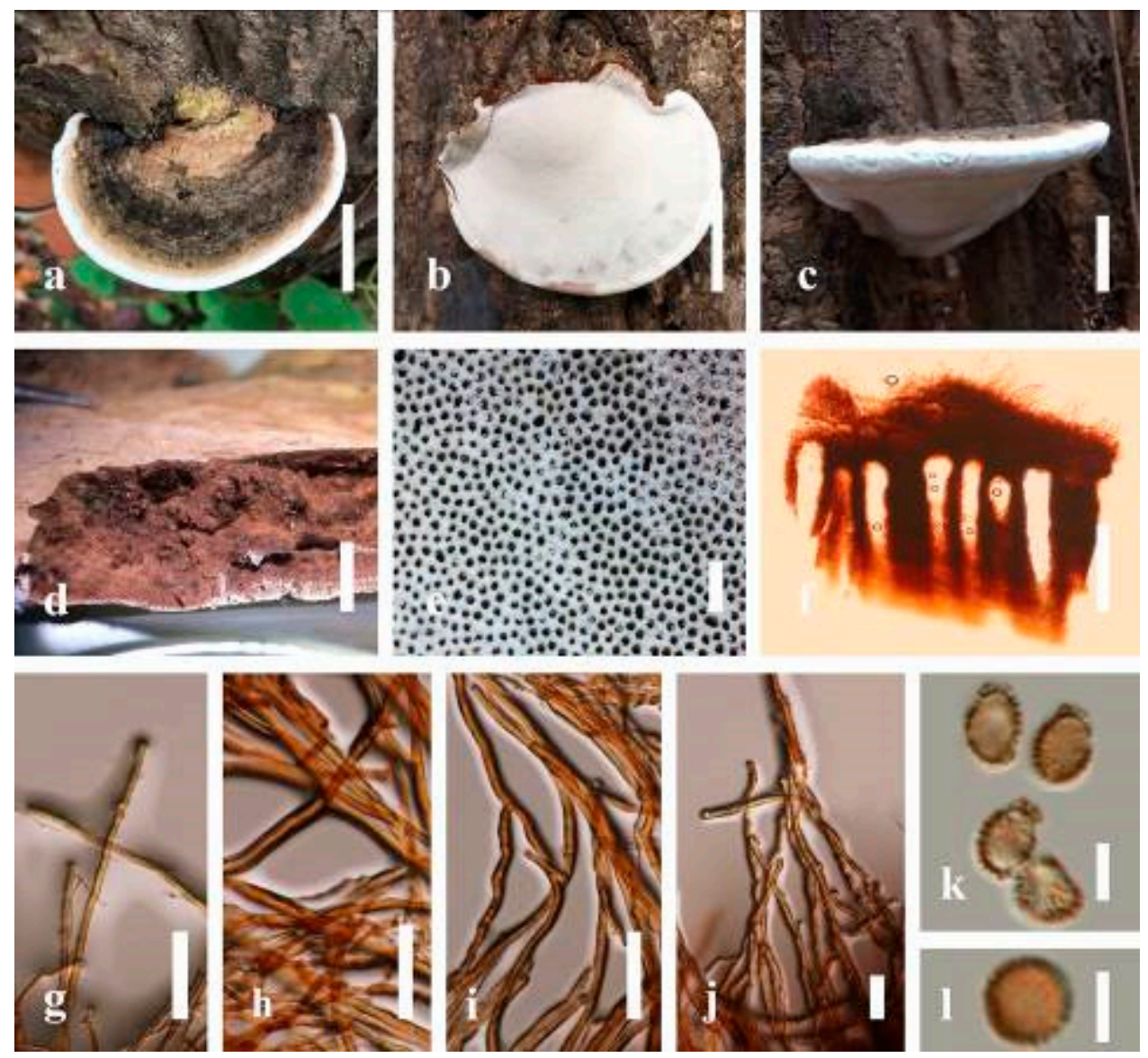

Figure 25. Ganoderma gibbosum (MFLU 19-2176): (a) the upper surface of mature basidiomes; (b) the lower surface of mature basidiomes; (c) margin; (d) context morphology; (e) pore characteristics; (f) tube layers; (g) generative hyphae of context in Melzer's reagent; (h,i) skeletal and binding hyphae of context in Melzer's reagent; $(j)$ hyphae and clamp connections of context in Melzer's reagent; $(\mathbf{k}, \mathbf{l})$ basidiospores in Melzer's reagent. Scale bars: $(\mathbf{a}-\mathbf{c})=2 \mathrm{~cm},(\mathbf{d})=1 \mathrm{~cm},(\mathbf{e})=500 \mu \mathrm{m},(\mathbf{f})=200$ $\mu \mathrm{m},(\mathbf{g}-\mathbf{i}, \mathbf{k}, \mathbf{l})=,5 \mu \mathrm{m},(\mathbf{j})=20 \mu \mathrm{m}$.

Facesoffungi number: FoF 06246

Description: Basidiomes annual or perennial, sessile. Pileus $2-12 \mathrm{~cm}$ in length, $2-8 \mathrm{~cm}$ in width, and $0.5-2.8 \mathrm{~cm}$ thick. Pileus sessile (without stipe), subflabellate or subdimidiate, convex, imbricate, umbonate, uneven, round when occurring, primordial, round and plump when youth, with broadly attached when mature, and thicker at base slightly soft at margin when mature. Pileus surface non-laccate (dull), smooth, soft, slightly dull and faded when mature to old, usually silky when young, furrowed, tuberculate to undulate, uneven, and incised when mature, compact and hard when mature, woody when mature to old, covered with a thick crust, and some cracked crust when old. Pileus color light orange (6A4-6A5) to grayish orange (6B3-6B5) at base toward the center of mature fruiting bodies become grayish-green (30E2-30E7) on the upper surface when mature to old. Context up to $0.4-2.3 \mathrm{~cm}$ thick, tri-dimitic hyphal, with clamps connections, brownish-orange (7C7-7C8) to reddish-brown (8D7-8D8), mostly dark brown (7F7) near the tube layers, Bovista-type ligative hyphae, hymenial with sword-like apices in the context. Tube $0.1-0.6 \mathrm{~cm}$ long, up to $80-160 \mu \mathrm{m}$ in width, and sulcate at different levels. Stipe almost sessile with broadly attached when present. Margin wavy, blunt-edged, slippery when wet, soft when young, thinner than the base and softer than the center, and often white (8A1) when young to mature. Pore angular, subcircular, 4-6 in number per $\mathrm{mm}$ in fresh. Pore surface initial white (7A1), turns light brown (7D6) to brown (7D8) when scratched or bruised, with a slippery surface when fresh. 
Hyphal structure: Hyphal system trimitric hyaline, with walls varying in thickness with simple septa, composed of narrow and sparingly branched; generative hyphae 1.3-4.6 $\mu \mathrm{m}$ broad $(n=30)$, thin-walled and hyaline hyphae; skeletal hyphae 4.0-7.3 $\mu \mathrm{m}$ broad $(n=$ $30)$, thick-walled and hyaline hyphae; binding hyphae $2.8-6.3 \mu \mathrm{m}$ broad $(n=30)$, usually with walls varying in thickness. Pileipellis a hymeniderm, brownish-orange (6C8) to brown (6D8), composed of apically acanthus-like branched cells, dextrinoid. Basidiospores (4.2-) 6.5-8.1-10.3(-11.2) $\times(3.9-) 4.8-4.6-5.7(-6.4) \mu \mathrm{m}(\bar{x}=8.2 \times 4.7 \mu \mathrm{m}, n=50) \mu \mathrm{m}$, with $\mathrm{Q}=$ $1.70-1.76, \mathrm{~L}=8.38 \mu \mathrm{m}, \mathrm{W}=4.85 \mu \mathrm{m}$ (including myxosporium), (4.5-)6.1-7.2-8.1(-9.2) $\times$ (3.9-)4.5-5.3-5.2(-6.9) $\mu \mathrm{m}(\bar{x}=7.4 \times 5.4 \mu \mathrm{m}, n=50)$, with $\mathrm{Q}=1.31-1.38, \mathrm{~L}=7.53 \mu \mathrm{m}$, $\mathrm{W}=5.60 \mu \mathrm{m}$ (excluding outer myxosporium), ellipsoid or some globose with double walls, overlaid by hyaline, dextrinoid, distinct echinulate, inner wall echinulate brown, light brown (6D4) to brown (6E8) in 5\% KOH. Basidia not seen.

Habitat: Solitary on standing trees of Dendrocalamus strictus.

Specimens examined: THAILAND, Chiang Rai Province, $19^{\circ} 48^{\prime} 20^{\prime \prime} \mathrm{N}, 100^{\circ} 04^{\prime} 19^{\prime \prime} \mathrm{E}$, 680 m elev., October 2017, T. Luangharn, MFLU 19-2176.

Ganoderma lucidum (Curtis) P. Karst., Revue Mycologique Toulouse. 3(9): 17 (1881) (Figure 26)

Facesoffungi number: FoF 06250

Description: Basidiomes annual or perennial, sub-reniform to reniform, stipitate. Pileus up to $2-6 \mathrm{~cm}$ in length, $1.5-3.0 \mathrm{~cm}$ in width, and $0.8-2.0 \mathrm{~cm}$ thick at the base. Pileus stipitate, sub-reniform to reniform, undefined imbricate, irregular, some laterally, and flabelliform with a contracted, concentrically sulcate zone, irregularly ruptured crust overlying the context, radial from center extending to the margin, tough when broken, often thick at center slightly soft at margin, and leathery when age when broken. Pileus surface smooth layer at center from young to old, usually furrowed, incised, undulate to sulcate, somewhat spathulate to uneven, some woody or corky texture when old, weakly laccate when present, strongly laccate and glossy when mature, and usually weakly laccate where the new hyphae are in active development (margin). Pileus color usually brownish-red $(8 \mathrm{C} 7-8 \mathrm{C} 8)$ at the center, slight to reddish-orange (7B7-7B8), and orange (6A7-6A8) on the upper pileus surface. Context up to $0.4-1.4 \mathrm{~cm}$ thick at base, abundant thick-walled, subsolid hyphae, concentric lines of various shades, bearing clamp connections, light brown (6D6) to brown $(6 \mathrm{D} 8,6 \mathrm{E} 8)$, with dark brown (7F7) melanoid bands. Tube usually hard, brown (7D7) to dark brown (7F7). Stipe up to $8-16 \mathrm{~cm}$ in length, up to $0.8-1.5 \mathrm{~cm}$ in width, eccentric stipe, cylindrical to slightly flattened, laccate, and reddish-brown (8D7-8D8, 8E7-8E8) from mature to old. Margin often $0.5-1.3 \mathrm{~cm}$, orange (6A7-6A8) upper surface, and reddish-yellow (4A8) under surface, thinner than the base, and softer than the center. Pore 4-6 in number per mm, (70-)110-145(-160) $\mu \mathrm{m}$, subcircular to circular, sometimes angular. Pore surface white (11A1) when present, yellowish-white (2A3) to light brown (7D6) from young to mature, turning brown (7D7-7D8) to dark brown (6F6) when scratched or bruised.

Hyphal structure: Hyphal system trimitic, with clamp connections, hyaline, walls varying in thickness with simple septa, sparingly branched, swollen by melanoid bands, usually brownish-orange (6C7-6C8) to brown (6D7-6D8) in $\mathrm{KOH}$; generative hyphae up to (1.8-) 2.0-2.3-2.7(-3.0) $\mu \mathrm{m}$ broad $(n=30)$, usually thin-walled, some thick-walled, with clamp connections, branched, and almost hyaline; skeletal hyphae (3.2-)4.3-5.4-6.1(-6.8) $\mu \mathrm{m}$ broad $(n=30)$, usually thick-walled with clamp connections, with unbranched; binding hyphae (2.4-)2.9-4.4-5.0(-5.9) $\mu \mathrm{m}$ broad $(n=30)$, walls usually varying in thickness with abundant branched and present the melanoid bands. Basidiospores ellipsoid, some subglobose to globose with double walls, with a truncate apex, size range of (8.2-)8.8-9.8-10.5 (-11.4) $\times$ (5.8-)6.2-6.8-7.5(-8.2) $\mu \mathrm{m},(\bar{x}=10.0 \times 6.9 \mu \mathrm{m}, n=50) \mu \mathrm{m}$, with $\mathrm{Q}=1.51-1.57, \mathrm{~L}=10.65 \mu \mathrm{m}$, $\mathrm{W}=6.92 \mu \mathrm{m}$, (including myxosporium), (6.3-)7.1-7.6-8.2(-8.4) $\times(4.8-) 5.4-5.7-6.1(-6.5) \mu \mathrm{m}$, $(\bar{x}=7.5 \times 5.8 \mu \mathrm{m}, n=50) \mu \mathrm{m}$, with $\mathrm{Q}=1.26-1.31, \mathrm{~L}=7.57 \mu \mathrm{m}, \mathrm{W}=5.89 \mu \mathrm{m}$ (excluding outer myxosporium) $(n=50)$, brownish-orange $(6 \mathrm{C} 8,6 \mathrm{D} 8)$ to brown $(6 \mathrm{E} 5)$ of endosporium (inner wall) with brown (7E7-7E8) exosporium (outer wall) in Congo red, brownish-orange 
(6C8) in 5\% $\mathrm{KOH}$, and yellowish-brown (5D8) in Melzer's reagent, mostly overlaid by hyaline, coarse echinulate, hyaline turgid vesicular appendix. forest.

Habitat: Solitary on decaying hardwood of Dendrocalamus strictus in dry evergreen

Specimens examined: THAILAND, Chiang Rai Province, $19^{\circ} 48^{\prime} 20^{\prime \prime} \mathrm{N}, 100^{\circ} 04^{\prime} 19^{\prime \prime} \mathrm{E}$, 680 m elev., 15 October 2017, T. Luangharn, MFLU 19-2162.
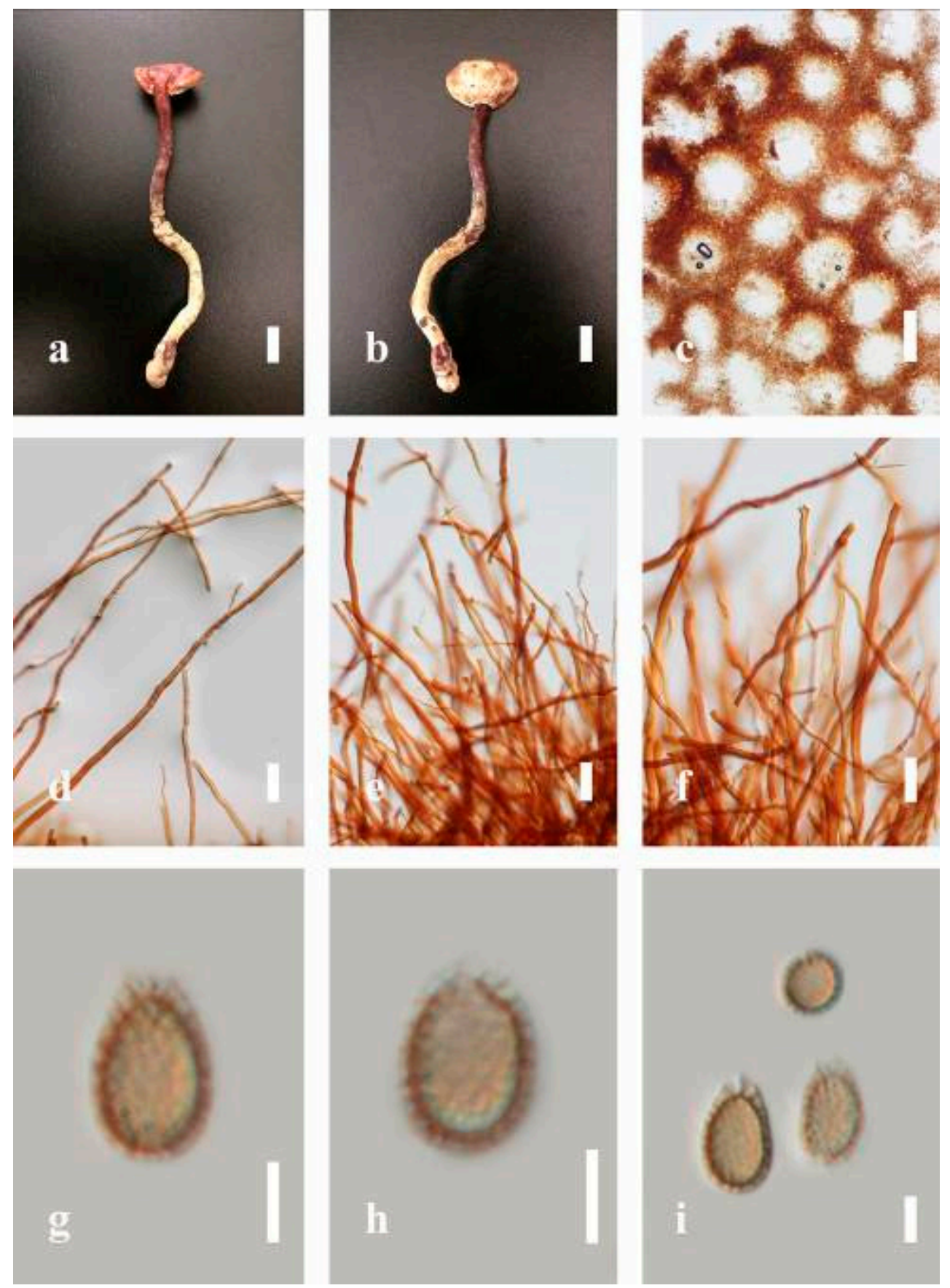

Figure 26. Morphology of Ganoderma lucidum (MFLU 19-2162): (a,b) mature basidiomes; (c) pore characteristics; (d) generative hyphae of context in $\mathrm{KOH} ;(\mathbf{e}, \mathbf{f})$ generative. skeletal and binding hyphae of context in $\mathrm{KOH} ;(\mathbf{g}-\mathbf{i})$ basidiospores. Scale bars: $(\mathbf{g}, \mathbf{i})=2 \mathrm{~cm},(\mathbf{c})=200 \mu \mathrm{m},(\mathbf{d}-\mathbf{f})=20 \mu \mathrm{m}$, $(\mathbf{g}-\mathbf{i})=5 \mu \mathrm{m}$.

Ganoderma multipileum Ding Hou. (1950) (Figure 27)

Facesoffungi number: FoF 06256 
Description: Basidiomes annual, stipitate. Pileus up to 6-11 cm in length, $4-9 \mathrm{~cm}$ in width, and 1-3 cm thick at base. Pileus sub-reniform to reniform, subflabellate to flabellate, concentrically sulcate zone, fleshed at center slightly to margin, radial or branched from center extend to the margin when seen from above, tough when break, often thick at center slightly soft at margin, and leathery when age when break. Pileus surface weakly laccate to strong laccate at center when mature to age, and faded or week laccate at active mycelial (margin), smooth, irregularly ruptured crust overlying the context, some woody or corky texture when old, usually furrowed, incised, sulcate to undulating, and somewhat spathulate to uneven on the surface. Pileus color usually homogenous brownish-red (8C7-8C8) at the base, slight yellowish-red (8A7-8A8, 8B7-8B8) at center, and light brown (7D5) to brown (7D7-7D8) on the upper margin surface. Context up to 0.3-1.2 cm thick at the base, with walls varying in thickness, subsolid hyphae, bearing clamp connections, usually light brown (6D4-6D6) to brown (6D8, 6E8) of hyphae, and dark brown (7F7) melanoid bands in $\mathrm{KOH}$. Tube hard, usually thin-thick-walled, often with brown (7D7) to dark brown (7F7). Stipe up to $4-9 \mathrm{~cm}$ in length, up to $1-2.5 \mathrm{~cm}$ in width, almost eccentric, sub-cylindrical to cylindrical, plump, strong laccate, often homogeneous with red (9A6) to brownish-red (9C6), and dark red (10C7) when mature to old. Margin often white (4A1) to pale yellow (4A4) where the new hyphae are in active development, light brown (7D5) to brown (7D7) when bruised, strong laccate, wavy, slippery when wet, softer, thin than the base, and soft than the center. Pore angular, 4-6 in number per mm, (99-)120-154(-170) $\mu \mathrm{m}$ in diam, subcircular to circular. Pore surface white (11A1) when present, pale yellow (4A3) to orange white (5A2) when young to mature, light brown (6D4) with age, turning to light brown (7D6), brown (7D7-7D8) when dried or scratched and bruised.

Hyphal structure: Hyphal system trimitic, with clamp connections, hyaline, walls varying in thickness with simple septa, sparingly branched, usually light orange (5A4-5A5) to orange (5A6-5A7) in $\mathrm{KOH}$; generative hyphae up to (1.6-)2.2-3.5-4.6(-5.2) $\mu \mathrm{m}$ broad $(n=30)$, usually thick-walled, unbranched, flexuous, and almost hyaline; skeletal hyphae (3.8-)4.2-5.1-5.9(-6.7) $\mu \mathrm{m}$ broad $(n=30)$, usually thick-walled, unbranched, sometimes subsolid; binding hyphae (1.4-)2.2-3.6-4.4(-5) $\mu \mathrm{m}$ broad $(n=30)$, usually walls varying in thickness, with flexuous, abundant branched, with Bovista-type binding hyphae, and occurred the melanoid bands. Basidiospores mostly ellipsoid, some ovoide, truncate at maturity, with double walls, (7.6-)8.8-11.7-12.4(-13.1) × (4.9-)5.3-6.1-6.9(-7.4) $\mu \mathrm{m}$, $(\bar{x}=11.8 \times 6.3 \mu \mathrm{m}, n=50) \mu \mathrm{m}$, with $\mathrm{Q}=1.84-1.89, \mathrm{~L}=11.84 \mu \mathrm{m}, \mathrm{W}=6.32 \mu \mathrm{m}$ (including myxosporium), (5.9-)6.9-8.2-9.3(-10.6) $\times(4.3-) 4.9-5.6-6.0(-6.5) \mu \mathrm{m},(\bar{x}=8.3 \times 5.8 \mu \mathrm{m}$, $n=50) \mu \mathrm{m}$, with $\mathrm{Q}=1.40-1.46, \mathrm{~L}=8.36 \mu \mathrm{m}, \mathrm{W}=5.85 \mu \mathrm{m}$ (excluding outer myxosporium), mostly overlaid by hyaline, brownish-orange (6C8), (6D8) of exosporium (outer wall), endosporium (inner wall) coarse echinulae, with hyaline turgid vesicular appendix, with orange (6A7), (6B7) in $\mathrm{KOH}$.

Habitat: Solitary on decaying stump of Pinus merkusii.

Specimens examined: THAILAND, Prachuap Khiri Khan Province, $12^{\circ} 08^{\prime} 52^{\prime \prime} \mathrm{N}, 99^{\circ} 45^{\prime} 41^{\prime \prime} \mathrm{E}$, 491 m elev., 26 June 2018, T. Luangharn, MFLU 19-2166.

Notes: Ganoderma multipileum was originally reported from Taiwan, PRC [44], which was presented over half a century ago from Taiwan, PRC [39]. This fungus was the earliest valid name with G. lucidum from tropical Asia [44]; however, Wang et al. [33] verified that G. multipileum is the correct name for this tropical fungus. This fungus is a distinctive form with its laccate to strong laccate pileus, stipitate, rarely sessile, irregularly ruptured crust overlying the context, yellow-brown to dark brown context, cream pore surface, flattened or sub-cylindrical, lateral, horizontally lateral, with ovoid to ellipsoid basidiospores $(7.6-13.5 \times 5.5-7.5 \mu \mathrm{m})$ (with myxosporium), 6.5-10.5 × 4.5-6.5 $\mu \mathrm{m}$ (without myxosporium)), mostly truncate, brown, with a dark brown [33]. Some researchers have shown in their phylogenies that G. tropicum is similar to G. multipileum [4,5], which is considered most resemble G. tropicum in morphology and habitat even though they are distinct species [33] and G. flexipes [4,76,129]. Our G. multiplicatum was collected from Thailand, are similar to the original description by Wang et al. [33] by its showed laccate to 
strong laccate pileus, radial or branched from center extends to the margin, with ellipsoid basidiospores.
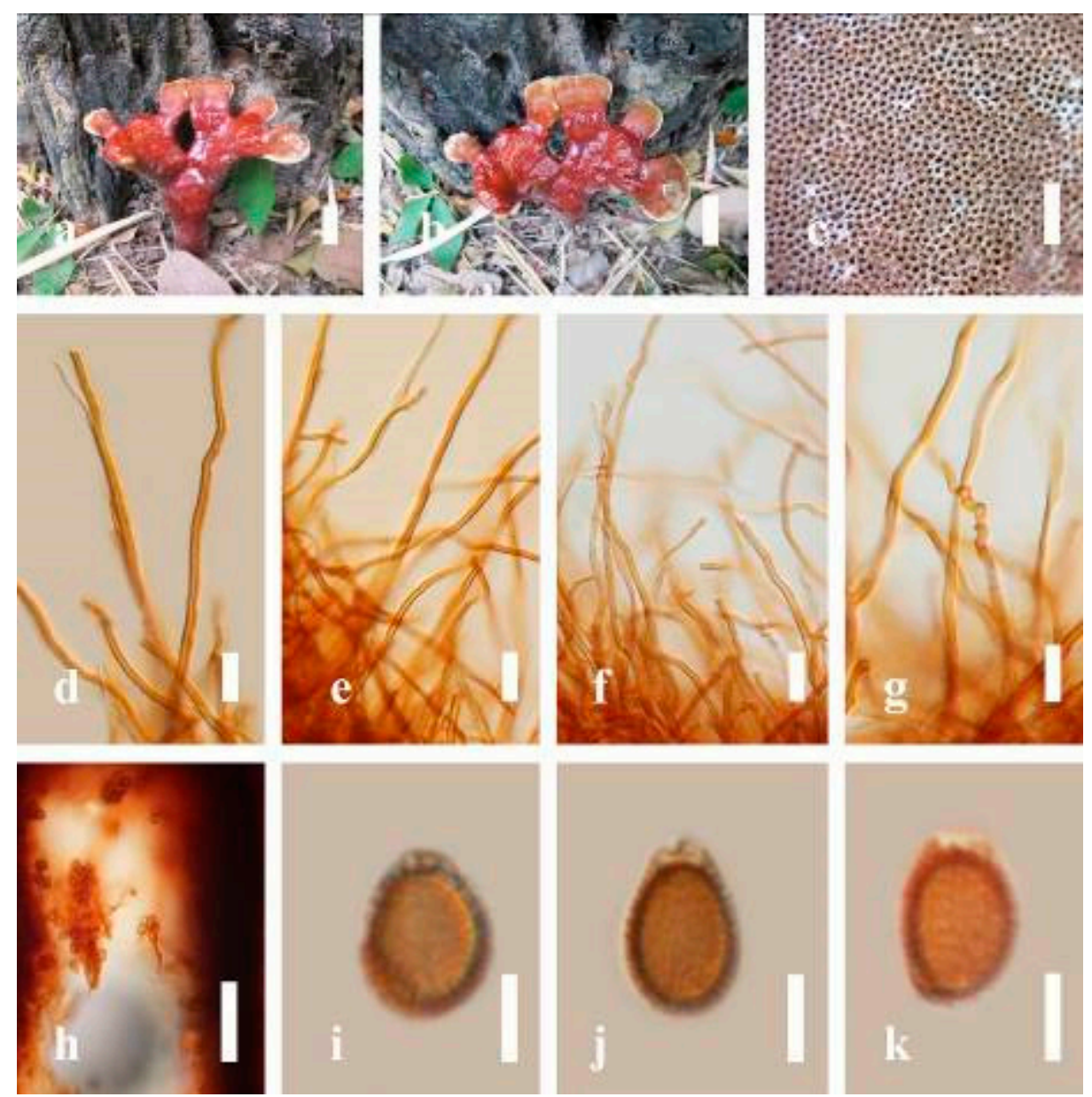

Figure 27. Morphology characteristics of Ganoderma multipileum (MFLU 19-2166): (a,b) mature basidiomes; (c) pore characteristics; (d) generative hyphae of context in $\mathrm{KOH}$; $(\mathbf{e}-\mathbf{g})$ generative. skeletal and binding hyphae of context in $\mathrm{KOH}$; (h) basidiospores with tube layers; (i-k) basidiospores in KOH. Scale bars: $(\mathbf{a}, \mathbf{b})=3 \mathrm{~cm},(\mathbf{c})=1000 \mu \mathrm{m},(\mathbf{d}-\mathbf{g})=20 \mu \mathrm{m},(\mathbf{h})=50 \mu \mathrm{m},(\mathbf{i}-\mathbf{k})=5 \mu \mathrm{m}$.

Ganoderma orbiforme (Fr.) Ryvarden, Mycologia. 92(1): 187 (2000) Figure 28) $\equiv$ Polyporus orbiformis Fr., Epicrisis Systematis Mycologici.: 463 (1838)

$\equiv$ Fomes orbiformis (Fr.) Cooke, Grevillea. 14 (69): 18 (1885)

$\equiv$ Scindalma orbiforme (Fr.) Kuntze, Revisio generum plantarum. 3(2): 519 (1898)

$\equiv$ Ganoderma lucidum var. orbiformis (Fr.) Rick, Iheringia. 7: 201 (1960)

$\equiv$ Ganoderma orbiformum (Fr.) Ryvarden (2000)

= Ganoderma mastoporum (Lév.) Pat., Bulletin de la Société Mycologique de France. 5: $71(1889)$

= Ganoderma fornicatum (Fr.) Pat., Bulletin de la Société Mycologique de France. 5: 71 (1889)

= Ganoderma boninense Pat., Bulletin de la Société Mycologique de France 5: 72 (1889)

= Ganoderma subtornatum Murrill, Bulletin of the Torrey Botanical Club. 34: 477 (1907)

= Ganoderma cupreum (Cooke) Bres., Annales Mycologici. 9: 268 (1911)

= Ganoderma densizonatum J.D. Zhao and X.Q. Zhang, Acta mycol. sin.: 86 (1986)

= Ganoderma limushanense J.D. Zhao and X.Q. Zhang, Acta mycol. sin.: 219 (1986) 

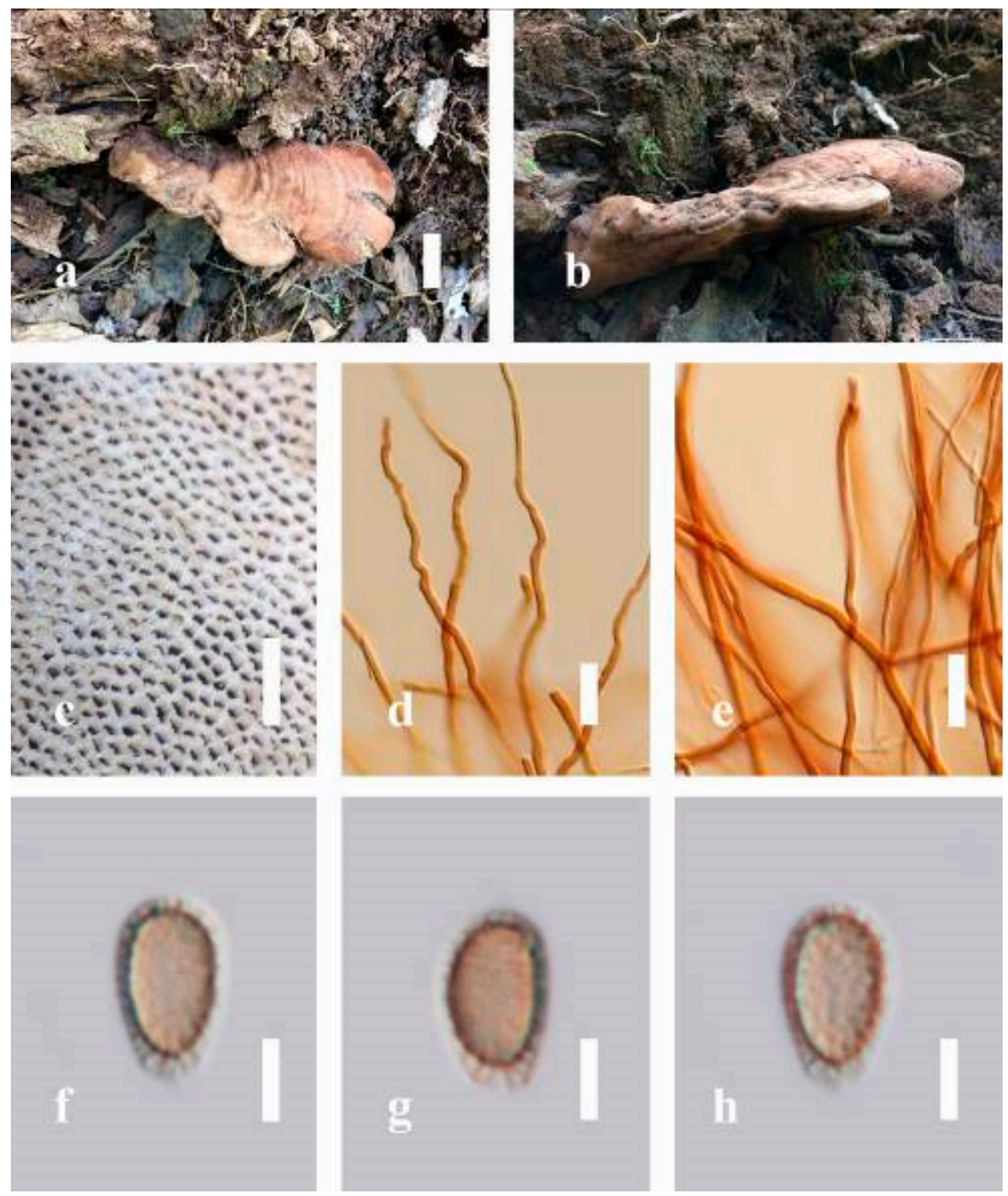

Figure 28. Morphology of Ganoderma orbiforme (MFLU 17-1933): (a,b) mature basidiomes; (c) pore characteristics; $(\mathbf{d}, \mathbf{e})$ context hyphae in $\mathrm{KOH} ;(\mathbf{f}-\mathbf{h})$ basidiospores in $\mathrm{KOH}$. Scale bars: $(\mathbf{a})=2 \mathrm{~cm}$, (c) $=1000 \mu \mathrm{m},(\mathbf{d}, \mathbf{e})=20 \mu \mathrm{m},(\mathbf{f}-\mathbf{h})=5 \mu \mathrm{m}$.

Facesoffungi number: FoF 06257

Description: Basidiomes annual or perennial, sessile. Pileus $4-11 \mathrm{~cm}$ in length, $3-6 \mathrm{~cm}$ in width, and 1-2.4 cm thick at base. Pileus sessile, flabelliform or spathulate, convex, imbricate, umbonate, uneven, ungulate, sub-reniform, sub-orbicular, subdimidiate, obtuse from host, broadly attached, somewhat imbricate, thicker at base, slightly soft at margin when mature. Pileus color usually homogenous with grayish-orange (6B3-6B6), brownishorange (6C5-6C6), and brown (6D7-6D8) at base extending to the margin of maturity to old. Pileus surface partly non-laccate (dull) to weakly laccate, faded texture when old, furrowed, incised, sulcate, undulating, and somewhat spathulate to uneven on the upper surface, silky and soft when fresh, woody when mature to older, and covered with compact and hard crust $(0.1-0.25 \mathrm{~mm})$. Context up to $0.4-1.0 \mathrm{~cm}$ thick, trimitic hyphae with clamp connections, hyaline, walls varying in thickness with simple septa, sparingly branched. Hymenophore brown (6D7-6D8) to reddish-brown (8D7). Tube layers $0.3-1.2 \mathrm{~cm}$ in length, light brown (6D4-6D5) to brown (7D7). Stipe almost sessile with broadly attached when present, with brownish-orange (6C8). Margin soft, wavy, blunt- 
edged, slippery when young, with grayish-orange (6B5-6B6) to brownish-orange (6C8) when old. Pore 4-6 in number per mm, circular or subcircular, or angular. Pore surface white (11A1), when present, turns light brown (7D5) to brown (7D7-7D8) when scratched or bruised, becoming discolored when touched.

Hyphal structure: Hyphal system trimitic, with clamp connections, usually orange (6A6-6A8) to brownish-orange (6C7-6C8) in $\mathrm{KOH}$; generative hyphae 1.4-5.0 $\mu \mathrm{m}$ broad $(n=30)$, hyaline, thin-walled with clamp connections; skeletal hyphae 2.6-5.6 $\mu \mathrm{m}$ broad $(n=30)$, usually thick-walled, unbranched; binding hyphae $1.2-4.8 \mu \mathrm{m}$ width $(n=30)$, usually walls varying in thickness, many branches, hymenial with sword-like apices in the context. Basidiospores mostly ellipsoid to oblong ellipsoid or broadly ellipsoid, with double walls, (7.1-)7.9-9.4-11.2(-11.8) $\times(5.2-) 5.97-6.7-7.1(-7.7) \mu \mathrm{m}(\bar{x}=9.6 \times 6.8 \mu \mathrm{m}$, $n=50) \mu \mathrm{m}$, with $\mathrm{Q}=1.38-1.44, \mathrm{~L}=9.63 \mu \mathrm{m}, \mathrm{W}=6.82 \mu \mathrm{m}$ (including myxosporium), (6.4-)5.2-6.0-6.7(-10.7) × (3.9-)4.5-5.3-6.1(-6.6) $\mu \mathrm{m}(\bar{x}=6.2 \times 5.1 \mu \mathrm{m}, n=50) \mu \mathrm{m}$, with $\mathrm{Q}=1.20-1.27, \mathrm{~L}=6.28 \mu \mathrm{m}, \mathrm{W}=5.10 \mu \mathrm{m}$ (excluding outer myxosporium), overlaid by hyaline, echinulate, inner wall echinulate brown, some turgid vesicular appendix, light yellow (4A5) to reddish-yellow (4B7-4B7) in 5\% $\mathrm{KOH}$. Basidia not seen.

Habitat: solitary, on the living tree of Albizia mollis in deciduous forest, and living tree of Indochinese spp.

Specimens examined: THAILAND, Chiang Rai Province, $19^{\circ} 48^{\prime} 20^{\prime \prime} \mathrm{N}, 100^{\circ} 04^{\prime} 19^{\prime \prime} \mathrm{E}$, 680 m elev., 21 October 2017, T. Luangharn, MFLU 17-1933.

Notes: Ganoderma orbiforme (Fr.) Ryvarden was first described as Polyporus orbiformis, with the original specimen from the tropical region of Guinea in Africa [136]. The fungus was characterized by its distinctive weakly laccate surface or some dull surface areas, brown context, brown pore surface, and brown tube layer, and ellipsoid or ovoid basidiospore. Ganoderma cupreum, G. densizonatum, G. fornicatum, G. limushanense, G. multiplicatum, and G. subtornatum are similar to G. orbiforme; however, taxonomy and molecular analysis treated those taxa as the earliest valid names for G. orbiforme [7,156]. This fungus has been recorded from China, Laos, Myanmar, and Thailand [30], with our collection is also the collection of G. orbiforme from Thailand. Our collection from Thailand agrees well with the description by Ryvarden [136] and Wang et al. [156] reported that this fungus posed rigid basidiomes, purplish-black laccate crust, brown pore surface, and tube layer, with ellipsoid or ovoid basidiospores, fine and short echinulate, clavate cells usually with several irregular lobes.

Ganoderma philippii Bres. and Henn. ex Sacc. Bres, Iconographia mycological. 21: 1014, t. 1014 (1932) (Figure 29)

$\equiv$ Fomes philippii Bres. and Henn. ex Sacc., Sylloge Fungorum. 9: 180 (1891)

$\equiv$ Scindalma philippii (Bres. and Henn. ex Sacc.) Kuntze, Revisio generum plantarum. 3(2): 519 (1898)

= Fomes pseudoferreus Wakef., Bulletin of Miscellaneous Informations of the Royal Botanical Gardens Kew. 1918: 208 (1918)

Facesoffungi number: FoF 06258

Description: Basidiomes annual, sessile. Pileus $2-9 \mathrm{~cm}$ in length, $2-5 \mathrm{~cm}$ in width, and $0.4-3.8 \mathrm{~cm}$ thick at the base. Pileus annual, convex, sessile, umbonate, ungulate, usually round when present, primordial, plump when present, broadly attached and thick at base, slightly soft at margin. Pileus surface non-laccate to weakly laccate, furrowed, incised, sulcate, smooth when young, undulating on the upper surface, spathulate to uneven, covered with a crust $(0.1-0.3 \mathrm{~mm})$, cracked crust when old, and woody when old. Pileus color usually homogenous, brown (7E7-7E8) at base at the center, extending to brownish-orange (6C8), and white (4A1) when present, slightly yellowish-white (2A2) on the upper margin surface of mature fruiting bodies. Context consists of trimitic hyphae, up to $0.3-1.8 \mathrm{~cm}$ thick, sparingly branched, walls varying in thickness, compact and hard, with clamp connections, hyaline; generative hyphae $1.8-3.3 \mu \mathrm{m}$ in width $(n=30)$, brownishyellow (5C7-5C8), thin-walled, simple septa, hyaline, with clamp connections; skeletal hyphae 2.8-4.9 $\mathrm{mm}$ broad $(n=30)$, brownish-yellow (5C7-5C8), usually thick-walled, 
unbranched; binding hyphae $2.0-4.2 \mu \mathrm{m}$ width $(n=30)$, brownish-yellow $(5 \mathrm{C} 7-5 \mathrm{C} 8)$ to brownish-orange (6C7-6C8), sparingly branched, walls varying in thickness, and without clamp connections. Hymenophore heterogeneous, brown (7C7-7C8, 7D8), and melanoid band present when mature. Tube layers $0.3-3.8 \mathrm{~cm}$ in length. Margin blunt-edged, wavy, and often white (8A1) where the new hyphae are in active development to yellowishwhite (2A2) from young to mature. Pore 4-7 in number per $\mathrm{mm}$, subcircular to circular. Pore surface white (11A1) when present, turning brown (7E7) to dark brown (7F7-7F8) when scratched or bruised.
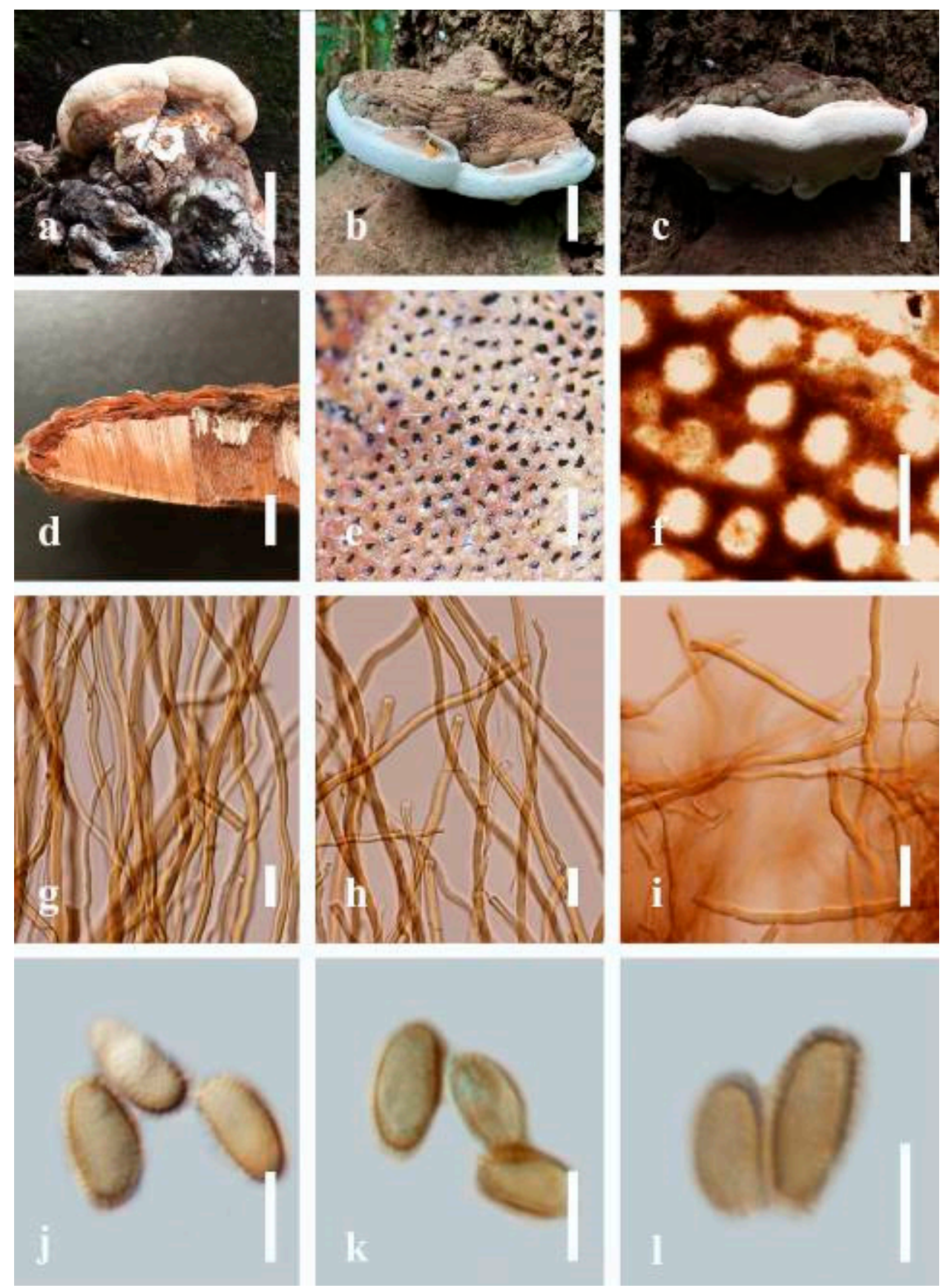

Figure 29. Morphology of Ganoderma philippii (MFLU 19-2222): (a) mature basidiomes of the collection MFLU 19-2222; (b,c) mature basidiomes of the collection MFLU 19-2223; (d) morphology of the tube layers; (e,f) pore characteristics; $(\mathbf{g}, \mathbf{h})$ context hyphae; (i) hyphae from tube layers; $(\mathbf{j}-\mathbf{l})$ basidiospores in $\mathrm{KOH}$. Scale bars: $(\mathbf{a}-\mathbf{d})=2 \mathrm{~cm},(\mathbf{e})=500 \mu \mathrm{m},(\mathbf{f})=150 \mu \mathrm{m},(\mathbf{g}-\mathbf{i})=20 \mu \mathrm{m},(\mathbf{j}-\mathbf{l})=5 \mu \mathrm{m}$.fi. 
Hyphal structure: Hyphal system trimitic, with clamp connections, usually brown (7E7); generative hyphae (1.7-)2.1-2.5-2.9(-3.3) $\mu \mathrm{m}$ broad $(n=30)$, branched, thin-walled, hyaline, unbranched, grayish-yellow (4B5) in $\mathrm{KOH}$, with clamp connections; skeletal hyphae (2.9-)3.4-4.0-4.4(-5.0) $\mu \mathrm{m}$ broad $(n=30)$, dextrinoid, abundant thick-walled, with unbranched; binding hyphae (2.1-)2.8-3.3-3.8(-4.3) $\mu \mathrm{m}$ broad $(n=30)$, walls varying in thickness, frequently branched, generative and skeletal hyphae usually intertwined, mostly brown (7E7) to dark brown (7F5) near the tube layer; Bovista-type ligative hyphae, hymenial with sword-like apices in the context. Basidiospores mostly oblong, double walls, (5.8-)6.4-7.3-7.8(-8.2) × (4.1-)4.6-6.1-6.7(-7.1) $\mu \mathrm{m}(\bar{x}=7.4 \times 6.0 \mu \mathrm{m}, n=50) \mu \mathrm{m}$, with $\mathrm{Q}=1.01-1.12, \mathrm{~L}=7.32 \mu \mathrm{m}, \mathrm{W}=6.98 \mu \mathrm{m}$ (including myxosporium), (5.2-)5.7-6.5-7.1 $(-7.5) \times(3.7-) 4.3-5.5-6.1(-6.5) \mu \mathrm{m}(\bar{x}=6.62 \times 5.58 \mu \mathrm{m}, n=50) \mu \mathrm{m}$, with $\mathrm{Q}=1.14-1.24$, $\mathrm{L}=6.56 \mu \mathrm{m}, \mathrm{W}=5.48 \mu \mathrm{m}$ (including myxosporium), overlaid by hyaline, dextrinoid, echinulate, inner wall echinulate, grayish-orange (5B4-5B5) in 5\% KOH, and yellowish-brown (5E8) to light brown (6D8). Basidia not seen.

Habitat: Solitary on rotten wood of unknown tree species.

Specimens examined: THAILAND, Chiang Mai Province, Mae Taeng, Mushroom Research Centre, $19^{\circ} 07^{\prime} 200^{\prime}$ N, $98^{\circ} 41^{\prime} 44^{\prime \prime}$ E, 770 m elev., 14 June 2019, P. E. Mortimer, MFLU 192222 and MFLU 19-2223.

Notes: Ganoderma philippii was introduced as Fomes philippii by Bresadola and Hennings in 1891 [126] and later transferred to Ganoderma [157]. Ganoderma philippii causes red root-rot disease, one of the most economically important diseases across a wide range of commercial perennial woody crops of tropical Acacia species [158]. Ganoderma philippii is distributed across Asia, from the Philippines in the north to southern Papua New Guinea [111]. This species is characterized by its sessile, non-laccate pileus surface, with melanoid bands that form a layer distinct from the context, with a di-trimitic hyphal system with clamped connections overlaid by hyaline, echinulate, inner wall echinulate, sometimes turgid vesicular appendix basidiospores [26]. In this study, our new record of G. philippii collected from Thailand is described based on characteristics and phylogenetic analyses. Our collection agrees well with the description by Wang et al. [33].

Ganoderma sichuanense S.H. Wu, Y. Cao, and Y.C. Dai. Fungal Diversity. 56(1): 54 (2012) (Figure 30)

Facesoffungi number: FoF 06248

Description: Basidiomes annual or perennial, stipitate. Pileus $15 \mathrm{~cm}$ in length, up to $10 \mathrm{~cm}$ in width, and $2 \mathrm{~cm}$ thick. Pileus shell-like (involute from margin into the center), subflabellate or reniform to circular when seen from above, often with undefined concentric zones at center and extend to the margin, thick at center slightly soft at margin, and leathery when age when break. Pileus surface usually laccate, faded or week laccate when young, and strongly laccate when mature to age, shiny, silky, smooth, and soft when fresh, furrowed on the surface with sulcate to undulating, somewhat spathulate to uneven, incised, hard, and woody when old, and some occurred the brown (7D5) lined when older. Pileus color usually homogenous at base at the center with red (9A6-9A7, 9B7-9B8), brownish-red (9C6-9C8), and dark red (10C7-10C8), extended to the margin with reddish-yellow (4A7), but do not change the color when touched. Context up to $0.3-0.5 \mathrm{~cm}$ thick at base, abundant thick-walled, some thin-walled, with subsolid hyphae, bearing clamp connections, and occurred the dark brown (7F7-7F8) melanoid bands. Tube layers usually thin-walled, frequently branched with clamp connections, and hard and woody when mature, often brown (7D7). Stipe up to $3-8 \mathrm{~cm}$ in lenge, up to $1-3 \mathrm{~cm}$ in width, centrally stipitate, almost sub-cylindrical to cylindrical, often red (9A6) to brownish-red (9C6), and dark red (10C7) when mature. Margin obtuse from the center, some wavy, slippery when wet, softer, strong laccate edged, thin than the base and soft than the center, often reddish-yellow (4A7, 4B7-4B8), deep yellow (4A8), and orange (5A6-5A7) to golden yellow (5B7-5B8) when mature to old. Pore angular, subcircular to circular, 4-7 in number per mm, (40-)80-140(-155) $\mu \mathrm{m}$. Pore surface white (11A1) to yellowish-white (3A2) when young to mature, turning yellow (3B8) to olive-yellow (3C7-3C8) when dried, as well as 
becoming discolored when touched, turns light brown (7D5), brown (7D7-7D8) to dark brown (7F6-7F8) when scratched or bruised.
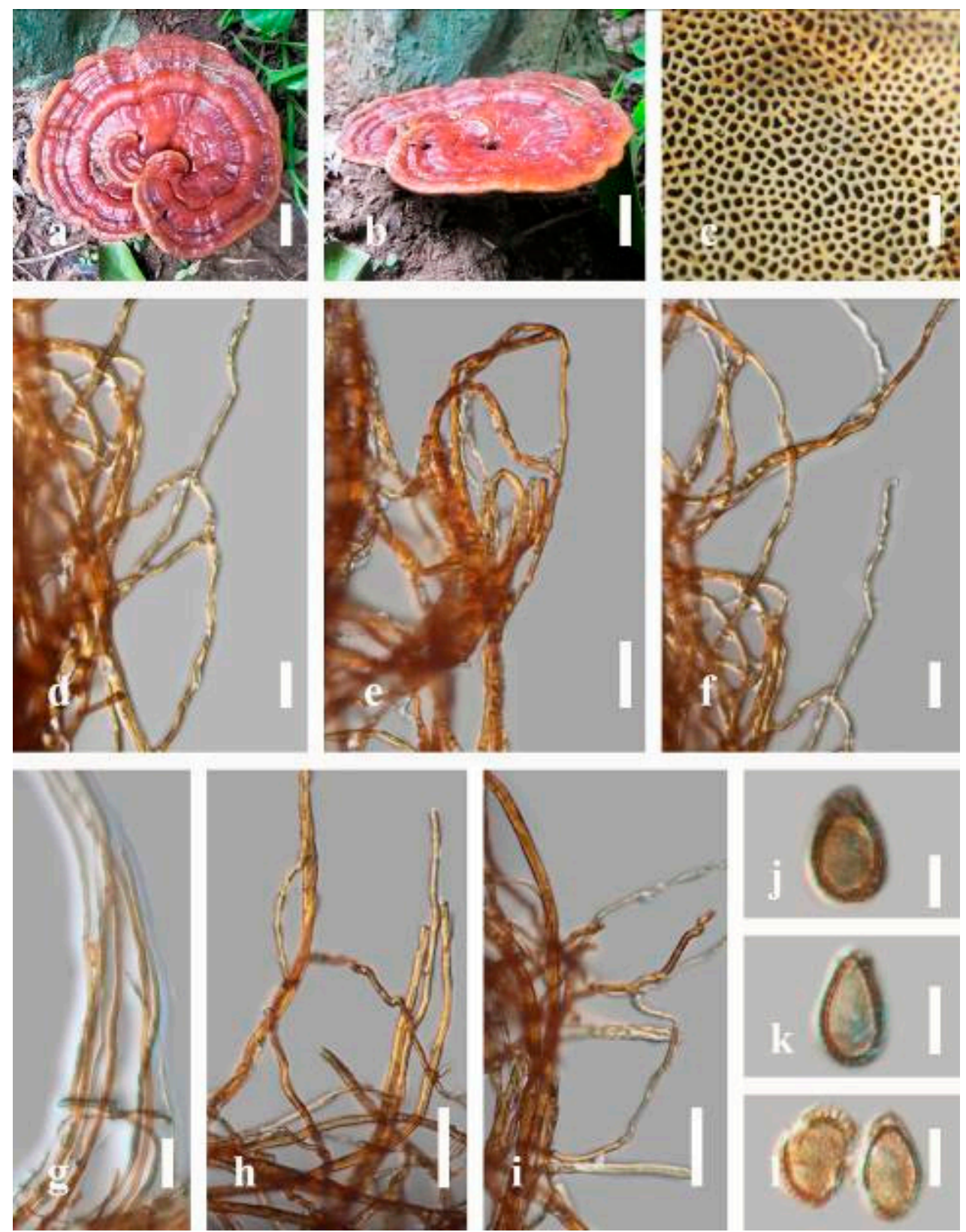

Figure 30. Morphology of Ganoderma sichuanense (MFLU 19-2164): (a,b) mature basidiomes; (c) pore characteristics; (d-f) walls varying in thickness sparing branched of generative and skeletal hyphae of context in upper part in Melzer's reagent; (g) generative hyphae of context in lower part in Melzer's reagent; $(\mathbf{h}, \mathbf{i})$ thick-walled sparing branched of generative and skeletal hyphae of context in lower part in Melzer's reagent; $(\mathbf{j}-\mathbf{1})$ basidiospores in Melzer's reagent. Scale bars: $(\mathbf{a}, \mathbf{b})=2 \mathrm{~cm},(\mathbf{c})=500 \mu \mathrm{m}$, $(\mathbf{d})=50 \mu \mathrm{m},(\mathbf{e}, \mathbf{f}, \mathbf{h}, \mathbf{i})=20 \mu \mathrm{m},(\mathbf{g})=30 \mu \mathrm{m},(\mathbf{j}-\mathbf{l})=5 \mu \mathrm{m}$.

Hyphal structure: Hyphal system trimitic, with bearing clamp connections, hyaline, with walls varying in thickness with simple septa, composed of narrow and sparingly branched; generative hyphae (1.3-)1.6-1.8-2.2(-2.4) $\mu \mathrm{m}$ broad $(n=30)$, thin-walled, hyaline, branched, with clamp connections; skeletal hyphae (1.6-)2.2-3.5-4.2(-4.9) $\mu \mathrm{m}$ broad $(n=30)$, walls varying in thickness, sometimes subsolid; binding hyphae (1.2-)1.5-1.7-2.0(-2.3) $\mu \mathrm{m}$ broad ( $n=30)$, usually thick-walled with narrow to subsolid, with pale orange (5A3) to light orange (5A4) of thin-walled, and orange (6B7) to brownish-orange (6C8) of thick- 
walled in Melzer's reagent, and occurred the melanoid bands. Pileipellis a hymeniderm, brown (7D7) with clavate-like cells, dextrinoid. Basidiospores mostly ellipsoid or oblong ellipsoid, truncate at maturity, with double walls, (8.0-)9.4-11.3-12.2(-13.3) $\times(4.9-) 5.4-6.5-$ 7.1(-7.4) $\mu \mathrm{m},(\bar{x}=11.2 \times 6.6 \mu \mathrm{m}, n=50) \mu \mathrm{m}$, with $\mathrm{Q}=1.64-1.51, \mathrm{~L}=11.24 \mu \mathrm{m}, \mathrm{W}=6.69 \mu \mathrm{m}$ (including myxosporium), (7.8-)8.1-8.6-9.9(-11.7) $\times(4.9-) 5.2-5.9-6.7(-7.4) \mu \mathrm{m}(\mathrm{Qm}=1.5$, $\mathrm{Q}=1.0-2.0$, excluding outer myxosporium $)(n=50),(\bar{x}=8.7 \times 5.8 \mu \mathrm{m}, n=50) \mu \mathrm{m}$, with $\mathrm{Q}=1.46-1.53, \mathrm{~L}=8.72 \mu \mathrm{m}, \mathrm{W}=5.84 \mu \mathrm{m}$ (excluding outer myxosporium), overlaid by hyaline, exosporium (outer wall) smooth and hyaline, endosporium (inner wall) coarse echinulate, with turgid vesicular appendix, light brown (7D7) to brown (7D8) in $\mathrm{KOH}$, and reddish-brown (8E6) to dark brown (8F4) in Melzer's reagent. Basidia 12-17 $\times 6-9 \mu \mathrm{m}$, with four sterigmata.

Habitat: Occasionally occurring on the stump of decaying Pterocarpus sp., living tree. Specimens examined: THAILAND, Prachuap Khiri Khan Province, $12^{\circ} 08^{\prime} 52^{\prime \prime} \mathrm{N}, 99^{\circ} 45^{\prime} 41^{\prime \prime} \mathrm{E}$, 491 m elev., 25 June 2018, T. Luangharn, MFLU 19-2164.

Ganoderma sinense J.D. Zhao, L.W. Hsu, and X.Q. Zhang, Acta Mycologica Sinica. 19: 272 (1979) (Figure 31)

Facesoffungi number: FoF 06253

Description: Basidiomes annual, stipitate, subdimidiate. Pileus $4-10 \mathrm{~cm}$ in length, 6-12 cm in width, $0.3-1.3 \mathrm{~cm}$ thick at base. Pileus stipitate, subdimidiate to dimidiate, flabelliform, spathulate, umbonate, concentrically sulcate zone, radial from center extending to the margin, tough when broken, often thick at center, slightly soft at margin, light in weight when dried, and non-woody. Pileus surface laccate, convex, some radial furrowed, imbricate, incised, glossy, shiny, spathulate, shallow sulcate when fresh, umbonate or uneven, strongly laccate and glossy when mature, and weakly laccate where the new hyphae are in active development (margin), usually smooth layers at center from young to old age, irregularly ruptured crust overlying the context, and leathery when broken in old age. Pileus color usually homogenous and brownish-red $(8 C 7-8 C 8)$ to reddish-brown (8D7-8D8) at center toward stipe and extending brownish-red (9C8) from the center slight to the margin when mature, usually reddish-brown (8E5-8E8) upper margin surface when old. Context up to $0.3-0.8 \mathrm{~cm}$ thick near the stipe, dried, upper layers brownish-orange (6C8) when fresh, lower layers grayish-orange (5B5), dark brown (8F7) when dried, soft and fibrous, covered with thin crust, some present woody, trimitic hyphae, hyaline, walls varying in thickness with simple septa, with branches. Tube $0.3-0.9 \mathrm{~cm}$ in length, brown (7D8). Stipe 3-12 cm in length, sub-cylindrical to cylindrical, almost stipitate, with broad and thick at base, irregularly ruptured crust overlying, usually strongly laccate, brown (7D8) to dark brown (8F8) when mature, usually dark brown (8F8) when old. Margin soft, some wavy, laccate when mature, weakly laccate when old, brownish-orange (6D8) from mature to old. Pore 4-6 in number per mm, subcircular to circular. Pore surface white (11A1) when present, to yellowish-white (2A2) when mature, turns brownish (6E7) to dark brown (6F7) when scratched or bruised.

Hyphal structure: Hyphal system trimitic, with clamp connections, usually light orange (5A5) to orange (5A7), golden yellow (5B7-5B8), sometimes brownish-red (8C7) in $\mathrm{KOH}$; generative hyphae $1.2-2.1 \mu \mathrm{m}$ broad $(n=30)$, hyaline, thin-walled, with clamp connections; skeletal hyphae 3.2-5.4 $\mu \mathrm{m}$ broad $(n=30)$, usually hyaline, thick-walled, unbranched, and solid; binding hyphae 3.3-5.7 $\mu \mathrm{m}$ width $(n=30)$, walls varying in thickness, with many branches, hymenial with sword-like apices in the context. Pileipellis a hymeniderm, grayish-orange (5B5) to brown (6E8), clavate-like cells, dextrinoid. Basidiospores mostly ellipsoid to broadly ellipsoid, double walls, $(9.8-) 10.4-11.7-12.5(-13.4) \times(7.3-) 7.7-8.9-10.0(-10.6) \mu \mathrm{m}(\bar{x}=11.8 \times 9.0 \mu \mathrm{m}, n=50)$ $\mu \mathrm{m}$, with $\mathrm{Q}=1.29-1.34, \mathrm{~L}=11.82 \mu \mathrm{m}, \mathrm{W}=9.02 \mu \mathrm{m}$ (including myxosporium), (8.9-)9.8-10.4$12.0(-12.8) \times(6.2-) 6.8-7.2-7.9(-8.3) \mu \mathrm{m}(\bar{x}=10.6 \times 7.3 \mu \mathrm{m}, n=50) \mu \mathrm{m}$, with $\mathrm{Q}=1.41-1.47$, $\mathrm{L}=10.47 \mu \mathrm{m}, \mathrm{W}=7.25 \mu \mathrm{m}$ (excluding outer myxosporium), overlaid by hyaline, apically and shortly echinulate, truncate, some turgid vesicular appendix, inner wall echinulate, orange (5A7), deep $(5 \mathrm{~A} 8,5 \mathrm{~B} 8)$, orange $(6 \mathrm{~B} 8)$, brownish-orange $(6 \mathrm{~B} 8)$, outer wall usually brownish-red (8C7-8C8) in 5\% $\mathrm{KOH}$. 
Habitat: Solitary, on the living tree of Dendrocalamus strictus and Dipterocarpus sp.

Specimens examined: THAILAND, Nakhon Phanom Province, 22 December 2018, T. Luangharn, MFLU 19-2172.
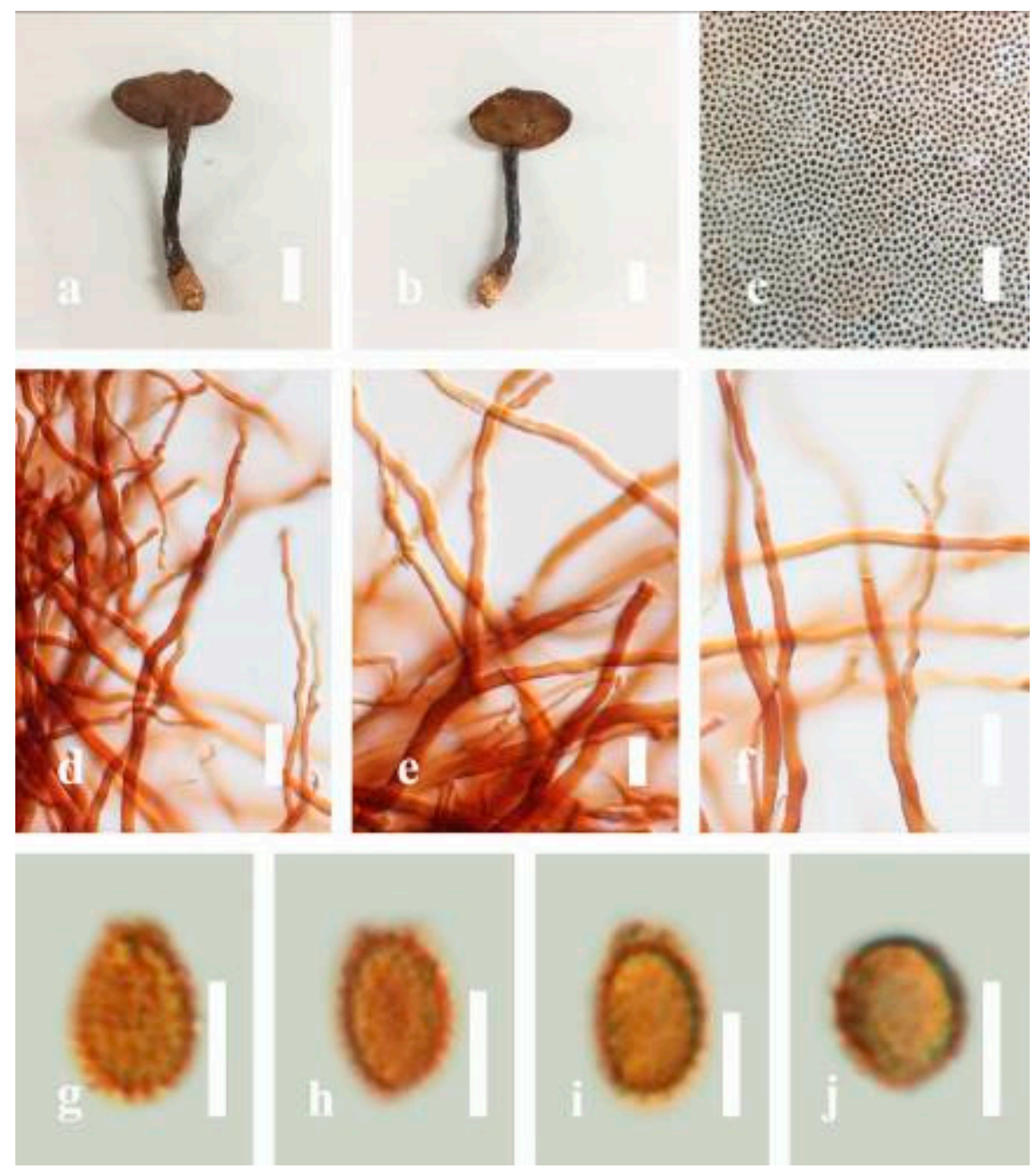

Figure 31. Morphology of Ganoderma sinense (MFLU 19-2172): (a,b) mature basidiomes; (c) pore characteristics; $(\mathbf{d}-\mathbf{f})$ generative skeletal and binding hyphae of context in $\mathrm{KOH} ;(\mathbf{g}-\mathbf{j})$ basidiospores in KOH. Scale bars: $(\mathbf{a}, \mathbf{b})=2 \mathrm{~cm},(\mathbf{c})=1000 \mu \mathrm{m},(\mathbf{d}-\mathbf{f})=20 \mu \mathrm{m},(\mathbf{g}-\mathbf{j})=5 \mu \mathrm{m}$.

Ganoderma subresinosum (Murrill) C.J. Humphrey, Mycologia. 30 (3): 332 (1938) (Figure 32)

$\equiv$ Fomes subresinosus Murrill, Bulletin of the Torrey Botanical Club. 35: 410 (1908)

$\equiv$ Trachyderma subresinosum (Murrill) Imazeki, Bulletin of the Government Forest Experimental Station Meguro. 57: 119 (1952)

$\equiv$ Magoderna subresinosum (Murrill) Steyaert, Persoonia. 7(1): 112 (1973)

$\equiv$ Amauroderma subresinosum (Murrill) Corner, Beihefte zur Nova Hedwigia. 75: 93 (1983)

= Polyporus mamelliporus Beeli, Bulletin de la Société Royale de Botanique de Belgique. 62(1): 62 (1929)

Facesoffungi number: FoF 06259

Description: Basidiomes annual, subdimidiate, sessile. Pileus 6-13 cm in length, $4-10 \mathrm{~cm}$ in width, and $0.6-2 \mathrm{~cm}$ thick. Pileus stipitate, flabelliform, spathulate, umbonate, subdimidiate to dimidiate, single, concentrically sulcate zone, radial from center extending to the margin, tough when broken, often thicker at center, slightly soft at margin, and light in weight when dried. Pileus surface convex, glossy, shiny, usually frequently furrowed, shallow sulcate, mostly rugulose, spathulate, umbonate to uneven, laccate when mature, 
strongly laccate when old, concentrically sulcate with irregularly ruptured crust overlying the context, hard from mature to old, and woody or corky texture when old. Pileus color usually dark brown (9F7-9F8) from center to the margin. Context up to $0.3-1 \mathrm{~cm}$ thick near the base, dry, upper layers grayish-orange (5B6) when fresh, lower layers grayish-orange (5B5), dark brown (8F7) when dried, covered with crust, woody when dried, trimitic hyphae, hyaline, walls varying in thickness, with simple septa, with branches. Tube 0.4-1.2 cm in length, brown (7D8). Stipe almost sessile, blunt, broadly attached, and thick at base, irregularly ruptured crust overlying, and usually strongly laccate with brown dark brown (9F7) from mature to old. Margin strongly laccate and dark brown (9F7) when mature to old. Pore 4-5 in number per mm, subcircular to circular. Pore surface pale yellow (4A3) to pale orange (5A3), turns dark brown (6F7) when scratched or bruised.
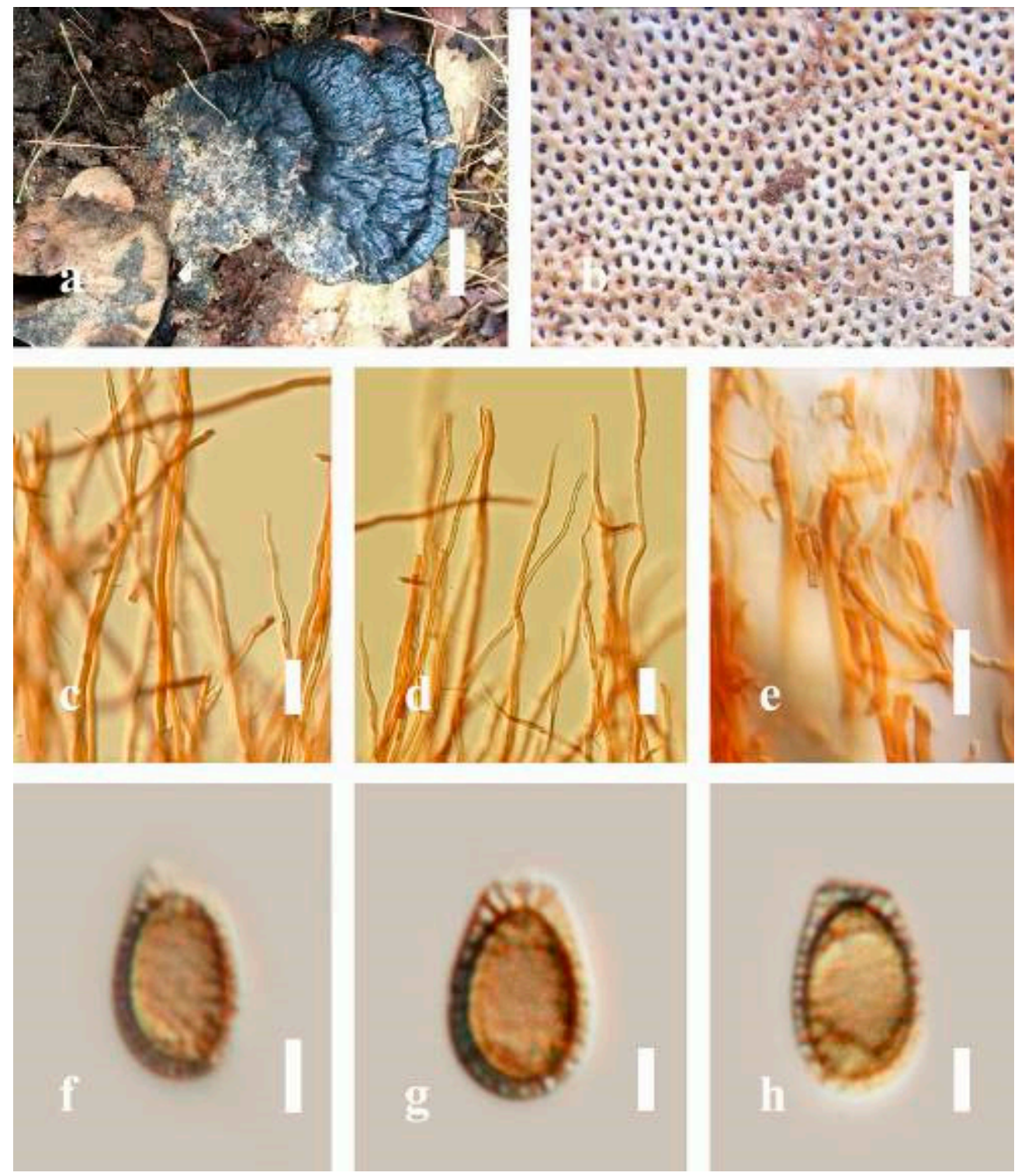

Figure 32. Morphology of Ganoderma subresinosum (MFLU 17-1912): (a) mature basidiomes; (b) pore characteristics; (c-e) generative hyphae of context in $\mathrm{KOH} ;(\mathbf{f}-\mathbf{h})$ basidiospores in $\mathrm{KOH}$. Scale bars: $(\mathbf{a})=2 \mathrm{~cm},(\mathbf{b})=1000 \mu \mathrm{m},(\mathbf{c}-\mathbf{e})=20 \mu \mathrm{m},(\mathbf{f}-\mathbf{h})=5 \mu \mathrm{m}$.

Hyphal structure: Hyphal system di-trimitic, with clamp connections, usually light yellow (3A5) to grayish-yellow (3B5), pale yellow (4A5), light orange (5A5) to orange (5B8) in $\mathrm{KOH}$; generative hyphae 1.0-2.1 $\mathrm{m}$ broad $(n=30)$, thin-walled, hyaline, with clamp connections; skeletal hyphae $2.8-5.2 \mu \mathrm{m}$ broad $(n=30)$, usually unbranched or few branches, 
and thick-walled; binding hyphae $2.5-5.0 \mu \mathrm{m}$ width $(n=30)$, walls varying in thickness, many branches, some hymenial with sword-like apices in the context. Pileipellis a hymeniderm, light orange (5A5), clavate-like cells, dextrinoid. Basidiospores mostly ellipsoid to broadly ellipsoid, double walls, (11.6-)12.1-13.5-14.5(-15.8) $\times(8.1-) 8.9-11.3-11.9(-12.5) \mu \mathrm{m}$ $(\bar{x}=13.2 \times 11.4 \mu \mathrm{m}, n=50) \mu \mathrm{m}$, with $\mathrm{Q}=1.12-1.19, \mathrm{~L}=13.24 \mu \mathrm{m}, \mathrm{W}=11.44 \mu \mathrm{m}$ (including myxosporium), (10.2-)10.9-12.8-13.7(-14.6) × (6.8-)7.9-8.9-9.6(-10.2) $\mu \mathrm{m}(\bar{x}=12.6 \times 8.8 \mu \mathrm{m}$, $n=50) \mu \mathrm{m}$, with $\mathrm{Q}=1.41-1.46, \mathrm{~L}=12.63 \mu \mathrm{m}, \mathrm{W}=8.84 \mu \mathrm{m}$ (excluding outer myxosporium), overlaid by hyaline, apically and echinulate, truncate, inner wall usually orange (6A7-6A8) to reddish-golden (6C7) in $\mathrm{KOH}$, brownish-orange (5C5-5C6) in Melzer's reagent, outer wall usually reddish-orange (7A8, 7B8) in 5\% $\mathrm{KOH}$ and brown (6D7-6D8) in Melzer's reagent.

Habitat: Solitary on the decaying hardwood of Peltophorum pterocarpum and Castanopsis sp.

Specimens examined: THAILAND, Chiang Rai Province, $20^{\circ} 15^{\prime} 03^{\prime \prime} \mathrm{N}, 100^{\circ} 14^{\prime} 17^{\prime \prime} \mathrm{E}$, 732 m elev., 9 October 2017, T. Luangharn, MFLU 17-1912.

Notes: Ganoderma subresinosum was introduced as Fomes subresinosus with the specimen from the Philippines [43]. Next, Humphrey [159] verified this fungus species to the genus Ganoderma, and then Imazeki [160] included this species in the genus Trachyderma. Ganoderma subresinosum is a species that is distributed worldwide, known from the Philippines to other Asian countries, and distributed across Eastern and Central Africa $[30,47,100,110]$. This fungus is distinctive in form with its laccate pileus, sessile, dark brown pileus surface, and concentrically sulcate with irregularly ruptured crust overlying the context, with ellipsoid to elongate basidiospores. Ganoderma subresinosum was regarded as a synonym of Trachyderma tsunodae Imazeki [160], Magoderna subresinosus [110], and Amauroderma subresinosum [113]. In China, this fungus was reported by Chinese researchers as Fomes subresinosum [132,161,162] and verified to A. subresinosum by Zhao [61] and Zhao and Zhang [13]. Recently, several studies have suggested that those three synonymous fungal species are different from G. subresinosum based on emergent morphological and molecular data $[163,164]$. However, this fungus name is in the Index Fungorum as G. subresinosum. So, in this study, we present the first record of G. subresinosum from Thailand.

Ganoderma thailandicum T. Luangharn, P.E. Mortimer, S.C. Karunarathna, and J.C. Xu, MycoKeys 59: 55 (2019)

Facesoffungi number: FoF 06129

Index Fungorum number: IF 556535

For characteristics, see Luangharn et al. [31].

Notes: Ganoderma thailandicum is characterized by its laccate, deep magenta close to stipe, brownish-red at center, and light yellow around active development toward the margin on pileal surface, white pore surface, brownish-red context, and absence of melanoid band.

Ganoderma tropicum (Jungh.) Bres., Annales Mycologici 8(6): 586 (1910)

三 Polyporus tropicus Jungh., Praemissa in floram cryptogamicam Javae insulae: 63 (1838)

$\equiv$ Fomes tropicus (Jungh.) Cooke, Grevillea. 14 (69): 19 (1885)

$\equiv$ Scindalma tropicum (Jungh.) Kuntze, Revisio generum plantarum. 3 (2): 519 (1898)

Facesoffungi number: FoF 05068

For characteristics, see Luangharn et al. [75].

Notes: Ganoderma tropicum was introduced as Polyporus tropicus by Junghuhn [165] with the specimen from Indonesia. Phylogenetic analysis has been well resolved with the aid of molecular data [5,129] and transferred this species to Ganoderma [166], where it is considered a member of the G. lucidum species complex [76,167]. The fungus is characterized by its distinctive reddish-brown pileal surface, dark brown context near the tubes, dense context layer, thick near the base, with strongly echinulate basidiospores. Its distribution is highly variable worldwide, scattered across tropical Asian regions, mainland China $[4,5,30]$, South 
America [137], and Taiwan, PRC [33], and it causes white root and butt rot on several tree species [8]. Furthermore, there are some similarities between G. tropicum and other Ganoderma species. According to Cao et al. [4], among the Chinese Ganoderma species, G. flexipes, G. multipileum, G. sichuanense, and G. tsugae are similar to G. tropicum, having a reddish-brown pileus surface, dark brown context, ellipsoid basidiospores, strongly echinulate basidiospores, and irregular cuticle cells. Our new record of G. tropicum from Northern Thailand was described based on characteristics together with phylogenetic analyses, the details of which are shown in Luangharn et al. [75].

Taxonomy of Ganoderma from Vietnam

Ganoderma hochiminhense Karunarathna, Mortimer, \& Luangharn, sp. nov. (Figure 33) Facesoffungi number: FoF 06334

Index Fungorum number: IF 556794

Diagnosis: Ganoderma hochiminhense is characterized by its strongly laccate appearance, with a reddish-brown color near the stipe, a deep orange to brownish-yellow at the center, a white that indicates active development on the margin of the pileal surface, a yellowish-white pore surface when fresh, an orange, deep orange to reddish-orange context, and absence of melanoid bands.

Holotype: Vietnam, Hochiminh City, on Areca sp. (as described by the seller), 12 June 2019, LT2019 Gano 305 (MFLU 19-2224) and LT2019 Gano 306 (MFLU 19-2225).

Etymology: The specific epithet "hochiminhense" refers to the place in Vietnam from where the holotype specimen was collected.

Description: Basidiomes sessile, orbicular. Pileus up to $0.8-2.2 \mathrm{~cm}$ in length, $0.5-1.4 \mathrm{~cm}$ width, and $1.3 \mathrm{~cm}$ thick at base. Pileus orbicular, undulated, tuberculate, sulcate, single or fused at the base, broadly attached, hard when dried. Pileus surface distinctively laccate when young, strongly laccate when mature or dried. Pileus color reddish-brown from the base, light to deep orange, golden yellow, brownish- to reddish-yellow at the center, with deep yellow to orange yellow at the margin of the upper surface, generally white where new hyphae are in active development, glossy, shiny, smooth, spathulate, sulcate when fresh, with a thin crust overlying the pileus, which is thicker at the base than at the margin, light weight when dried. Hymenophore mostly orange to brownishorange in $\mathrm{KOH}$, up to $0.8 \mathrm{~cm}$ thick, with a dense but not fully homogenous context layer, bearing distinct layers of concentric growth zones at the center that extend to the margins, thick near the base, non-corky or woody texture when dried, bearing a simple septum at base, tough to break when dried, melanoid bands absent. Context reddishorange in $\mathrm{KOH}$; generative hyphae up to $2.72-3.82 \mu \mathrm{m}(\bar{x}=3.54, n=50)$ in diam, almost colorless, thin-walled, some expanded at the apex, unbranched, with clamp connections; skeletal hyphae-dominant, up to 3.56-7.47 $\mu \mathrm{m}(\bar{x}=5.85, n=50)$, orange to brown, thickwalled, unbranched, without clamp connections; binding hyphae 3.23-5.96 $\mu \mathrm{m}(\bar{x}=4.32$, $n=50)$, almost colorless, walls varying in thickness, with some narrow lumen to subsolid, frequently branched, tortuous, and interwoven at the distal end. Tubes hard, brown, up to $0.2-0.5 \mathrm{~cm}$ long. Tubes layers generative hyphae $2.21-3.03 \mu \mathrm{m}$ in diam, pale brown to brown, thin-walled, some thick-walled, with clamp connections, unbranched; skeletal hyphae 3.23-6.15 $\mu \mathrm{m}$ in diam, distinctly brown, thick-walled, some narrow lumen to subsolid, frequently branched; binding hyphae 2.28-4.86 $\mu \mathrm{m}$ in diam, brownish-yellow, thick-walled to solid, and frequently branched. Stipe short stipe, laccate when developing to maturity, and strongly laccate from maturity to old age. Margin white when present to maturity, light brown to brown between the young to mature stages, turning light brown when dry, and silky, soft, and slippery to the touch between youth and maturity, usually bruising when touched and tough to break. Pore angular to round, 4-6 in number per mm, with dissepiments slightly thick to thick. Pore surface white when fresh, yellowish-white when dried, turns brown to dark brown when touched. 

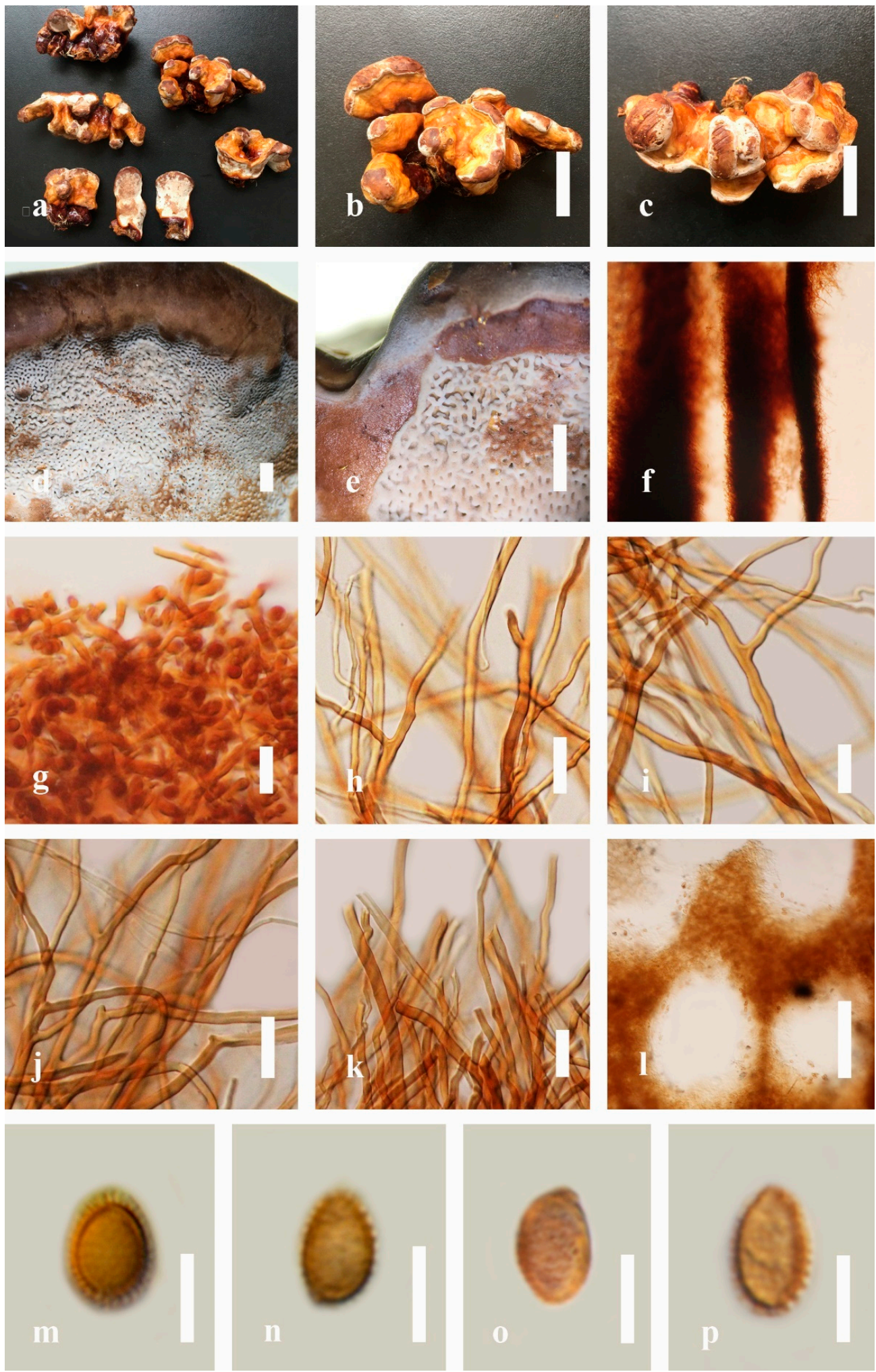

Figure 33. Characteristics of Ganoderma hochiminhense: (a) basidiomes of the strain MFLU 19-2224; (b) mature basidiomes of the strain MFLU 19-2224; (c) mature basidiomes of the strain MFLU 19-2225; (d,e) pores characteristics; (f) tube layers; (g) hyphae from tube layers; (h,i) hyphae from context in $\mathrm{KOH}$; (j) clamp connection from context; (k) hyphae from trama in $\mathrm{KOH}$; (l) pores characteristics; $(\mathbf{m}-\mathbf{p})$ basidiospores in $\mathrm{KOH}$. Scale bars: $(\mathbf{b}, \mathbf{c})=2 \mathrm{~cm},(\mathbf{d}, \mathbf{e})=1000 \mu \mathrm{m},(\mathbf{g}-\mathbf{k})=20 \mu \mathrm{m}, \mathrm{L}=150 \mu \mathrm{m}$, $(\mathbf{m}-\mathbf{p})=5 \mu \mathrm{m}$. 
Hyphal structure: Hyphal system trimitic, with tissues yellow, light orange to orange and brown in $\mathrm{KOH}$; generative hyphae up to $2.70-3.25 \mu \mathrm{m}(\bar{x}=3.09, n=50)$ in diam, almost colorless, thin-walled, unbranched, with clamp connections, some slightly swollen at the distal end; skeletal hyphae-dominant, up to $3.49-7.67 \mu \mathrm{m}$ broad $(\bar{x}=5.98$, $n=50$ ), pale brown to distinctly brown, thick-walled, unbranched, without clamp connections, occasionally with narrow lumen, some subsolid, interwoven; binding hyphae $3.12-5.87 \mu \mathrm{m}$ broad $(\bar{x}=4.28, n=50)$, grayish-orange, walls varying in thickness, frequently branched, tortuous, and interwoven in the distal end. Basidia clavate, 4-sterigmatic, $10.2-14.3 \times 8.6-12.5 \mu \mathrm{m}$, yellowish to pale brown in $\mathrm{KOH}$. Basidiospores ellipsoid, sometimes broadly ellipsoid or almond-shaped at maturity, reddish-yellowish, light brown to brownish-orange, slightly truncate, double walls, exospore smooth, endospore with coarse echinulate, (6.8)8.5-10.4(11.8) × (5.8)6.9-9.3(10.2) $\mu \mathrm{m}(\bar{x}=9.4 \times 8.8 \mu \mathrm{m}, n=50)$, with $\mathrm{Q}$ $=1.02-1.14, \mathrm{~L}=9.38 \mu \mathrm{m}, \mathrm{W}=8.82 \mu \mathrm{m}$ (including myxosporium), (6.6)7.9-9.4(10.9) $\times$ (5.4)6.3-8.5(9.3) $\mu \mathrm{m}(\bar{x}=9.0 \times 7.7 \mu \mathrm{m}, n=50) \mu \mathrm{m}$, with $\mathrm{Q}=1.08-1.21, \mathrm{~L}=8.98 \mu \mathrm{m}, \mathrm{W}=7.73$ $\mu \mathrm{m}$ (excluding outer myxosporium), strongly echinulate, cuticle cells irregular. Culture characteristics white active mycelium on PDA, reaching $8 \mathrm{~cm}$ diam after 14 days at $25^{\circ} \mathrm{C}$.

Habitat: solitary, on Areca spp. stumps.

Specimens examined: VIETNAM, Hochiminh City local market, $8^{\circ} 54^{\prime} 32^{\prime \prime} \mathrm{N}, 98^{\circ} 31^{\prime} 09^{\prime \prime} \mathrm{E}$, 427 m elev., 12 June 2019, S.C. Karunarathna, LT2019 Gano 305 (MFLU 19-2224, holotype) and LT2019 Gano 306 (MFLU 19-2225, paratype).

\section{Discussion and Conclusions}

The present study demonstrates the nomenclatural status, characteristics, phylogenetic analysis, host preference, growing season, climate, and substrate details of Ganoderma species from the GMS. Detailed characteristics and molecular analyses allow us to define the Ganoderma species used in our study as a distinctive well-supported clade, within Ganoderma, with new insights to resolve species delimitation. Altogether, this study describes a total of six new records and two new species of Ganoderma comprising two new records (G. hoehnelianum and G. williamsianum) as well as a new species (G. myanmarense) from Myanmar, four new records (G. ellipsoideum, G. multipileum, G. philippii, G. subresinosum) from Thailand, and one new species (G. hochiminhense) from Vietnam.

Ganoderma orbiforme specimens were collected from living Albizia mollis and Indochinese spp. in a deciduous forest from Thailand. These G. orbiforme specimens from the Thailand group in the non-laccate Ganoderma clade with G. orbiforme from Laos [30] and China [37]. The Thai G. orbiforme shares similar features as mentioned by Hapuarachchi et al. [30] and Wang et al. [156], such as possessing an annual to perennial, flabelliform or applanate pileus, with a weakly laccate surface, the presence of several thick layers, an undulate margin, and subcircular or circular pores. The pileus size of the Thai collection of G. orbiforme $(4-11 \times 3-6 \mathrm{~cm})$ is within the range of Asian collections $(3.5-21 \times 2.5-12 \mathrm{~cm})$ [63] but exceeds the Chinese collection $(3-8 \times 2.5-6 \mathrm{~cm})$ [88]. These findings are consistent with Ryvarden [136], who demonstrated that G. orbiforme are widely distributed in tropical and temperate regions. The present study also reports an additional record of G. orbiforme from a tropical region in Thailand.

Three G. sinense were collected from decaying as well as living Albizia mollis (Wall.) Boiv. and Quercus spp. in temperate Yunnan Province, China, and two collections were gathered from living Dendrocalamus strictus (Roxb.) Nees. and Dipterocarpus spp. in tropical Thailand. The present collections of $G$. sinense grouped together as a sister taxon to the G. nasalaense from Laos. Ganoderma sinense is regarded as having a high degree of phenotypic plasticity and genetic diversity and was associated with substantial intraspecific morphological variation $[88,167]$. When considering the morphological differences between these, the Chinese G. sinense has a smaller-sized pileus $(2-6 \times 2-4 \mathrm{~cm})$ and brownishorange context, while the Thai $G$. sinense has a larger-sized pileus $(4-10 \times 6-12 \mathrm{~cm})$ with a brown to dark brown context. However, the Chinese and Thai G. sinense also share some characteristics, such as having stipitate, subdimidiate to dimidiate basidiocarps 
with a laccate radial pileus that extends from the center to the margin, a colored dark brown, cylindrical stipe, and basidiospores measuring 8.5-11.8 $\times 7.2-10.6 \mu \mathrm{m}$. The current findings of $G$. sinense are in agreement with Hapuarachchi et al. [88], who demonstrated morphological variations across G. sinense collected from Hainan and Guizhou Provinces, China. In this study, G. sinense from Yunnan Province, China, and Thailand were also recorded.

Ganoderma tropicum was introduced by Luangharn et al. [75] based on the collection made from northern Thailand. In this study, phylogenetic analysis demonstrated that this fungus served as the sister clade to G. multipileum, G. parvulum, and G. destructans, and the Thai G. tropicum also grouped together with the Chinese G. tropicum, forming a sister clade with G. multiplicatum and G. philippii.

The present study describes a new species, G. hochiminhense (MFLU 19-2224 and MFLU 19-2225), from Vietnam. Phylogenetic analyses revealed G. hochiminhense collections grouped as sister taxa to the laccate Ganoderma clade, and morphological characteristics and molecular analyses provided insights to resolve species delimitation. Ganoderma hochiminhense grouped together as a distinct clade with 100\% ML, 98\% MP, and $0.99 \mathrm{PP}$ support. Ganoderma hochiminhense forms a sister clade with G. zonatum from the U.S. [76], the holotype G. ryvardenii from Cameroon [98], and the holotype G. angustisporum from Africa [37]. However, G. hochiminhense, G. zonatum, and G. ryvardenii share similarities and are sessile, laccate to strongly laccate on the upper pileus surface, and ellipsoid to broadly ellipsoid with truncated apices basidiospores at maturity [76,98].

Although in the present phylogenetic tree G. hochiminhense clustered with G. zonatum and G. ryvardenii, their macro- and micro-characteristics differ. Ganoderma hochiminhense can be easily distinguished from $G$. zonatum by the size range of its small fruiting bodies $(0.8-2.2 \times 0.5-1.4 \mathrm{~cm}$ diam), single or fused fruiting bodies on hosts, orbicular when present, undulated pileus, reddish-brown at base, deep orange, golden yellow, reddishyellow at its center from maturity to old age, deep yellow and orange yellow on the margin, white pore, reddish-orange context, $(6.6-11.8 \times 5.4-10.2 \mu \mathrm{m})$ basidiospore size range, while the fruiting bodies of $G$. zonatum are brown on the upper pileus surface, have cream pores, are finely echinulated, $(9.4-8.8 \times 9.0-7.7)$ basidiospore size range. Ganoderma ryvardenii differs from $G$. hochiminhense by its large pileus size range $(13 \times 8.5 \mathrm{~cm})$, annual, dimidiate, or circular pileus, reddish margin, dark brown context, and basidiospore size range $(9.0-14.0 \times 4-8 \mu \mathrm{m})$. Ganoderma zonatum was regarded as a species distributed in subtropical to tropical climates $[57,136,168]$, and our G. hochiminhense was also collected from a tropical region. Consequently, we propose that taxa in this clade comprise species isolated from tropical regions. This study confirmed that the new G. hochiminhense was collected on Areca spp. stumps in tropical Vietnam. Considering overall morphology, G. hochiminhense appears to be similar to G. boninense Pat. However, G. boninense is readily distinguished from $G$. hochiminhense by its thicker and broader basidiocarp, reddish bay pileus with reddish-brown pores, and differently sized basidiospores 10-12 $\times 7-8 \mu \mathrm{m}$ in G. boninense vs. 6.8-11.8 × 5.8-10.2 $\mu \mathrm{m}$ (including myxosporium), 6.6-10.9 × 5.4-9.3 $\mu \mathrm{m}$ (excluding outer myxosporium) in G. hochiminhense [41].

For detailed characteristics and phylogenetic analyses of G. casuarinicola, G. thailandicum, and G. enigmaticum, see Xing et al. [37] and Luangharn et al. [31]. In the present study, G. calidophilum collected from China formed a sister clade with the above three Ganoderma species, and the clade is distinguished with suitable statistical support values. Although G. calidophilum is sister to the laccate clade, its macro-characteristics are very distinctive, such as a stipitate, subdimidiate to dimidiate pileus, homogenous brownish-red, reddish-brown at the center, brownish-orange toward the stipe, light brown at the margin from maturity to old age, brownish-orange context, and cylindrical stipe.

Ganoderma williamsianum was collected from tropical Myanmar, and the phylogenetic analysis grouped the present collection with $G$. williamsianum collected from Thailand [37]. Both G. williamsianum strains grouped as sister taxa to the holotype G. mbrekobenum from Ghana [90], with low support. The description of our collected G. williamsianum 
is distinctive, having characteristics such as small fruiting bodies with a size range of $0.5-1.5 \times 0.5-1 \mathrm{~cm}$, rarely with a stipe-like base, subflabellate to circular fruiting bodies, smooth and soft, weakly laccate, and homogenous orange to deep orange context, though the basidiospore could not be observed. The current study allows for comparison between G. williamsianum and G. mbrekobenum. G. mbrekobenum is macro-micro morphologically very different from G. williamsianum, with its distinctive dimidiate, lateral stipe, dimitic hyphal system, with ovoid to broadly ellipsoid basidiospore [90]. Xing et al. [37] also reported the collection of $G$. williamsianum from Thailand with providing a phylogenic analysis of their specimens but failing to provide any morphological descriptions. Ganoderma williamsianum has been reported as a species distributed across China [154], Indonesia [110,155], Malaysia [110], and the Philippines [110,169]. Here, this study introduces a new record of G. williamsianum from Myanmar.

Ganoderma adspersum was collected near the root of the living tree Mangifera indica L. in Laos, while the Thai G. adspersum strain was collected from the decaying hardwood of Pterocarpus spp. Macro-characteristics of our collected G. adspersum share features with what has already been described by Moncalvo et al. [45], such as having a nonlaccate, sessile, perennial, subdimidiate to dimidiate pileus, a sulcate, brown pileus surface and context, and a yellowish-white pore surface, with a similar basidiospore size range (6.9-10.6 × 4.7-7.8). However, some characteristics are also quite different, as the G. adspersum from Laos is mostly ellipsoid to broadly ellipsoid, with brownish-orange inner walls of basidiospores, while the Thai G. adspersum is mostly ellipsoid, with brownish-yellow inner walls and brown to dark brown outer walls. It was observed that our Thai G. adspersum had a di-trimitric hyphal system, while Hapuarachchi et al. [30] reported that their Thai G. adspersum was composed of a trimitic hyphal system. This fungus is frequently reported in temperate and tropical climates [45,152], where it grows on many hardwood tree species [152,170]. Ganoderma adspersum has been reported in Europe [171], India [150], Korea [92], Italy [172], Myanmar, and Thailand [30]. In this study, additional specimens of G. adspersum from Laos and Thailand are presented for use in updated descriptions of this species using detailed morphological observations and phylogenetic studies.

This study introduces a new record of G. ellipsoideum, collected from Chiang Mai Province, Thailand, growing on rotten wood. The newly collected G. ellipsoideum serves as the sister group to $\mathrm{G}$. adspersum ( $\mathrm{ML}=97 \%, \mathrm{MP}=96 \%, \mathrm{PP}=0.95$ ). It is also correlative to the results by Hapuarachchi et al. [88]. Our collection from Thailand allows us to conduct comparisons with the holotypes of G. ellipsoideum from Hainan Province, China. The current G. ellipsoideum specimen shares similarities with the holotype collection in its annual, sessile, several-layers-thick circular or subcircular pores, and presence of ellipsoid basidiospores. However, the Chinese holotype of G. ellipsoideum presents quite a different basidiospore size range (6.1-7.3 $\times 3.7-4.6 \mu \mathrm{m})$, including myxosporium, while the Thai G. ellipsoideum was $(4.8-7.7 \times 3.1-5.4 \mu \mathrm{m})$ including myxosporium. The Chinese G. ellipsoideum was initially yellowish-white, later having a yellowish-brown to brownish-yellow pore surface, while Thai G. ellipsoideum presented white (11A1) to pale yellow (2A3) coloration. G. ellipsoideum also serves as the sister group to the G. gibbosum and G. austral clade. Our G. gibbosum collections were collected from China, Laos, and Thailand. G. gibbosum macro- and microcharacteristics are quite different. For variations in G. gibbosum, see Luangharn et al. [173], while G. australe from Thailand has been described in Luangharn et al. [5].

Ganoderma multipileum was collected from Thailand after the rainy season. Phylogenetic analysis showed our G. multipileum specimen matched closely within the clade to G. multipileum (CWN 04670) from Taiwan. Our collection was grouped as a sister to G. steyaertianum B. J. Smith and Sivasith, G. mizoramense Zothanzama, Blanchette, Held, C.W., Barnes, G. martinicense Welti and Courtec, and G. destructans M.P.A. Coetzee, Marinc. and M.J. Wingf. These Ganoderma species, including G. steyaertianum, G. mizoramense, G. martinicense, G. destructans, and G. multipileum, share similarities in that they have a laccate to strongly laccate upper pileus surface at maturity. Although G. steyaertianum can be easily distinguished from G. multipileum by its distinctive kidney-shaped basiodomata 
with a dark brown pileus surface, this species is also similar to G. multipileum in that its basiodomata rarely extend completely to the margin [128]. Ganoderma mizoramense can be differentiated from G. multipileum by its reddish-brown when fresh to liver-brown when dry upper pileus surface, dark-brownish to dark-reddish brown context, and lower surface white when fresh [94]. Ganoderma martinicense can be differentiated from G. multipileum by its generally sessile basidiomata and dark-cinnamon-brown context [35], while our G. multipileum specimen rarely displayed sessile basidiomata and had a light brown to brown context; however, phylogenetic analysis revealed G. martinicense as a close relative to the Asian taxon G. multipileum [35,93]. G. destructans is significantly different, with its pileus containing a creamy and soft context and presenting mostly ovoid basidiospores [9].

Ganoderma philippii was collected in tropical Chiang Mai Province, Thailand. Phylogenetic analysis reveals it to be close to Malaysian G. philippii strains [97]. Ganoderma philippii is a unique species that grows especially actively in heavy soils with high water content [111]. Macro- and micro-characteristics were also correlative to results by Singh et al. [26], who reported this fungus as easily identifiable by its non-laccate pileus surface and sessile basidiome mostly presenting oblong basidiospores. Ganoderma philippii formed a sister clade to G. multiplicatum and G. tropicum. G. philippii are very different, with their distinctive non-laccate, often convex, umbonate, and plump pileus and sessile, with mostly oblong basidiospores, while G. multiplicatum is laccate to strongly laccate, radial or branched from the center, extending to the margin, and presenting mostly as ellipsoid basidiospores [33]. G. tropicum was collected from Thailand; although it closed a sister clade with G. multiplicatum, its macro- and micro-characteristics are noticeably different and were detailed by Luangharn et al. [31].

In this study, our G. sichuanense specimens were collected in the temperate climate zone of Yunnan Province, China, and a tropical part of Thailand. Phylogenetic analysis placed our collections as sister taxa to the laccate Ganoderma clade and close to the previously reported G. sichuanense from China [99]. Our collections also share macro- and micro-characteristics similar to the holotype described of G. lingzhi [4], with their shelllike, reniform to circular pileus, reddish-brown pileal surface, strongly laccate, stipitate, and mostly present ellipsoid basidiospores that truncate at maturity; however, G. lingzhi was verified to G. sichunense in the records of Index Fungorum. Among the Chinese Ganoderma species, G. flexipes, G. multipileum, G. sichuanense, G. tropicum, and G. tsugae are the species that most closely resemble G. sichuanense, as their macro- and micro-characteristics share a reddish-brown pileal surface, similar basidiospores, and cuticle cells. Nevertheless, differences between these Ganoderma species have been detailed in Dai et al. [34] and Yao et al. [174].

Ganoderma resinaceum has long been reported in temperate climates [38,76], and our collection is also from a temperate part of Yunnan Province, China. Our Chinese G. resinaceum is close to the G. resinaceum collected in England and the Netherlands, with suitable clade support. Our result is also similar to the phylogenetic analysis by Douanla-Meli and Langer [46]. However, G. resinaceum from England and the Netherlands lacks macro-micro descriptions. Moreover, G. resinaceum collections have also been reported from India [143], although the macro- and micro-characteristics of these Indian specimens differ from our Yunnan collections. The Yunnan strain of G. resinaceum is distinctive with its short stipe, varying reddish-brown upper pileus surface, grayish-yellow to dark brown context covered by an irregularly ruptured thin crust, and larger pileus size range $(1.5-12.5 \times 1-7 \mathrm{~cm})$, while the Indian strain is stipitate, with a brown upper pileus surface, round margin, light brown context, and smaller pileus size range $(8-9 \times 6-7.5 \mathrm{~cm})$ [143]. Therefore, we conclude that despite phylogenetic similarities placing the various specimens, from temperate and tropical regions, of $G$. resinaceum in the same clade, there remains a high degree of morphological variance within this species $[38,46,76,143]$.

We introduce G. hoehnelianum as a new record from Myanmar. This mushroom was collected on the decaying stump of an unidentified dicotyledonous tree species in tropical Myanmar. The phylogeny of our G. hoehnelianum specimen is close to the Chinese 
G. hoehnelianum collection [91] and is well supported. Our collection shares similar macroand micro-characteristics to Wang and Wu [154] and Hapuarachchi et al. [88], with its distinctive annual, sessile, plano concave, dark brown upper pileus surface and context, and concentrically sulcate zones with broadly ovoid basidiospores. Our G. hoehnelianum grouped with the G. austroafricanum H. Xing, B.K. Cui, and Y.C. Dai and G. carocalcareum Douanla-Meli clade. G. austroafricanum is distinctive from G. hoehnelianum, with its reddishbrown pileus surface, smooth surface, round margin, with subglobose basidiospores. Ganoderma carocalcareum collected from a tropical region in Cameroon is distinctive from G. hoehnelianum, with its friable context, and thick toward the margin and downwards to the pore margin (part of hymenophore), red-brown to brown-orange margin, and forming a concentrical aporoid zone [46].

Ganoderma applanatum was collected from temperate China and tropical Thailand. Phylogenetic analysis shows our G. applanatum clustering as a distinctive group with suitable support. The name G. lipsiense has been treated and corrected to G. applanatum [15], and it is mentioned that G. applanatum also belongs to this complex species. Macroand micro-characteristics of our collections are similar to those described in detail in Ryvarden and Gilbertson [105]. Our Chinese and Thai G. applanatum collections have quite different macro-characteristics. The Chinese G. applanatum shows a smaller pileus size range $(1.5-5.8 \times 0.5-4.5 \mathrm{~cm})$ and is up to $1.5 \mathrm{~cm}$ thick at the base, while the Thai G. applanatum was $2-12 \times 2.5-6 \mathrm{~cm}$ and $0.8-3.1 \mathrm{~cm}$ thick at the base. The Chinese G. applanatum is distinctive and non-laccate, faded from maturity to old age, while Thai G. applanatum had differentiated zones of peach red and reddish-orange at the base, brownish-orange with the radius, light brown at the center, and extending to dark brown close to active mycelium (margin). Our results are also correlative to Wang et al. [5], who has reported on the high morphological variation within Chinese Ganoderma. Ganoderma species from different geographic areas have also shown separate lineages in phylogenetic analyses [38,153].

In this study, we describe a new Ganoderma species, G. myanmarense, collected in tropical Myanmar. The two G. myanmarense collections grouped as sister taxa to the laccate Ganoderma clade, and their characteristics and molecular analyses provided insights to resolve species delimitation. This new species, G. myanmarense, forms a sister clade with G. wiiroense E.C. Otto, Blanchette, C.W. Barnes and Held. from Ghana, G. destructans M.P.A. Coetzee, Marinc, M.J. Wingf. from South Africa, and our G. flexipes from China. Ganoderma wiiroense has an annual, dimidiate pileus; sessile, yellowish-brown to dark-reddish-brown basidiocarps [101], while our G. myanmarense has its distinctive sectorial to shell-shaped, sub-reniform to reniform pileus; golden yellow, yellowish-red at center, slightly reddishorange and reddish-brown (8E8) basidiocarps. Ganoderma destructans has its distinctive globular pileus, with creamy soft non-poroid tissues [9], and G. flexipes is very different from G. myanmarense by having sub-reniform to reniform pileus, small pileus size range $(0.5-3.2 \times 0.5-3 \mathrm{~cm})$, homogenous reddish-brown to dark brown upper pileus surface, and sub-cylindrical to the cylindrical stipe.

Our G. lucidum collections came from both China and Thailand. Phylogenetic analysis showed our strains clustered with G. lucidum from France, with suitable statistical support. The results indicated that our G. lucidum grouped as sister taxa to the laccate G. leucocontextum from China. G. lucidum has a high degree of morphological variability, often resulting in taxonomic and phylogenetic confusion [38]. However, our Chinese and Thai G. lucidum specimens displayed a degree of morphological variability. The Chinese G. lucidum possessed a cylindrical stipe, and when viewed from above, one can observe the presence of a central stipe at the center of the pileus, while the Thai G. lucidum presented a cylindrical and eccentric stipe. However, both strains also shared key features, with their distinctive stipitate, furrowed, incised, undulate to sulcate, undefined imbricate, yellowish-red, brownish-red to reddish-orange with laccate upper pileus surface, light brown to dark brown context, and presence of dark brown melanoid bands. Our results are also in agreement with those of Wang et al. [5], who reported that Chinese G. lucidum has a deeper-colored context that is even darker near the tube layer. Although both G. lucidum 
and G. leucocontextum form a sister clade, their morphological characteristics are different. Ganoderma leucocontextum shows its distinctive white context, thickset stipe, and broadly ellipsoid basidiospores (9.5-12.5 × 7-9 $\mu \mathrm{m})$. For descriptive details, please see Li et al. [62].

Ganoderma tsugae is one of the Ganoderma species that share similar characteristics with G. lucidum [4]. In this study, we collected G. tsugae from Yunnan Province, China. In the phylogenetic analysis, it clustered with G. tsugae from the USA [76] and grouped as a sister to G. oregonense [76,175]. However, G. tsugae has smaller basidiospores $(9-11 \times 6-8 \mu \mathrm{m})$ [176] than G. oregonense $(13-17 \times 8-10 \mu \mathrm{m})$ [109].

In this study, we introduce a new record of G. subresinosum collected in Thailand during the rainy season. Phylogenetic analysis indicated our G. subresinosum to be a distinct clade with suitable support. Macro- and micro-characteristics of G. subresinosum are similar to Hapuarachchi et al. [30], who demonstrated that this fungal species has a distinctively annual, sessile, laccate, dark brown upper pileus surface, concentrically sulcate, irregularly grayish-orange when dried and woody when old, presenting ellipsoid to elongate basidiospores.

Based on comprehensive characteristics and molecular analyses, we report 23 Ganoderma species from GMS, including G. adspersum, G. applanatum, G. australe, G. calidophilum, G. ellipsoideum, G. flexipes, G. gibbosum, G. heohnelianum, G. hochiminhense, G. leucocontextum, G. lucidum, G. multiplicatum, G. multipileum, G. myanmarense, G. orbiforme, G. philippii, G. resinaceum, G. sichuanense, G. sinense, G. subresinosum, G. williamsianum, G. tropicum, and G. tsugae, of which 13 Ganoderma species were collected from Yunnan Province, China, 3 species from Laos, three species from Myanmar, and 12 species from Thailand, including G. hochiminhense from Vietnam and G. myanmarense from Myanmar. We noted a high degree of intraspecies morphological variability between specimens collected from different parts of this region, confirming why it is hard to correctly identify Ganoderma to the species level using only morphological observations and why phylogenetic analyses are crucial in maintaining correct taxonomic placement within this group.

Supplementary Materials: The following are available online at https: / www.mdpi.com/article / 10.3390/jof7100819/s1, Figure S1: Collection sites of specimens used in this study in China, Laos, Myan-mar, Thailand, and Vietnam. Black triangles indicate collection locations for the specimens; Table S1: The extant Ganoderma species in the GMS.

Author Contributions: Conceptualization, T.L., S.C.K., P.E.M., I.P. and J.X.; methodology, T.L., S.C.K., A.K.D. and P.E.M.; formal analysis, T.L., S.P. and S.C.K.; investigation, T.L. and S.C.K.; data curation, T.L., S.C.K., A.K.D., T.L. and S.P.; writing-original draft preparation, T.L.; writing-review and editing, J.X., K.D.H., S.C.K. and P.E.M.; visualization, P.E.M.; supervision, J.X. and P.E.M.; S.C.K.; project administration, J.X. and P.E.M.; funding acquisition, J.X. and P.E.M. All authors have read and agreed to the published version of the manuscript.

Funding: This work was supported by the National Science Foundation of China (NSFC) (grant number Y71L481211), the CAS President's International Fellowship Initiative (PIFI) young staff under (grant number 2020FYC0002), the National Science Foundation of China (NSFC) (grant number 31851110759), and the Thailand Science Research and Innovation (TSRI) grant "Macro fungi diversity research from the Lancang-Mekong Watershed and surrounding areas" (grant number DBG6280009).

Acknowledgments: We appreciate the kind support given by the University of Chinese Academy of Sciences, Beijing 100049, China; Centre for Mountain Futures (CMF), Kunming Institute of Botany, Kunming 650201, Yunnan, China and Center of Excellence in Fungal Research, Mae Fah Luang University, Chiang Rai, Thailand. This research work was partially supported by Chiang Mai University. Cin Khan Lian at Ar Yone Oo social development association, Yangon, Myanmar, is thanked for his help on field work. We thank the Germplasm Bank of Wild Species, Kunming Institute of Botany, Kunming 650201, Yunnan, China, for enabling our molecular laboratory work. Kasiphat Limsakul, Wilawan Punyaboon, Thilina Sudarshana Nimalrathna and Deping Wei are acknowledged for their invaluable assistance. We acknowledge the Kunming Institute of Botany, the Chinese Academy of Sciences, for providing the laboratories and instruments for molecular work. Shaun Pennycook is thanked for help in naming the new fungal species. 
Conflicts of Interest: The authors declare no conflict of interest.

\section{References}

1. Karsten, P. Enumeratio Boletinearum et Polyporearum Fennicarum, systemate novo dispositarum. Rev. Mycol. Toulouse 1881, 3, $16-19$.

2. Moncalvo, J.M.; Ryvarden, L. A nomenclatural study of the Ganodermataceae Donk. Fungi Flora 1997, 10, 1-114.

3. Pilotti, C.A. Stem rots of oil palm caused by Ganoderma boninense: Pathogen biology and epidemiology. Mycopathologia 2005, 159, 129-137. [CrossRef] [PubMed]

4. Cao, Y.; Wu, S.H.; Dai, Y.C. Species clarification of the prize medicinal Ganoderma mushroom "Lingzhi". Fungal Divers. 2012, 56, 49-62. [CrossRef]

5. Wang, X.C.; Xi, R.J.; Li, Y.; Wang, D.M.; Yao, Y.J. The species identity of the widely cultivated Ganoderma, "G. lucidum" (Lingzhi), in China. PLOS ONE 2012, 7, e40857.

6. Cao, Y.; Yuan, H.S. Ganoderma mutabile sp. nov. from southwestern China based on morphological and molecular data. Mycol. Prog. 2013, 12, 121-126. [CrossRef]

7. Ryvarden, L. Neotropical Polypores Part 1, Synopsis Fungorum; Fungi Flora: Oslo, Norway, 2004; pp. 1-227.

8. Dai, Y.C.; Cui, B.K.; Yuan, H.S.; Li, B.D. Pathogenic wood-decaying fungi in China. For. Pathol. 2007, 37, 105-120. [CrossRef]

9. Coetzee, M.P.A.; Marincowitz, S.; Muthelo, V.G.; Wingfield, M.J. Ganoderma species, including new taxa associated with root rot of the iconic Jacaranda mimosifolia in Pretoria, South Africa. IMA Fungus 2015, 6, 249-256. [CrossRef]

10. Kirk, P.M.; Cannon, P.F.; Minter, D.W.; Stalpers, J.A. Dictionary of the Fungi, 10th ed.; CAB International: Wallingford, UK, 2008; p. 272.

11. Index Fungorum. Available online: http://www.indexfungorum.org (accessed on 5 May 2021).

12. MycoBank. Available online: http:/ / www.mycobank.org (accessed on 5 May 2021).

13. Zhao, J.D.; Zhang, X.Q. Flora Fungorum Sinicorum. Ganodermataceae; Science Press: Beijing, China, 2000; Volume 8, pp. 1-204.

14. Smith, B.J.; Sivasithamparam, K. Internal transcribed spacer ribosomal DNA sequence of five species of Ganoderma from Australia. Mycol. Res. 2000, 104, 943-951. [CrossRef]

15. Richter, C.; Wittstein, K.; Kirk, P.M.; Stadler, M. An assessment of the taxonomy and chemotaxonomy of Ganoderma. Fungal Divers. 2015, 71, 1-15. [CrossRef]

16. Wu, X.L.; Mao, X.L.; Tuli, G.E.; Song, B.; Li, T.H. Medicinal Fungi of China; Science Press: Beijing, China, 2013 ; p. 375.

17. Szedlay, G. Is the widely used medicinal fungus the Ganoderma lucidum (fr.) Karst. sensu stricto? Acta Microbiol. Immunol. Hung. 2002, 49, 235-243. [CrossRef] [PubMed]

18. Ahmadi, K.; Riazipour, M. Effect of Ganoderma lucidum on cytokine release by peritoneal macrophages. Iran. J. Immunol. 2007, 4, 220-226.

19. Chan, W.K.; Law, H.K.; Lin, Z.B.; Lau, Y.L.; Chan, G.C. Response of human dendritic cells to different immunomodulatory polysaccharides derived from mushroom and barley. Int. Immunopharmacol. 2007, 19, 891-899. [CrossRef] [PubMed]

20. Chen, A.W.; Seleen, J. Potential benefits of Ling-Zhi or Reishi mushroom Ganoderma lucidum (W. curt. Fr.) P. Karst. (Aphyllophoromycetideae) to breast cancer patients. Int. J. Med. Mushrooms 2007, 9, 29-38.

21. Liu, X.; Yuan, J.P.; Chung, C.K.; Chen, X.J. Antitumor activity of the sporoderm broken germinating spores of Ganoderma lucidum. Cancer Lett. 2002, 182, 155-161. [CrossRef]

22. Teng, B.S.; Wang, C.D.; Yang, H.J.; Wu, J.S.; Zhang, D.; Zheng, M.; Fan, Z.H.; Pan, D.; Zhou, P. A protein tyrosine phosphatase $1 \mathrm{~B}$ activity inhibitor from the fruiting bodies of Ganoderma lucidum (Fr.) Karst and its hypoglycemic potency on streptozotocininduced type 2 diabetic mice. J. Agric. Food Chem. 2011, 59, 6492-6500. [CrossRef]

23. De Silva, D.D.; Rapior, S.; Hyde, K.D.; Bahkali, A.H. Medicinal mushrooms in prevention and control of diabetes mellitus. Fungal Divers. 2012, 56, 1-29. [CrossRef]

24. De Silva, D.D.; Rapior, S.; Fons, F.; Bahkali, A.H.; Hyde, K.D. Medicinal mushrooms in supportive cancer therapies: An approach to anti-cancer effects and putative mechanisms of action. Fungal Divers. 2012, 55, 1-35. [CrossRef]

25. Hyde, K.D.; Xu, J.C.; Rapior, S.; Jeewon, R.; Lumyong, S.; Niego, A.G.T.; Abeywickrama, P.D.; Aluthmuhandiram, J.V.S.; Brahamanage, R.S.; Brooks, S.; et al. The amazing potential of fungi, 50 ways we can exploit fungi industrially. Fungal Divers. 2019, 1-136. [CrossRef]

26. Singh, S.K.; Doshi, A.; Pancholy, A.; Pathak, R. Biodiversity in wood-decay macro-fungi associated with declining arid zone trees of India as revealed by nuclear rDNA analysis. Eur. J. Plant Pathol. 2013, 136, 1-10. [CrossRef]

27. Li, H.L.; Guo, J.Y.; Karunarathna, S.C.; Ye, L.; Xu, J.C.; Hyde, K.D.; Mortimer, P.E. Native forests have a higher diversity of macrofungi than comparable plantation forests in the Greater Mekong Subregion. Forest 2018, 9, 402. [CrossRef]

28. Mortimer, P.E.; Karunarathna, S.C.; Li, Q.; Gui, H.; Yang, X.; Yang, X.; He, J.; Ye, L.; Guo, J.; Li, H. Prized edible Asian mushrooms: Ecology, conservation and sustainability. Fungal Divers. 2012, 56, 31-47. [CrossRef]

29. Hyde, K.D.; Norphanphoun, C.; Chen, J.; Dissanayake, A.J.; Doilom, M.; Hongsanan, S.; Jayawardena, R.S.; Jeewon, R.; Perera, R.H.; Thongbai, B.; et al. Thailand's amazing diversity-up to $96 \%$ of fungi in northern Thailand are novel. Fungal Divers. 2018, 93, 215-239. [CrossRef] 
30. Hapuarachchi, K.K.; Karunarathna, S.C.; Phengsintham, P.; Yang, H.D.; Kakumyan, P.; Hyde, K.D.; Wen, T.C. Ganodermataceae (Polyporales): Diversity in Greater Mekong Subregion countries (China, Laos, Myanmar, Thailand and Vietnam). Mycosphere 2019, 10, 221-309. [CrossRef]

31. Luangharn, T.; Karunarathna, S.C.; Mortimer, P.E.; Hyde, K.D.; Xu, J.C. Additions to the knowledge of Ganoderma in Thailand: Ganoderma casuarinicola, a new record; and Ganoderma thailandicum sp. nov. MycoKey 2019, 59, 47-65. [CrossRef] [PubMed]

32. Pilotti, C.A.; Sanderson, F.R.; Aitken, A.B.; Armstrong, W. Morphological variation and host range of two Ganoderma species from Papua New Guinea. Mycopathologia 2004, 158, 251-265. [CrossRef] [PubMed]

33. Wang, D.M.; Wu, S.H.; Li, T.H. Two records of Ganoderma new to mainland China. Mycotaxon 2009, 108, 35-40. [CrossRef]

34. Dai, Y.C.; Zhou, L.W.; Hattori, T.; Cao, Y.; Stalphers, J.A. Ganoderma lingzhi (Polyporales, Basidiomycota): The scientific binomial for the widely cultivated medicinal fungus Lingzhi. Mycol. Prog. 2017, 16, 1051-1055. [CrossRef]

35. Loyd, A.L.; Barnes, C.W.; Held, B.W.; Schink, M.J.; Smith, M.E.; Blanchette, R.A. Elucidating "lucidum": Distinguishing the diverse laccate Ganoderma species of the United States. PLoS ONE 2018, 13, e0199738. [CrossRef]

36. Hapuarachchi, K.K.; Karunarathna, S.C.; McKenzie, E.H.C.; Wu, X.L.; Kakumyan, P.; Hyde, K.D.; Wen, T.C. High phenotypic plasticity of Ganoderma sinense (Ganodermataceae, Polyporales) in China. Asian J. Mycol. 2019, 2, 1-47. [CrossRef]

37. Xing, J.H.; Sun, Y.F.; Han, Y.L.; Cui, B.K.; Dai, Y.C. Morphological and molecular identification of two new Ganoderma species on Casuarina equisetifolia from China. MycoKeys 2018, 34, 93-108. [CrossRef]

38. Moncalvo, J.M.; Wang, H.H.; Hseu, R.S. Phylogenetic relationships in Ganoderma inferred from the internal transcribed spacers and $25 \mathrm{~S}$ ribosomal DNA sequences. Mycologia 1995, 87, 223-238. [CrossRef]

39. Hou, D. A new species of Ganoderma from Taiwan. Quart. J. Taiwan Mus. 1950, 3, 101-105.

40. Zhao, J.D.; Hsu, L.W.; Zhang, X.Q. Taxonomic studies on the family Ganodermataceae of China II. Acta Mycol. Sin. 1983, 2, 159-167.

41. Patouillard, N.T. Le genre Ganoderma. Bull. Trimest. Soc. Mycol. 1889, 5, 64-80.

42. Murrill, W.A. The polyporaceae of North America: I. the genus Ganoderma. Bull. Torr. Bot. 1902, 29, 599-608. [CrossRef]

43. Murrill, W.A. Polyporaceae, Part 2. N. Am. Flora 1908, 9, 73-131.

44. Moncalvo, J.M.; Ryvarden, L. Ganoderma hildebrandii, a forgotten species. Mycotaxon 1995, 56, 175-180.

45. Moncalvo, J.M. Systematics of Ganoderma. In Ganoderma Diseases of Perennial Crops; Flood, J., Bridge, P.D., Holderness, M., Egham, M., Eds.; CABI Bioscience: Wallingford, UK, 2000; pp. 23-45.

46. Douanla-Meli, C.; Langer, E. Ganoderma carocalcareus sp. nov., with crumbly-friable context parasite to saprobe on Anthocleista nobilis and its phylogenetic relationship in G. resinaceum group. Mycol. Prog. 2009, 8, 145-155. [CrossRef]

47. Wu, X.L.; Dai, Y.C. Coloured Illustrations of Ganodermataceae of China; Science Press: Beijing, China, 2005; p. 229.

48. Moore, D.; Gange, A.C.; Gange, E.G.; Boddy, L. Fruit bodies: Their production and development in relation to environment. In Ecology of Saprotrophic Basidiomycetes; Boddy, L., Frankland, J.C., West, P.V., Eds.; Springer: London, UK, 2008 ; pp. 79-103.

49. Aubin-Horth, N.A.; Renn, S.C. Genomic reaction norms: Using integrative biology to understand molecular mechanisms of phenotypic plasticity. Mol. Ecol. 2009, 18, 3763-3780. [CrossRef]

50. Moore, D.; Robson, G.D.; Trinci, A.P.J. 21st Century Guidebook to Fungi; Cambridge University: Cambridge, UK, 2011.

51. Murren, C.J.; Auld, J.R.; Callahan, H.; Ghalambor, C.K.; Handelsman, C.A.; Heskel, M.A.; Kingsolver, J.G.; Maclean, H.J.; Maughan, H.; Pfennin, D.W.; et al. Constraints on the evolution of phenotypic plasticity: Limits and costs of phenotype and plasticity. Heredity 2015, 115, 293-301. [CrossRef]

52. Sun, S.J.; Gao, W.; Lin, S.Q.; Zhu, J.; Xie, B.G.; Lin, Z.B. Analysis of genetic diversity in Ganoderma populations with a novel molecular marker SRAP. Appl. Microbiol. Biotechnol. 2006, 72, 537-543. [CrossRef] [PubMed]

53. Ekandjo, L.K.; Chimwamurombe, P.M. Traditional medicinal uses and natural hosts of the genus Ganoderma in North-Eastern parts of Namibia. J. Pure Appl. Microbiol. 2012, 6, 1139-1146.

54. Wong, C.L.; Bong, J.F.C.; Idris, A.S. Ganoderma species associated with basal stem rot disease of oil palm. Am. J. Appl. Sci. 2012, 9 , 879-885. [CrossRef]

55. Ćilerdžić, J.; Galić, M.; Vukojević, J.; Brčeski, I.; Stajić, M. Potential of selected fungal species to degrade wheat straw, the most abundant plant raw material in Europe. BMC Plant Biol. 2017, 17, 249-255. [CrossRef]

56. Kües, U.; Nelsn, D.R.; Liu, C.; Yu, G.J.; Zhang, J.; Li, J.; Cun, X.; Sun, H. Genome analysis of medicinal Ganoderma spp. with plant-pathogenic and saprotrophic life-styles. Phytochemistry 2015, 114, 18-37. [CrossRef]

57. Cong, V.T. Ganoderma spp.-Biology, Species and Culture in Vietnam and in the Czech Republic. Ph.D. Thesis, Mendel University in Brno, Brno, Czech Republic, 2010.

58. Chalermpongse, A. Fungal diseases in mangrove ecosystem. In Proceedings of the 5th Silviculture Seminar in Thailand; Division of Silviculture, Royal Forest Department: Bangkok, Thailand, 1991; pp. 307-338.

59. Luangharn, T.; Karunarathna, S.C.; Khan, S.; Xu, J.C.; Mortimer, P.E.; Hyde, K.D. Antibacterial activity, optimal culture conditions and cultivation of the medicinal Ganoderma australe, new to Thailand. Mycosphere 2017, 8, 1108-1123. [CrossRef]

60. Tompong, S.; Kunasakdakul, K. Causal agent, symptoms and environmental factors of root rot disease of organic Assam tea in Mae Taeng district, Chiang Mai province. Int. J. Agric. Technol. 2014, 10, 767-777.

61. Zhao, J.D. New "Ling-Zhi" of China; Science Press: Beijing, China, 1989.

62. Li, T.H.; Hu, H.P.; Deng, W.Q.; Wu, S.H.; Wang, D.M.; Tsering, T. Ganoderma leucocontextum, a new member of the G. lucidum complex from southwestern China. Mycoscience 2015, 56, 81-85. [CrossRef] 
63. Utomo, C.; Werner, S.; Niepold, F.; Deising, H.B. Identification of Ganoderma, the causal agent of basal stem rot disease in oil palm using a molecular method. Mycopathologia 2005, 159, 159-170. [CrossRef]

64. Dai, Y.C.; Wei, Y.L.; Wu, X.L. Polypores from Hainan Province 1. J. Fungal Res. 2004, 2, 53-57.

65. Lodge, D.J.; Ammirati, F.J.; O'Dell, T.E.; Mueller, G.M. Collecting and Describing Macrofungi. In Biodiversity of Fungi Inventory and Monitoring Methods; Mueller, G.M., Bills, G.F., Foster, M.S., Eds.; Elsevier Academic Press: London, UK, 2004; pp. 128-154.

66. Ridgeway, R. Color Standards and Color Nomenclature; Ridgeway: Washington, DC, USA, 1912; pp. $12-225$.

67. Largent, D.L. How to Identify Mushrooms to Genus; Mad River Press: Eureka, CA, USA, 1986.

68. Kreisel, H.; Schauer, F. Methoden des Mykologischen Laboratoriums; VEB Gustav Fischer Verlag: Jena, Germany, $1987 ;$ p. 181.

69. Tulloss, R.E. Amaniteae: Amanita, Limacella \& Torrendia. By Pierre Neville \& Serge Poumarat, etc. Mycotaxon 2005, 92, 474-484.

70. Miettinen, O.; Larsson, K.H. Trechispora elongata species nova from North Europe. Mycotaxon 2006, 96, $193-198$.

71. Vilgalys, R.; Hester, M. Rapid genetic identification and mapping of enzymatically amplified ribosomal DNA from several Cryptococcus species. J. Bacteriol. 1990, 172, 4238-4246. [CrossRef]

72. White, T.J.; Bruns, T.; Lee, S.; Taylor, J.W. Amplification and direct sequencing of fungal ribosomal RNA genes for phylogenetics. In PCR Protocols: A Guide to Methods and Applications; Innis, M.A., Gelfand, D.H., Sninsky, J.J., White, T.J., Eds.; Academic Press: New York, NY, USA, 1990; pp. 315-322.

73. Liu, Y.J.; Whelen, S.; Hall, B.D. Phylogenetic relationships among ascomycetes: Evidence from an RNA polymerase II subunit. Mol. Biol. Evol. 1999, 16, 1799-1808. [CrossRef] [PubMed]

74. Sung, G.H.; Sung, J.M.; Hywel-Jones, N.L.; Spatafora, J.W. A multi-gene phylogeny of Clavicipitaceae (Ascomycota, Fungi): Identification of localized incongruence using a combinational bootstrap approach. Mol. Phylogenet. Evol. 2007, 44, 1204-1223. [CrossRef] [PubMed]

75. Luangharn, T.; Karunarathna, S.C.; Mortimer, P.E.; Hyde, K.D.; Thongklang, N.; Xu, J.C. A new record of Ganoderma tropicum (Basidiomycota, Polyporales) for Thailand and first assessment of optimum conditions for mycelia production. MycoKeys 2019, 51, 65-83. [CrossRef] [PubMed]

76. Zhou, L.W.; Cao, Y.; Wu, S.H.; Vlasak, J.; Li, W.D.; Dai, Y.C. Global diversity of the Ganoderma lucidum complex (Ganodermataceae, Polyporales) inferred from morphology and multilocus phylogeny. Photochemistry 2015, 114, 7-15. [CrossRef] [PubMed]

77. Katoh, K.; Standley, D.M. MAFFT multiple sequence alignment software version 7: Improvements in performance and usability. Mol. Biol. Evol. 2013, 30, 772-780. [CrossRef]

78. Hall, T.A. BioEdit: A user-friendly biological sequence alignment editor and analysis program for Windows 95/98/NT. Nucleic Acids Symp. Ser. 1999, 41, 95-98.

79. Thompson, J.D.; Gibson, T.J.; Plewniak, F.; Jeanmougin, F.; Higgins, D.G. The CLUSTAL X windows interface: Flexible strategies for multiple sequence alignment aided by quality analysis tools. Nucleic Acids Res. 1997, 25, 4876-4882. [CrossRef]

80. Swofford, D.L. PAUP*. Phylogenetic Analysis Using Parsimony (* and Other Methods), Version 4.0 Beta Version; Sinauer Associates: Sunderland, MA, USA, 2002.

81. Stamatakis, A. RAxML v. 8: A tool for phylogenetic analysis and post-analysis of large phylogenies. Bioinformatics 2014, 30, 1312-1313. [CrossRef]

82. Miller, M.A.; Pfeiffer, W.; Schwartz, T. Creating the CIPRES Science Gateway for inference of large phylogenetic trees. In Proceedings of the Gateway Computing Environments Workshop (GCE), New Orleans, LA, USA, 14 November 2010; pp. 1-8.

83. Silvestro, D.; Michalak, I. raxmlGUI: A graphical front-end for RAxML. Org. Divers. Evol. 2011, 12, 335-337. [CrossRef]

84. Nylander, J.A.A. MrModeltest v.2 Program Distributed by the Author; Evolutionary Biology Centre, Uppsala University: Uppsala, Sweden, 2004.

85. Huelsenbeck, J.P.; Ronquist, F. MRBAYES: Bayesian inference of phylogenetic trees. Bioinformatics 2001, 17, 754-755. [CrossRef] [PubMed]

86. Rambaut, A. FigTree Version 1.4.0. Available online: http:/ / tree.bio.ed.ac.uk/software/soft-ware/figtree/ (accessed on 5 March 2012).

87. Xing, J.H.; Song, J.; Decock, C.; Cui, B.K. Morphological characters and phylogenetic analysis reveal a new species within the Ganoderma lucidum complex from South Africa. Phytotaxa 2016, 266, 115-124. [CrossRef]

88. Hapuarachchi, K.K.; Karunarathna, S.C.; Raspé, O.; De Silva, K.H.W.L.; Thawthong, A.; Wu, A.L.; Kakumyan, P.; Hyde, K.D.; Wen, T.C. High diversity of Ganoderma and Amauroderma (Ganodermataceae, Polyporales) in Hainan Island, China. Mycosphere 2018, 9, 931-982. [CrossRef]

89. Crous, P.W.; Luangsa-ard, J.J.; Wingfield, M.J.; Carnegie, A.J.; Hernández-Restrepo, M.; Lombard, L.; Roux, J.; Barreto, R.W.; Baseia, I.G.; Cano-Lira, J.F.; et al. Fungal planet description sheets: 785-867. Persoonia 2018, 41, 238-417. [CrossRef]

90. Crous, P.W.; Wingfield, M.J.; Richardson, D.M.; Le Roux, J.J.; Strasberg, D.; Edwards, J.; Roets, F.; Hubka, V.; Taylor, P.; Heykoop, M.; et al. Fungal planet description sheets: 400-468. Persoonia 2016, 36, 316-458. [CrossRef]

91. Song, J.; Xing, J.H.; Decock, C.; He, X.L.; Cui, B.K. Molecular phylogeny and morphology reveal a new species of Amauroderma (Basidiomycota) from China. Phytotaxa 2016, 260, 47-56. [CrossRef]

92. Jargalmaa, S.; Eimes, J.A.; Park, M.S.; Park, J.Y.; Oh, S.Y.; Lim, Y.W. Taxonomic evaluation of selected Ganoderma species and database sequence validation. PeerJ 2017, 5, 1-16. [CrossRef]

93. Welti, S.; Courtecuisse, R. The Ganodermataceae in the French West Indies (Guadeloupe and Martinique). Fungal Divers. 2010, 43, 103-126. [CrossRef] 
94. Crous, P.W.; Wingfield, M.J.; Burgess, T.I.; Hardy, G.E.J.; Barber, P.A.; Alvarado, P.; Barnes, C.W.; Buchanan, P.K.; Heykoop, M.; Moreno, G.; et al. Fungal Planet description sheets: 558-624. Persoonia 2017, 38, 240-384. [CrossRef]

95. Kaliyaperumal, M.; Kalaichelvan, P.T. Ganoderma australe from southern India. Microbiol. Res. 2008, 163, 286-292. [CrossRef]

96. Park, Y.J.; Kwon, O.C.; Son, E.S.; Yoon, D.E.; Han, W.; Nam, J.Y.; Yoo, Y.B.; Lee, C.S. Genetic diversity analysis of Ganoderma species and development of a specific marker for identification of medicinal mushroom Ganoderma lucidum. Afr. J. Microbiol. Res. 2012, 6, 5417-5425.

97. Glen, M.; Bougher, N.L.; Francis, A.A.; Nigg, S.Q.; Lee, S.S.; Irianto, R. Ganoderma and Amauroderma, species associated with root-rot disease of Acacia mangium plantation trees in Indonesia and Malaysia. Australas. Plant Pathol. 2009, 38, 345-356. [CrossRef]

98. Kinge, T.R.; Mih, A.M. Ganoderma ryvardense sp. nov. associated with basal stem rot (BSR) disease of oil palm in Cameroon. Mycosphere 2011, 2, 179-188.

99. Yao, Y.J.; Wang, X.C.; Wang, B. Epitypification of Ganoderma sichuanense J. D. Zhao and X. Q. Zhang (Ganodermataceae). Taxon 2013, 62, 1025-1031. [CrossRef]

100. Glen, M.; Yuskianti, V.; Puspitasari, D.; Francis, A.; Agustini, L.; Rimbawanto, A.; Indrayadi, H.; Gafur, A.; Mohammed, C.L. Identification of basidiomycete fungi in Indonesian hardwood plantations by DNA barcoding. For. Pathol. 2014, 44, 496-508. [CrossRef]

101. Crous, P.W.; Wingfield, M.J.; Le Roux, J.; Richardson, D.M.; Strasberg, D.; Shivas, R.G.; Alvarado, P.; Edwards, J.; Moreno, G.; Sharma, R.; et al. Fungal planet description sheets: 371-399. Persoonia 2015, 35, 264-327. [CrossRef] [PubMed]

102. Li, G.J.; Hyde, K.D.; Zhao, R.L.; Hongsanan, S.; Abdel-Aziz, F.A.; Abdel-Wahab, M.A.; Alvarado, P.; Alves-Silva, G.; Ammirati, J.F.; Ariyawansa, H.A.; et al. Fungal diversity notes 253-366: Taxonomic and phylogenetic contributions to fungal taxa. Fungal Divers. 2016, 78, 1-237. [CrossRef]

103. Justo, A.; Miettinen, O.; Floudaas, D.; Ortiz-Santana, B.; Sjökvist, E.; Lindner, D.; Nakasone, K.; Niemela, T.; Larsson, K.H.; Ryverden, L.; et al. A revised family-level classification of the Polyporales (Basidiomycota). Fungal Biol. 2017, 121, 798-894. [CrossRef]

104. Cui, B.K.; Li, H.J.; Ji, X.; Zhou, J.L.; Song, J.; Si, J. Species diversity, taxonomy and phylogeny of Polyporaceae (Basidiomycota) in China. Fungal Divers. 2019, 97, 137-392. [CrossRef]

105. Ryvarden, L.; Gilbertson, R.L. European Polypores. 1. Abortiporus_Lindtneria; Fungi Flora: Oslo, Norway, 1993 ; p. 387.

106. Pegler, D.N.; Yao, Y.J. Oriental species of Ganoderma section Ganoderma . In Botany and Mycology for the Next Millennium: Collection of Scientific Articles Devoted to the 70th Anniversary of Academician Sytnik KM; Wasser, S.P., Ed.; National Academy of Sciences of Ukraine: Kyiv, Ukraine, 1996; pp. 336-347.

107. Leonard, A.C. Two Ganoderma species compared. Mycologist 1998, 12, 65-68. [CrossRef]

108. Thawthong, A.; Hapuarachchi, K.K.; Wen, T.C.; Raspé, O.; Thongklang, N.; Kang, J.C.; Hyde, K.D. Ganoderma sichuanense (Ganodermataceae, Polyporales) new to Thailand. MycoKeys 2017, 22, 27-43. [CrossRef]

109. Gilbertson, R.L.; Ryvarden, L. North American Polypores 1; Fungi Flora: Oslo, Norway, 1986; pp. 1-433.

110. Steyaert, R.L. Species of Ganoderma and related genera mainly of the Bogor and Leiden Herbaria. Persoonia 1972, 7, 55-118.

111. Steyaert, R.L. The concept and circumscription of Ganoderma tornatum. Trans. Br. Mycol. Soc. 1975, 65, 451-467. [CrossRef]

112. Ryvarden, L.; Johansen, I. A Preliminary Polypores Flora of East Africa; Fungi Flora: Oslo, Norway, 1980 ; pp. 1-636.

113. Corner, E.J.H.; Ad Ployporaceas, I. Amauroderma and Ganoderma. Nova Hedwig. 1983, 75, 1-182.

114. Buchanan, P.K.; Wilkie, J.P. Taxonomy of New Zealand Ganoderma: Two Non-Laccate Species. Ganoderma: Systematics, Phytopathology and Pharmacology. In Proceedings of the Contributed Symposia 59A, B, Fifth International Mycological Congress, Vancouver, BC, Canada, 14-21 August 1995; pp. 7-17.

115. León, F.; Valencia, M.; Rivera, A.; Nieto, I.; Quintana, J.; Estévez, F.; Bermejo, J. Novel cytostatic lanostanoid triterpenes from Ganoderma australe. Helv. Chim. Acta 2003, 86, 3088-3095. [CrossRef]

116. Schwarze, F.W.M.R.; Ferner, D. Ganoderma on trees-Differentiation of species and studies of invasiveness. Arboric. J. 2003, 25, 57-77.

117. Ryvarden, L.; Melo, I. Poroid Fungi of Europe; Synopsis Fungorum; Fungi Flora: Oslo, Norway, 2014.

118. Overall, A. Southern Bracket or Artist's Conk? Field Mycol. 2016, 17, 124-128. [CrossRef]

119. Zhao, J.D.; Xu, L.W.; Zhang, X.Q. Taxonomic studies on the subfamily Ganodermataceae of China III. Acta Mycol Sin. 1979, 19, 265-279.

120. Li, H.J.; He, S.H.; Cui, B.K. Polypores from Bawangling Nature Reserve, Hainan Province. Mycosystema 2010, $29,828-833$.

121. Dai, Y.C.; Cui, B.K.; Yuan, H.S.; He, S.H.; Wei, Y.L.; Qin, W.M.; Zhou, L.W.; Li, H.J. Wood-inhabiting fungi in southern China. 4. Polypores from Hainan Province. Ann. Bot. Fenn. 2011, 48, 219-231. [CrossRef]

122. Wang, D.M.; Wu, S.H. Two species of Ganoderma new to Taiwan. Mycotaxon 2007, 102, 373-378.

123. Bi, Z.; Zheng, G.; Taihui, L. The Macrofungus Flora of China's Guangdong Province; Chinese University Press: Hong Kong, China, 1993; p. 119.

124. Patouillard, N. Champignons du Kouytcheou. Le Monde Des Plants 1907, 2, 31-32.

125. Ryvarden, L. Type Studies in the Polyporaceae 14. Species Described by N. Patouillard, Either Alone or with Other Mycologists; Harvard University Herbaria: Cambridge, UK, 1983; pp. 1-39.

126. Saccardo, P.A. Supplementum Universale, Pars I. Agaricaceae-Laboulbeniaceae. Syll. Fung. 1891, 9, 1-1141. 
127. Hseu, R.S. An Identification System for Cultures of Ganoderma Species. Ph.D. Thesis, National Taiwan University, Taipei, Taiwan, 1990.

128. Smith, B.J.; Sivasithamparam, K. Morphological studies of Ganoderma (Ganodermataceae) from the Australasian and Pacific region. Aust. Syst. Bot. 2003, 16, 487-503. [CrossRef]

129. Yang, L.Z.; Feng, B. What is the Chinese "Lingzhi"?-A taxonomic mini-review. Mycology 2013, 4, 1-4.

130. Zhou, X.W.; Li, Q.Z.; Yin, Y.Z.; Chen, Y.Y.; Lin, J. Identification of medicinal Ganoderma species based on PCR with specific primers and PCR-RFLP. Planta Med. 2008, 74, 197-200.

131. Teng, S.C. Notes on Polyporaceae from China. Sinensia 1934, 5, 198-200.

132. Tai, F.L. Sylloge Fungorum Sinicorum; Science Press: Beijing, China, 1979; p. 1527.

133. Núñez, M.; Ryvarden, L. East Asian Polypores: Ganoderma Taceae and Hymenochaetaceae; Fungi Flora: Oslo, Norway, 2000; pp. 6-50.

134. Bazzalo, M.E.; Wright, J.E. Survey of the Argentine species of the Ganoderma lucidum complex. Mycotaxon 1982, 16, 295-325.

135. Wasser, S.P. Reishi or Ling Zhi (Ganoderma lucidum), Encyclopedia of Dietary Supplements; Marcel Dekker: New York, NY, USA, 2005.

136. Ryvarden, L. Studies in Neotropical Polypores 2: A preliminary key to neotropical species of Ganoderma with a laccate pileus. Mycologia 2000, 92, 180-191. [CrossRef]

137. Gottlieb, A.M.; Wright, J.E. Taxonomy of Ganoderma from southern South America: Sub genus Ganoderma. Mycol. Res. 1999, 103, 661-673. [CrossRef]

138. Bolaños, A.C.; Bononi, V.L.R.; Gugliotta, A.M.; Muñoz, J.E. New records of Ganoderma multiplicatum (Mont.) Pat. (Polyporales, Basidiomycota) from Colombia and its geographic distribution in South America. Check List 2016, 12, 1-7. [CrossRef]

139. Correia de Lima, J.N.; Baptista Gibertoni, T.; Malosso, E. Delimitation of some neotropical laccate Ganoderma (Ganodermataceae): Molecular phylogeny and morphology. Rev. Biol. Trop. 2014, 62, 1197-1208. [CrossRef]

140. Steyaert, R.L. Study of some Ganoderma species. Bull. Jard. Bot. Natl. Belg. 1980, 50, 135-186. [CrossRef]

141. Bhosle, S.; Ranadive, K.; Bapat, G.; Garad, S.; Deshpande, G.; Vaidya, J. Taxonomy and diversity of Ganoderma from the Western parts of Maharashtra (India). Mycosphere 2010, 1, 249-262.

142. Hong, S.G.; Jung, H.S. Phylogenetic analysis of Ganoderma based on nearly complete mitochondrial small-subunit ribosomal DNA sequences. Mycologia 2004, 96, 742-755. [CrossRef]

143. Mohanty, P.S.; Harsh, N.S.K.; Pandey, A. First report of Ganoderma resinaceum and G. weberianum from north India based on ITS sequence analysis and micromorphology. Mycosphere 2011, 2, 469-474.

144. Atkinson, G.F. Observations on Polyporus lucidus Leys. and some of its allies from Europe and North America. Bot. Gaz. 1908, 46, 321-338. [CrossRef]

145. Haddow, W.R. Studies in Ganoderma. J. Arnold Arbor. 1931, 12, 25-46.

146. Steyaert, R.L. Basidiospores of two Ganoderma species and others of two related genera under the scanning electron microscope. Kew Bull. 1977, 31, 437-442. [CrossRef]

147. Donk, M.A. Notes on European polypores. IV. on some species of Ganoderma. Kon. Neth. Akad. Wetensch. Proc. Ser. C Biol. Med. Sci. 1969, 72, 273-282.

148. Tortić, M. Ganoderma adspersum (S. Schulz.) Donk (= Ganoderma europaeum Steyaert) and its distribution in Jugoslavia. Acta Bot. Croat. 1971, 30, 113-118.

149. Ryvarden, L. Type studies in the Polyporaceae, 7. Species Described by JM Berkeley from 1836 to 1843. Kew Bull. 1976, 1, 81-103. [CrossRef]

150. Arulpandi, I.; Kalaichevan, P.T. Ganoderma adspersum and Ganoderma cupreum from South India, first report based on molecular phylogeny. Int. J. Curr. Microbiol. Appl. Sci. 2013, 2, 693-702.

151. Guglielmo, F.; Gonthier, P.; Garbeloto, M.; Nicolotti, G. A PCR-based method for the identiфcation of important wood rotting fungal taxa within Ganoderma, Inonotus s.l. and Phellinus s.l. FEMS Microbiol. Lett. 2008, 282, 228-237. [CrossRef] [PubMed]

152. De Simone, D.; Annesi, T. Occurrence of Ganoderma adspersum on Pinus pinea. Phytopathol. Mediterr. 2012, 51, $374-382$.

153. Gottlieb, A.M.; Ferrer, E.; Wright, J.E. rDNA analyses as an aid to the taxonomy of species of Ganoderma. Mycol. Res. 2000, 104, 1033-1045. [CrossRef]

154. Wang, D.M.; Wu, S.H. Ganoderma hoehnelianum has priority over G. shangsiense, and G. williamsianum over G. meijiangense. Mycotaxon 2010, 113, 343-349. [CrossRef]

155. Lowe, J.L.; Gilbertson, R.L. Synopsis of the Polyporaceae of the Western United States and Canada. Mycologia 1961, 53, 474-511. [CrossRef]

156. Wang, D.M.; Wu, S.H.; Yao, Y.J. Clarification of the concept of Ganoderma orbiforme with high morphological plasticity. PLoS ONE 2014, 9, e98733. [CrossRef]

157. Bresadola, G. Iconographia Mycologica. Mediolani 1932, 21, 1001-1050.

158. Agustini, L.; Francis, A.; Glen, M.; Indrayadi, H.; Mohammed, C.L. Signs and identification of fungal root-rot pathogens in tropical Eucalyptus pellita plantations. For. Pathol. 2014, 44, 486-495. [CrossRef]

159. Humphrey, C.J. Notes on some basidiomycetes from the Orient. Mycologia 1938, 30, 327-335. [CrossRef]

160. Imazeki, R.A. Contribution to the Fungus Flora of Dutch New Guinea; Bulletin of the Government Forest Experiment Station: Tokyo, Japan, 1952; pp. 87-128.

161. Teng, S.C. Fungi of China; Science Press: Beijing, China, 1963; pp. 1-808.

162. Teng, S.C. Fungi of China. Mycotaxon 1996, 14, 1-586. 
163. Costa-Rezende, D.H.; Gugliotta, A.M.; Góes-Neto, A.; Reck, M.A.; Robledo, G.R.; Drechsler-Santos, E.R. Amauroderma calcitum sp. nov. and notes on taxonomy and distribution of Amauroderma species (Ganodermataceae). Phytotaxa 2016, 244, 101-124. [CrossRef]

164. Costa-Rezende, D.H.; Robledo, G.L.; Goes-Neto, A.; Reck, M.A.; Crespo, E.; Drechsler-Santos, E.R. Morphological reassessment and molecular phylogenetic analyses of Amauroderma s.lat. raised new perspectives in the generic classification of the Gaodermataceae family. Persoonia 2017, 39, 254-269. [CrossRef] [PubMed]

165. Junghuhn, F.W. Praemissae in floram cryptogamicam Java insulae (Batavia). Verh. Batav. Genootsch. 1838, 17, 1-86.

166. Bresadola, G. Adnotanda in fungos aliquot exoticos regii Musei lugdunensis. Ann. Mycol. 1910, 8, 585-589.

167. Pilotti, C.A.; Sanderson, F.R.; Aitken, E.A.B. Genetic structure of a population of Ganoderma boninense on oil palm. Plant Pathol. 2003, 52, 455-463. [CrossRef]

168. Foroutan, A.; Jafary, N. Diversity of heart and root rot fungi on park and roadside trees in Maharashtra, India. J. Appl. Sci. Environ. Manag. 2007, 11, 55-58.

169. Murrill, W.A. Some Philippine Polyporaceae. Bull. Torr. Bot. 1907, 34, 465-481. [CrossRef]

170. Bernicchia, A. Fungi Europaei: Polyporaceae s.l.; Edizioni Candusso: Savona, Italy, 2005; p. 808.

171. Johnson, B. Ganoderma Root and Butt Rot: An Emerging Threat to California Almonds; University of California: Davis, CA, USA, 2017; pp. 1-6.

172. Nicolotti, G.; Negri, M.; Anselmi, N. Incidence and biology of Ganoderma species causing decline of trees in northern Italy. Petria 1992, 2, 159-170.

173. Luangharn, T.; Karunarathna, S.C.; Mortimer, P.E.; Hyde, K.D.; Xu, J. Morphology, phylogeny and culture characteristics of Ganoderma gibbosum collected from Kunming, Yunnan Province, China. Phyton 2020, 89, 1-22. [CrossRef]

174. Yao, Y.J.; Du, Z.; Du, Z.; Wang, K.; Wang, X.C.; Kirk, P.M.; Spooner, B.M. On the typification of Ganoderma sichuanense (Agaricomycetes)-The widely cultivated Lingzhi. Int. J. Med. Mushrooms 2020, 22, 45-54. [CrossRef]

175. Torres-Torres, M.G.; Ryvarden, L.; Guzmán-Dávalos, L. Ganoderma subgénero Ganoderma en México. Rev. Mex. Micol. 2015, 41, 27-45.

176. Overholts, L.O. The Polyporaceae of the United States, Alaska, and Canada); University of Michigan Press: Ann Arbor, MI, USA, 1953. 